\title{
Development of an on-board compressed gas storage system for hydrogen powered vehicle applications
}

Thomas H. Evans

West Virginia University

Follow this and additional works at: https://researchrepository.wvu.edu/etd

\section{Recommended Citation}

Evans, Thomas H., "Development of an on-board compressed gas storage system for hydrogen powered vehicle applications" (2009). Graduate Theses, Dissertations, and Problem Reports. 4460.

https://researchrepository.wvu.edu/etd/4460

This Dissertation is protected by copyright and/or related rights. It has been brought to you by the The Research Repository @ WVU with permission from the rights-holder(s). You are free to use this Dissertation in any way that is permitted by the copyright and related rights legislation that applies to your use. For other uses you must obtain permission from the rights-holder(s) directly, unless additional rights are indicated by a Creative Commons license in the record and/ or on the work itself. This Dissertation has been accepted for inclusion in WVU Graduate Theses, Dissertations, and Problem Reports collection by an authorized administrator of The Research Repository @ WVU.

For more information, please contact researchrepository@mail.wvu.edu. 


\title{
DEVELOPMENT OF AN ON-BOARD COMPRESSED GAS STORAGE SYSTEM FOR HYDROGEN POWERED VEHICLE APPLICATIONS
}

\author{
Thomas H. Evans
}

Dissertation submitted to the College of Engineering and Mineral Resources at West Virginia University, in partial fulfillment of the requirements for the degree of

\section{Doctor of Philosophy \\ in \\ Mechanical Engineering}

\author{
Samir N. Shoukry, Ph.D., Chair \\ Jacky C. Prucz, Ph.D. \\ Gergis W. William, Ph.D. \\ Mourad Riad, Ph.D. \\ Eduardo M. Sosa, Ph.D. \\ Department of Mechanical and Aerospace Engineering \\ Morgantown, West Virginia \\ 2009
}

Keywords: pressure vessels, compressed gas hydrogen storage, composite materials 


\title{
ABSTRACT \\ DEVELOPMENT OF AN ON-BOARD COMPRESSED GAS STORAGE SYSTEM FOR HYDROGEN POWERED VEHICLE APPLICATIONS
}

\author{
Thomas H. Evans
}

The hydrogen economy envisioned in the future requires safe and efficient means of storing hydrogen fuel for either use on-board vehicles, delivery on mobile transportation systems or high-volume storage in stationary systems. Leading edge technologies are currently under development for storing hydrogen safely and efficiently on-board vehicles in the form of either compressed gas $\left(\mathrm{CGH}_{2}\right)$, cryogenic liquid $\left(\mathrm{LH}_{2}\right)$, or solid matter $\left(\mathrm{SSH}_{2}\right)$. The main emphasis of this work is placed on the high pressure storing of gaseous hydrogen on-board vehicles.

As a result of its very low density, hydrogen gas has to be stored under very high pressure, ranging from 35 to $70 \mathrm{MPa}$ for current systems, in order to achieve practical levels of energy density in terms of the amount of energy that can be stored in a tank of a given volume. The optimal design configuration of such high pressure storage tanks includes an inner liner used as a gas permeation barrier, geometrically optimized domes, inlet/outlet valves with minimum stress concentrations, and directionally tailored exterior reinforcement for high strength and stiffness. Filament winding of pressure vessels made of fiber composite materials is the most efficient manufacturing method for such high pressure hydrogen storage tanks. The complexity of the filament winding process in the dome region is characterized by continually changing the fiber orientation angle and the local thickness of the wall.

The research conducted for this dissertation reveals that the continuously changing angle orientation and local laminate thickness in the dome regions can be modeled by a unique approach that utilizes suitable transformations of the macromechanical composite properties and the local coordinate system. Accurate representation of the exterior reinforcement allows for detailed analysis of the dome structure as well as the nozzle/valve connection. A metallic insert is utilized to connect the dome structure to the valve system. A comparative study between different insert geometries and locations in the dome has been performed. It shows that an insert extending through the dome geometry increases the resulting stress at the cylinder-dome juncture. The most effective design approach entails an insert to the boss region. 


\section{TABLE OF CONTENTS}

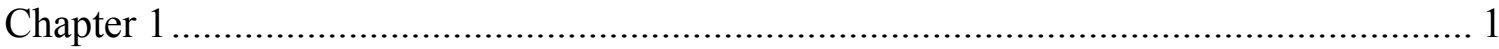

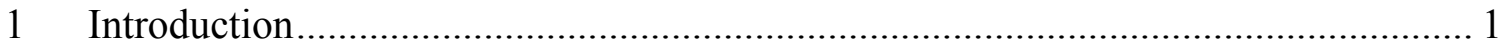

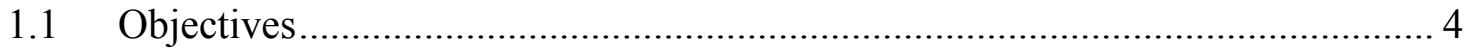

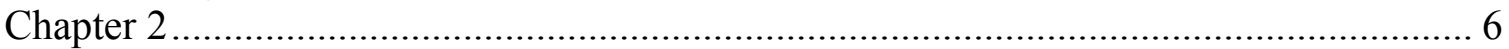

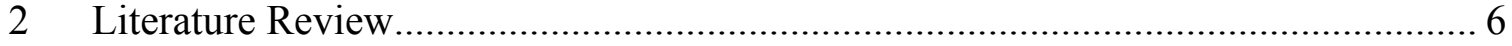

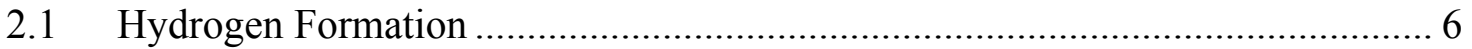

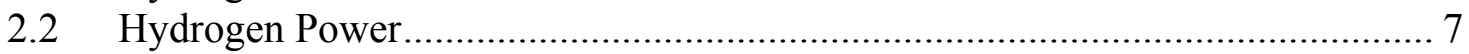

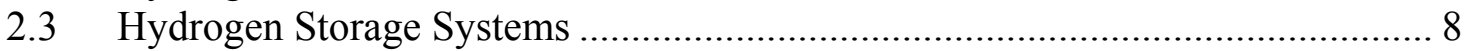

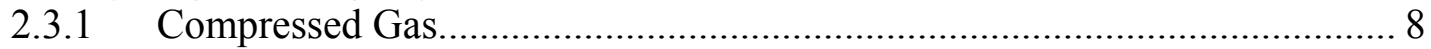

2.3.2 QUANTUM TriShield Hydrogen Storage Systems .................................. 9

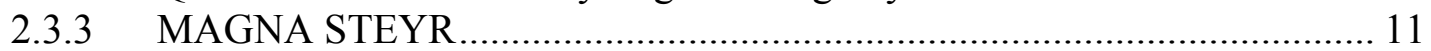

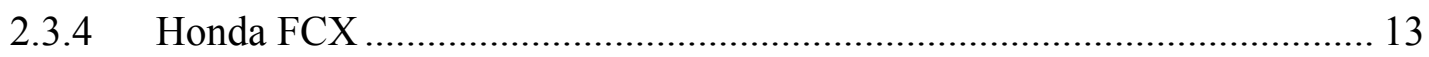

2.3.5 Daimler Chrysler F-Cell Vehicle _........................................................ 14

2.3.6 Liquid Hydrogen Storage.................................................................... 14

2.3.7 Liquid Hydrogen Storage System Design................................................... 16

2.3.8 Hydride Hydrogen Storage ................................................................... 18

2.4 Manufacturing Methods for a Compressed Gas Storage System........................ 21

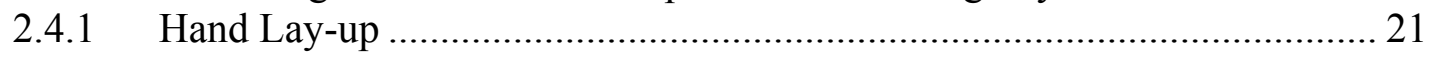

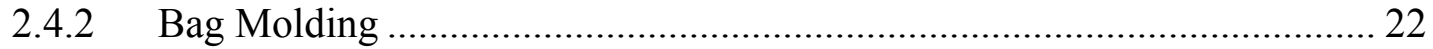

2.4.3 Autoclave Processing........................................................................ 22

2.4.4 Compression Molding.......................................................................... 23

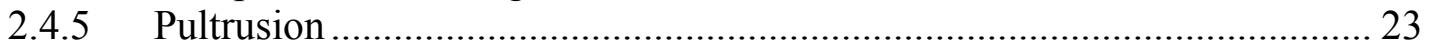

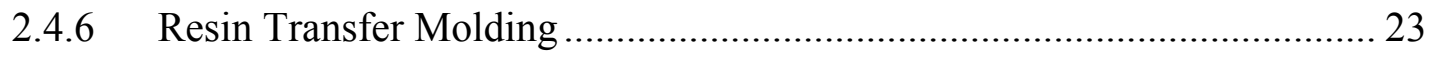

2.4.7 Filament Winding .............................................................................. 24

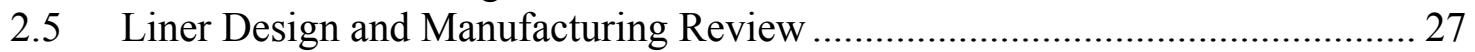

2.5.1 Permeation and Embrittlement ………………..................................... 27

2.5.2 Manufacturing Processes ..................................................................... 28

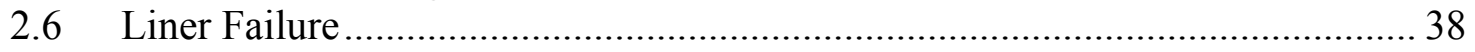

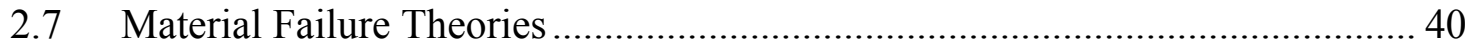

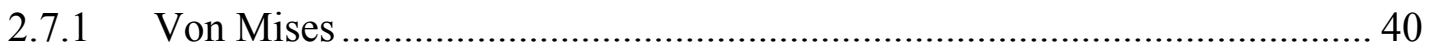

2.8 Macromechanical Failure Theories in Composite Materials ............................ 40

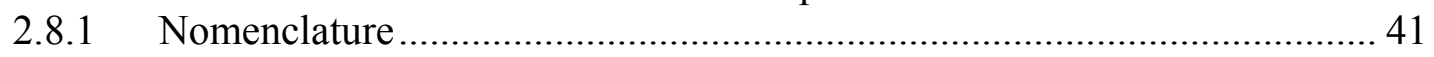

2.8.2 Maximum Stress Theory ........................................................................ 41

2.8.3 Maximum Strain Theory .................................................................... 42

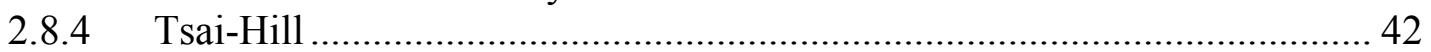

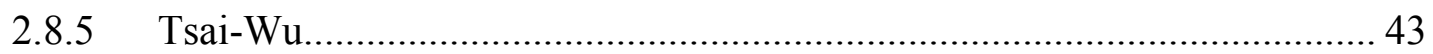

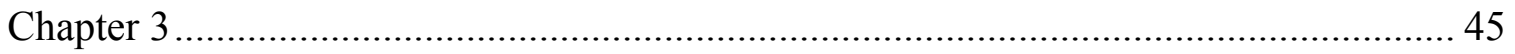

3 Initial Analysis into Hydrogen Pressure Vessel Configurations................................ 45

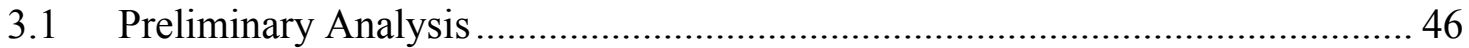

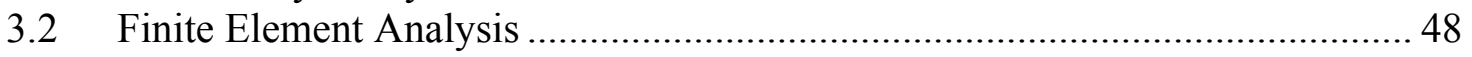

3.2.1 Carbon fiber pressure vessel - Orientation One ......................................... 49

3.2.2 Carbon fiber pressure vessel - Orientation Two.......................................... 50

3.2.3 Carbon fiber reinforced aluminum pressure vessel - Orientation One....... 51

3.2.4 Carbon fiber reinforced aluminum pressure vessel - Orientation Two...... 53 


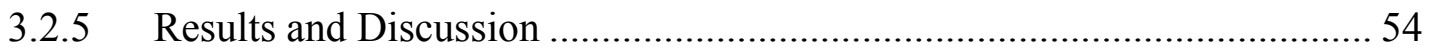

3.2.6 Hydrogen Storage Capacity ……………………...................................... 57

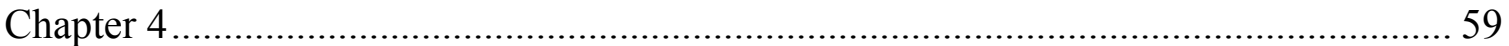

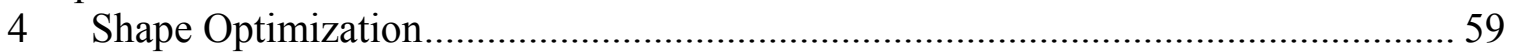

4.1 Spherical versus Cylindrical Design Configuration............................................. 59

4.2 Finite Element Analysis of Hydrogen Tanks ……….......................................... 61

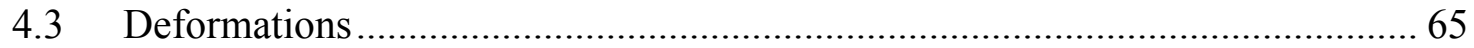

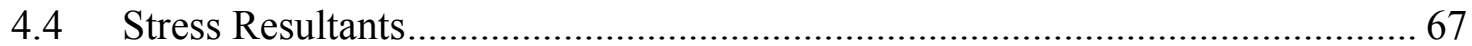

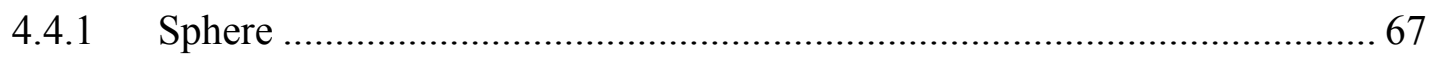

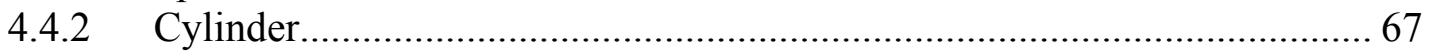

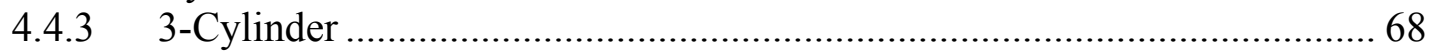

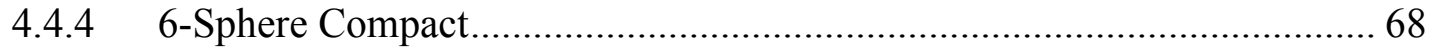

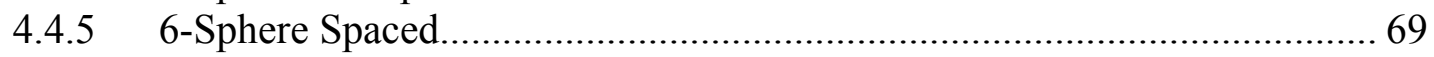

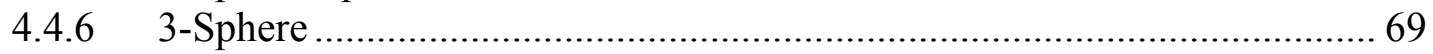

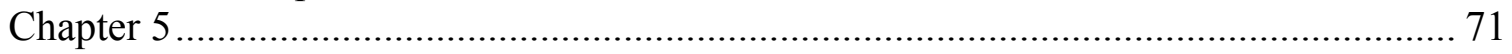

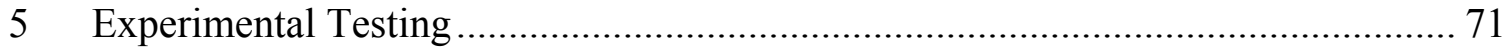

$5.1 \quad$ Four-Point Bending Tests............................................................................ 72

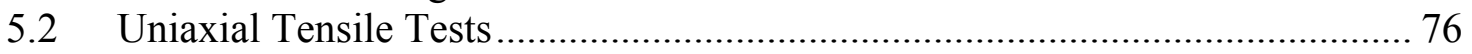

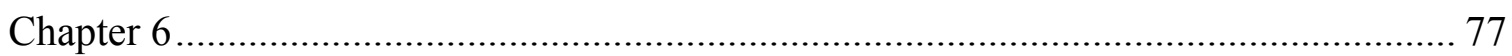

6 Preliminary Study of Filament Wound Composite Pressure Vessels ....................... 77

6.1 Netting Analysis and Isotensoid Theory .......................................................... 78

6.2 Initial Winding Angle and Thickness Calculations.......................................... 83

6.3 Determination of Transient Material Properties by Composite Macromechanics

for Axisymmeteric Finite Element Analysis................................................................ 87

6.3.1 Material Transformation to Obtain Global Laminate Properties ................. 87

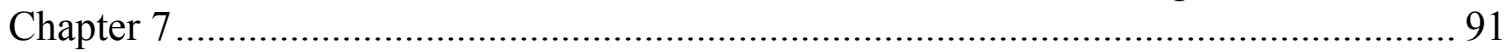

7 Finite Element Study of Composite Over-Wrapped Pressure Vessels ..................... 91

7.1 Finite Element Analysis Approach .............................................................. 91

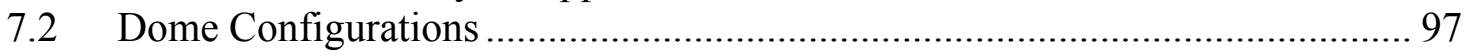

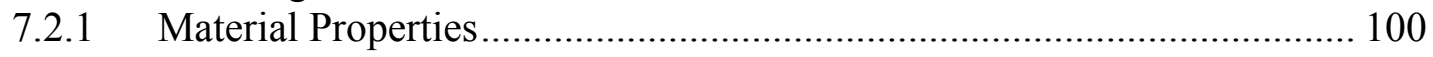

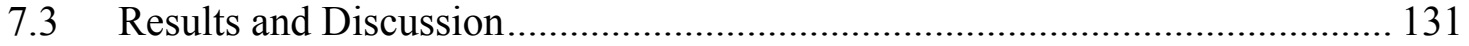

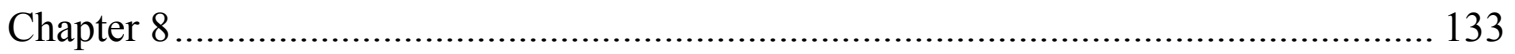

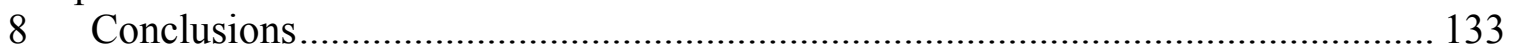

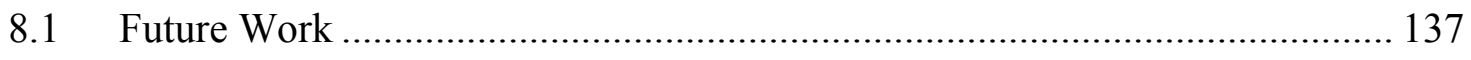

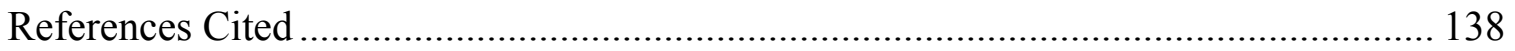

Appendix A: MATLAB Input Code - Isotensoid Analysis............................................ 143

Appendix B: MATLAB Input Code - Fiber Material Property Transformations ........... 147

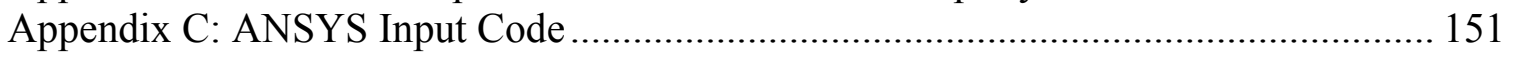




\section{LIST OF FIGURES}

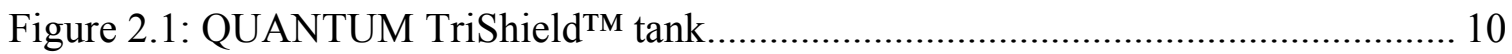

Figure 2.2: Details of the QUANTUM TriShield Tank Construction ............................ 11

Figure 2.3: Plastic liners of different volume and a complete 700 bar cylindrical hydrogen

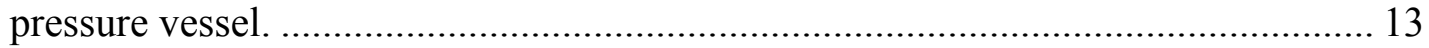

Figure 2.4: Energy density of gaseous and liquid hydrogen as a function of pressure..... 15

Figure 2.5: Detailed description of a MAGNA STEYR liquid hydrogen storage system.17

Figure 2.6: Liquid hydrogen storage system by Linde. ............................................... 18

Figure 2.7 Hydrogen adsorption and disassociation of molecules into the metal crystal lattice

Figure 2.8: Filament winding Process. Reference: www.azom.com AZo Journal of Materials Online, 2009.

Figure 2.9: In shear forming, the wall thickness of the formed part is reduced. $\mathrm{P}$ and $\mathrm{P}^{\prime}$ show how the material is shifted during the forming process. Reference: Halten, Metal Spinning: From Ancient Art to High-Tech Industry, 2002. 36

Figure 2.10: Failure location of a composite over-wrapped pressure vessel metallic liner.

Figure 3.1: Internal Forces within an axisymmetric cylindrical pressure vessel............. 46 Figure 3.2: (a) Displacement [in] (b) and (c) Von Mises stress [psi] (d) layer orientation for the carbon fiber pressure vessel with $45 \%-0^{\circ}$ plies, $45 \%-90^{\circ}$ plies and $10 \%-45^{\circ}$ plies.

Figure 3.3: (a) Displacement [in] (b) and (c) Von Mises stress [psi] (d) layer orientation for the carbon fiber pressure vessel with $30 \%-0^{\circ}$ plies, $60 \%-90^{\circ}$ plies and $10 \%-45^{\circ}$ plies.

Figure 3.4: (a) Displacement [in] (b) and (c) Von Mises stress [psi] (d) layer orientation for the carbon fiber reinforced aluminum pressure vessel with $45 \%-0^{\circ}$ plies, $45 \%$ $90^{\circ}$ plies and $10 \%-45^{\circ}$ plies.

Figure 3.5: (a) Displacement [in] (b) and (c) Von Mises stress [psi] (d) layer orientations for the carbon fiber reinforced aluminum pressure vessel with $30 \% 0^{\circ}$ plies, $60 \% 90^{\circ}$ plies and $10 \% 45^{\circ}$ plies. 54

Figure 4.1: Multi-Sphere Tank Designs (a) 6-Sphere design with merged connections (b) Multiple sphere design without merged connections.

Figure 4.2: Spherical tank finite element model. 62

Figure 4.3: Stresses in 15-Gallon Spherical Tanks (Thickness $=1.4$ in.) (a) vertical meridian stress (b) hoop stress (c) horizontal meridian stress and (d) shear stress [psi].

Figure 4.4: Shape configurations with constant volume, material properties and thickness (a) Sphere (b) Cylinder (c) 3-Cylinder (d) 6-Sphere Compact (e) 6-Sphere Spaced (f) 3-Sphere.

Figure 4.5: Displacement [in] results for pressure vessel configurations (a) Sphere (b) Cylinder (c) 3-Cylinder (d) 6-Sphere Compact (e) 6-Sphere Spaced (f) 3-Sphere. . 66 Figure 4.6: Sphere stress resultants (a) stress in the x-direction (b) stress in the z-direction [psi].

Figure 4.7: Cylinder stress resultants (a) hoop stress (b) axial stress [psi] 67

Figure 4.8: 3-Cylinder stress resultants (a) hoop stress (b) axial stress [psi]. 68 
Figure 4.9: 6-Sphere Compact stress resultants (a) x-direction hoop stress (b) z-direction axial stress [psi].

Figure 4.10: 6-Sphere Spaced stress resultants (a) x-direction stress (b) z-direction stress [psi].

Figure 4.11: 3-Sphere stress resultants (a) x-direction stress (b) z-direction stress [psi]. 69

Figure 5.1: Carbon fiber specimens used for material testing. ................................... 71

Figure 5.2: (a) Four-point bending test setup. (b) Uniaxial tensile test setup................. 72

Figure 5.3: Deformed specimen during a four-point bending test and its respective bending moment diagram.

Figure 5.4: Four-point bending test of $10 \mathrm{~mm}$ thick specimens (a) tensile and compressive strains (b) stress-strain diagram (c) failure mode showing compression of top fibers.

Figure 5.5: Four-point bending test of $18 \mathrm{~mm}$ thick specimens (a) tensile and compressive strains (b) stress-strain diagram (c) failure mode

Figure 5.6: (a) Tensile test specimen (b) delamination and fracture of the top composite

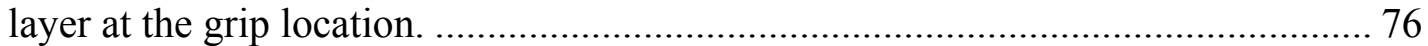

Figure 6.1: Geometric representation of a filament wound pressure vessel and

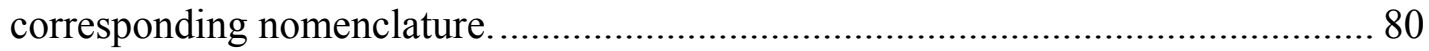

Figure 6.2: Normalized isotensoid dome contour.................................................. 82

Figure 6.3: Normalized winding angle variation for an isotensoid dome contour. ......... 83

Figure 6.4: Summation of forces in axial direction of a cylindrical pressure vessel...... 84

Figure 6.5: Summation of forces in the hoop direction of a cylindrical pressure vessel.. 85

Figure 6.6: Thickness variation for a normalized axial component and boss radius of 0.25

Figure 7.1: (a) Dome contour with area divisions and local coordinate systems (b) schematic of area local coordinate system 16 relating to a fiber angle of $16^{\circ}$ from the meridian.

Figure 7.2: Transformations to local coordinate systems. 95

Figure 7.3: (a) Dome contour points imported from MATLAB output (b) addition of thickness contour to dome geometry (c) 2D model with local coordinate systems (d) winding angle orientation as a function of the radius.

Figure 7.4: (a) Geometry of the Isotensoid dome and HDPE model (b) displacement (c) stress in fiber directions.

Figure 7.5: Isotensoid dome with added hoop reinforcement in the cylindrical body (a) displacement (b) stress in the fiber direction (c) stress in the fiber direction after tapering $90^{\circ}$ fiber reinforcement in the stress concentration zone.

Figure 7.6: Hemispherical dome with (a) area material divisions and local coordinate systems (b) displacement sum (c) stress in the fiber directions...

Figure 7.7: Hemispherical dome with hoop reinforcement in the cylinder (a) displacement (b) stress in the fiber directions

Figure 7.8: Isotensoid dome with full aluminum liner and only helical winding in the cylindrical body (a) geometry (b) displacement (c) stress in the fiber directions (d) equivalent stress in the aluminum liner.

Figure 7.9: Hemispherical dome with a full aluminum liner (a) geometry (b) displacement (c) equivalent stress in the aluminum liner (d) stress in the fiber directions of the composite reinforcement. 
Figure 7.10: Isotensoid dome with aluminum liner extending to the cylinder-dome juncture (a) dimensions and (b) geometry showing the aluminum liner (purple) in the dome and $90^{\circ}$ hoop fibers (yellow) in the cylinder body (c) displacement (d) stress in the fiber directions (e) equivalent stress in the aluminum insert.............. 117

Figure 7.11: (a) Dimensions of the hemispherical dome aluminum liner extending to the cylinder dome juncture (b) geometry (c) displacement (d) stress in the fiber directions (d) equivalent stress in the aluminum insert.

Figure 7.12: Isotensoid dome with metallic insert (a) dimensions and (b) geometry with inset showing annular ring (c) displacement (d) stress in the fiber directions (e) equivalent stress in the aluminum boss insert.

Figure 7.13: Hemispherical dome with metallic insert (a) geometry with inset of insert (b) displacement without tapering of hoop reinforcement (c) displacement with tapering of hoop reinforcement (d) stress in the fiber directions (e) equivalent stress of aluminum boss insert. 


\section{LIST OF TABLES}

Table 2.1: Hydrogen Properties.

Table 3.1: Preliminary Thickness Calculations of Composite Storage Tanks for Compressed Hydrogen Gas Storage ................................................................ 48

Table 3.2: Maximum Stress and Displacement Values Calculated through 3-D FEA ..... 55

Table 3.3: Results of Carbon Fiber Failure Analysis Based on Von Mises Failure ......... 56

Table 4.1: Effect of Varying the Wall Thickness on Critical Stress in 9-inch Diameter Spherical Tank Due to a Burst Pressure of 23,000 psi

Table 4.2: Effect of Varying the Wall Thickness on Critical Stress in 13-inch Diameter Spherical Tank Due to a Burst Pressure of 23,000 psi ......................................... 63

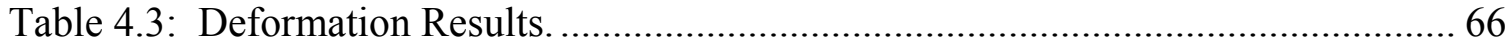

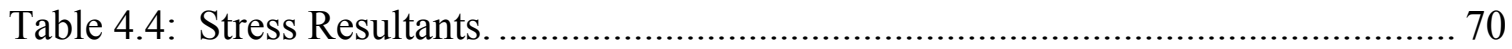

Table 7.1: Material Property of T800/Epoxy. Reference: Kim et al.2004..................... 92

Table 7.2: High Density Polyethylene material properties. Reference: Velosa et al. 2007

Table 7.3: Material Properties of Steel. Reference: Hibbeler, 2005 ........................... 100

Table 7.4: Material Properties of Aluminum. Reference: Hibbeler, 2005 ................... 100

Table 7.5: Comparison of full aluminum liner to HDPE liner for an isotensoid dome. . 111

Table 7.6: Material Properties for Ti-6Al-4V Titanium Ref: Collins, 2003 ................... 128

Table 7.7: Material Properties for Am 1004-T61 Magnesium Alloy. Ref: Collins, 2003

Table 7.8: Material Properties for AM 350 Stainless Steel. Ref: Collins, 2003 ........... 129

Table 7.9: Material Properties for AISI UHS 4340 Ultra High Strength Steel. Ref: Collins, 2003

Table 7.10: Analysis for Liner Systems of Isotensoid and Hemispherical Dome Shapes of a COPV with 6 inch Internal Radius. 


\section{Chapter 1}

\section{Introduction}

Alternative fuel and drive train solutions represent one of the biggest challenges for eliminating a petroleum based transportation economy and developing the vehicle of the future. The need to eliminate dependency on oil economics is initiated by greenhouse effects including pollution and global warming concerns, and increasing costs and limited sources of fossil fuels. The realization of a hydrogen economy has steadily gained over the last several years and increasing research gives credibility to the future of hydrogen as an energy carrier and the idea of a stable hydrogen infrastructure. Hydrogen, as a fuel source, differs from combustible fossil fuels by its properties to release energy through a chemical reaction with oxygen, a process dominated by fuel cell research. The energy from this type of chemical reaction can not only be used for fuel cells delivering electric output but can be implemented in internal combustion engines similar to present vehicles.

The application of hydrogen into a new fuel structure is not the only governing research criteria. One the main developmental barriers to preventing hydrogen as an efficient energy carrier is a safe and reliable storage system. The process development of hydrogen energy includes the ability to provide the user with an adequate driving range and functionality comparable to and ultimately surpassing ideals of current gasoline powered vehicles. This criterion applies to on-board hydrogen storage, transportation of hydrogen, and stationary storage systems which are the components of a hydrogen energy infrastructure.

High pressure containment is a method to store the adequate amount of hydrogen energy on-board hydrogen powered vehicles. Compressed gas tanks are the primary solution to hydrogen storage for on-board vehicle applications due to their potential to store an adequate amount of hydrogen energy without a multi-layer insulation system required by hydrogen cryogenic storage applications.

The development of compressed gas hydrogen storage tanks and the system requirements have been outlined by the U.S. Department of Energy. The requirements 
account for a complete system to attain a hydrogen storage level of 5-7 $\mathrm{kg}$ and achieve a 300-mile vehicle driving range while maintaining refueling times comparable to conventional internal combustion engines (ICE). A complete system is defined by all of the components used to make hydrogen a useable fuel source; this includes but is not limited to, the tank, valves, regulators, piping, mounting, insulation, etc. The following technical targets for On-Board Hydrogen storage span the years of 2007, 2010, and 2015. Unless otherwise indicated, all targets are for both internal combustion engines and fuel cell powered vehicles based on the unlikely scenario of power-plant specific fuel being commercially viable. Also, systems must be energy efficient, for reversible systems greater than $90 \%$ energy efficiency; for systems off-board, greater than $70 \%$ life-cycle efficiency.

\section{System Gravimetric Capacity}

\begin{tabular}{|c|c|c|c|c|}
\hline Specific Gravimetric Capacity & Units & $\mathbf{2 0 0 7}$ & $\mathbf{2 0 1 0}$ & $\mathbf{2 0 1 5}$ \\
\hline $\begin{array}{c}\text { (net useful energy/max system } \\
\text { mass) }\end{array}$ & $\mathrm{kWh} / \mathrm{kg}$ & 1.5 & 2 & 3 \\
$(\mathrm{~kg} \mathrm{H} 2 / \mathrm{kg} \mathrm{system})$ & $(0.045)$ & $(0.06)$ & $(0.09)$ \\
\hline
\end{tabular}

- Specific gravimetric capacity is the specific energy of the system.

- Specific gravimetric capacity for gasoline powered vehicles is $3.5 \mathrm{kWh} / \mathrm{kg}$.

\section{System Volumetric Capacity}

\begin{tabular}{|c|c|c|c|c|}
\hline Specific Volumetric Capacity & Units & $\mathbf{2 0 0 7}$ & $\mathbf{2 0 1 0}$ & $\mathbf{2 0 1 5}$ \\
\hline $\begin{array}{c}\text { (net useful energy/max system } \\
\text { volume) }\end{array}$ & $\mathrm{kWh} / \mathrm{L}$ & 1.2 & 1.5 & 2.7 \\
& $(\mathrm{~kg} \mathrm{H} 2 / \mathrm{L}$ system) & $(0.036)$ & $(0.045)$ & $(0.081)$ \\
\hline
\end{tabular}

- Volumetric capacity is the energy density of the system.

- The fuel system volume of a gasoline powered vehicle is around 107 liters equaling an energy density of $2.5 \mathrm{kWh} / \mathrm{L}$.

\section{Durability and Operating Conditions}

\begin{tabular}{|c|c|c|c|c|}
\hline Durability/Operability & Units & $\mathbf{2 0 0 7}$ & $\mathbf{2 0 1 0}$ & $\mathbf{2 0 1 5}$ \\
\hline $\begin{array}{c}\text { Operating Ambient } \\
\text { Temperature }\end{array}$ & ${ }^{\circ} \mathrm{C}$ & $-20 / 50$ & $-30 / 50$ & $-40 / 60$ \\
\hline
\end{tabular}




\begin{tabular}{|c|c|c|c|c|}
\hline $\begin{array}{c}\text { Min/Max Delivery } \\
\text { Temperature }\end{array}$ & ${ }^{\circ} \mathrm{C}$ & $-30 / 85$ & $-40 / 85$ & $-40 / 85$ \\
\hline $\begin{array}{c}\text { Cycle life } \\
(1 / 4 \text { tank to full })\end{array}$ & Cycles & 500 & 1000 & 1500 \\
\hline $\begin{array}{c}\text { Max delivery pressure } \\
\text { from tank }\end{array}$ & psi & 1500 & 1500 & 1500 \\
\hline
\end{tabular}

\section{Environmental, Health \& Safety}

\begin{tabular}{|l|l|}
\hline Permeation and Leakage & $<1 \mathrm{~cm}^{3} / \mathrm{hr}$ per tank-liter \\
\hline Toxicity & No defined standard \\
\hline Safety & No defined standard \\
\hline
\end{tabular}

- Permeation and leakage pertains to the possibility of generating a combustible hydrogen-air mixture outside the storage tank.

- Toxicity encompasses the possibility of consumer exposure to the storage material in normal or abnormal conditions.

- Safety covers certification and operation of vehicles, manufacturing, transporting and dispensing fuel and end of life issues.

\section{Hydrogen loss}

\begin{tabular}{|c|c|c|}
\hline & Units & Requirement \\
\hline $\begin{array}{c}\text { Loss of useable } \\
\text { hydrogen }\end{array}$ & $(\mathrm{g} / \mathrm{h}) / \mathrm{kg} \mathrm{of} \mathrm{H}_{2}$ Stored & $0.1-0.05$ \\
\hline
\end{tabular}

\section{Compressed Gas}

\begin{tabular}{|c|c|}
\hline Pressure Level & Grams $\mathbf{H}_{\mathbf{2}}$ per Liter \\
\hline Atmospheric & $1 / 11$ \\
\hline $5,000 \mathrm{psi}$ & 23.5 \\
\hline $10,000 \mathrm{psi}$ & 38.7 \\
\hline
\end{tabular}

- One gram of hydrogen occupies approximately 11 liters (2.9 gallons) of volume at atmospheric pressure.

\section{Impact Resistance}

\begin{tabular}{|c|c|}
\hline Direction of change in acceleration & Acceleration \\
\hline In the direction of travel & $200 \mathrm{~m} / \mathrm{s}^{2}$ \\
\hline Perpendicular to the direction of travel & $80 \mathrm{~m} / \mathrm{s}^{2}$ \\
\hline
\end{tabular}




\subsection{Objectives}

The objectives within this scope of work include the study of utilizing the lightweight and high strength properties of composite materials to increase the options of an alternative fuel system, in this case, hydrogen. Hydrogen gas and its characteristics must be completely understood to develop a safe storage system as a fuel tank reservoir. Through analysis such as closed-form solutions, finite-element modeling, and experimental endeavors the prospects of composite material design for high pressure systems will be studied. The knowledge to be obtained is the shape and construction, size and thickness parameters in correlation to pressure containment and strength, feasibility of on-board storage with commercial vehicle storage restraints, while including manufacturing methods and capabilities.

The following objectives wish to be attained and studied within the scope of this work:

1. Perform initial development of high-pressure composite reinforced tanks by closed form solutions and preliminary finite element analysis.

a. Use closed form solutions of stress resultants to determine thickness requirements of fiberglass, kevlar and carbon fiber reinforcement for cylindrical pressure vessels

b. Analyze cylindrical pressure vessels with exterior composite reinforcement corresponding to the previously determined thickness at various fiber orientations without a polar boss opening.

c. Introduce a metallic liner system into the finite element model and determine its effect as a load-bearing structure.

2. Experimentally characterize carbon fiber composite specimens manufactured to the previously determined wall thickness by four point bending tests and tensile tests.

a. Determine the strength at failure and failure mode of carbon fiber specimens with thickness values of 0.375 " and $0.8 "$ ". 
3. Utilize available theory and develop a finite element modeling method to analyze composite overwrapped pressure vessels.

a. Experimental testing of pressure vessel systems is costly and complex, therefore a method to compare pressure vessel designs by finite element modeling is to be achieved and studied.

b. Input parameters such as pressure vessel geometry, composite material exterior reinforcement thickness, and fiber orientation are to be determined for accurate finite element analysis.

4. Perform a comparative study with the previously determined finite element approach to specifically analyze dome shape configurations and approach to liner system applications of composite overwrapped pressure vessels.

a. A two-dimensional axisymmetric finite element modeling approach will be used in conjunction with fiber local coordinate systems to represent the nature of the composite exterior reinforcement. 


\section{Chapter 2}

\section{Literature Review}

Hydrogen $\left(\mathrm{H}_{2}\right)$ is an element that poses many important properties for the development of a non-oil based fuel economy. Hydrogen is the most simple of all elements but its energy content is the highest per unit weight of any known fuel $(52,000$ Btu/pound). Hydrogen energy content per unit weight is three times that of gasoline. However, the energy content per unit volume is approximately four times lower than that of gasoline due to the low density of hydrogen.

Hydrogen properties related to storage systems and utilization as an energy source are listed in Table 2.1. These properties are to be considered in design applications and for determining system requirements for storing applications.

Table 2.1: Hydrogen Properties.

\begin{tabular}{ll}
\hline \multicolumn{1}{c}{ Property } & \multicolumn{1}{c}{ Value } \\
Melting Point * & $\mathrm{T}_{\mathrm{m}}=-259.34{ }^{\circ} \mathrm{C}$ \\
Boiling Point * & $\mathrm{T}_{\mathrm{b}}=-252.87{ }^{\circ} \mathrm{C}$ \\
Density of Gas* & $\rho_{\mathrm{g}}=0.08987 \mathrm{~kg} / \mathrm{m} 3$ \\
Density of Liquid* & $\rho_{\mathrm{l}}=70.99 \mathrm{~kg} / \mathrm{m} 3$ \\
Flammability Concentration in Air & $4.1 \%-72.5 \%$ \\
Autoignition Temperature & $\mathrm{T}_{\mathrm{ai}}=530{ }^{\circ} \mathrm{C}$ \\
Higher Heat Value (HHV) & $\mathrm{HHV}=141.79 \mathrm{MJ} / \mathrm{kg}=39.39 \mathrm{kWh} / \mathrm{kg}$ \\
Lower Heat Value (LHV) & $\mathrm{LHV}=119.96 \mathrm{MJ} / \mathrm{kg}=33.39 \mathrm{kWh} / \mathrm{kg}$ \\
\hline
\end{tabular}

* Pressure value of $1 \mathrm{~atm}$.

\subsection{Hydrogen Formation}

The presence of hydrogen occurs in conjunction with other elements, for example, water $\left(\mathrm{H}_{2} \mathrm{O}\right)$ or methane $\left(\mathrm{CH}_{4}\right)$. Water and methane are two examples of hydrogen energy carriers. An extraction process must be done to remove the hydrogen molecules to provide the energy source. 
Electrolysis is a process that splits the hydrogen molecule from water. Other applications apply to methanol and various other hydrogen energy carriers.

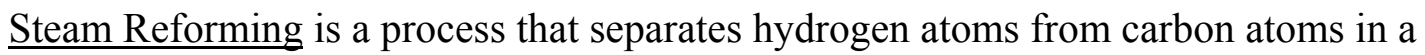
methane molecule.

Electrolysis can effectively separate hydrogen from water without any emission penalties; however it is an expensive procedure. Steam reforming is the most widely used process accounting for $95 \%$ of currently used hydrogen and it is also the least expensive hydrogen forming process. Because methane is a fossil fuel, greenhouse gases are emitted during the process, this is a concern since a major reason to initiate hydrogen as a fuel source is to reduce fossil fuel emissions.

\subsection{Hydrogen Power}

The transition to hydrogen as a new energy carrier requires enhancements and investments in energy formulation, distribution of energy supply, storage media, and vehicle, power-station or end source technology. Hydrogen is projected as a source of energy and power by the media of a cleaner combustion process through hydrogen internal-combustion engines and for use in fuel cells which combine oxygen with hydrogen to produce electricity and heat (Larminie, 2002).

Fuel cells provide the most efficient method to use hydrogen as an energy source. Fuel cells play and important role in the concept of hydrogen energy as systems which utilize the energy stored in hydrogen in the form of electricity. In comparison with fossil fuel internal-combustion engines, hydrogen fuel cells are nearly twice as efficient per a given equivalent unit of fuel. Unlike conventional engines, fuel cells emit only water vapor and heat. Fuel cells are characterized by high working efficiencies with clean and quiet operation (Wald, 2004). Fuel cells are versatile and have implications in large-scale power generation in centralized power plants and also in small scale electricity production. 


\subsection{Hydrogen Storage Systems}

The key determinants for the use of hydrogen as a fuel cell, as for any fuel, are the cost and safety of the fuel distribution system from the site of manufacture to the end user. The development of a future hydrogen economy depends on a safe and efficient means of storing hydrogen in portable, mobile and stationary applications. Hydrogen presents more challenges than oil-based fuels due to its extremely low density as a gas and liquid, high diffusivity, and its broad flammability range relative to hydrocarbons and low-molecular weight alcohols. These unique properties of hydrogen present special safety and cost issues at each step of distribution, from manufacturing to on-board vehicle storage (Committee, 2004).

Hydrogen is formed in various procedures as mentioned in section 2.2 and it also can be transported or stored in different chemical states. Hydrogen can be stored as a pressurized gas or as a cryogenic liquid. At standard temperature and pressure, hydrogen is a colorless, odorless, nonmetallic, highly flammable diatomic gas. These hydrogen parameters are essential guidelines for the study of compressed gas hydrogen storage. Decreasing the temperature of hydrogen to cryogenic levels $\left(-252.87^{\circ} \mathrm{C}\right)$ changes the hydrogen form from a gas to a liquid creating the liquid hydrogen storage application. Temperature change and control of a cryogenic temperature level are two important parameters of liquid hydrogen storage.

\subsubsection{Compressed Gas}

The application of compressing hydrogen gas for storage applications is in accordance with hydrogen properties categorizing it as a low energy density medium. To quantify the low density of hydrogen, it can be stated that one gram of hydrogen occupies approximately 11 liters (2.9 gallons) of volume at atmospheric pressure. For an acceptable fuel usage, $5-13 \mathrm{~kg}$ of hydrogen are required on-board a vehicle to account for an approximate driving range of 300 miles, depending on the vehicle size. A range of 300 miles is an average driving range of a gasoline or diesel powered vehicle. Therefore, to 
decrease the size of the compressed hydrogen gas storage system, pressure is applied to compact the gas molecules and increase the system energy density. At a pressure level of $5.0 \mathrm{ksi}(34.5 \mathrm{MPa})$, a storage tank with a volume of 67.5 gallons will achieve a hydrogen energy density level of $6 \mathrm{~kg}$. Although, the energy level requirement would be reached, a system of this volume would not likely be stored successfully onboard a standard vehicle and without jeopardizing the vehicle performance and operation. Increasing the system pressure to $10 \mathrm{ksi}(69 \mathrm{MPa})$, increases the hydrogen density to $38.7 \mathrm{~g} / \mathrm{L}$, at this level, the tank volume required to reach $6 \mathrm{~kg}$ of hydrogen is 41 gallons $(155 \mathrm{~L})$. To structurally support high internal pressure systems, advanced structural reinforcement is required. Pressure vessels utilizing thick-walled metallic design will undoubtedly resist the induced stresses but these designs are not beneficial to on-board hydrogen storage because of high weight factors.

The initial designs and prototypes of high pressure storage systems have utilized carbon fiber composite material design to carry the structural loading from high magnitude internal pressures of compressed hydrogen gas while aiming to maintain valid size and weight characteristics. The high-strength and stiffness characteristics of

orthotropic fiber-reinforced composite materials are implemented by a complete overwrapping of the pressure vessel liner by filament winding operations. Several manufacturers who specialize in pressure vessels or composite material manufacturing systems have initiated developments to high pressure hydrogen containment systems. Two companies which have initiated research in compressed gas hydrogen storage systems are QUANTUM and MAGNA STEYR.

\subsubsection{QUANTUM TriShield Hydrogen Storage Systems}

Quantum Fuel Systems Technologies Worldwide, Inc (QFSTW) started a research program sponsored by USDOE and Lawrence Livermore National Laboratory to develop ultra lightweight, low-cost hydrogen storage tanks (Sirosh, 2002). Quantum developed carbon fiber-reinforced 5,000-psi and 10,000-psi compressed hydrogen storage cylinders as an alternative that would be compatible with the cost expectations of the automotive industry, and also meet safety standards. 


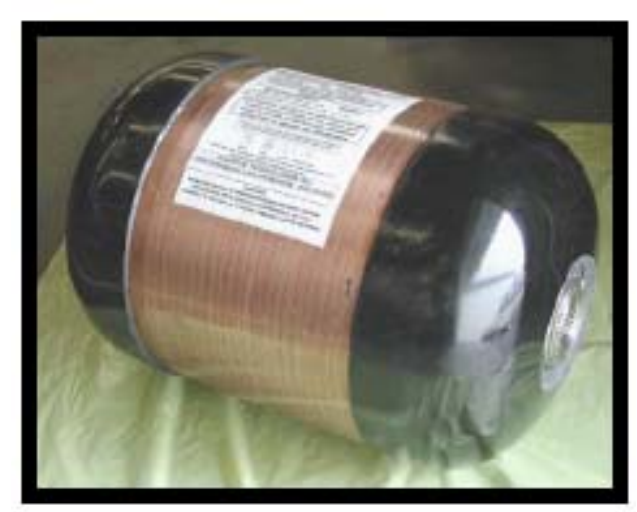

Figure 2.1: QUANTUM TriShield ${ }^{\mathrm{TM}}$ tank

The inner liner of the tank is a high molecular weight polymer that serves as a hydrogen gas permeation barrier. A carbon fiber-epoxy resin composite shell is placed over the liner and constitutes the gas pressure load-bearing component of the tank. Finally, an outer shell is placed on the tank for impact and damage resistance. The pressure regulator for the $10,000-p s i(70 \mathrm{MPa})$ tank is located in the interior of the tank (Ko et al., 2005). Such tanks, as shown in Figure 2.1, were close to meeting the 2007 targets for weight, energy density, and specific energy of $6 \%$ hydrogen by weight. However, they utilized premium aerospace-grade carbon fiber reinforcement to satisfy the structural requirement of supporting 23,500 psi burst pressure. Therefore, they could not achieve the cost goal of $\$ 5$ per $\mathrm{kW}-\mathrm{h}$, since the reported cost was $\$ 10-\$ 17$ per $\mathrm{kW}-\mathrm{h}$ (Able, 2006). Low-cost, commercial grade carbon fibers were employed to fabricate 10,000-psi storage tanks for compressed hydrogen with the same level of performance as tanks fabricated from high-cost, aerospace grade carbon fibers (Ko et al., 2005). Although such tanks can yield a specific energy density of, approximately, $1.3 \mathrm{~kW}-\mathrm{hr} / \mathrm{kg}$, further design improvements are necessary, most likely through unconventional means, to exceed this value (Dubno, 2007).

The researchers of QFSTW also demonstrated that the use of active sensors to monitor the health of the storage system might be an attractive and safe approach for integrated design of hydrogen storage tanks. Their results showed that for each tank design considered in the study, the strain signature of a damaged tank deviates from its initial strain signature, when the tank was in a healthy condition. Thus, if a sufficiently economical and robust sensor array can be mounted on a tank to monitor continuously the 
status of its entire health, then such an instrumentation system would enable weight and cost reductions while also acting as an active safety feature. The schematics of the operating system are show in Figure 2.2.

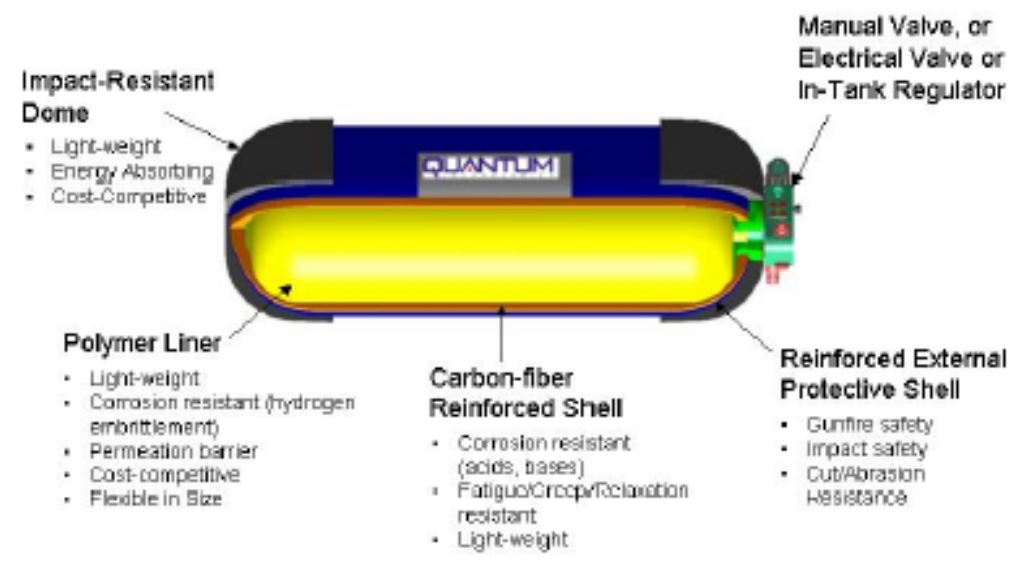

Figure 2.2: Details of the QUANTUM TriShield Tank Construction

The current hydrogen tanks designed by QUANTUM are designed to reach service pressures of 10,000 psi (700 bar) for maximum hydrogen energy storage density. Hydrogen pressure vessels are designed with a 2.35 factor of safety which attains a burst strength of 23,500 psi. This factor of safety accommodates increases in gas temperature during fast refilling rates.

\subsubsection{MAGNA STEYR}

As an independent engineering and manufacturing partner to automakers located in Graz, Austria, MAGNA STEYR has partnered with Mercedes-Benz, Chrysler, SAAB, BMW and others to provide solutions to engineering applications within the automotive industries. MAGNA STEYR coordinated an Integrated Project named "StorHy", as part of the European initiative, driven by major European car manufacturers, on automobile hydrogen storage (Strubel, 2004). This initiative covers the full spectrum of currently qualified technologies. The project aims at developing robust, safe and efficient onboard hydrogen storage systems suitable for use in hydrogen-fueled fuel cells or internal 
combustion engines. The project addresses the compressed gas, cryogenic and solid hydrogen storage applications (Strubel, 2006).

In the compressed gas initiative, MAGNA STEYR conducted research work to develop a lightweight compressed hydrogen vessel capable of storing hydrogen gas at a nominal pressure of $700 \mathrm{bar}(10,152 \mathrm{psi})$, along with the necessary peripheral equipment. The main characteristics of the desired tank are summarized as follows (Strubel, 2006):

- At $20^{\circ} \mathrm{C}$, the pressure of 700 bars $(10,152 \mathrm{psi})$ corresponds to a volumetric energy density greater than $1.4 \mathrm{kWh} /$ liter.

- At this pressure, a 125 liter reservoir (inner volume) can store approximately $5 \mathrm{~kg}$ of hydrogen so that ranges of 420-500 km driving autonomy per filling can be achieved with a car equipped with a typical $\sim 70 \mathrm{kWh}$ fuel cell.

- The tank has to achieve gravimetric energy density larger than $2.2 \mathrm{kWh} / \mathrm{kg}$. Since the calorific power of hydrogen is $33.33 \mathrm{kWh} / \mathrm{kg}$, the corresponding targeted hydrogen storage capacity (system mass fraction) is about $6 \mathrm{wt} \%$.

- The tank has to withstand operating temperatures between $-40^{\circ} \mathrm{C}$ and $+85^{\circ} \mathrm{C}$, and the overall hydrogen permeation/leak rate of the tank should be maintained below $1 \mathrm{~cm}^{3} / \mathrm{hr}$ per tank-liter in order to meet the ISO TC 197 standard and the TRANS/WP29/GPRE/2004/3 regulations.

During research at MAGNA STEYR more than 50 liner systems were developed and analyzed during the first two years to address the issues of hydrogen permeation and chemical compatibility during compressed gas storage. Two different composite systems were developed and investigated for high pressure storage of hydrogen:

- The first system is based on a thermoset resin wet winding process on thermoplastic liners or metallic liners, with special emphasis on tank manufacturing and the development of a processing technology for high volume production. Both 6 liter and 34 liter, 700 bar tank prototypes were manufactured and characterized for design validation and cycling behavior. 
- The second system is a thermoplastic-based modular multi-cylinder storage system, with special emphasis on continuous cylinder production, dome production and joining. The feasibility of manufacturing composite tubes with thermoplastic matrix material in combination with reinforcement fibers and a thermoplastic liner has been successfully demonstrated. The device for thermoforming the cylindrical section to the metallic end-caps has been already set up. The first tanks based on this system were manufactured and tested; the results obtained will contribute to the optimization of the process (Strubel, 2007).

The MAGNA STEYR hydrogen tank prototypes of varying size are shown in Figure 2.3. The results indicated that such developed 700-bar tanks can achieve gravimetric densities about $5 \mathrm{wt} \%$ and volumetric and $0.6 \mathrm{kWh} /$ liter. Preliminary cost analysis indicated that large scale production of the thermoset and thermoplastic tank will cost approximately 500 dollars for each kilogram of the stored hydrogen.
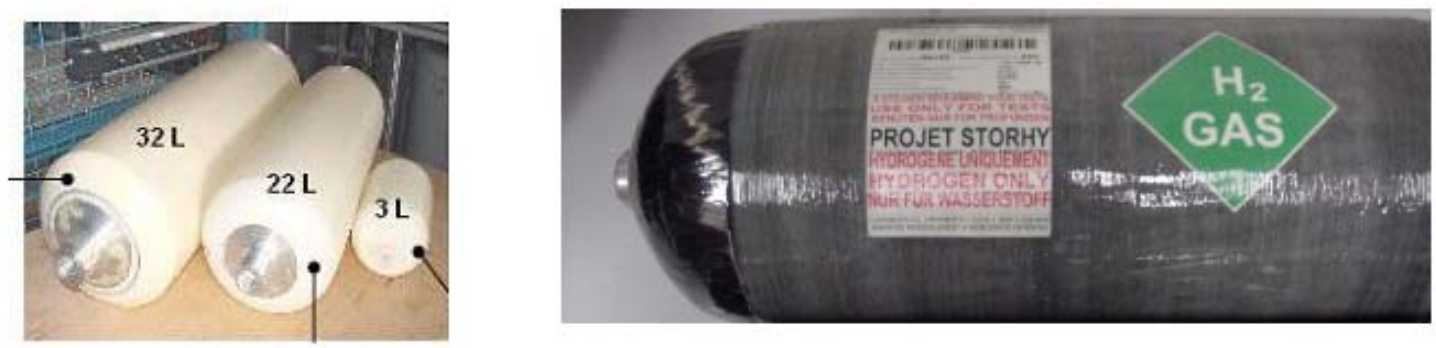

Figure 2.3: Plastic liners of different volume and a complete 700 bar cylindrical hydrogen pressure vessel.

\subsubsection{Honda FCX}

Honda demonstrated the use of compressed hydrogen tanks in its new fuel cell vehicle FCX (Honda, 2008). The vehicle utilizes a high-pressure hydrogen tank that is made of an aluminum liner wrapped with carbon fibers. The fuel capacity of this tank is $3.75 \mathrm{~kg}$ of hydrogen with an internal pressure of $34.5 \mathrm{MPa}(5,000 \mathrm{psi})$. The FCX brochure, shown in Appendix I, indicates that the tank is cylindrical in shape with oblate end caps. Sarkar and Banerjee (2005) assumed that the liner thickness is $0.241 \mathrm{~cm}$ at the cylindrical parts and thickens by factor of 3.5 at the domes of the end caps. As a result, 
the tank mass was estimated to be $56.91 \mathrm{~kg}$, i.e. can achieve gravimetric density of about $6.6 \mathrm{wt} \%$. They also estimated that the net energy required to produce and compress $1 \mathrm{~kg}$ of hydrogen in such a tank is $202 \mathrm{MJ} / \mathrm{kg}$.

\subsubsection{Daimler Chrysler F-Cell Vehicle}

The F-cell vehicle has been built by Daimler Chrysler based ob the MercedesBenz A-class technology (Daimler Chrysler, 2006). This test vehicle was built under near production conditions. The entire fuel system cell system is located in the sandwich construction floor, which kept the interior space of the car the same. The system utilized two cylindrical hydrogen tanks of maximum pressure of 350 bar $(5,000 \mathrm{psi})$. It is reported that the performance of this vehicle is comparable to that of an internal combustion engine vehicle. In 2007, the company Daimler Research and Development team started testing the new B-Class F-Cell in Sweden. In this version, the pressure in the hydrogen tank was doubled from 350 to 700 bars, which boosted the vehicle's driving range to 400 kilometers (Daimler Chrysler, 2008).

\subsubsection{Liquid Hydrogen Storage}

Storing hydrogen in a liquid form is another method to increase the hydrogen energy density within a storage volume. However, issues concerning liquid hydrogen $\left(\mathrm{LH}_{2}\right)$ storage systems are complex and entail hydrogen boil-off, the means for generating the energy required for hydrogen liquefaction, volume, weight, and tank cost. The liquefaction process of hydrogen requires a large amount of energy. The energy value to reach a liquefied state of hydrogen is typically $30 \%$ of the heating value of hydrogen (Zittel, 1996). Current research to develop liquefied hydrogen at lower energy requirements and therefore reducing cost is extensive. Issues such as hydrogen boil-off, efficiency, driving range, and safety requirements must also be addressed for cost consideration and system functionality. A cryogenic temperature level of $77^{\circ} \mathrm{K}\left(-321^{\circ} \mathrm{F}\right)$ must be reached and maintained to convert and keep hydrogen at a liquid medium. This low level of operating temperature requires a tank that is highly insulated thus creating 
penalties in the system gravimetric and volumetric capacity. In comparison to a compressed gas system, the volumetric capacity of liquid hydrogen is $0.070 \mathrm{~kg} / \mathrm{L}$ as opposed to $0.030 \mathrm{~kg} / \mathrm{L}$ for a 10,000 psi gas tank (Amasedar, 2006) Therefore, the advantages of liquid hydrogen storage are high energy density at low pressures and transportation characteristics that do not require extensive pressurization. Storing liquid hydrogen at an operation pressure of $72.5 \mathrm{psi}(0.5 \mathrm{MPa})$ has an equivalent hydrogen energy density as a compressed gas storage system with a pressure level of $29 \mathrm{kpsi}$ (200 MPa) (Krainz, 2004). The low pressure state of an $\mathrm{LH}_{2}$ storage tank allows for geometries other than spherical or cylindrical tanks to be used, thus creating options to conform the container to open spaces on-board vehicles.

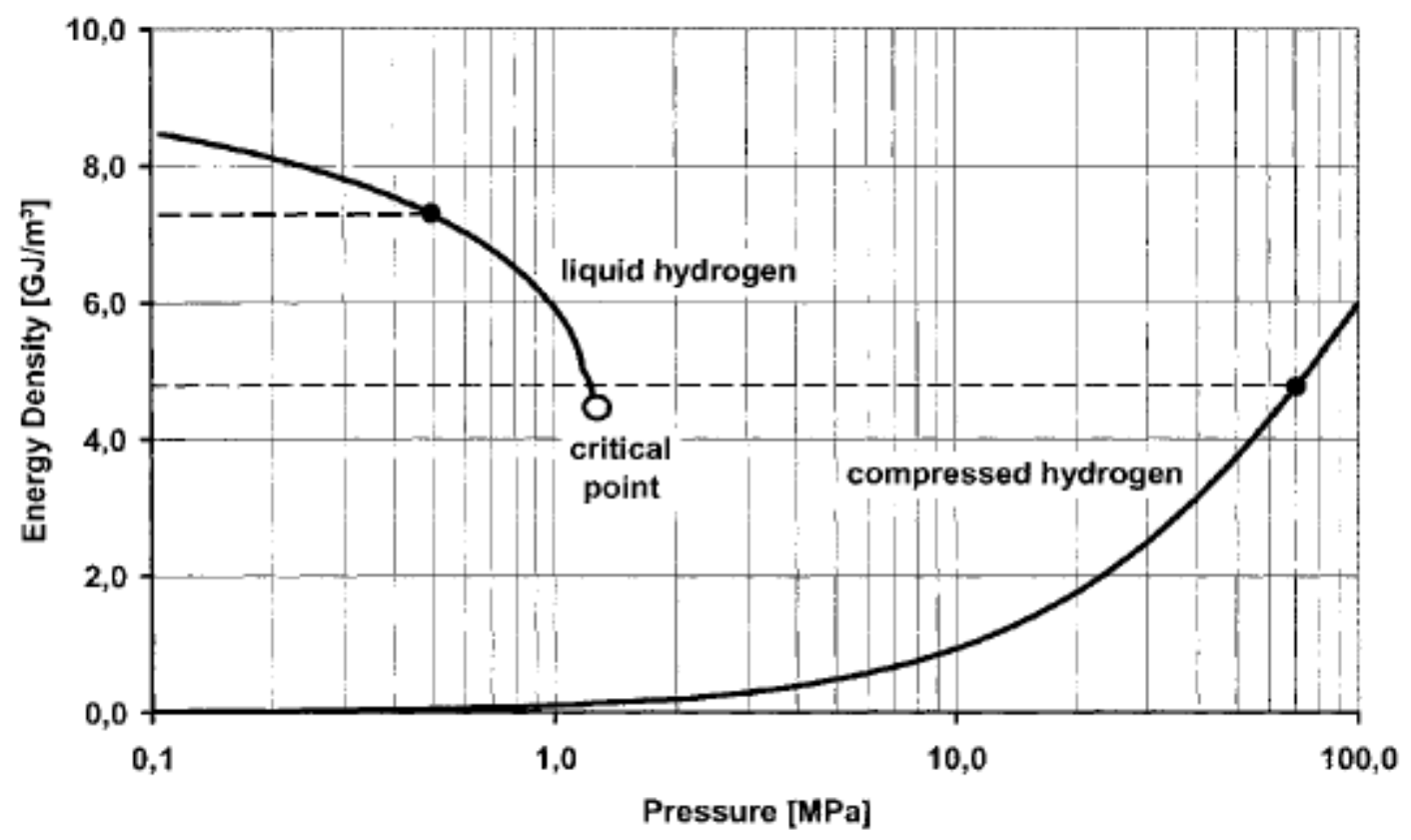

Figure 2.4: Energy density of gaseous and liquid hydrogen as a function of pressure.

Figure 2.4 graphically displays the energy density comparison of storage mediums between liquefied hydrogen and compressed gas hydrogen as a function of pressure (Peschka, 1997). Liquid hydrogen is beneficial by the criteria of low storage pressure levels, however, the drawbacks to this type of storage are characterized by boil- 
off due to finite heat inleak to the isolated container and sophisticated thermal insulation systems to maintain cryogenic temperatures. Boil-off of hydrogen fuel is a characteristic of hydrogen at cryogenic temperatures the rate at which hydrogen boils off is governed by the heat leakage of the insulating system (Dumn, 2001).

\subsubsection{Liquid Hydrogen Storage System Design}

Some manufacturers of compressed gas storage systems also have initiated design configurations for other methods of hydrogen storage. MAGNA STEYR, a company who was previously mentioned for fabricating compressed gas systems also has designed a liquid hydrogen storage unit in detailed measure. A detailed description of an LH2 design from a publication by Krainz et al., titled Development of Automotive Liquid Hydrogen Storage Systems is summarized in this section.

According to the authors, an advanced liquid hydrogen storage system will consist of double-wall cylindrical tanks of stainless steel or aluminum alloy due to their resistance to hydrogen brittleness and hydrogen permeation. The double-wall design allows for spacing between the inner and outer vessels which will house thermal insulation. The spacing between the two vessels is created by carbon fiber support structures to keep the inner tank and outer tank fixed in position. The insulation is composed of reflective aluminum or aluminized polymer foils with a separation of glass fiber spacers. A vacuum condition is created between the inner and outer vessels to minimize thermal convection. 


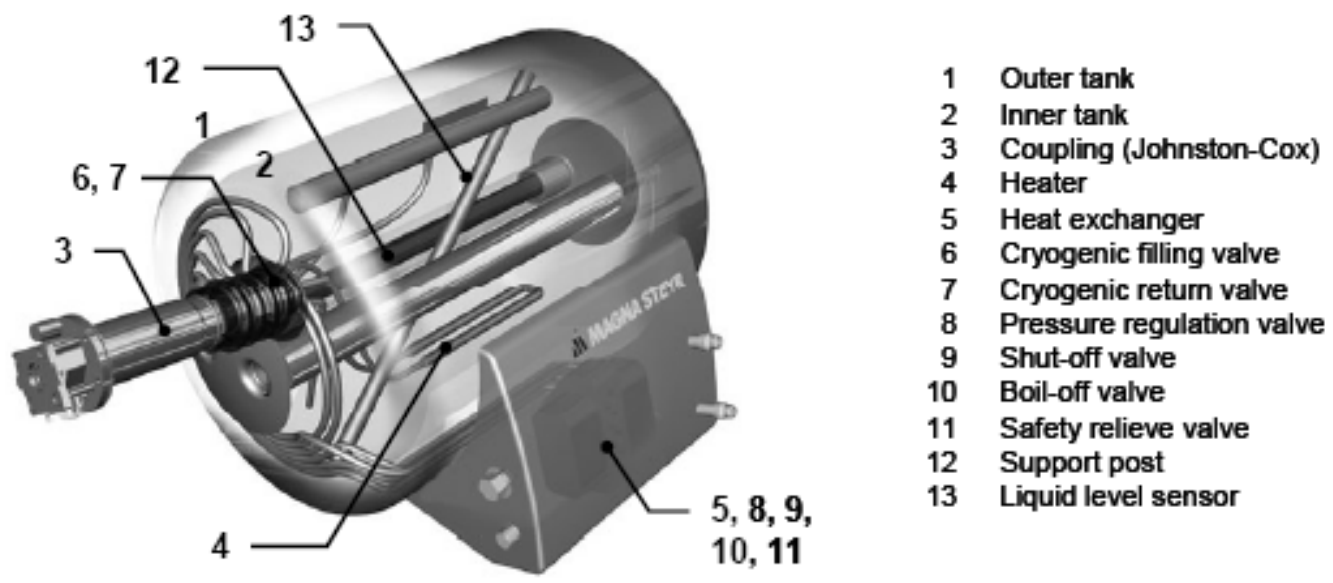

Figure 2.5: Detailed description of a MAGNA STEYR liquid hydrogen storage system.

A schematic of the detailed parts and location within the liquid hydrogen storage system are displayed in Figure 2.5. For a stainless steel design having a wall thickness of $2 \mathrm{~mm}$, the weight of the entire tank is projected at $100 \mathrm{~kg}$.

British automaker, BMW, in conjunction with The Linde Group Engineering Co. has also developed a liquid hydrogen storage system with similar principles as the previously mentioned design. Figure 2.6 details the design concept which is a doublewall, vacuum pressure design to attain and maintain cryogenic temperature levels. Between the double-walls, approximately 70 layers of aluminum coated synthetic foil are used as a thermal insulation barrier (Greencarcongress.com, 2006) 


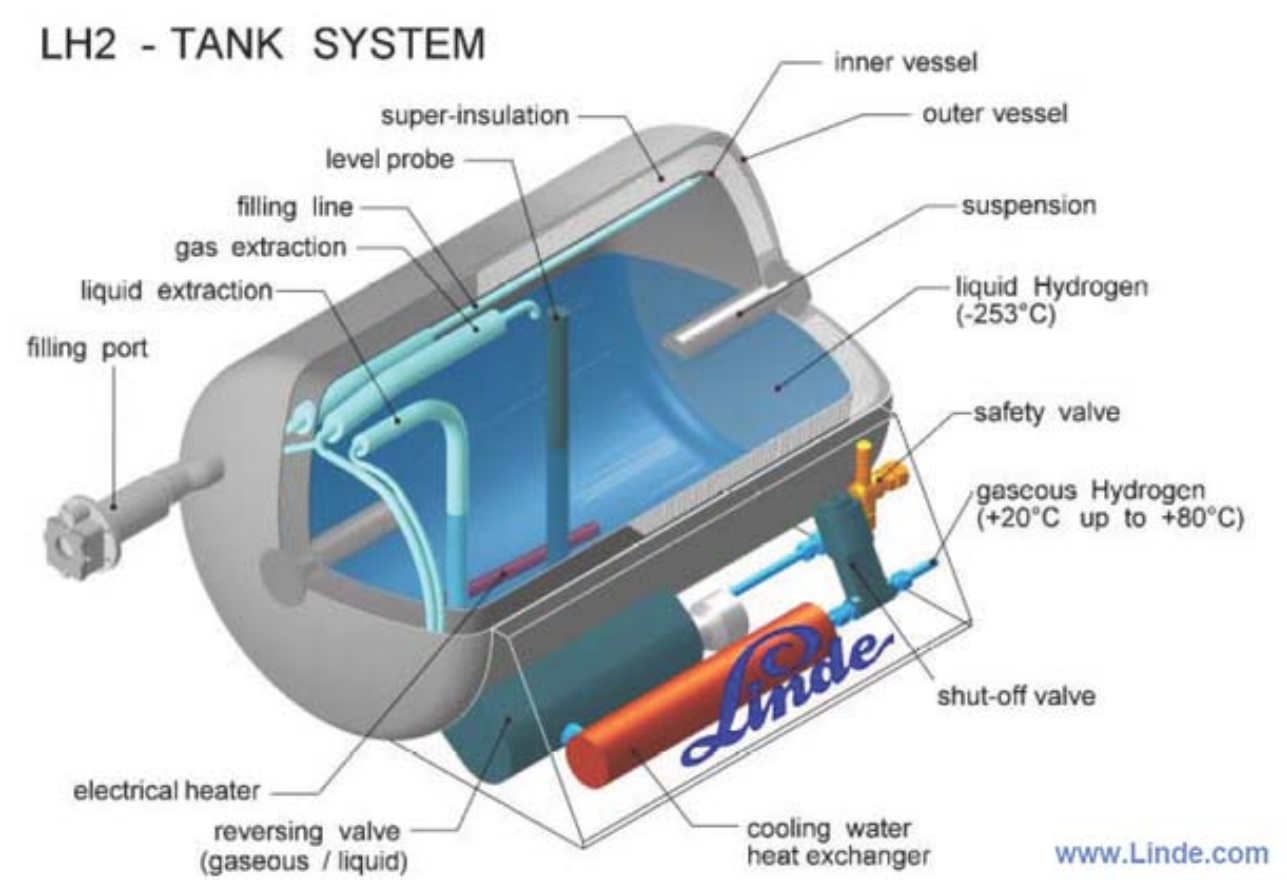

Figure 2.6: Liquid hydrogen storage system by Linde.

\subsubsection{Hydride Hydrogen Storage}

A solution to avoiding the high operating pressures of a compressed gas storage system and the cryogenic temperature levels of liquid hydrogen storage is the storage of hydrogen in a hydride form. This method utilizes an alloy capable of absorbing and storing large amounts of hydrogen through chemical bonds. The bonds form hydrides which are compounds of hydrogen and another more electropositive element or group (Wronzki, 2001). Metal hydrides have the capability to release hydrogen energy at low temperatures and pressures along with the reversibility of storage or output within the system. The common temperature and pressure range for suitable metal hydride operation is $25-120^{\circ} \mathrm{C}$ and $1-10 \mathrm{~atm}$, respectively.

The metal hydride storage system has developed substantially in part because of the increased field of research for a hydrogen economy and energy carrier. Metal hydrides are referred to as rechargeable because they have the ability to create hydrogenalloy bonds, release the bonds and then create them again as a storage-release process. Rechargeable metal hydrides are an alternative to compressed gas and liquid hydrogen 
storage and are capable of storing large amounts of hydrogen at ambient temperatures and pressures. Other advantages of metal hydride storage is the ability to deliver very pure hydrogen which is beneficial when operating Proton Exchange Membrane (PEM) fuel cells which use a platinum catalyst that can be easily poisoned by impurities, and the negligible loss of hydrogen during hydride storage (Eichenberg, 2005).

In studies by Sandrock, (Yurum,1996) the general process of hydrogen absorption by a metal first follows a physic-absorption phase on the surface and then dissociates and chemisorbs via a strong bond of individual hydrogen atoms. The small and light hydrogen atoms can quickly diffuse from the surface to the periodic sites in the metal crystal lattice as seen in Figure 2.7.

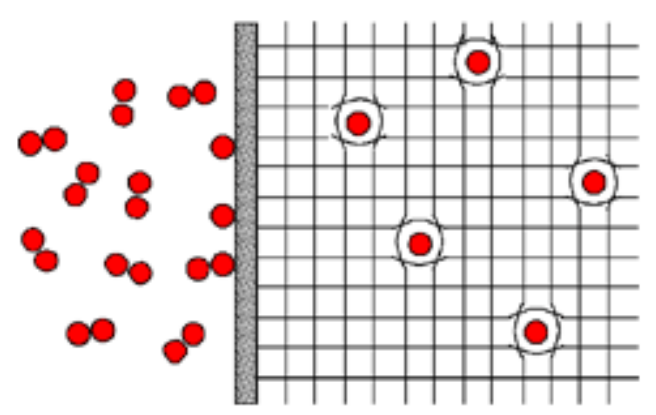

Figure 2.7 Hydrogen adsorption and disassociation of molecules into the metal crystal lattice

The strength and type of the hydrogen-metal bond determines whether the reaction is exothermic (liberates heat) or endothermic (absorbs heat). The process of which depends on the property of the metal, if the metal has a high affinity for hydrogen then it will absorb hydrogen into its lattice only with the addition of heat, yielding an endothermic reaction. The majority of hydride systems are exothermic; however, there are three classifications that govern the type of hydride: Ionic, Covalent and Metallic hydrides. Ionic hydrides are formed by alkali and alkaline earth metals such as $\mathrm{LiH}$ and $\mathrm{CaH}_{2}$. They are highly exothermic and composed of very stable bonds. Covalent hydrides involve shared bonds which are typically weak. Metals of $\mathrm{Ge}, \mathrm{Sn}$ and $\mathrm{Pb}$ make up covalent hydride metals and are relatively unstable and gaseous at room temperature.

Ovonic Hydrogen Systems has had success in the field of solid-state hydrogen metal hydride storage. Ovonic's solid hydrogen storage system currently can provide a 200 mile driving range utilizing the same volume allotment as a standard sedan size 
gasoline tank (Stanley, 2006). This unit stored $3 \mathrm{~kg}$ of hydrogen and weighed $190 \mathrm{~kg}$ with a volume of $70 \mathrm{~L}$, relating to a $1.6 \mathrm{wt} \%$ and $0.042 \mathrm{~kg} \mathrm{H} / \mathrm{L}$.

The type of hydride determines its operating conditions and storage properties. The simplest hydrides are metal or intermetallic hydrides such as FeTi and LaNi. These hydrides have a high volumetric hydrogen storage density $(\sim 0.11 \mathrm{~kg} \mathrm{H} / \mathrm{L})$ but a low storage weight percentage of (2-3 wt\%) of hydrogen per unit weight of the material. For higher gravimetric and volumetric storage densities, temperature hydrides $\mathrm{MgH} 2$ and $\mathrm{MgNiH} 2$ are options. These hydrides operate at pressures between 5 and $10 \mathrm{~atm}$ and temperatures around $350 \mathrm{C}$. These hydrides have higher weight percentage (3-8 wt $\%)$ and volume storage (0.13-0.15 kg H2/L). $\mathrm{MgH} 2$ and $\mathrm{MgNiH} 2$ hydrides are considered high temperature hydrides and due to high operating temperatures their operation in light duty vehicles is minimal. NaAlH4 highlights a type of hydrides using alanates or combinations of alkali metals and aluminum (Bogdanovic, Schwickardi, 2001) Through the use of a catalyst the operating temperature of $\mathrm{NaAlH} 4$ hydride is reduced from $300-400 \mathrm{C}$ to 100 $\mathrm{C}$ with pressures around $10 \mathrm{~atm}$, leading to $4-5 \mathrm{wt} \%$ and $0.08 \mathrm{~kg} \mathrm{H} 2 / \mathrm{L}$ storage conditions. Due to higher wt $\%$, low operating temperature, and cost efficiency, NaAlH4 is revered as the leading candidate as a metallic hydride for hydrogen storage.

Chemical hydrides generate hydrogen through a chemical reaction. The most common reactions involve chemical hydrides with water or alcohols. When water is combined with the chemical hydride the process is called hydrolysis. Sodium borohydride (NaBH4) is the most common chemical hydride and through hydrolysis it yields high purity hydrogen. NaBH4 hydrolysis produces a system gravimetric capacity of $4 \mathrm{wt} \%$. $\mathrm{MgH} 2$ produces an even higher system gravimetric capacity with a value as high as $11 \mathrm{wt} \%$. Both hydride hydrolysis processes are limited by the necessity to carry water on-board for the chemical reaction and regeneration of both $\mathrm{NaBH} 4$ and $\mathrm{MgH} 2$ must occur off board. 


\subsection{Manufacturing Methods for a Compressed Gas Storage System}

A complex system such as a compressed gas storage system for hydrogen fuel initiatives is tailored by its strength and weight performance. Composite materials such as fiberglass and carbon fiber are beneficial over standard metal and alloy materials because of their exceptional strength and tailorability to design. Also, composite material applications are common for weight saving initiatives where excessive weight has unfavorable effects on the system in which the part is performing.

Several manufacturing methods are used to create composite parts. A brief description of the various methods of manufacturing composites follows in this section.

\subsubsection{Hand Lay-up}

The hand lay-up process is also referred to as a wet lay-up. It combines the reinforcement fibers with a liquid resin in a mold. Layers of fibers are placed into the mold and saturated with the resin. The part is hand rolled to create a uniform resin coat and extract any voids or air pockets within the combination. Layers are added until the thickness or desired orientation of fibers is reached. The curing process is the final stage of the hand lay-up manufacturing; it involves the chemical process of the resin changing state from a liquid to a solid (Barbero, 1999).

The lay-up process begins with the development of a proper mold to accommodate the desired part geometry and requirements of the curing process. The material used for a mold depends on the number of times the mold will be used, temperature and pressure of the curing process, and the manufacturing of the mold itself. To avoid the resin curing to the mold and damaging the finished part by forced removal, a release agent is applied to the areas where the mold and resin come into contact. Common release agents are wax, poly vinyl alcohol, silicones, and release fabric.

The fibers are then placed on the mold to be saturated with resin. The proper measurements of mixing ratio of the resin and catalyst must be carefully followed and mixed thoroughly before application. After the different layers of fabric have been applied to the mold and saturated with the resin, hand rollers are used to compress the 
layers together and against the mold. Hand rolling of the lay-up ensures removal of any air pockets that will become voids during the curing process if not removed. The curing process is usually done at room temperature. However, elevated pressures are sometimes applied to the part during the curing process to remove excess resin and air via bag molding (Barbero, 1999).

\subsubsection{Bag Molding}

Pressure can be applied to a laminate during the curing process by using bag molding techniques. Vacuum bagging uses a flexible plastic or bag that is placed over the laminate and sealed. A vacuum pump is connected so the air is pumped out from the inside of the bag which ultimately applies a uniform pressure onto the top surface of the laminate. The pressure forces the laminate against the mold creating an accurate resemblance to the mold geometry while removing excess resin and air (Slobodzinsky 1982).

The three main methods of applying a pressure to a laminate are by pressure bag, vacuum bag, and autoclave manufacturing. Vacuum bagging is a popular manufacturing process because it is relatively inexpensive, allows large size parts to be manufactured, and the quality of the resulting part is mainly dependent on the manufacturer's skill and not a machining process.

\subsubsection{Autoclave Processing}

Autoclave processing assists vacuum bag and pressure bag molding by applying heat and pressure to a laminate during the entire curing cycle. Curing pressures for autoclave processing are usually in the range of $50-100 \mathrm{psi}\left(377.5-755 \mathrm{~kg} / \mathrm{m}^{2}\right)$. The benefits of autoclave processing are to produce a laminate with higher density and reduce the amount of time to completely cure a laminate (Meade, 1982).

Autoclave processing is expensive, timely and laborious. The high cost of autoclave processing is a result of the autoclave itself, industrial gases such as nitrogen used for pressurization, and specialized lay-up materials that are not affected by elevated temperature and pressure. However, autoclave processing produces high quality, complex laminates and is beneficial for large parts and average production quantities. The method 
is very common in aerospace applications but for the research done at the university level, autoclaves are not as common because of the expense involved. An autoclave was not used for the research in this work because of cost reasons.

\subsubsection{Compression Molding}

Compression molding is a molding method in which the molding material, generally preheated, is placed in an open heated mold with matching male and female dies. The dies then close onto the material by the means of a hydraulic press, the assistance of heat and fairly high pressure cures the fibers and resin. After the part has completely cured the mold dies are lifted and the finished part is removed from the mold (Young, 1982). Compression molding is a fairly simple method which allows for high productive rates and moderate operation costs.

\subsubsection{Pultrusion}

Pultrusion is a continuous process for manufacturing composites with a continuous cross-sectional shape. In this process, fibers are impregnated with resin and carried through a die which forms the reinforcement to the desired shape and then heat is applied to cure the part (Starr, 2000). Pultrusion is effective because it is inexpensive and can produce parts of any length by converting continuous fibers and resin into a solid laminate. The process is performed by pulling continuous fibers through a heated die which shapes and cures the fiber and resin.

\subsubsection{Resin Transfer Molding}

Resin transfer molding (RTM) is an effective method to produce large continuous fiber composites. Complex shapes can be produced under short cycle times and the method provides the manufacturer with control of part specifications such as fiber orientation for optimum material properties (Mallick, 1993).

The RTM process is performed by a mold with ports to inject resin into the dry fiber and outlets which allow air to escape. The process consists of placing the dry fiber in the mold and closing it. The liquid resin is pumped into the closed mold until it is 
completely full. The ports are then sealed and heat is applied. After the part has cured, the mold is opened and the finished composite part is then removed (Astrom, 2002).

\subsubsection{Filament Winding}

Filament winding is the oldest and most frequently considered process for machine dominated composite structures manufacturing (Shen, 1995). It is an automated process in which continuous filament is treated with resin and wound on a mandrel in a pattern which will provide strength in one direction (Peters et al., 1991). The process is performed by drawing the reinforcement from a spool or creel through a bath of resin, then winding it on the mandrel under controlled tension and in a predetermined pattern. The mandrel may be stationary, in which event the creel structure rotates above the mandrel, or it may be rotated on a lathe about one or more axes. By varying the relative amounts of resin and reinforcement, and the pattern of winding, the strength of filament wound structures may be controlled to resist stresses in specific directions. After sufficient layers have been wound, the structure is cured at temperature. The most common shapes to produce by this process are revolved surfaces such as pipes, cylinders, and spheres (Lee and Suh, 2006).

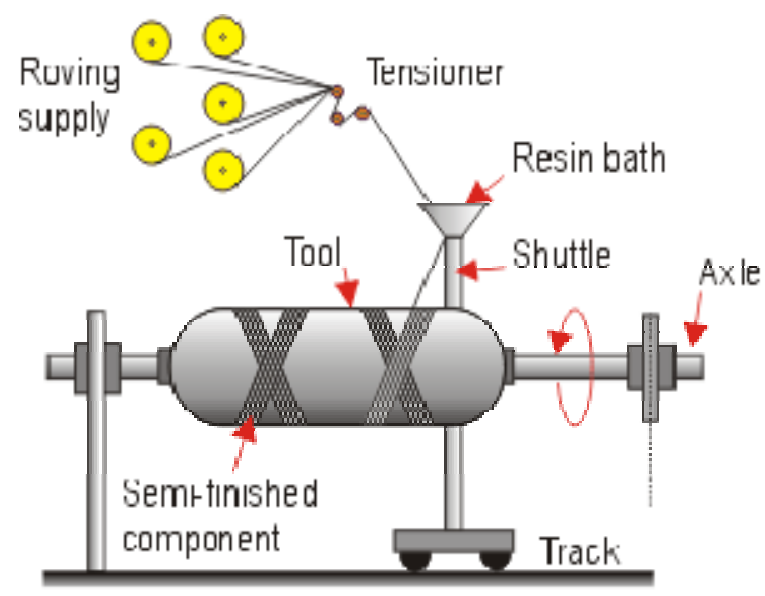

Figure 2.8: Filament winding Process. Reference: www.azom.com AZo Journal of Materials Online, 2009.

Figure 2.8 is a schematic showing the general concept of filament winding. The precise geometric patterns created by the filament winding process are accomplished by 
rotating the mandrel while a delivery head precisely positions fibers on the mandrel surface. The principle of filament winding operation is to control the machine motion through various axes of rotation or motion. The most basic of these motions are the spindle or mandrel rotational axes, the horizontal carriage motion axis and the cross or radial carriage motion axis. Additional axes can be added to meet the manufacturing demands, typically a rotating eye axis or a yaw motion axis.

As shown in Figure 2.8, the shape of the part produced takes the form of the mandrel. The need for a mandrel limits the shapes that can be produced, especially in cases where the mandrel needs to be removed after the winding process. Many types of mandrels have been developed to facilitate removal; other designs utilize a metallic liner as a mandrel which is left as an integral part of the end product.

\section{Applications}

Piping, Pressure vessels, rocket motor casings, storage tanks and basically all general tubular structures are commonly produced by filament winding. Many years of development leading to optimization of more advanced filament winding techniques has increased the possible complexity of shapes and geometries ably produced by filament winding. This is mainly attributed more advanced winding machine systems applied in conjunction with design software. New applications in filament winding include bushings, bearings, driveshafts, fuselages, bicycle frames, pressure rollers, shafts, bent shafts, and tubes.

Major advancements in filament winding have been made in the area of pressure vessels, particularly rocket motor casings and hydrogen storage systems. In these types of structures the fiber reinforcement is loaded solely in tension. Using the filament winding process to fabricate a part for this type of application ensures the arrangement of the fibers will coincide with the directions of the principal stresses. Therefore, the utilization of advanced composite materials is applied by high strength and stiffness in the reinforcing direction. 


\section{Materials}

The materials used in a filament winding machine are the yarns or continuous fibers and a thermoset resin. The type of resin whether it is in "wet" or in a preimpregnated form depends on the filament winding machine. A wet winding process involves saturating the yarn in a resin bath before winding and a prepreg form uses a fiber tow with a dry resin previously applied. The advantages of using prepreg tows are keeping a uniform fiber distribution and resin content throughout the thickness of the part. Carbon, glass, and kevlar fibers all can be used in the filament winding process. Which type of material to be used depends on the application of the part and the desired cost. Glass is commonly used for low cost applications. Carbon and Kevlar are used in lightweight, high performance applications.

There are many different types of resins used in the composite industry, the majority or structural parts are made with three main types epoxy, polyester and vinylester. These types of resins are categorized as thermoset resins. Thermoset resins are characterized by a chemical reaction where the mixture of the resin and hardener creates a nonreversible reaction to form a hard infusible plastic. After curing, thermoset resins will not return to liquid form when heated. Thermoplastics resins such as, nylon, polypropylene, ABS, soften and eventually liquefy when exposed to heat and harden again with cooling.

\section{Wet Winding}

A "wet" filament winding process is characterized by the distribution of the resin onto the fiber filament. In this process, spools of dry fiber (tows) supported by a creel and threaded around tension bars which regulate the constant fiber tension by a closedloop, servo driven system. The tension of the fiber is an important parameter for the filament winding process. The amount of applied tension is dependent on the fiber material, part diameter, and wind pattern. The tension of the wound fibers affects the void content and fiber volume of the fabricated composite part.

The fiber is unwound from the spool; it is dipped into a resin bath and fed through a comb into the fiber payout eye. To initialize the automated filament winding process, the impregnated fiber must first be wrapped by hand onto a clean mandrel which 
has been prepared by a proper mold release agent. At this point, the operator now initializes the filament winding machine which continues the winding process by automated programming.

\section{Tow-Preg Winding}

The tow-preg winding method is characterized by winding with the fibers preimpregnated in resin these types of fiber filaments are known as tow-preg. After several layers of tow-preg are wound, the part is cured and removed from the mandrel.

\subsection{Liner Design and Manufacturing Review}

The desired application of compressed gas hydrogen storage pressure vessels is to reach the allowable maximum working pressure and maximize the hydrogen energy density within the system. The constraints of staying within a minimum volume capacity, maintaining a low weight design, and cost effectiveness affect the possibilities of applicable designs. The first step in the design process is to understand the liner construction and its overall purpose within a compressed gas system. The initial concept for consideration when designing a liner to be used in a pressure vessel is the material. Common liner materials for light-weight on-board hydrogen storage tanks include polymers and aluminum and in some cases, stainless steel. Steels are effective but cannot overcome the weight constraints due to the high weight density properties of steel and are also affected by hydrogen embrittlement on the metallic interior when contacted with hydrogen under internal pressure.

\subsubsection{Permeation and Embrittlement}

Prevention of hydrogen permeation through the liner barrier is another important point of interest affecting the liner design. Several studies have been performed to characterize the aspects of hydrogen permeation, such as, permeation and diffusion in different metals, hydrogen permeation at varying pressure levels, methods of measuring hydrogen permeation, etc. (Leon, 2008). Hydrogen permeation is an issue within 
hydrogen storage system design and is directly contributed to the chemical nature of hydrogen and its minute atomic size.

Hydrogen embrittlement is another issue concerning the interaction between the compressed hydrogen and metallic liner structure. Metallurgical studies have considered the effects of hydrogen and its capacity to embrittle many metals and have shown how hydrogen interactions with metals reduce their ductility and also strength (Rogers, 1999). Hydrogen absorbed into a metallic surface may react irreversibly with oxides or carbides in some metals to produce a permanently degraded structure. Hydrogen may also recombine at internal surface defects to form gaseous molecular hydrogen and under pressures sufficiently high metallic blisters are formed. In other metals, brittle hydrides that lower the mechanical properties of the metal are formed. According to different theories hydrogen interferes with the processes of plastic deformation in metals, while according to others it enhances the tendency for cracking (Kirchheim, 1988).

\subsubsection{Manufacturing Processes}

The overall manufacturing process of a complete compressed gas polymer composite hydrogen storage system includes the fabrication of the polymeric or metallic liner, filament winding of the composite reinforcing shell, thermal processing of the resin matrix, preliminary pressurization and permeation testing, and subsequent assembly of various components to complete operation. However, the fabrication of the liner itself is a challenging task when considering its structural performance requirements. In addition to selecting a material for the liner compatible with permeation and embrittlement constraints, a seamless liner without imperfections is required to prevent stress concentrations and premature failure under pressure loading.

\subsubsection{Nonmetallic Polymer Liners}

Seamless polymer liners are manufactured by a thermoplastic molding process, such as blow molding or rotational molding. Blow molding is method to produce hollow polymer structures. The process involves melting of the polymer into a preform medium then mounting to a mandrel where compressed gas is passed into the preform to stretch the plastic to meet the exterior mold. The mold is then ejected leaving the solid polymer 
part. Rotational molding is a method of producing stress free parts, utilizing hollow metal molds that are rotated bi-axially in a heated oven. It is possible to incorporate metallic hardware into the polymer liner by careful design and process optimization. Injection molding is another method of liner fabrication which involves molding end domes to encapsulated end bosses and applying a weld connection to a prefabricated cylindrical pipe portion. The introduction of welds involves careful and precise fabrication to ensure the welds are free of voids and match the mechanical properties of the rest of the liner.

The leading candidate material for composite pressure vessels with nonmetallic polymer liner is high density polyethylene (HDPE). HDPE has been established within the automotive industry for several years due to its lightweight, inexpensive and manufacturability properties. A HDPE liner is advantageous to hydrogen storage because it provides a leak-proof permeation barrier. Brunswick Composites located in Lincoln, Nebraska has extensively studied the use of high density polyethylene as a liner material. The research at Brunswick states that HDPE is resistant to hydrocarbons and can effectively resist and contain petroleum based fuels and oil mediums. It is also resistant to moisture and corrosive agents such as hydrogen sulfide. HDPE is usable over $\mathrm{s}$ temperature range and through the study of cyclic tests Brunswick has shown the minimum operating temperature to be $-40^{\circ} \mathrm{F}$ and softening temperature to exceed $250^{\circ} \mathrm{F}$. HDPE was characterized to have good fracture toughness and impact properties. A high cyclic fatigue life was achieved when HDPE was used as a pressure vessel liner. Permeation characteristics for HDPE have shown to be low for contained gases with measured values less than $10^{-5} \mathrm{scc} / \mathrm{sec}$ helium at 3,000 psi. Further reduction of permeation rates can be achieved by additives such as surface treatments of fluorination of sulfonation or by combining HDPE with other materials through a co-extrusion process (Murray et. al., 1992).

Several manufacturing methods are used to create plastic, nonmetallic liners. These methods are thermal spray, blow molding, injection molding, rotational molding, extrusion, and welding. 


\section{Thermal Spray}

Thermal spray is a manufacturing method to form polymer coatings. NASA has innovated a method to form a sprayable polymer film using powdered precursor materials and an in-process heating method (Coguill et.al., 2008). This process directly applies the powdered polymer onto a substrate forming an adherent film. The thickness of the film is regulated throughout the process which can produce both fully dense and porous coatings. The thermal spray coating process can achieve a thickness of 0.0001 to greater than 0.750 inch. The process can create functional gradient coatings by layering dissimilar coating materials so their properties work together. Thermal spray coating and forming is applicable to metallic and nonmetallic substrates. Three different thermal spray coating and forming processes are listed:

- Vacuum Plasma Spray - applies metals in thick layers but is costly and requires vacuum chamber operations.

- High Velocity Oxyfuel Spray - applies many material types and is cost effective. This method has no coating thickness restrictions providing an end result of a dense, well-adhered coating.

- Wire Arc Spray - a cost-effective method for material applications. The application process melts two advancing wires through an electrical arc then introduces a high velocity gas that propels the coating toward the substrate. This allows for rapid prototyping and can coat a foam mandrel and then wash out the foam, leaving a working prototype. This prototyping method can directly create vessel liner geometry.

This method of thermal polymer spray does not require solvents which keeps the process from being toxic and releasing volatile organic compounds. The differences between the previously mentioned processes are layering thickness, cost, and type of base material being coated. These methods do not produce molecular bonds within the layered coating; therefore removal of coated layers is possible through machining techniques. 


\section{Blow Molding}

Blow molding or blow forming is a process used to create hollow plastic parts . The process of blow molding starts with melting the plastic material to form a parison or preform. The parison is a tube structure with an opening in one end to pass compressed air into the hollow cavity of the plastic. The parison is clamped into a mold and air is pumped into it. The air pressure displaces the plastic out against the form of the mold. The plastic is then cooled and hardened. Once hardening is complete, the mold is removed and the solid plastic part is ejected (Lee, N. 1998).

Hollow blow molding parts can range in volume from 1/10 gallon to 55 gallon. The manufacturing process is inexpensive and highly controlled. The plastic materials used are thermoplastics including polyethylene (PE), polyvinyl chloride (PVC), and polyethylene terephthalate (PET) (Roasato, 1989).

\section{Injection Molding}

Injection molding uses thermoplastic and thermosetting plastic materials. In this process a mold is created with the desired geometry of the finished part. The plastic material is heated until a fluid state is attained. The liquefied plastic is injected into the mold where it is cooled and hardened in the mold cavity geometry. Injection molding is capable of achieving tolerances of \pm 0.008 in. for thermoplastics and $\pm 0.002 \mathrm{in}$. for thermoset plastics. Thickness values of injection molded parts range from 2 to 20 inches and a uniform thickness throughout the part can be maintained (Maunfacturing Processes Reference Guide, 1994).

Common materials used in injection molding are epoxy, nylon, polyethylene, and polystyrene.

\section{Rotational Molding}

Rotational Molding is a plastic forming process that utilizes biaxial rotation in cooperation with high-temperature and pressurization to produce hollow, one-piece parts. 
The process involves loading a measured quantity of powdered polymer into a mold. The mold is heated and rotated until the entire polymer has melted and adhered to the mold wall. In order to create a uniform thickness and avoid accumulation of the polymer powder rotation through two or more axes and at various speeds is done. The mold is then cooled to solidify the plastic. The mold is then removed leaving the finished plastic structure (Crawford, 2002).

Rotational molding produces stress-free parts and can incorporate metallic hardware in the polymer liner. Accurately manufacturing liners with included hardware is an intricate process and requires careful design steps and process optimization. Metal hardware is implanted in the liner for nozzle and valve connections in the polar boss region.

\section{Extrusion Molding and Plastic Welding}

Extrusion molding is a process used to create parts of a constant cross-sectional profile. The process involves drawing a material through a die made to the desired crosssectional shape and dimension. Plastic extrusion involves heating of the polymer resin to a molten state. An extruding screw forces the resin through a die which forms the desired shape of the part. The extruded part is cooled and solidified as it is pulled through the die (Rosato, 2002).

As mentioned, extruded parts can only be manufactured by with a constant crosssectional profile. Therefore, a one-piece liner can not be fabricated. Extrusion is used to create the cylindrical section of a plastic liner and then a plastic welding process is performed to connect the cylindrical body to the end domes. Plastic welding is a process of connecting plastic parts. There are several welding methods used to perform plastic welding which include hot gas, speed tip, extrusion, contact, high frequency welding, ultrasonic, friction, spin, and laser welding (Rosato, 2002). The processes of the different types of plastic welding mentioned all differ but utilize the reforming properties of plastics as the means of connecting two separate plastic entities. 


\subsubsection{Metallic Liners}

Fabrication processes have been developed for thin metallic liners to eliminate the need of welds as a joining concept. Thin metallic liners are made by flow forming prefabricated tubes to achieve the desired diameter and wall thickness. Spin closing then forms the end domes of the vessel liner. Heat treating is applied to the liner to achieve the desired design strength and threads are tapped at both ends. A careful examination of the liner is performed to check for surface defects. If a surface defect is present it can lead to a localized stress concentration which may increase the emergence of hydrogen embrittlement. Manufacturing methods to create metallic liners include impact extrusion, deep drawn extrusions, and spinning or swaging.

\section{Impact Extrusion}

Impact extrusion is a metal forming process that utilizes a high-velocity force to impact a metal slug into a die or mold. A punch is the part used to impact the virgin metal material into the mold. The punch is connected to a hydraulic press and is responsible for part of the geometry of the end product. At impact the metal forced around the end of the punch taking its shape and that of the mold. By prior lubrication to the mold and punch, the finished part is ejected (Todd, 1994).

The process of impact extrusion can successfully create two liner halves which can then be machined and welded to form a cylindrical pressure vessel liner. Welds within a liner system are not practical due to weakness and stress risers at the weld zone.

\section{Deep Drawn Extrusions}

Deep drawn extrusions or deep drawing is a sheet metal forming process in which a stock of sheet metal or blank is formed into desired shapers of various geometries. It is required that the formed shapes be greater than half their diameters in depth. The details of the process involve fitting the metal blank around a plug and then moving it into a molding cutter or die.

Deep drawn extrusion parts are used in industrial applications in fields such as aerospace, automotive, health and medicine, pharmaceutical, plastics, and more. Deep 
drawing is similar to metal spinning process by both producing circular and seamless components.

\section{Swaging}

Swaging is a process that is used to increase or reduce the diameter of tubes and rods. This process is performed by placing the rod or tube inside a die which applies a compressive radially hammering the part against the die. In a study by Murray et. al. swaging techniques were used to manufacture one-piece, non-welded pressure vessel liners (Murray et.al., 1992).

\section{Spin Forming}

Spin forming is a metalworking process in which a disc or tube of metal is rotated at high speed and formed into an axially symmetric part. The process of spin forming starts with mounting the form or mold on the drive section of a lathe. The pre-sized material is then clamped to the mandrel. The mandrel and working material are rotated at high speed. During rotation a shaping tool applies a force to the working material causing it to flow over and take the shape of the mandrel mold. When creating a closed geometry, such as a one-piece cylindrical pressure vessel, the mold must be removed from the inside of the finished part. This is accomplished by using wax molds strong enough to resist the tooling force or ice molds that can melt away after shaping. Materials used in a spin forming process must be ductile metals which can be alumimum, stainless steel, or high-strength and high temperature alloys.

Halten and Halten summarize three critical metal spinning processes, multi-pass spinning, reducing, and shear forming.

Multi-Pass Spinning - The spinning roller is programmed to make a series of sweeping motions progressively forming the metal onto the mandrel. Finishing operations are carried out by finishing operations such as, profiling, machining, edge trimming, curling, beading and flanging.

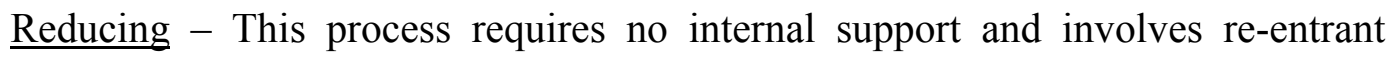
shapes where form and finish are of secondary importance. The preform is clamped 
externally in a retaining chuck as opposed to internal clamping of other spinning methods.

Shear Forming - This variation displaces the metal volume in an axial plane. A single pass of the tool creates conical, concave and convex hollow parts with symmetrical contours. The geometry is limited by the shear angle requirement of maintaining an angle between 12 and 80 degrees. The wall thickness of the formed part is reduced during the forming process. Equations to explicitly determine the wall thickness relations as shown in Figure 2-9 are:

$$
S 1=S o \times \sin \alpha
$$

Where :

$$
\begin{aligned}
& \text { So }=\text { Blank thickness } \\
& \text { S1 = Wall thickness of the finished part. } \\
& \alpha=\text { Shear angle } \\
& P=\text { Section of original material } \\
& P^{\prime}=\text { Deformed section of material }
\end{aligned}
$$




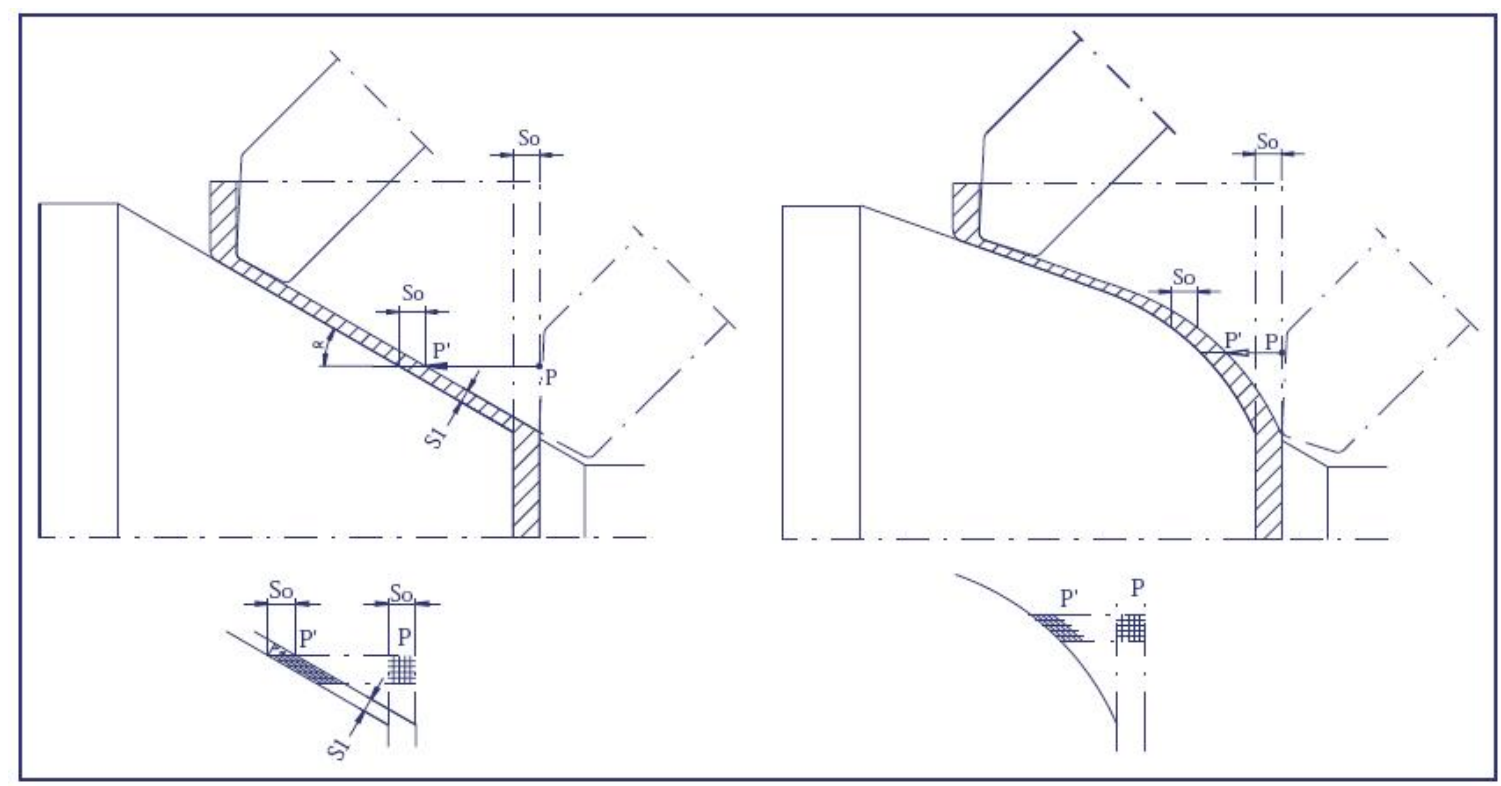

Figure 2.9: In shear forming, the wall thickness of the formed part is reduced. $P$ and $P^{\prime}$ show how the material is shifted during the forming process. Reference: Halten, Metal Spinning: From Ancient Art to High-Tech Industry, 2002.

Part strength is increased during the shear forming process due to cold working the forming material. Forming displaces the material axially and with knowledge of plastic deformation behavior strengthening $50 \%$ of the material can be saved based on the strength requirement. For example, cold-work hardening a 16-gauge mild steel material can result in the same structural strength of thicker, 11-gauge mild steel.

\section{Electrodeposition}

NASA has devised a process to fabricate a pressure vessel comprised of a composite material outer shell with an interior metallic liner. In this design the main priority of the liner is to serve as a permeation barrier to prevent pressurized gas within the tank from diffusing through the composite material outer shell. The unique approach utilizes electrodeposition to manufacture a seamless metallic liner which can range in thickness from 0.001 " to 0.01 " (1 to 10 mils) (Delay, 2005). The process is described by the following steps. 
1. Tooling wax is molded or machined to serve as a mandrel for defining the size and shape of the composite-overwrapped metal liner.

2. Silver paint is applied to the mandrel surface to induce electrical conductivity.

3. Metal bosses are fitted to the end of the mandrel.

4. The mandrel is placed into a plating bath where the metal liner is electrodeposited. The storage applications decide the material of the liner. Candidate materials are copper, nickel, gold, or an alloy.

5. The wax is then melted within the liner leaving a solid metallic shell.

6. A hollow shaft containing ports and fittings is sealed to both ends of the liner and allows gas flow to the interior for pressurization of the liner. An internal pressure stiffens and stabilizes the liner for application of the exterior reinforcement.

7. The pressurized liner is planed in a filament winding machine. The machine is operated to overwrap the liner with multiple layers of uncured graphitefiber/epoxy-matrix.

8. The filament wound part is then removed from the machine and placed in a high temperature over to cure.

9. After cure, the pressure inside the tank is relieved and the hollow shaft is removed. The tank is now ready for service.

\subsubsection{Exterior Reinforcement}

The finished metallic or polymeric liners used in composite over-wrapped pressure vessels are reinforced by filament winding of a composite shell on the exterior liner surface. The completed liner is used as a mandrel during the filament winding process. The filament winding process was previously discussed in the Composite Manufacturing section of this document and is extended here for a complete understanding. A filament winding machine is a multi-axis machine that can be programmed to place resin-impregnated fiber reinforcements in polar, helical and/or hoop directions. Polar winding directions are close to a $0^{\circ}$ degree winding angles with respect to the longitudinal axis. The filament pass tangent to the polar boss region at one end of the vessel and extend along the longitudinal axis to the opposing polar boss region and 
then pass tangent to its boss end. Helical winding directions are described as being oriented at angles to the longitudinal axis of the liner. Hoop oriented fibers are applied in a circumferential direction along the liner at $90^{\circ}$ variation from the longitudinal axis. The winding process is either wet-winding or tow-preg winding. More precise control of resin content and increased fiber delivery rate is achieved by tow-preg winding therefore it is favored in current manufacturing objectives.

\section{Isotensoid Design}

The fibers being wound on the mandrel liner are held in tension to control the consistency and quality of the composite shell. Gleich (1982) showed that the isotensoid (constant tension) fiber wrap patterns essentially achieve the full uniaxial strength of fibers which permits the metals and fibers to share the pressure load. The load-sharing state results in no shear stress transfer to the resin matrix or at the metal fiber mating interface. Compatibility of displacements and load sharing between metal and fibers is provided by bearing pressure at the fiber metal interface. Characteristics must be addressed in the liner design and fabrication to account for the exterior forces onto the outer surface of the liner during filament winding. The liner thickness can be adjusted to withstand the wrapping tension or in some applications an interior pressure in the liner is applied to provide rigidity during winding.

\subsection{Liner Failure}

The method of failure within pressure vessels is dependent on the material and manufacturing characteristics of each design. For example, a metallic liner which has been manufactured with the liner halves impact extruded then connected by a secondary welding process will potentially fail at the weld location due to stress cracking corrosion, hydrogen embrittlement due to hydrogen molecule accumulation at the weld site, or stress concentration from the weld geometry (Song et.al. 2007). Metallic liners with a one-part, weld-free design tend to fail under fatigue loading and cracking due to cyclic 
loads of depressurization and pressurization over the lifetime of the tank (Newhouse, 2008). Current manufacturing technology of metallic liners has made the use of welds within pressure vessel liners obsolete. Therefore, a new failure method has become prevalent in the metallic liner. This failure location is in the polar boss region of the cylindrical or spherical pressure vessel. A high stress and strain region occurs at the transition point from the spherical or geodesic dome to the nozzle geometry. Stress and strain contour plots of finite element analysis of liners and pressure vessels are shown later in this work to detail this region of interest.

Experimental evaluations have shown the location of failure in the dome region of pressure vessel systems. In a specific failure analysis study of a composite wound pressure vessel liner failure was shown to occur in the dome region due to inhomogeneous deformations which gave rise to local necks and local strains at the specific point of failure (dtbtest.com, 2008). The liner was made of 6061-T6 aluminum. The liner had a dome radius of 12 inches and was of spherical geometry. The location and fracture of the pressure vessel liner is shown in Figure 2.10.

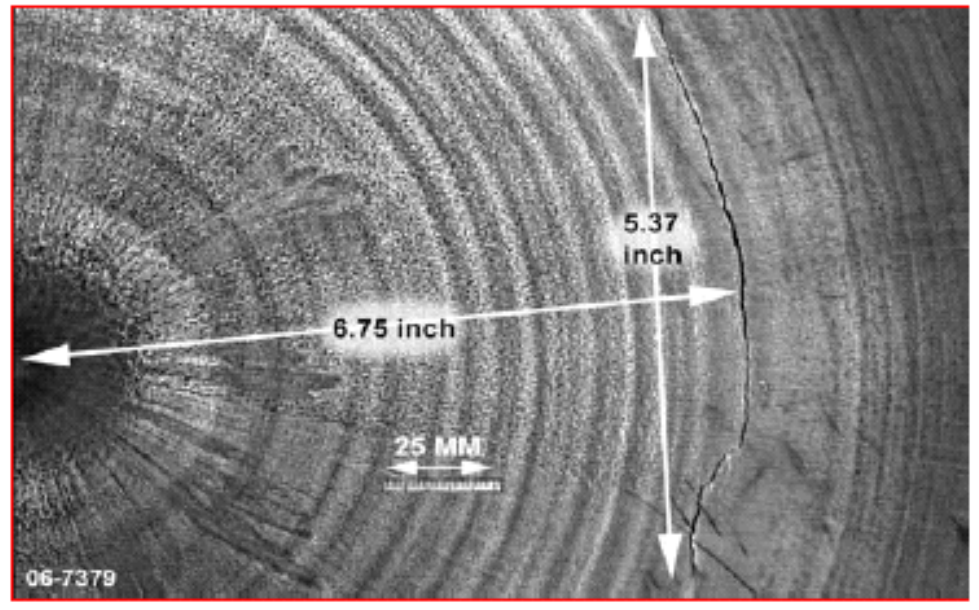

Figure 2.10: Failure location of a composite over-wrapped pressure vessel metallic liner.

The crack propagation in the liner occurs at 6.75 inches from the center of the tank. For a spherical dome geometry having a radius of 12 inches, the location of the failure crack is in the relative area of the slope transition which occurs at the change in geometry of the pressure vessel from the end dome to the nozzle region. 


\subsection{Material Failure Theories}

\subsubsection{Von Mises}

A triaxial state of stress is developed within the structures of the composite overwrapped pressure vessels during the loading procedure. A triaxial state of stress initiates the use of an equivalent stress value or failure criterion to investigate the effect of material yielding. Von-Mises stress is a stress parameter that expresses the octahedral shear stress, or the strain energy of distortion, at any point within a body which undergoes a triaxial state of stress (Hibbeler, 2005). Von-Mises stress criteria uses the stress components at any point within the body and is expressed as:

$$
S_{e q}=\sqrt{\frac{1}{2}\left[\left(\sigma_{x}-\sigma_{y}\right)^{2}+\left(\sigma_{y}-\sigma_{z}\right)^{2}+\left(\sigma_{z}-\sigma_{x}\right)^{2}+3 \tau_{x y}^{2}+3 \tau_{y z}^{2}+3 \tau_{x z}^{2}\right]}
$$

The Von-Mises failure criteria states that material yielding begins if the equivalent stress at any point reaches the material yielding point.

\subsection{Macromechanical Failure Theories in Composite Materials}

Composite material structures characterized by orthotropic material properties can be analyzed in failure criteria by different theories. The theories reviewed are the maximum stress theory, maximum strain theory, Tsai-Hill and Tsai-Wu theory. With all theories, the first step is to calculate the stress and strain in the material coordinates. This is done by resolving the stress and strain values in the global $(\mathrm{x}, \mathrm{y}, \mathrm{z})$ coordinate system and through macromechanical transformations to the stresses and strains in the local material coordinate system $(1,2,3)$. Once the local stresses and strains are known they are compared to the strength properties of the material in the lamina to predict failure. 


\subsubsection{Nomenclature}



$\mathrm{S}_{\mathrm{Lt}}=\mathrm{F}_{1 \mathrm{t}}=$ Tensile strength in the longitudinal (1) direction

$\mathrm{S}_{\mathrm{Lt}}=\mathrm{F}_{1 \mathrm{c}}=$ Compressive strength in the longitudinal direction

$\mathrm{S}_{\mathrm{Tt}}=\mathrm{F}_{2 \mathrm{t}}=$ Tensile Strength in the transverse (2) direction

$\mathrm{S}_{\mathrm{Tc}}=\mathrm{F}_{2 \mathrm{c}}=$ Compressive strength in the transverse direction

$\mathrm{S}_{\mathrm{LTs}}=\mathrm{F}_{12}=$ Shear strength in the 1-2 coordinates

$\varepsilon_{\mathrm{LT}}=\varepsilon_{11}=$ Ultimate strain in the longitudinal direction

$\varepsilon_{\mathrm{LC}}=-\varepsilon_{11}=$ Ultimate compressive strain in the longitudinal direction

$\varepsilon_{\mathrm{Tt}}=\varepsilon_{22}=$ Ultimate tensile strain in the transverse direction

$\varepsilon_{\mathrm{TC}}=-\varepsilon_{22}=$ Ultimate compressive strain in the longitudinal direction

$\gamma_{\text {LTS }}=\gamma_{12}=$ Ultimate shear strain

\subsubsection{Maximum Stress Theory}

The Maximum Stress Theory states that in order to avoid failure the following criteria must be met: 


$$
\begin{aligned}
& -S_{L C}<\sigma_{11}<S_{L T} \\
& -S_{T c}<\sigma_{22}<S_{T t} \\
& -S_{L T s}<\tau_{12}<S_{L T s}
\end{aligned}
$$

Failure is stated to occur when at least one stress component along the principal material axes exceeds the material strength in the corresponding direction. When tensile stresses are a resultant of the loading condition, a fiber break is predicted to occur when $\sigma_{11} \geq F_{1 t}$ and matrix failure occurs when $\sigma_{22} \geq F_{2 t}$. In the condition of compressive stress, fiber crushing is predicted when $\sigma_{11} \leq F_{1 c}$ and matrix yielding occurs when $\sigma_{22} \leq F_{2 c}$. Shear stress failure in the form of shear cracking occurs when $\left|\tau_{12}\right| \geq F_{12}$.

\subsubsection{Maximum Strain Theory}

The maximum strain theory states that in order to prevent failure induced by strain components within the composite laminate the following criteria must be met:

$$
\begin{aligned}
& -\varepsilon_{L C}<\varepsilon_{11}<\varepsilon_{L T} \\
& -\varepsilon_{T c}<\varepsilon_{22}<\varepsilon_{T t} \\
& -\gamma_{L T S}<\tau_{12}<\gamma_{L T S}
\end{aligned}
$$

Failure is predicted to occur when at least one strain component along the principal material axes exceeds the ultimate strain of the material in the corresponding direction. Failure in the fiber caused by a tensile elongation is predicted when $\varepsilon_{11} \geq \varepsilon_{1 t}^{u}$. Failure in the matrix caused by transverse strain is predicted when $\varepsilon_{22} \geq \varepsilon_{2 t}^{u}$. Compressive strain failures are predicted to occur when $\varepsilon_{11} \leq \varepsilon_{1 c}^{u}$ or $\varepsilon_{22} \leq \varepsilon_{2 c}^{u}$. Failure induced by shear strain is predicted to occur when $\left|\gamma_{12}\right| \geq \gamma_{12}^{u}$.

\subsubsection{Tsai-Hill}

Unlike the maximum stress and maximum strain failure theories, the Tsai-Hill failure criterion considers the interaction among the three unidirectional strengths of the lamina. There is no distinction between the tensile and compressive strengths in the governing equation. Therefore, this theory may underestimate the maximum allowable 
applied load. Since the unidirectional transverse compressive strength is typically much higher than the transverse tensile strength.

The governing equation for the Tsai-Hill failure criteria is:

$A \sigma_{11}^{2}+B \sigma_{22}^{2}+C \sigma_{11} \sigma_{22}+D \tau_{12}^{2}=1$

The coefficients A, B, C, and D are determined by longitudinal, transverse, and shear experimental tests on a uniaxial laminate and are defined as:

$$
\begin{aligned}
& A=\frac{1}{F_{1}^{2}} \\
& B=\frac{1}{F_{2}^{2}} \\
& C=-\frac{1}{F_{1}^{2}} \\
& D=\frac{1}{F_{12}^{2}}
\end{aligned}
$$

The Tsai-Hill failure criterion in terms of material strength parameters can then be written as:

$$
\frac{\sigma_{11}^{2}}{F_{1}^{2}}+\frac{\sigma_{22}^{2}}{F_{2}^{2}}-\frac{\sigma_{11} \sigma_{22}}{F_{1}}+\frac{\tau_{12}^{2}}{F_{12}^{2}}=1
$$

\subsubsection{Tsai-Wu}

The Tsai-Wu failure criterion is used for anisotropic composite materials having different strength properties in tension and compression. For orthotropic materials having three planes of symmetry coinciding with the global coordinate system and assuming that the material strength parameters $F i j=F j i$ where $i$ and $j$ take values from 1 to 6 , the criteria for predicting failure is:

$$
\frac{\sigma_{11}^{2}}{S_{L t} S_{L c}}-\frac{\sigma_{11} \sigma_{22}}{\sqrt{S_{L t} S_{L c} S_{T t} S_{T c}}}+\frac{\sigma_{22}^{2}}{S_{T t} S_{T c}}+\frac{\tau_{12}^{2}}{S_{L T S}^{2}}+\left(\frac{1}{S_{L t}}-\frac{1}{S_{L c}}\right) \sigma_{11}+\left(\frac{1}{S_{T t}}-\frac{1}{S_{T c}}\right) \sigma_{22}<1
$$


$F_{11} \sigma_{11}^{2}+2 F_{12} \sigma_{11} \sigma_{22}+F_{22} \sigma_{22}^{2}+F_{66} \tau_{12}^{2}+F_{1} \sigma_{11}+F_{2} \sigma_{22}<1$

where:

$$
\begin{array}{ll}
F_{11}=\frac{1}{S_{L t} S_{L c}} & F_{22}=\frac{1}{S_{T t} S_{T c}} \\
F_{12}=-\frac{1}{2} \sqrt{F_{11} F_{22}} & F_{66}=\frac{1}{S_{L T s}^{2}} \\
F_{1}=\frac{1}{S_{L t}}-\frac{1}{S_{L c}} & F_{2}=\frac{1}{S_{T t}}-\frac{1}{S_{T c}}
\end{array}
$$




\section{Chapter 3}

\section{Initial Analysis into Hydrogen Pressure Vessel Configurations}

The primary analysis into the study of a composite pressure vessel comprised closed form analysis to develop an understanding of the resultant internal forces as a function of the internal pressure, material, and cross section thickness. Finite element analysis (FEA) involved determining the stress resultants and deformations as a result of applied internal pressure. The FEA included various layup configurations and orientation percentages to provide thorough insight into the effects of altering manufacturing methods. The finite element analysis was further utilized to provide a shape optimization which acknowledged cylindrical, spherical and various configurations of both structures.

The design and development of a hydrogen storage vessel is governed by size, weight, and hydrogen storage capacity. Several criteria must be met to store hydrogen on-board a vehicle and successfully provide a fuel source to meet the standard 300-mile driving range. All the lightweight designs devised and evaluated focus on compressed hydrogen gas storage. The primary objective for the efficient design of a composite overwrapped pressure vessel for storing compressed gas medium is to achieve a minimal volume while attaining a maximum storage pressure level. As several other studies have shown, the implementation of advanced composite materials is essential to withstand the high tensile hoop stresses associated with containing a high-pressure gas without significant weight penalties.

Several criteria, as listed below, must be addressed in order to achieve the above objective:

1. High pressure containment

2. Minimization of tank volume

3. Lightweight design

4. Hydrogen containment

5. Thermal insulation 
6. Heat exchange system and configuration

7. Optimization

The research conducted encompasses the first and the second criteria previously stated. The design goal is to achieve a level of 10,000 psi (70 MPa) of internal pressure, while optimizing the tradeoffs between the maximum pressure and the volume capacity of the tank.

\subsection{Preliminary Analysis}

Closed form calculations were performed to determine the internal forces within the walls of an axisymmetric pressure vessel when a 10,000 psi (70 MPa) internal pressure load is applied. The first tank was assumed to have an inner radius of 4.95 inches and the length of the cylindrical part is 22.5 inch in order to accommodate a volume capacity of 15 gallons $\left(3,450 \mathrm{in}^{3}\right)$. The second tank occupies a 30 gallon $(6,900$ in3) volume composed of 45.0 inch cylindrical section and a 9.90 inch radius. The axial force per unit length $\left(\mathrm{P}_{\mathrm{z}}\right)$ and the hoop force per unit length $\left(\mathrm{P}_{\mathrm{x}}\right)$, shown in Figure 3.1, were calculated for pressure vessels made of composite materials with two different sizes. Three different types of fibers: fiberglass, kevlar, and carbon fiber were analyzed for each pressure vessel size. The minimum wall thickness of each pressure vessel was calculated for a factor of safety of 1.5 .
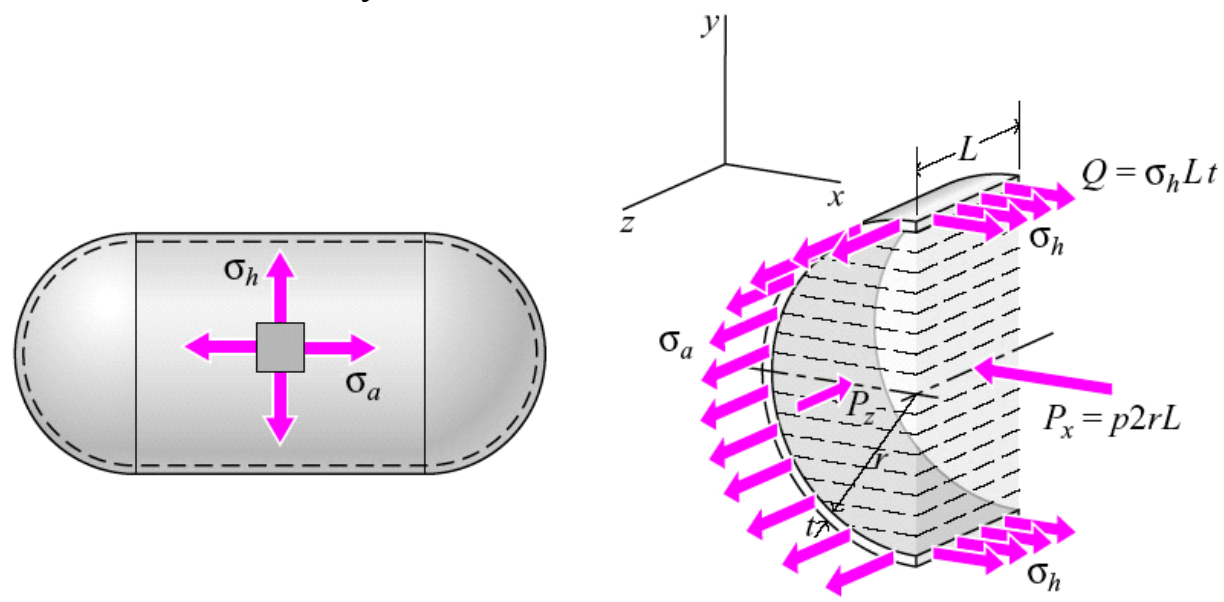

Figure 3.1: Internal Forces within an axisymmetric cylindrical pressure vessel. 
The following equations from the thin-wall pressure vessel theory were used to determine the internal stresses in the pressure vessel, $\sigma_{h}$ and $\sigma_{a}$. The corresponding results are presented in Table 3.1 below. Because of the symmetry around the longitudinal axis, the resultant force has only a component along the longitudinal z-axis, defined in terms of the internal pressure $p$ by:

$$
P_{z}=p \pi r^{2}
$$

In the tangential direction, the resultant force can be calculated by

$$
Q=p L(2 r)
$$

By satisfying the equilibrium of the forces in the z-direction, the axial tensile stress in the vessel wall $\sigma_{a}$ can be calculated by:

$$
\sigma_{a}=\frac{P\left(\pi r^{2}\right)}{2 \pi r t}=\frac{p r}{2 t}
$$

The hoop stresses $\sigma_{h}$ can also be calculated by satisfying the equilibrium condition in that direction as:

$$
\sigma_{a}=\frac{P(2 r L)}{2 r t}=\frac{p r}{t}
$$

A composite laminate with a combination of 0 -degree, 90 -degree, and \pm 45 -degree layers was used to build the vessel walls to the minimum thickness values listed in Table 3.1. The 0 -degree and 90 -degree layers represent $90 \%$ of the overall laminate thickness, and their role is to provide the necessary stiffness and strength levels in the axial and hoop directions. The reinforcement layers with \pm 45 -degree fiber orientations form $10 \%$ of the overall thickness of the wall, and they are included to provide shear stiffness and strength, as well as to provide additional integrity to the vessel structure. The values of the tensile strengths of this laminate were determined and reported as $F_{a t}$ and $F_{h t}$ as in Table 3.1. 
Table 3.1: Preliminary Thickness Calculations of Composite Storage Tanks for Compressed Hydrogen Gas Storage

\begin{tabular}{|c|c|c|c|c|c|c|c|c|c|}
\hline \multirow[b]{2}{*}{ Material } & \multicolumn{2}{|c|}{ Vessel Dimensions } & \multirow{2}{*}{$\begin{array}{c}\text { Pressure } \\
\text { psi }\end{array}$} & \multicolumn{2}{|c|}{ Resultant Forces lb/in. } & \multirow{2}{*}{$\begin{array}{l}\mathbf{F}_{a t} \\
\text { psi }\end{array}$} & \multirow{2}{*}{$\begin{array}{l}\mathbf{F}_{h t} \\
\text { psi }\end{array}$} & \multirow{2}{*}{$\begin{array}{c}\text { Thickness } \mathbf{F}_{h} \\
\text { (in.) }\end{array}$} & \multirow{2}{*}{$\begin{array}{c}\text { Thickness } \mathrm{F}_{\mathrm{a}} \\
\text { (in.) }\end{array}$} \\
\hline & Length (in) & Radius (in) & & $\mathbf{F}_{\mathrm{h}}$ & $\mathbf{F}_{a}$ & & & & \\
\hline E-glass & 22.50 & 4.95 & 10,000 & 49,500 & 24,750 & 61,200 & 81,000 & 1.38 & 0.91 \\
\hline Kevlar & 22.50 & 4.95 & 10,000 & 49,500 & 24,750 & 59,000 & 58,000 & 1.92 & 0.94 \\
\hline Carbon Fiber & 22.50 & 4.95 & 10,000 & 49,500 & 24,750 & 120,000 & 124,000 & 0.90 & 0.46 \\
\hline E-glass & 45.00 & 9.90 & 10,000 & 99,000 & 49,500 & 61,200 & 81,000 & 2.75 & 1.82 \\
\hline Kevlar & 45.00 & 9.90 & 10,000 & 99,000 & 49,500 & 59,000 & 58,000 & 3.84 & 1.89 \\
\hline Carbon Fiber & 45.00 & 9.90 & 10,000 & 99,000 & 49,500 & 120,000 & 124,000 & 1.80 & 0.93 \\
\hline
\end{tabular}

Table 3.1 and equations (3.3) and (3.4) verify that the primary concern for a pressure vessel design is the hoop force per unit length, $\mathrm{F}_{\mathrm{h}}$, since the magnitude of the force $F_{h}$ is half the magnitude of $F_{a}$. Therefore, the required thickness in the circular or hoop direction is twice that of the wall thickness required in the longitudinal direction. The results of Table 3.1 show that carbon and glass fibers are the best candidates for the selection criterion based on the minimal wall thickness of the tank. Carbon fiber is the best selection since it requires the minimal overall wall thickness in both the axial and hoop directions. The ability to tailor the lay-up of composite material configurations offers the possibility of using less material in the axial direction and more material in the hoop direction to attain the strength required to ultimately withstand the internal forces associated with the high internal pressure of compressed hydrogen gas.

\subsection{Finite Element Analysis}

The results listed in Table 3.1 provide preliminary designs for the lay-up configurations of hydrogen storage vessels made of composite materials, which can be further expanded by using finite element analysis. ANSYS finite element software was used to model two pressure vessels with different lay-up configurations

Two different designs were modeled under different layup configurations:

1. Carbon fiber pressure vessel

2. Carbon fiber reinforced aluminum pressure vessel 
A uniform internal pressure of 10,000 psi (70 MPa) was applied to each vessel. For both configurations, finite element analysis was used to determine the maximum deformation and stress contour plots in the pressurized vessels. The main input parameters, material and geometric characteristics, as well as the corresponding results are summarized below.

\subsubsection{Carbon fiber pressure vessel - Orientation One}

Material: Carbon Fiber/Epoxy

Layup: 0/90/ \pm 45

Layup composition by percentage of fibers in the $0^{\circ} / 90^{\circ} / 45^{\circ}$ direction: $45 \% / 45 \% / 10 \%$

Layer thickness: 0.009 in. $(0.23 \mathrm{~mm})$

Number of Layers: 100

Total thickness: 0.9 in. $(23 \mathrm{~mm})$

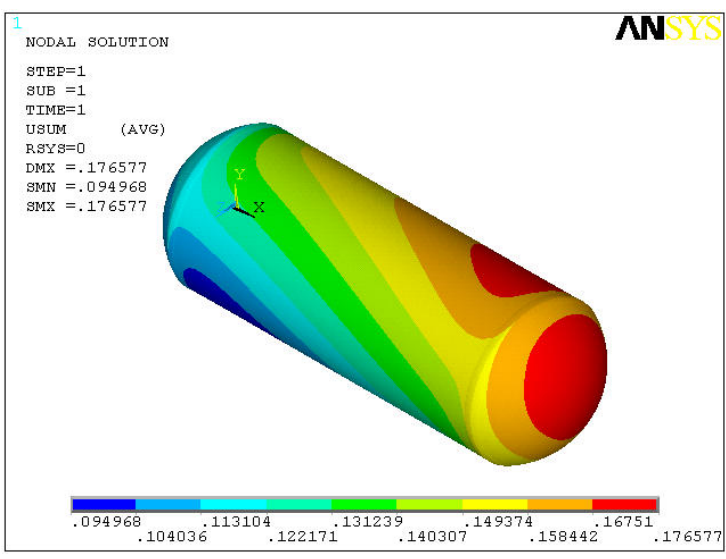

(a)

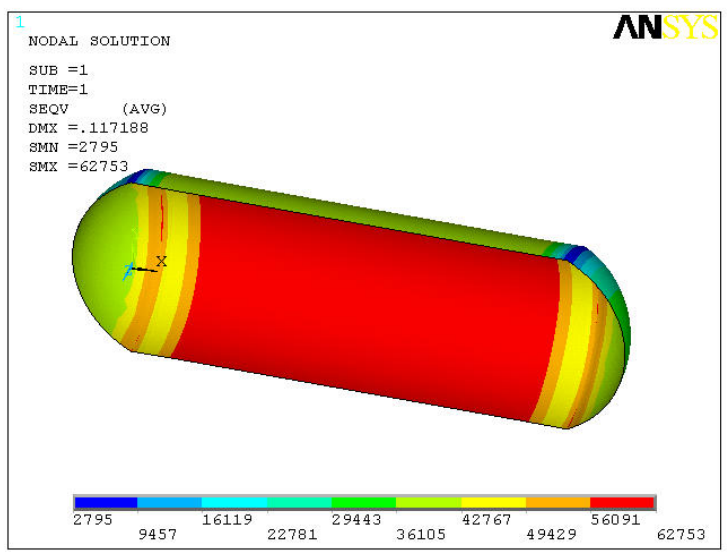

(c)

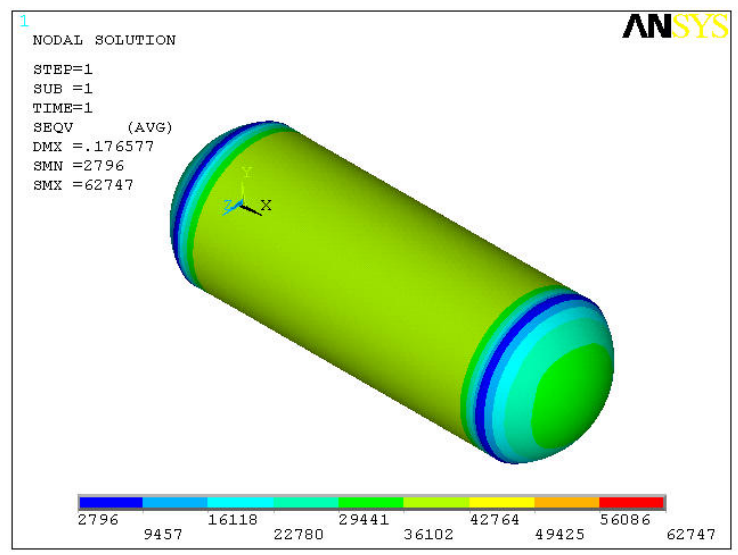

(b)

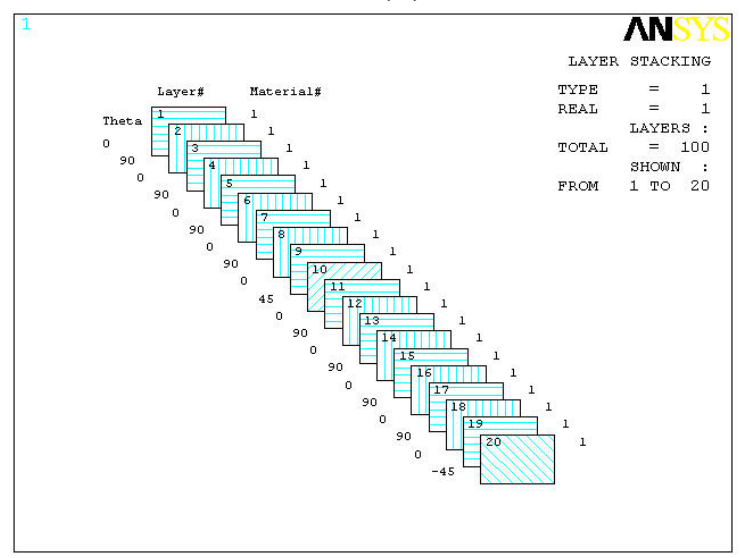

(d)

Figure 3.2: (a) Displacement [in] (b) and (c) Von Mises stress [psi] (d) layer orientation for the carbon fiber pressure vessel with $45 \%-0^{\circ}$ plies, $45 \%-90^{\circ}$ plies and $10 \%-45^{\circ}$ plies. 
In this configuration, it is assumed that an equal number of 0-degree and 90degree layers are used, each fiber orientation forming a fraction of $45 \%$ of the overall wall thickness, whereas the \pm 45 - degree layers form $10 \%$ of the overall wall thickness. Figure 3.2 illustrates by colored fringe patterns the Von Mises equivalent stress and the displacement fields generated in the vessel wall by an applied internal pressure of 10,000 psi. A uniform stress field with a value of $42.77 \mathrm{ksi}(30 \mathrm{MPa})$ was calculated on the outer wall surface of the vessel, while an equivalent Von Mises stress of 62.77 ksi was calculated on the inner surface of the vessel. This indicates that a pressure vessel of such design configuration behaves as a thick shell, which brings up the approximate nature of the preliminary calculations used to predict the results shown in Table 3.1.

\subsubsection{Carbon fiber pressure vessel - Orientation Two}

\section{Material: Carbon Fiber/Epoxy}

Layup: 0/90/ \pm 45

Layup composition by percentage of fibers in the $0^{\circ} / 90^{\circ} / 45^{\circ}$ direction: $30 \% / 60 \% / 10 \%$ Layer thickness: 0.009 in. $(0.23 \mathrm{~mm})$

Number of Layers: 100

Total thickness: 0.9 in. $(23 \mathrm{~mm})$

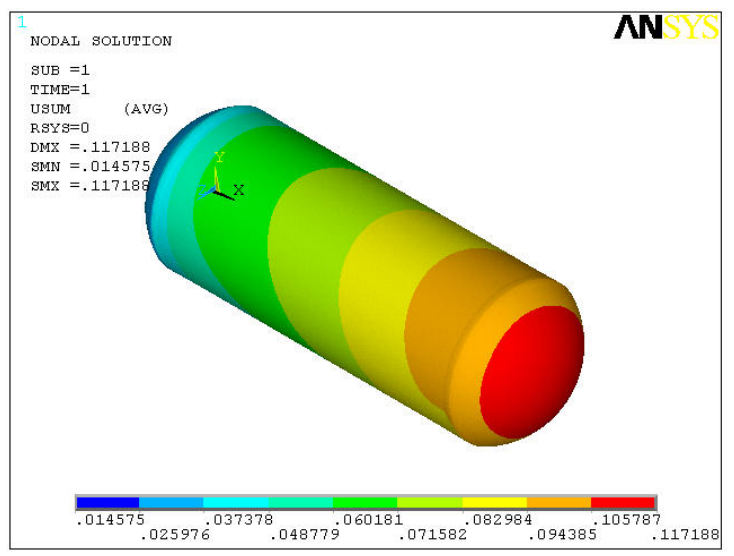

(a)

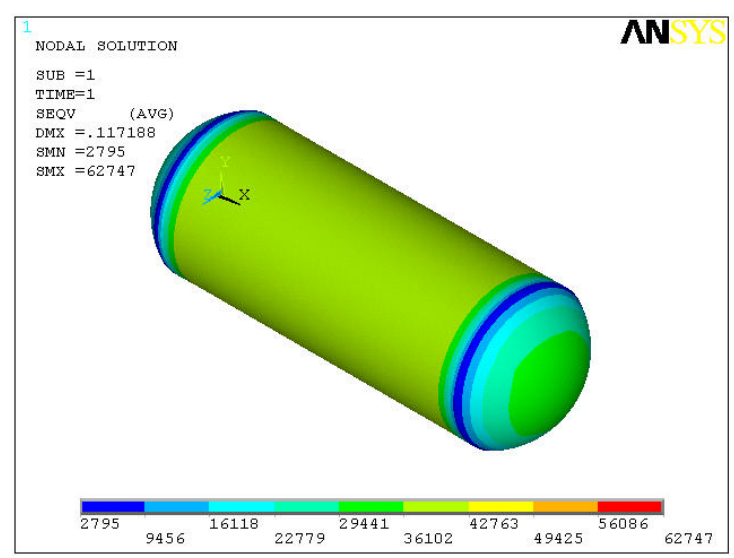

(b) 


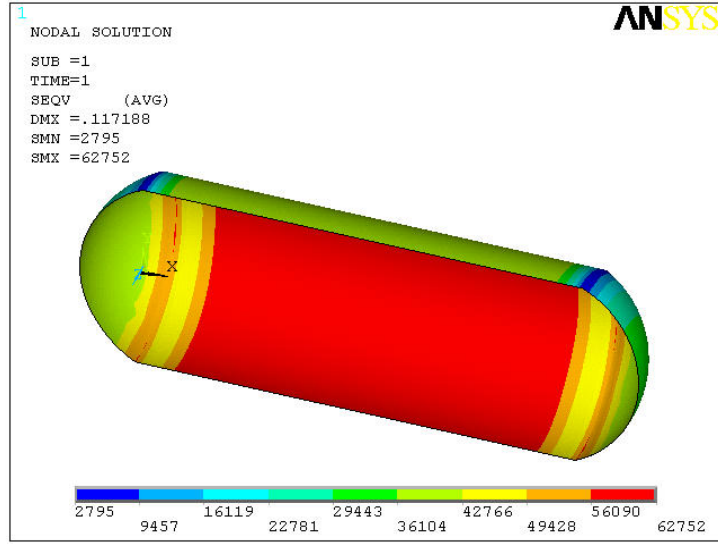

(c)

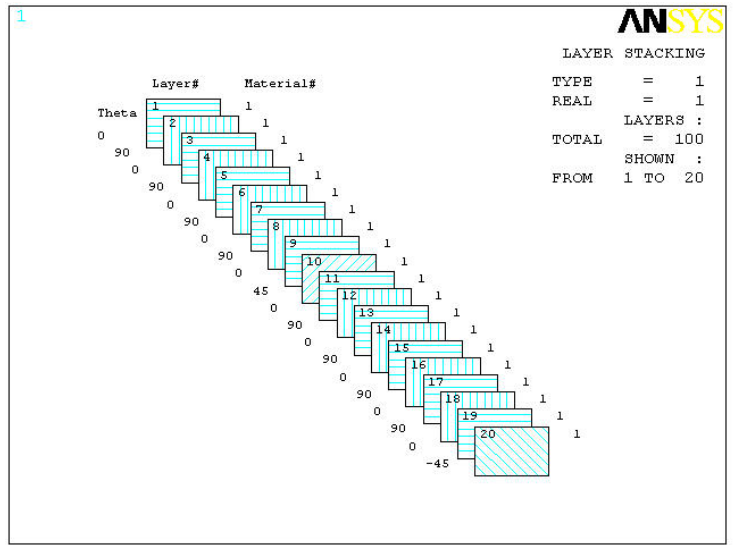

(d)

Figure 3.3: (a) Displacement [in] (b) and (c) Von Mises stress [psi] (d) layer orientation for the carbon fiber pressure vessel with $30 \%-0^{\circ}$ plies, $60 \%-90^{\circ}$ plies and $10 \%-45^{\circ}$ plies.

The configuration of Figure 3.3, assumes that $30 \%$ of the carbon fibers are oriented at 0-degree and $60 \%$ are oriented at 90-degrees, thus providing further reinforcements in the hoop direction, in which the maximum stresses are expected to develop. Figure 3.3 depicts the distributions of the stress and displacement fields generated in the vessel wall by an applied internal pressure of 10,000 psi (70 MPa). No significant change was observed in the stress field from that developed in Configuration 1. However, about 34 percent reduction in the axial displacement was noticed when using the lay-up Configuration 2, which uses fewer fibers in the axial direction. As more stiffening occurs in the hoop direction due to the increase of the amount of fibers, the Poisson's effect yields smaller deformation in the axial direction

\subsubsection{Carbon fiber reinforced aluminum pressure vessel - Orientation One}

In this design, carbon fiber plies were applied around a 0.54-inch thick aluminum cylinder that has the same internal radius of 4.95 inches as the all-carbon fiber vessel analyzed previously. Furthermore, two different lay-up configurations of the carbon fiber plies were examined by using 3D finite element modeling as in the previous design. The applied internal pressure was also kept constant at 10,000 psi (70 MPa). 
Material: Aluminum vessel reinforced with a carbon fiber/epoxy composite shell Aluminum thickness: 0.54 in.

Layup: 0/90/ \pm 45

Layup composition by percentage of fibers in the $0^{\circ} / 90^{\circ} / 45^{\circ}$ direction: $45 \% / 45 \% / 10 \%$ Layer thickness: 0.009 in. $(0.23 \mathrm{~mm})$

Number of Layers: 40

Carbon Fiber Thickness: 0.36 in. $(9.14 \mathrm{~mm})$

Total Thickness: 0.9 in $(23 \mathrm{~mm})$

Figure 3.4 illustrates the fringe patterns of the Von-Mises equivalent stresses and axial displacements developed in this configuration as the internal pressure of $10,000 \mathrm{psi}$ is applied. The maximum stress was calculated at the inner surface of the shell and it is equal to $71.75 \mathrm{ksi}$ (1.5\% less than that developed in the all-carbon fiber vessel). However, due to the thick aluminum core, this design was much stiffer than the allcarbon vessel, which is evident from the smaller axial displacement field shown in Figure $3.4(a)$.

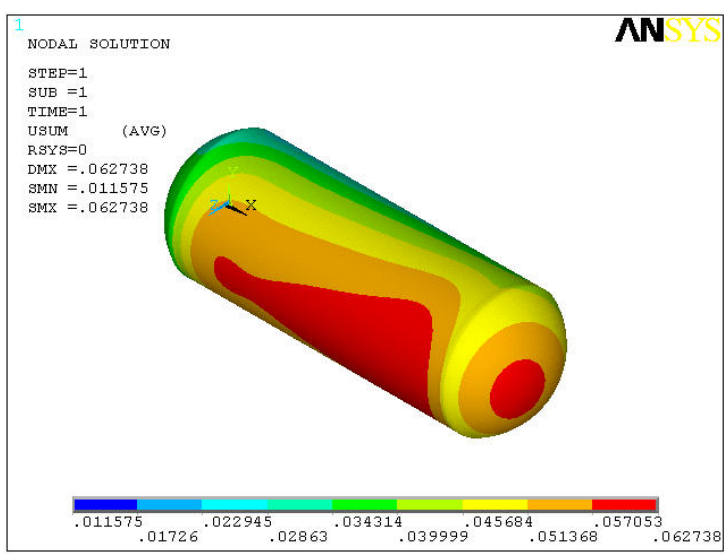

(a)

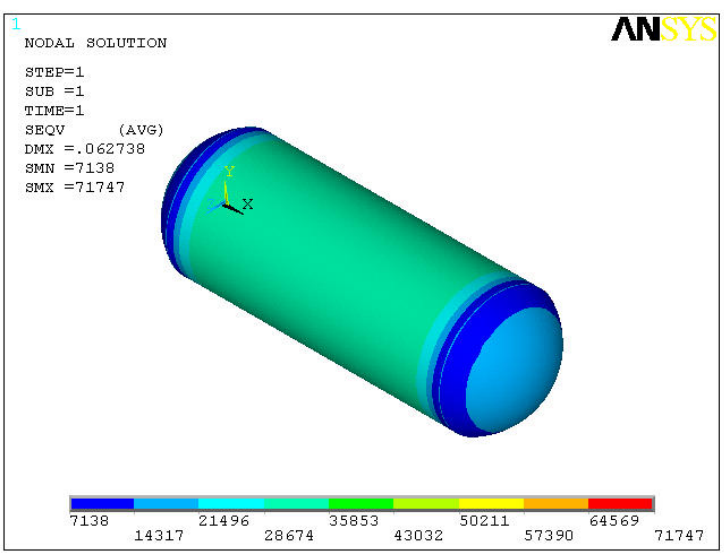

(b) 


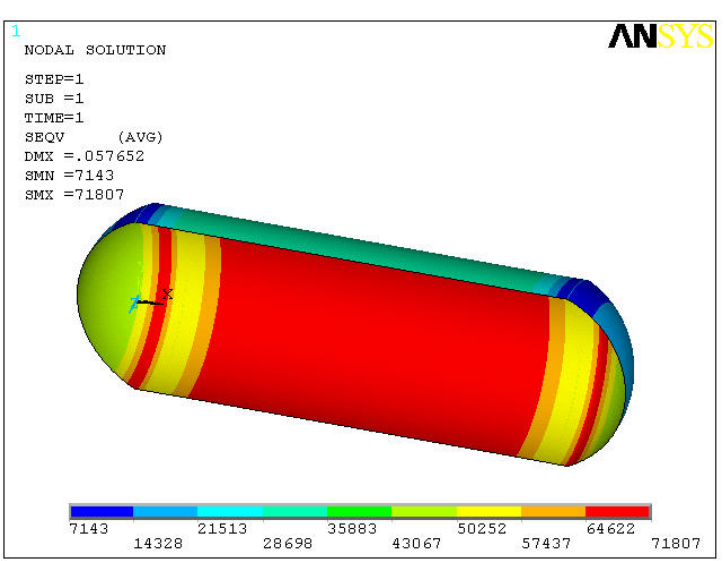

(c)

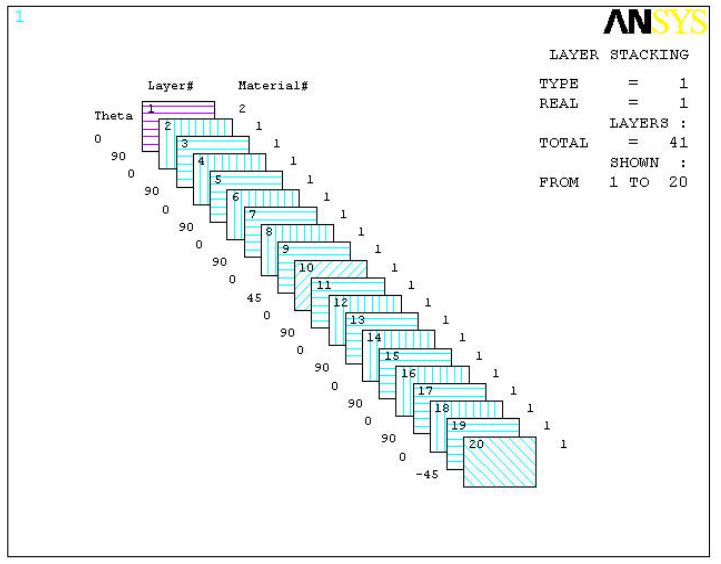

(d)

Figure 3.4: (a) Displacement [in] (b) and (c) Von Mises stress [psi] (d) layer orientation for the carbon fiber reinforced aluminum pressure vessel with $45 \%-0^{\circ}$ plies, $45 \%-90^{\circ}$ plies and $10 \%-45^{\circ}$ plies.

\subsubsection{Carbon fiber reinforced aluminum pressure vessel - Orientation Two}

Material: Aluminum vessel reinforced with a carbon fiber/epoxy composite shell Aluminum thickness: 0.54 in.

Layup: $0 / 90 / \pm 45$

Layup percentage: $30 \% / 60 \% / 10 \%$

Layer thickness: 0.009 in.

Number of Layers: 40

Total Thickness: 0.9 in

In this configuration, it is assumed that $30 \%$ of the carbon fiber reinforcements are oriented at 0 -degree and $60 \%$ are oriented at 90-degree. Figure 3.5 depicts the distributions of the Von Mises stress and axial displacement fields generated in the vessel wall by an applied internal pressure of 10,000 psi (70 MPa). No significant change was observed in the stress field from that developed in Configuration 1. However, an $8 \%$ reduction in the axial displacement was noticed when using the lay-up configuration 2. Thus, this configuration provides a stiffer pressure vessel. 


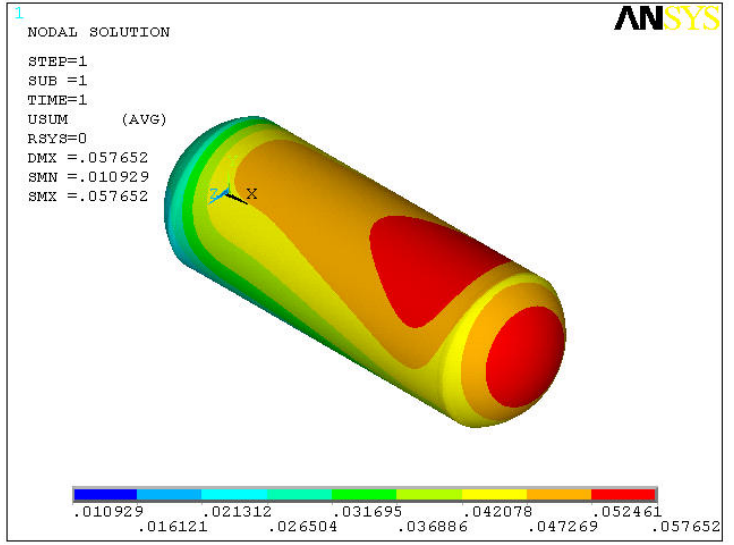

(a)

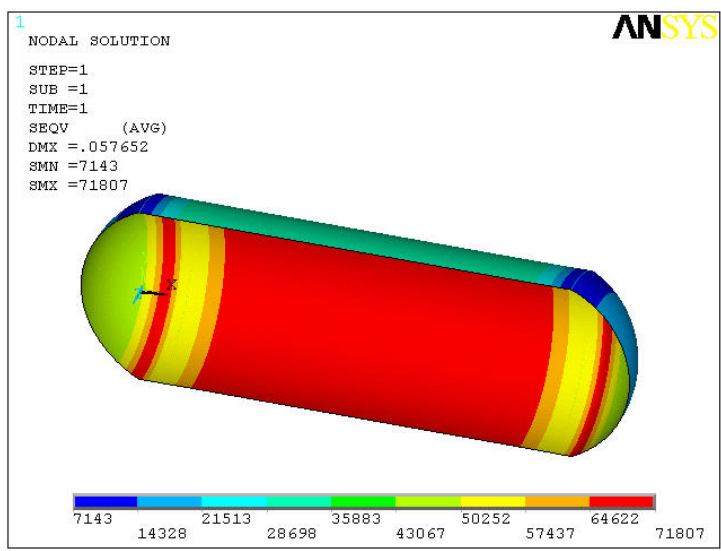

(c)

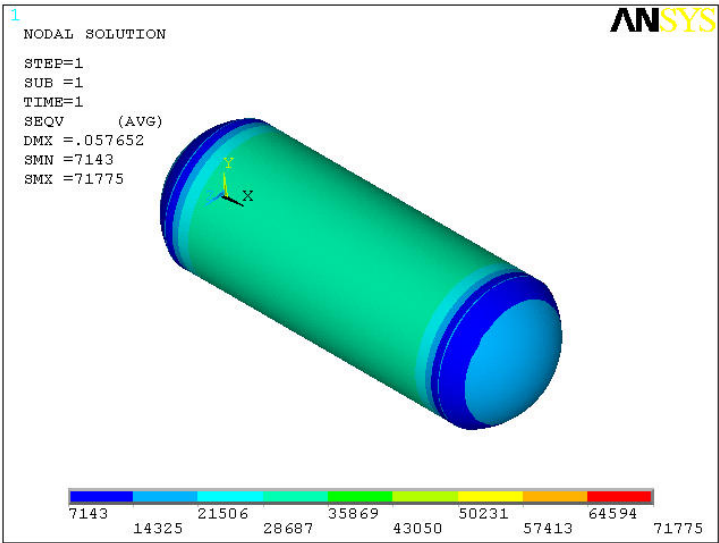

(b)

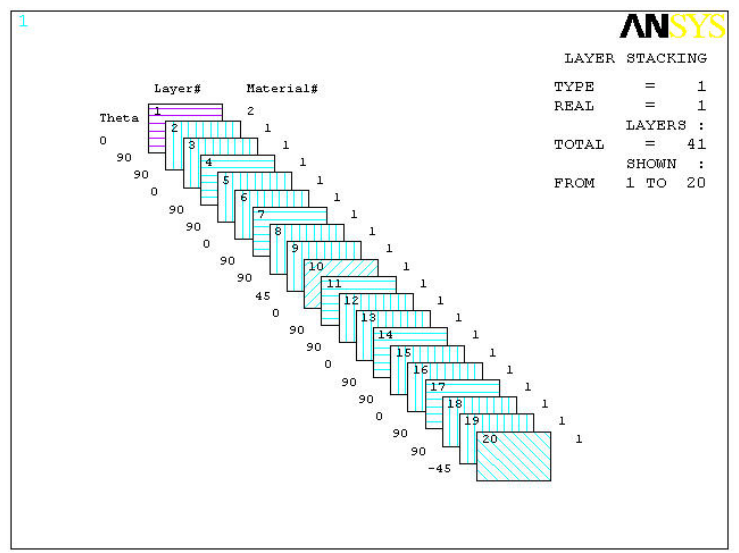

(d)

Figure 3.5: (a) Displacement [in] (b) and (c) Von Mises stress [psi] (d) layer orientations for the carbon fiber reinforced aluminum pressure vessel with $30 \% 0^{\circ}$ plies, $60 \% 90^{\circ}$ plies and $10 \% 45^{\circ}$ plies.

\subsubsection{Results and Discussion}

The process of the pressure vessel design started with closed form solutions to determine the internal forces developed when the tank is loaded by a uniform internal pressure of 10,000 psi $(70 \mathrm{MPa})$. Subsequently, the minimum wall thickness that is required to withstand the internal forces and maintain a 2.25 factor of safety was calculated for three different candidate fiber materials. This required thickness was then used in four different finite element models to closely examine the detailed state of stress developed in the vessel wall by the applied internal pressure of 10,000 psi. The finite element models consisted of an all-carbon fiber design and an aluminum vessel reinforced with layers of carbon fiber. The overall wall thickness of each model was held 
constant. The lay-up configurations were altered to examine the effects of different relative percentages of the $0^{\circ} / 90^{\circ} / 45^{\circ}$ layers. The $30 \% / 60 \% / 10 \%$ configuration was found to be beneficial in reducing the maximum axial displacements for both design configurations. Table 3.2 summarizes the maximum values of Von Mises stresses and axial displacements calculated for each design configuration.

Table 3.2: Maximum Stress and Displacement Values Calculated through 3-D FEA

\begin{tabular}{|c|c|c|}
\hline \multicolumn{3}{|c|}{ Finite Element Results } \\
\hline & Maximum Displacement (in) & Maximum Stress (ksi) \\
\hline $\begin{array}{c}\text { Carbon Fiber } \\
45 / 45 / 10-\%\end{array}$ & 0.1765 & 62.7 \\
\hline $\begin{array}{c}\text { Carbon Fiber } \\
30 / 60 / 10 \text { - \% }\end{array}$ & 0.1172 & 62.7 \\
\hline $\begin{array}{c}\text { Carbon Fiber } \\
\text { Reinforced Al. } \\
\text { 45/45/10 - \% }\end{array}$ & 0.0627 & 71.7 \\
\hline $\begin{array}{c}\text { Carbon Fiber } \\
\text { Reinforced Al. } \\
\text { 30/60/10 - \% }\end{array}$ & 0.0577 & 71.7 \\
\hline
\end{tabular}

For the all-carbon fiber design, a 34\% reduction in the axial displacement was attained when changing the lay-up from the $45 / 45 / 10 \%$ composition to the $30 / 60 / 10 \%$ configuration. An $8 \%$ reduction in displacement was achieved for the aluminum vessel reinforced with carbon fiber as a result of the same change in the lay-up configuration, from the $45 / 45 / 10 \%$ composition to the $30 / 60 / 10 \%$ composition. This indicates that the $30 / 60 / 10 \%$ lay-up orientation is beneficial for increasing the stiffness of composite reinforced cylindrical pressure vessels.

Equivalent Von-Mises stress distributions were obtained from the finite element analysis. These results were used in a failure analysis based on the Von-Mises failure criterion to determine the factor of safety for each design. The resulting factor-of-safety values are listed in Table 3.3. It is necessary to remember that a 2.25 factor of safety value was incorporated into the preliminary calculations of the minimum wall thickness 
required to withstand the internal forces $F_{h}$ and $F_{a}$ associated with an applied internal pressure of 10,000 psi. The values of the safety factors resulting from the finite element models are about 2.0, which is less than 2.25, most likely due to the fact that the throughthe-thickness variations of the Von Mises stresses are considered in the finite element analysis, whereas a uniform through-the-thickness stress distribution is assumed in the closed form solution. Additionally, it should be remembered that the closed form solution is based on the hoop and axial stress components not the Von-Mises stress, which is utilized in the finite element analysis.

Table 3.3: Results of Carbon Fiber Failure Analysis Based on Von Mises Failure

\begin{tabular}{|c|c|c|c|c|}
\hline \multirow{2}{*}{ Design } & $\begin{array}{c}\text { Strength } \\
\text { Parameter }\end{array}$ & $\begin{array}{c}\text { Carbon } \\
\text { Strength } \\
\text { Values } \\
\mathbf{( k s i )}\end{array}$ & $\begin{array}{c}\text { Corresponding } \\
\text { Stress Values } \\
\text { (ksi) }\end{array}$ & $\begin{array}{c}\text { Factor } \\
\text { Of } \\
\text { Safety }\end{array}$ \\
\hline \multirow{2}{*}{ Carbon Fiber } & $F_{1 t}$ & 80.0 & 62.7 & 1.28 \\
\cline { 2 - 5 } & $F_{2 t}$ & 82.5 & 62.7 & 1.32 \\
\hline Carbon Fiber & $F_{1 t}$ & 80.0 & 71.7 & 1.12 \\
\cline { 2 - 5 } Reinforced Al. & $F_{2 t}$ & 82.5 & 71.7 & 1.15 \\
\hline
\end{tabular}

The results shown in Table 3.3 indicate that:

- The benefits of adopting an integrated material-structure approach to achieve weight savings in the design of high pressure tanks for storing gaseous hydrogen are illustrated by the above results, mostly in terms of the higher factors of safety associated with the all-carbon tanks, as compared to the carbon reinforced aluminum tanks.

- The benefits of tailoring the geometry and material design to the specific loading environment of hydrogen tanks are evident from the changes in the value of the safety factor as the lay-up orientation or composition changes.

- The aluminum core is not suitable for lightweight design of hydrogen tanks, since it does not reduce the stress levels developed on the inner wall surface of the pressure vessel. Additionally, the presence of the aluminum at the inner surface will make the aluminum always subjected to the maximum stress due to an internal pressure. Although the aluminum can sustain such stress at pressures in 
the magnitude of 5,000 psi, the results in Table 3.3 indicates that it will fail under pressures of 10,000 psi or higher.

\subsubsection{Hydrogen Storage Capacity}

The calculation of the weight and volume of the storage hydrogen tank involves the determination of the compressibility factor for the hydrogen gas, $z$, as a function of internal pressure (Jones and Dugan, 1996; Takeichi, 2003; Dogan, 2006). The values compressibility factor of the hydrogen gas at $298^{\circ} \mathrm{K}\left(77^{\circ} \mathrm{F}\right)$ to calculate the hydrogen storage performance as a function of the internal pressure are given in Table 3.6 (Takeichi, 2003). The weight of the compressed hydrogen gas is calculated using Equation 3.5.

$$
W_{H 2}=\frac{M P V_{i}}{z R T}
$$

Where $\mathrm{M}$ is the molar mass of the Hydrogen $=2.016 \mathrm{lbm} / \mathrm{lbmol}$

$\mathrm{P}$ is the internal pressure in the pressure vessel

$\mathrm{V}$ internal volume of the tank $=2,240 \mathrm{in}^{3}$

$\mathrm{R}$ is the universal gas constant $=1,545.3 \mathrm{ft} .1 \mathrm{bf} / \mathrm{lbmol} . \mathrm{R}$

$\mathrm{T}$ is the hydrogen gas temperature inside the tank, Rankines 


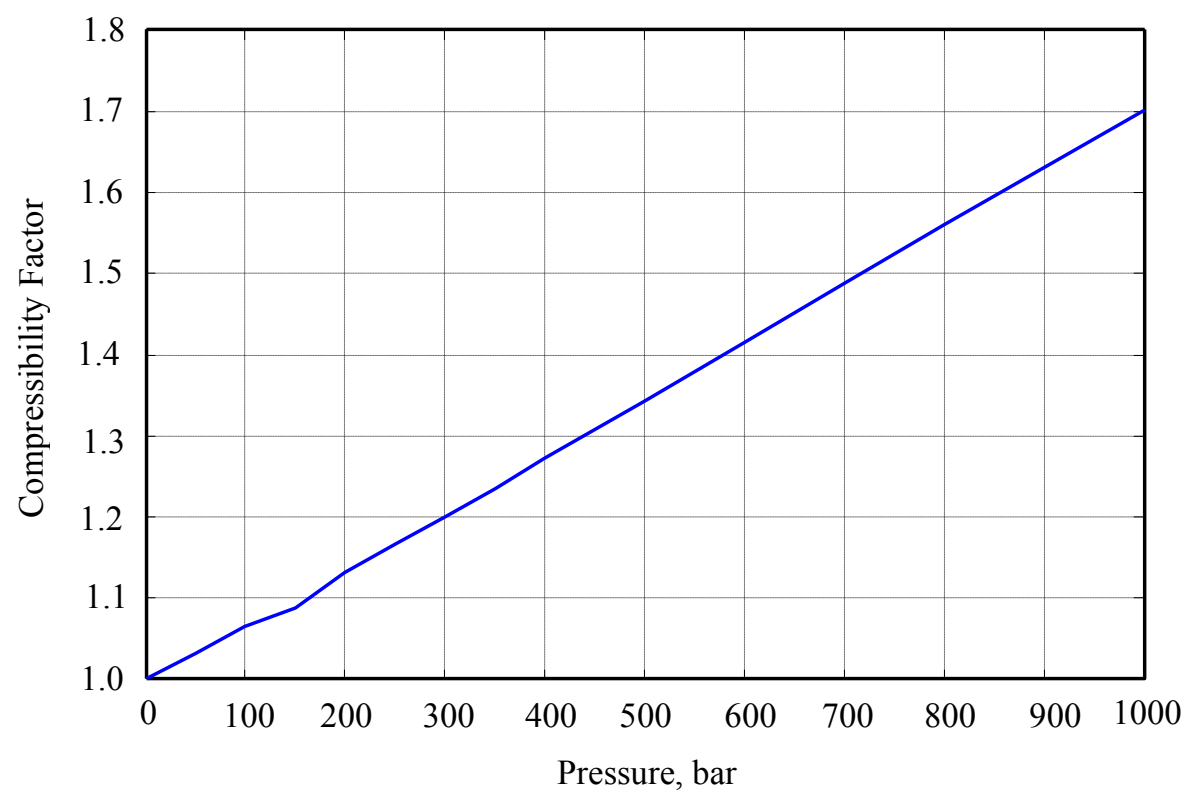

Figure 3.6 Values of Compressibility Factor of the Hydrogen Gas at $77^{\circ} \mathrm{F}$.

Substituting the above values into Equation 3.5 yield the weight of stored compressed hydrogen in the tank is $3.06 \mathrm{lb}$. As a result, the design configurations shown above would result in specific energy densities of $10 \%$ for an all-carbon fiber vessel and $4.88 \%$ for the vessel with an aluminum liner reinforced by carbon fiber. 


\section{Chapter 4}

\section{Shape Optimization}

The preliminary design of on-board hydrogen storage tanks presented in chapter three as well as the design configurations found in the available literature are based upon utilizing a cylindrical tank with two end caps as shown in Figures 3.1 through 3.5. One of the major problems with this design configuration is high weight of the storage tank due to the required high pressure capability. As a result, such tanks could not meet the DOE energy density requirements presented in Table 1.1. Another problem is the large tank size, which reduces the available space in the vehicle trunk (Neira and Scudelari, 2005). These challenges motivated the development of new storage tanks with unconventional geometries. These design configurations are projected to provide conformability with respect to the available vehicle cargo space.

Initial designs for a hydrogen storage system utilized closed-form solutions to attain the internal forces developed due to high pressure levels. From attainment of the internal forces, the required material thickness to withstand these forces was determined. With the thickness requirements attained, finite element analysis was used to compare the use of carbon fiber and aluminum design and a homogenous carbon fiber configuration as presented in Chapter Three. Acknowledging the basic engineering principles that internal stresses are half in magnitude for a spherical tank as opposed to cylindrical tank designs, the focus of tank configuration moved to address the spherical concepts.

\subsection{Spherical versus Cylindrical Design Configuration}

A shape optimization was performed to analyze various spherical and cylindrical tank configurations. Table 4.1 presents a sample of the results generated during this process. Therefore, a multi-spherical approach which combines spheres to attain a single volume of 15 gallons of hydrogen under an internal pressure of 10,000 psi (700 bar) is 
pursued to address the issue of practical on-board storage applications as well as the higher stress levels attained in cylindrical tanks.

The factors for introducing a spherical hydrogen storage concept are based on basic engineering principles that state the derived stress is a function of the pressure, radius, and thickness. Spherical tanks were shown to have much less stress than that in cylindrical vessels of the same volume. Such a reduction in stress due only to the change in geometry is a significant increase and is beneficial because:

- A stress reduction by a geometry change only will increase the amount of pressure sustained inside the vessel and ultimately increase the amount of hydrogen stored per volume.

- Stress reductions will decrease the thickness dimension required to achieve a particular factor of safety in a direct comparison to a cylindrical design. Minimal thickness will reduce the cost per storage system by limiting the usage of high performance materials i.e. carbon fiber.

- Options to vary the spherical dimensions will utilize free space on-board a standard vehicle. Various sizes of spherical tanks can be dimensioned to allowable free space inside a vehicle frame, chassis, cargo areas, etc.

- Several small spherical tanks will address the pressure drop inside a tank as the fuel is depleted. Maintaining several smaller storage systems as seen in Figure 4.1 (b) will minimize the pressure drop as fuel is used as opposed to single storage tank or various larger storage systems. 


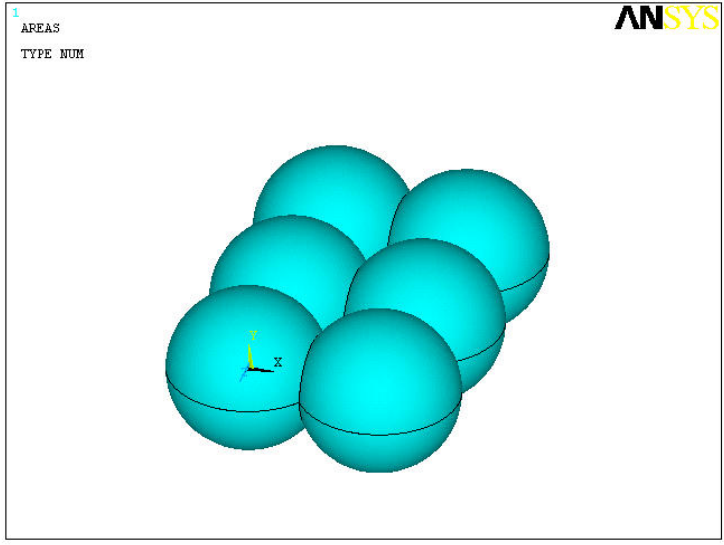

(a)

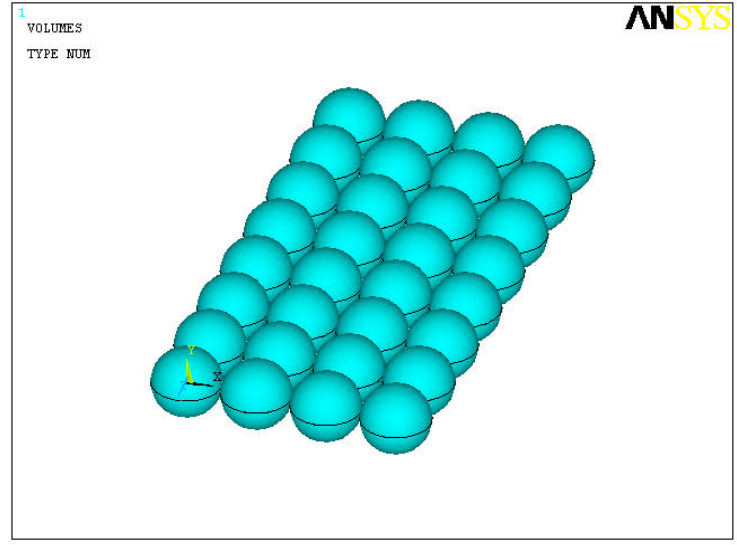

(b)

Figure 4.1: Multi-Sphere Tank Designs (a) 6-Sphere design with merged connections (b) Multiple sphere design without merged connections.

\subsection{Finite Element Analysis of Hydrogen Tanks}

A set of finite element models for hydrogen tanks of spherical configuration were created to investigate the state of stress that develops in the tank wall and optimize the wall thickness. All models were built using four-node shell elements as shown in Figure 4.2. The tank wall was assumed to be carbon fiber/epoxy composite, whose strength in the tensile direction of the composite is $85 \mathrm{ksi}$. Although this value for the composite strength seems to be very conservative, it matches the strength that we obtained from the material testing that was performed on coupon level testing during prototyping as it will be described in Chapter Five of this report.

Spherical tanks of internal diameters of 18.8 in. (15-gallon tank) and 13 inch (5gallon tank) were modeled. Different thickness dimensions were assumed for each model and the stresses were calculated under the effect of an internal burst pressure of $23,000 \mathrm{psi}$. As the service pressure expected in these tanks is $10,000 \mathrm{psi}$, a factor of safety of 2.3 is kept the same for all designs. 


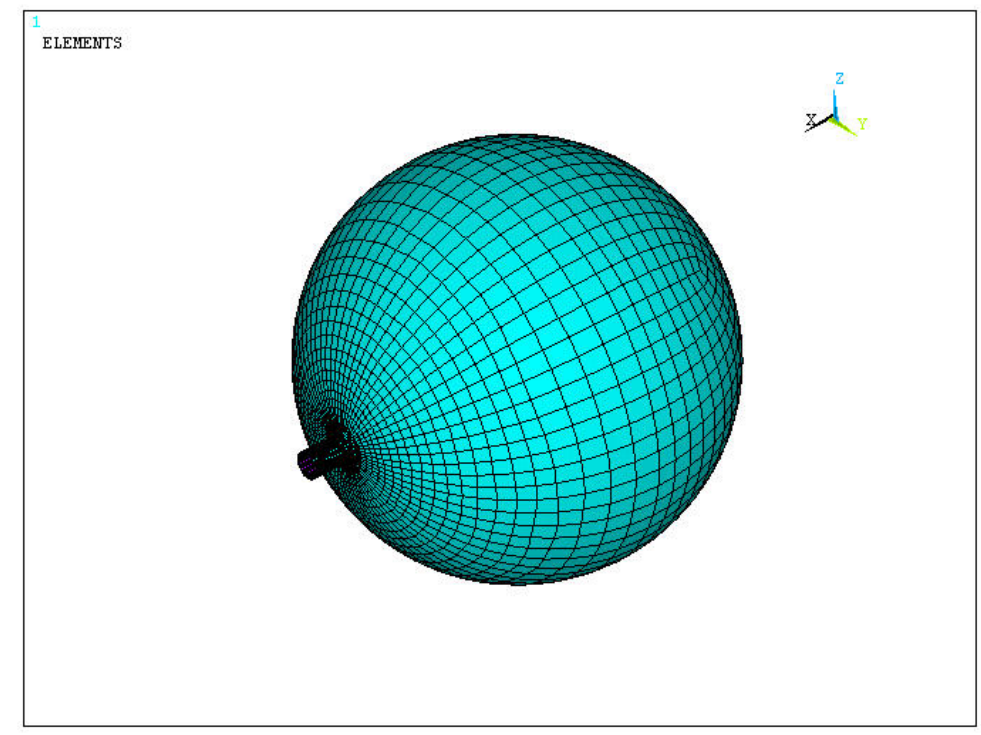

Figure 4.2: Spherical tank finite element model.

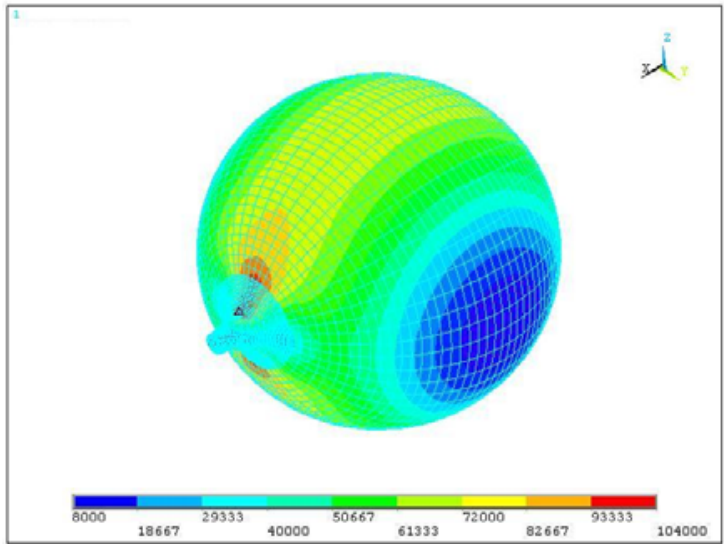

(a)

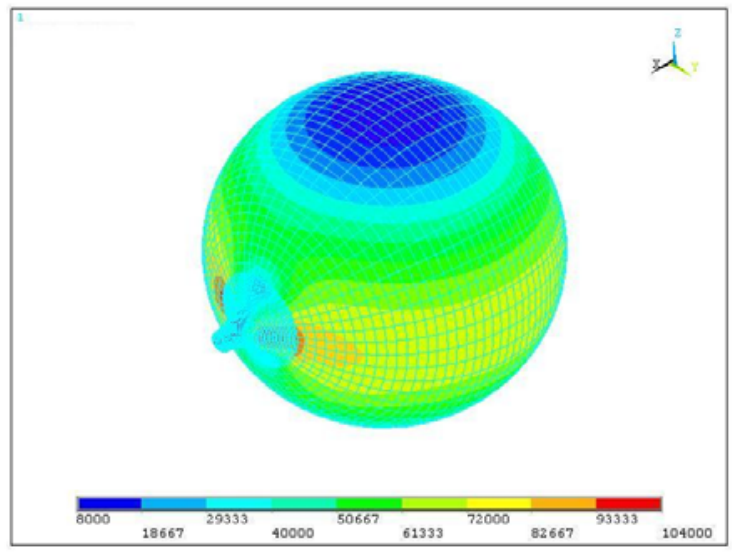

(c)

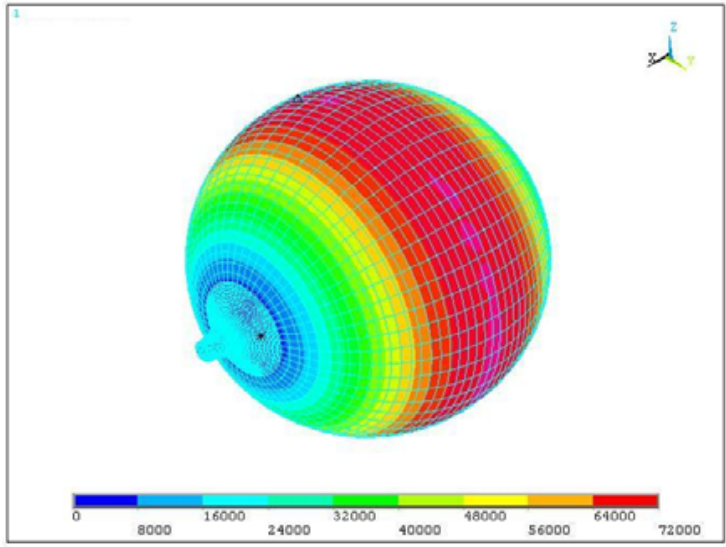

(b)

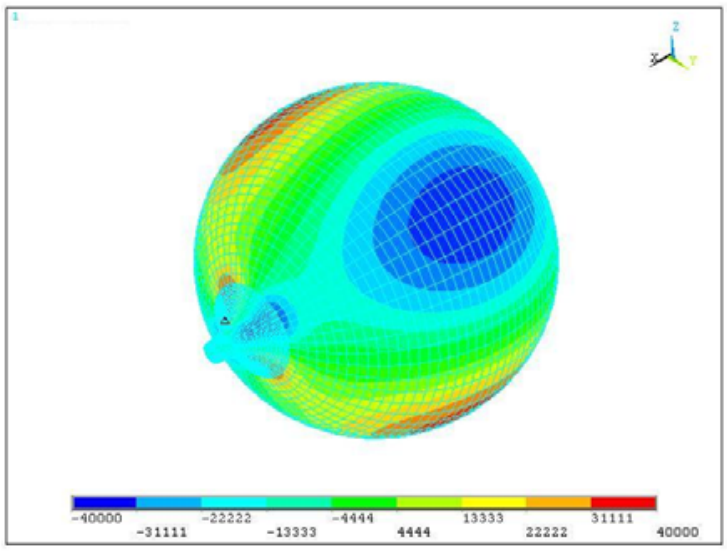

(d) 
Figure 4.3: Stresses in 15-Gallon Spherical Tanks (Thickness $=1.4$ in.) (a) vertical meridian stress (b) hoop stress (c) horizontal meridian stress and (d) shear stress [psi].

Figure 4.3 illustrates by fringes the stress distribution in the tank wall due to an internal pressure of 23,000 psi. Noticeable are the stress concentration zones that developed around the neck vicinity in Figures 4.3 (a), (c) and (d). These regions constitute a critical area for potential tank failure.

Table 4.1: Effect of Varying the Wall Thickness on Critical Stress in 9-inch Diameter Spherical Tank Due to a Burst Pressure of 23,000 psi

\begin{tabular}{|c|c|c|c|c|c|c|}
\hline $\begin{array}{c}\text { Thickness } \\
\text { (inches) }\end{array}$ & Stress-11 & Stress-12 & Stress-13 & Stress-22 & Stress-23 & Stress-33 \\
\hline 1.0 & 59,136 & 128,310 & 127,650 & 137,706 & 31,593 & 145,084 \\
\hline 0.9 & 65,254 & 139,625 & 138,596 & 140,250 & 34,641 & 143,617 \\
\hline 0.8 & 72,819 & 151,447 & 150,021 & 147,599 & 38,418 & 147,888 \\
\hline 0.7 & 81,922 & 143,965 & 143,488 & 157,929 & 49,346 & 159,630 \\
\hline 0.6 & \multicolumn{7}{|c|}{ Model Failed due to Large Pressure } \\
\hline
\end{tabular}

Table 4.2: Effect of Varying the Wall Thickness on Critical Stress in 13-inch Diameter Spherical Tank Due to a Burst Pressure of 23,000 psi

\begin{tabular}{|c|c|c|c|c|c|c|}
\hline $\begin{array}{c}\text { Thickness } \\
\text { (inches) }\end{array}$ & Stress-11 & Stress-12 & Stress-13 & Stress-22 & Stress-23 & Stress-33 \\
\hline 2 & 36236 & 244017 & 244155 & 154721 & 40026 & 156678 \\
\hline 1.9 & 38235 & 254445 & 254685 & 159126 & 40762 & 162790 \\
\hline 1.8 & 40540 & 257687 & 257597 & 155148 & 47135 & 161106 \\
\hline 1.7 & 43320 & 255714 & 256959 & 154225 & 55467 & 159401 \\
\hline 1.6 & 46735 & 240142 & 242075 & 155268 & 58363 & 160476 \\
\hline 1.5 & 51463 & 213059 & 213832 & 156916 & 63473 & 162318 \\
\hline 1.4 & \multicolumn{7}{|c|}{ Model Failed due to Large Pressure } \\
\hline
\end{tabular}




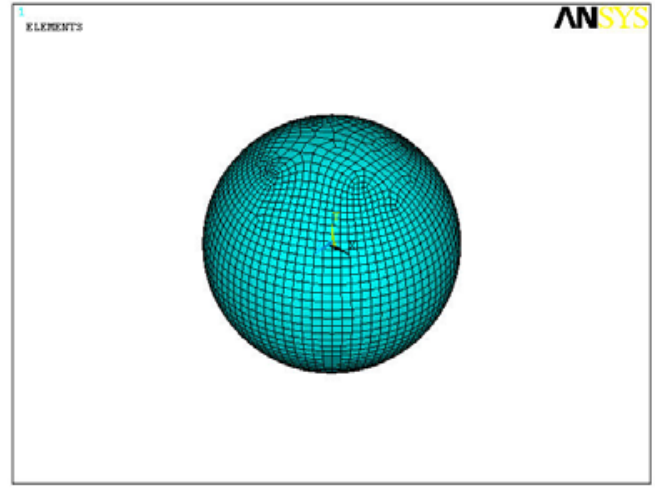

(a)

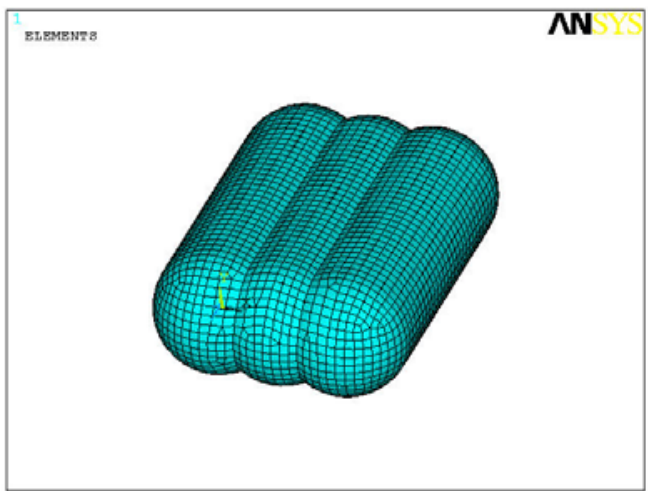

(c)

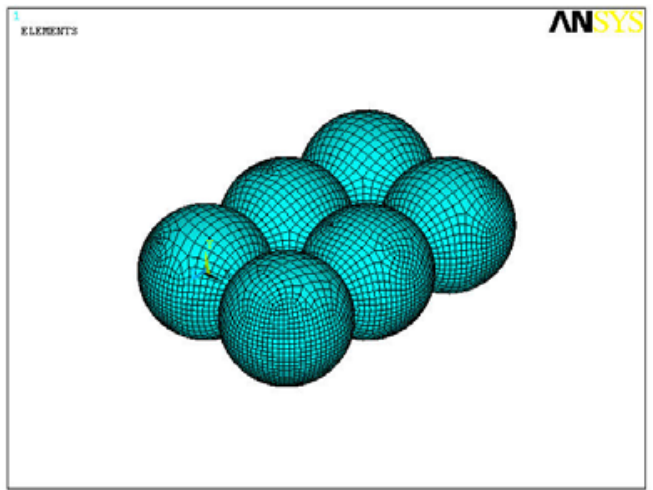

(e)

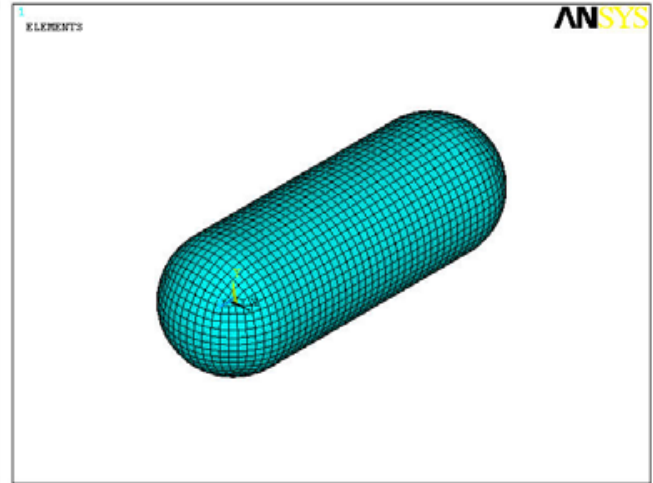

(b)

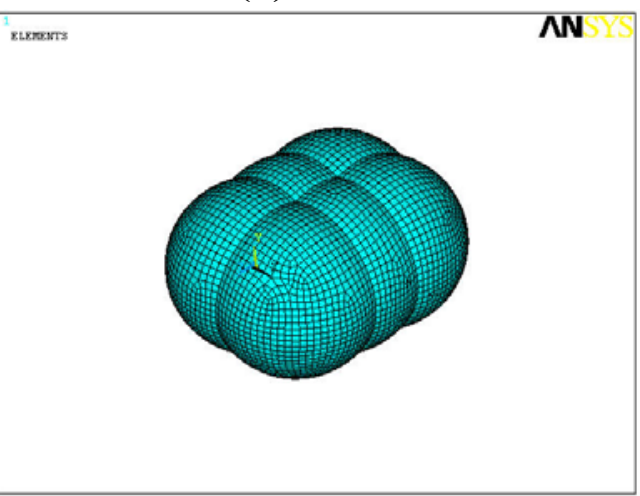

(d)

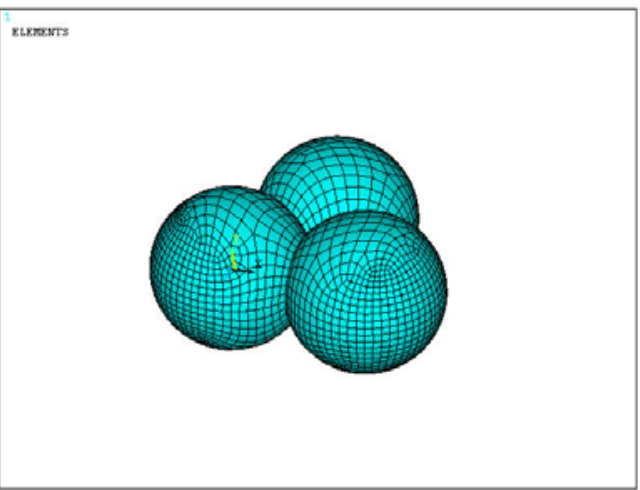

(f)

Figure 4.4: Shape configurations with constant volume, material properties and thickness (a) Sphere (b) Cylinder (c) 3-Cylinder (d) 6-Sphere Compact (e) 6-Sphere Spaced (f) 3-Sphere.

The parameters for the shape optimization are to hold the volume, material properties, and thickness constant and analyze the displacement and resulting stress. The volume is contained at 15 gal. (56.78 1), which was chosen based on a comparison value to the average standard volume occupied by current gas-combustion engine. The material properties are standard steel properties of $\mathrm{E}=29 \times 10^{6} \mathrm{lb} / \mathrm{in}^{2}$ and $v=0.32$. 
Comparison Parameters

Volume is held constant at 15 gal.

Material properties are constant $E=29 \times 10^{6} \mathrm{lb} / \mathrm{in}^{2}$ and $v=0.32$

Thickness is constant, $\mathrm{t}=0.125$ in.

Deformation and stress results are compared results

\subsection{Deformations}

The displacements for the shape optimization prototype models are shown in Figure 4.5 (a) through (f).

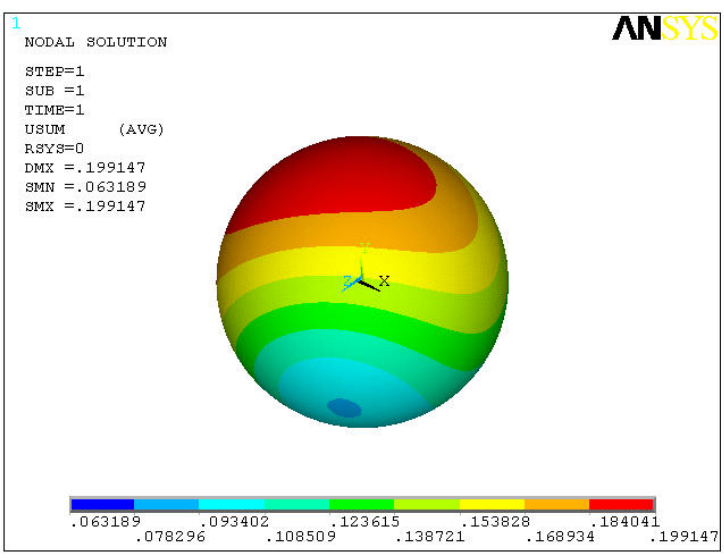

(a)

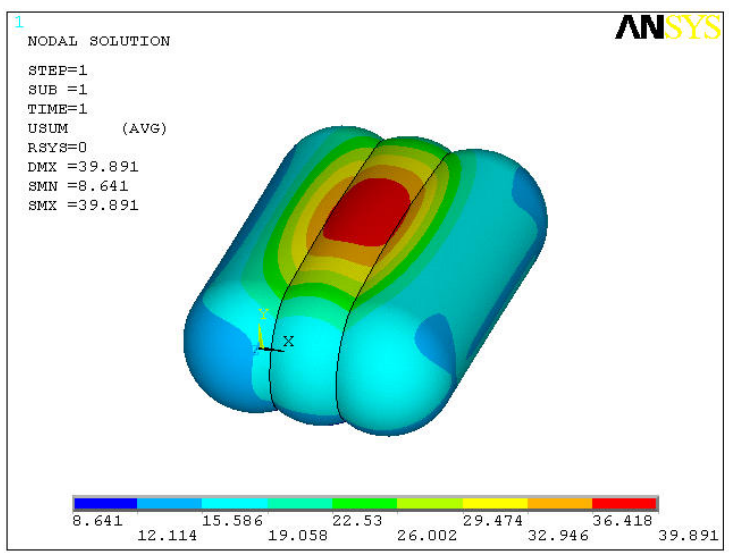

(c)

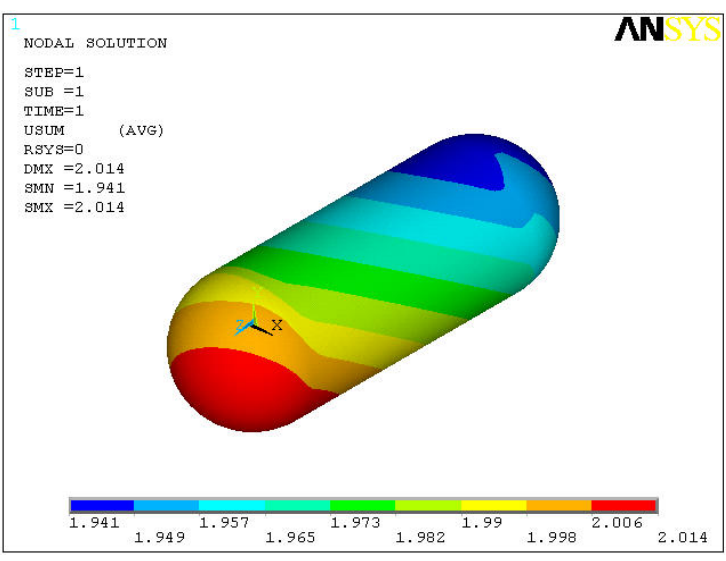

(b)

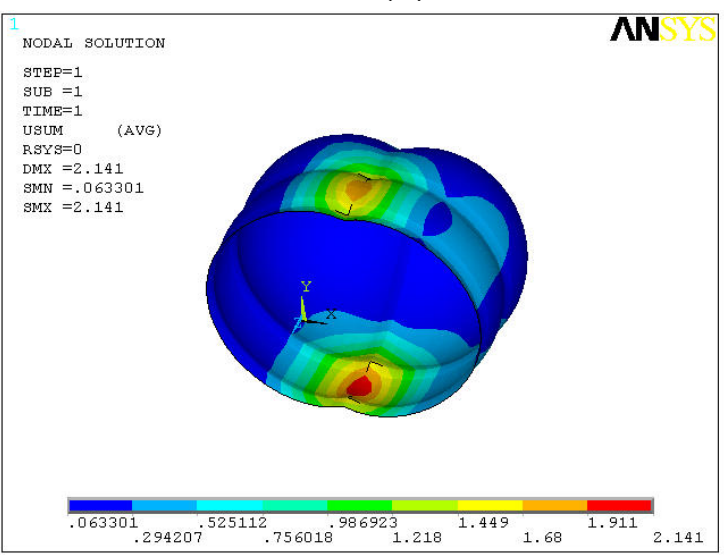

(d) 


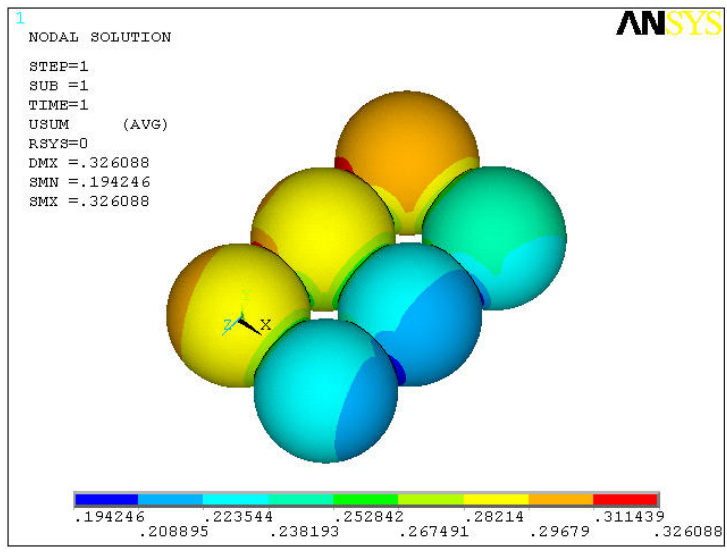

(e)

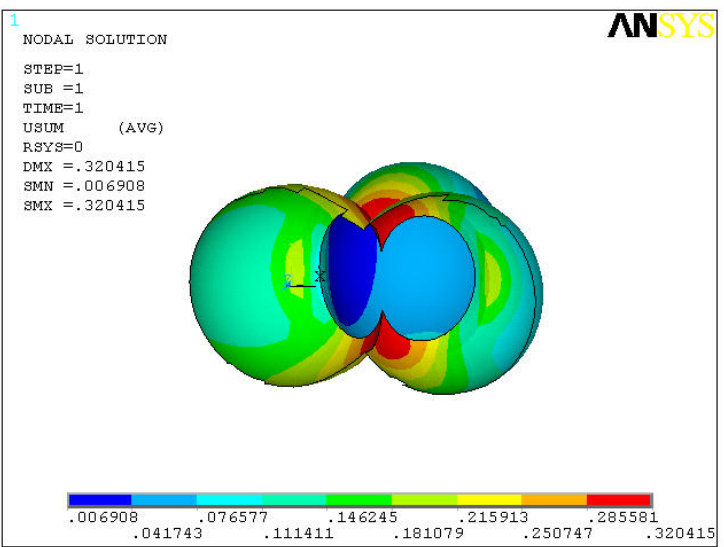

(f)

Figure 4.5: Displacement [in] results for pressure vessel configurations (a) Sphere (b) Cylinder (c) 3Cylinder (d) 6-Sphere Compact (e) 6-Sphere Spaced (f) 3-Sphere.

Comparing the spherical and cylindrical tank, Figure 4.5 (a) and Figure 4.5 (b), respectively, it is noted that the maximum displacement of the spherical vessel is 0.199 inches to 2.014 inches in the cylindrical vessel. The 3-Cylinder merged configuration, Figure 4.5 (c) shows the least favorable displacement result, attaining a large displacement and clear failure in the structure under the applied loading conditions.

The displacement results are defined in Table 4.3 which normalizes the displacement values to the standard cylindrical tank design, Figure 4.5 (b).

Table 4.3: Deformation Results.

\begin{tabular}{|l|c|c|}
\hline \multicolumn{3}{|c|}{ Deformation Results } \\
\hline Sphere & inches & Normalized to Cylinder \\
\hline Cylinder & 0.199 & 0.020 \\
\hline 3-Cylinder & 2.014 & 1.000 \\
\hline 6-Sphere Compact & 39.09 & 19.45 \\
\hline 6-Sphere Spaced & 2.141 & 1.063 \\
\hline 3-Sphere & 0.326 & 0.162 \\
\hline
\end{tabular}




\subsection{Stress Resultants}

The resulting stress of the shape configurations are plotted in Figure 4.6 through Figure 4.11 and summarized in Table 4.4.

\subsubsection{Sphere}

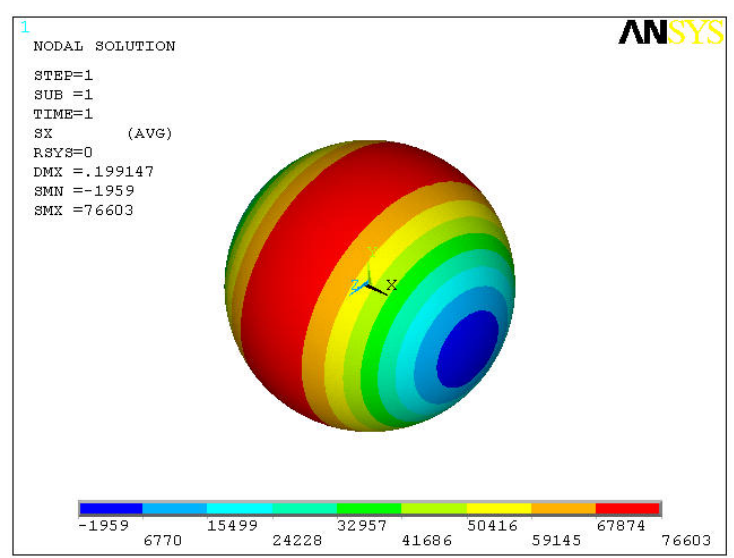

(a)

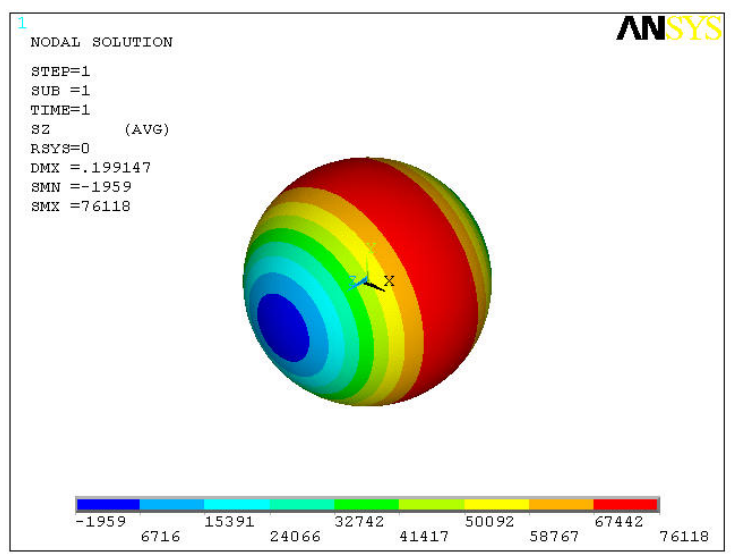

(b)

Figure 4.6: Sphere stress resultants (a) stress in the x-direction (b) stress in the z-direction [psi].

Figure 4.6 plots the stress in the $\mathrm{x}$-direction and z-direction, as expected for the spherical design, the stress in each direction is equivalent and having a magnitude of 76 ksi.

\subsubsection{Cylinder}



(a)

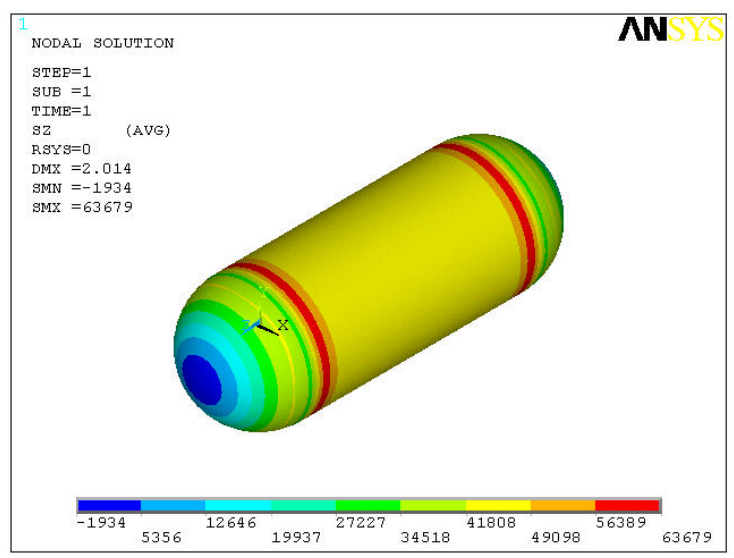

(b)

Figure 4.7: Cylinder stress resultants (a) hoop stress (b) axial stress [psi]. 
The resulting stress in the cylindrical tank is shown in Figure 4.7. The hoop stress (x-direction) is shown in Figure 4.7 (a) and has a magnitude of 98 ksi. Figure 4.7 (b) shows the plot of the stress in the axial direction of the cylinder with a maximum of 63 ksi.

\subsubsection{3-Cylinder}

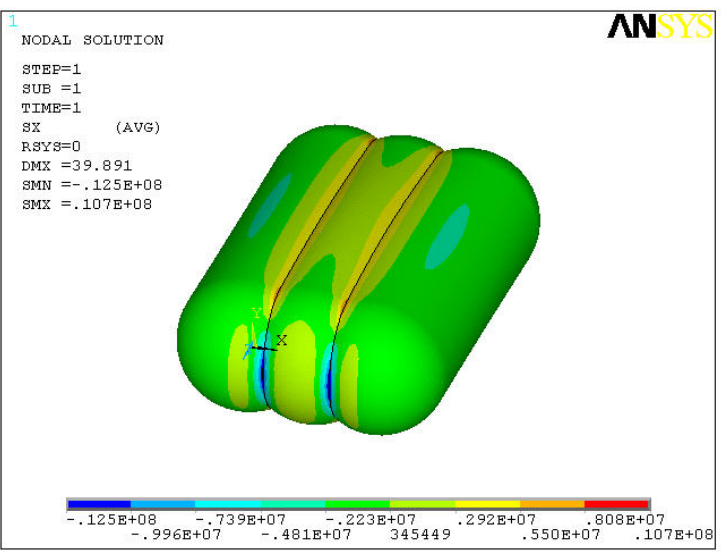

(a)

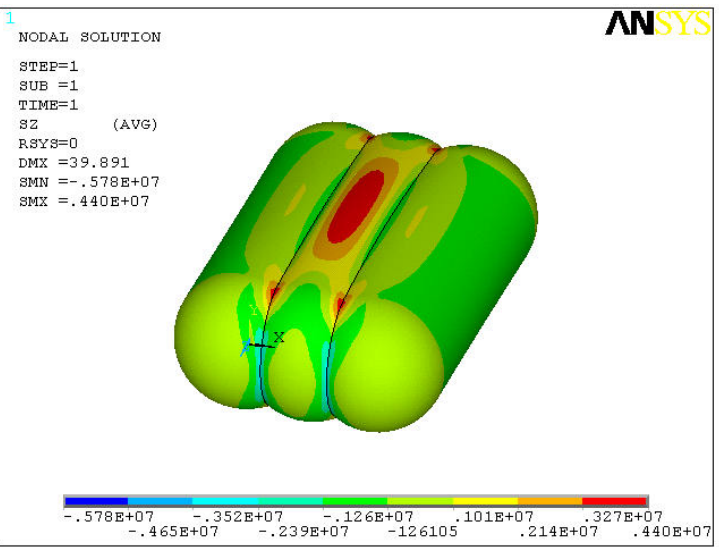

(b)

Figure 4.8: 3-Cylinder stress resultants (a) hoop stress (b) axial stress [psi].

\subsubsection{6-Sphere Compact}

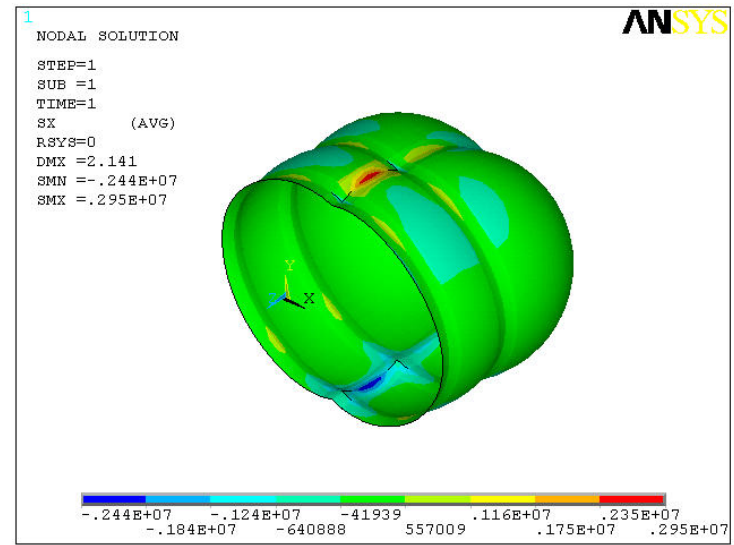

(a)

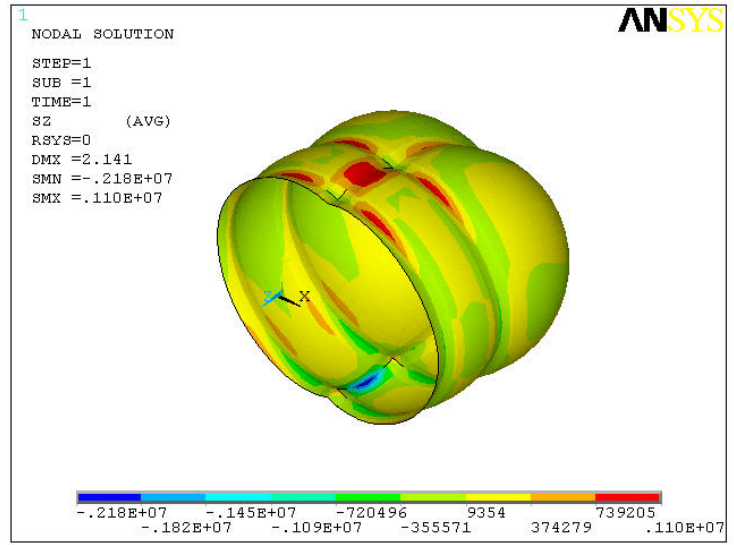

(b)

Figure 4.9: 6-Sphere Compact stress resultants (a) x-direction hoop stress (b) z-direction axial stress [psi]. 


\subsubsection{6-Sphere Spaced}

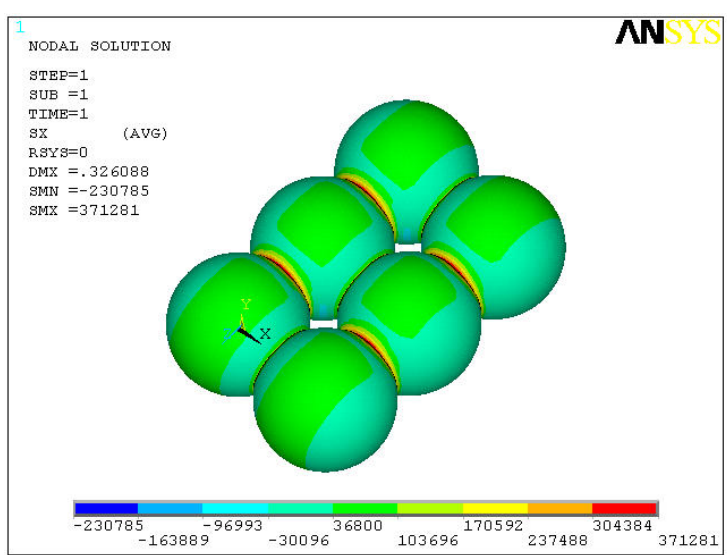

(a)

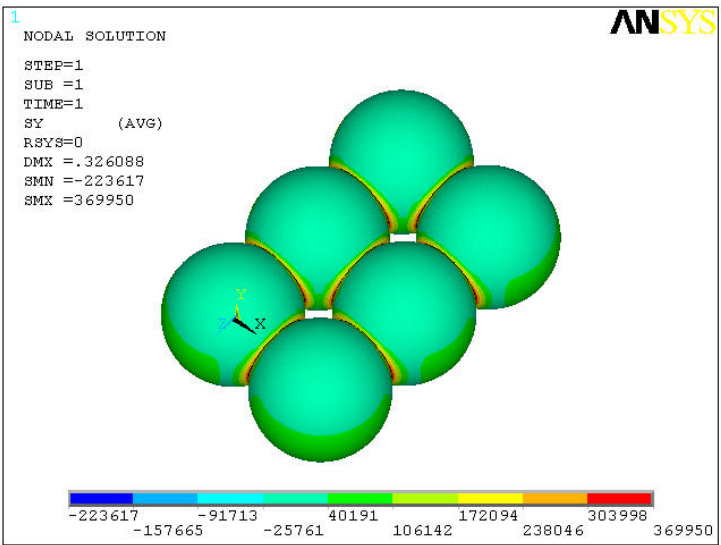

(b)

Figure 4.10: 6-Sphere Spaced stress resultants (a) x-direction stress (b) z-direction stress [psi].

\subsubsection{3-Sphere}
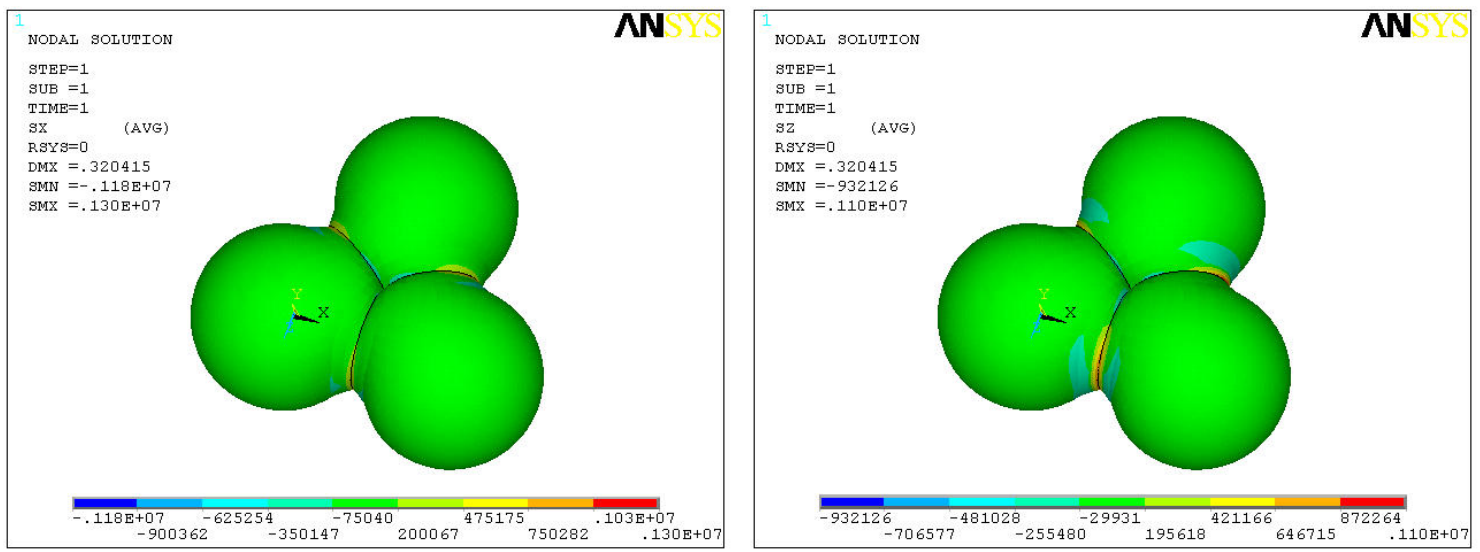

Figure 4.11: 3-Sphere stress resultants (a) x-direction stress (b) z-direction stress [psi].

The configurations shown in Figures 4.8 through 4.11 depict the resulting stress. The configurations show large stress concentrations at the merge connections which will certainly induce failure at the applied internal pressure. The magnitude of the stress concentrations are defined in Table 4.4. The 3-Cylinder configuration attains the highest stress level within the body of the structure and correlates to its large displacement, as previously shown in Figure 4.5 (c).

As a result, the merged configurations do not show any promise as high pressure hydrogen containment tanks. The impact these designs would have towards volume capacity on-board a hydrogen powered vehicle can not be explicitly stated until the allotment and dimension of available cargo space is provided based on the vehicle size 
and shape. The standard spherical and cylindrical tank designs will be the most effective approach for a compressed gas high pressure storage system.

Table 4.4: Stress Resultants.

\begin{tabular}{|c|c|c|c|c|}
\hline \multicolumn{5}{|c|}{ Stress Resultants } \\
\hline & $\begin{array}{c}\text { Stress x- } \\
\text { direction } \\
\left(10^{-6} \mathrm{psi}\right)\end{array}$ & $\begin{array}{c}\text { Stress z- } \\
\text { direction } \\
\left(10^{-6} \mathrm{psi}\right)\end{array}$ & $\begin{array}{c}\text { Normalized to } \\
\text { Cylinder } \\
\text { x-direction }\end{array}$ & $\begin{array}{c}\text { Normalized to } \\
\text { Cylinder } \\
\text { y-direction }\end{array}$ \\
\hline Sphere & 0.076 & 0.076 & 0.775 & 1.188 \\
\hline Cylinder & 0.098 & 0.064 & 1 & 1 \\
\hline 3-Cylinder & 10.70 & 4.400 & 109.2 & 68.75 \\
\hline 6-Sphere Compact & 2.951 & 1.130 & 30.11 & 17.66 \\
\hline 6-Sphere Spaced & 0.371 & 0.370 & 3.786 & 5.78 \\
\hline 3-Sphere & 1.300 & 1.100 & 13.27 & 17.19 \\
\hline
\end{tabular}




\section{Chapter 5}

\section{Experimental Testing}

Layers of carbon fiber were laid up using the same technique and carbon fiber material used in building the spherical pressure vessel in order to manufacture coupon specimens to be used in material characterization. Figure 5.1 illustrates the final composite plates as well as the coupon specimens after they were cut from such plates.

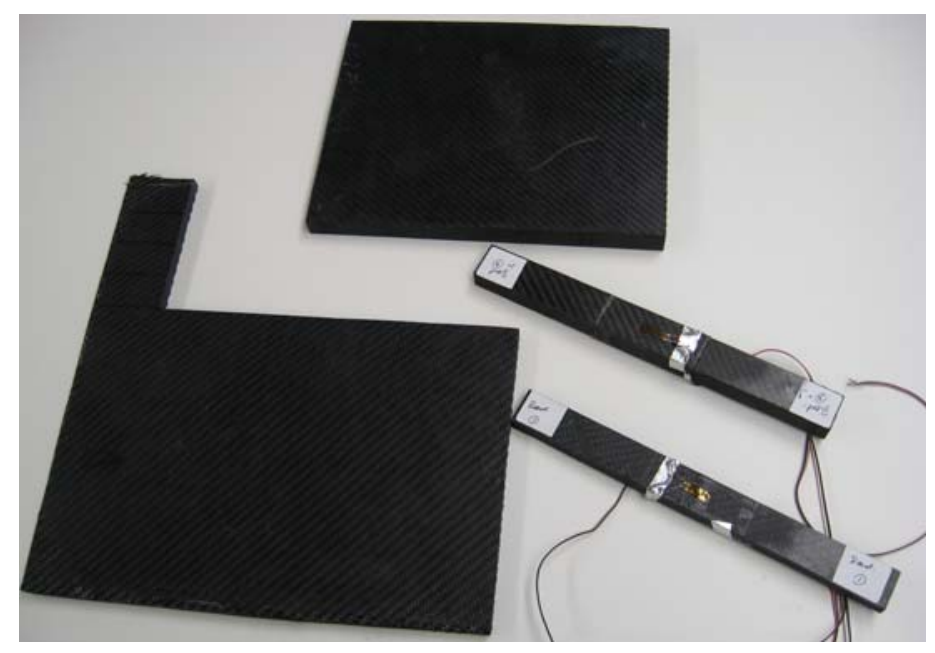

Figure 5.1: Carbon fiber specimens used for material testing.

The carbon fiber plates were made to thicknesses of 0.375 inch $(10 \mathrm{~mm})$ and $0.875 \mathrm{inch}(18 \mathrm{~mm})$. Coupon specimens were cut to have one inch in width and 10 inches in length. Each specimen was fitted in its center length and middle width with two wire resistance strain gages on top and bottom as shown in Figure5.1. Uniaxial tensile tests as well as 4-point bending tests were performed on the specimens as shown in Figure 5.2 as a method to determine the uniaxial and bending tensile strengths of each specimen. 


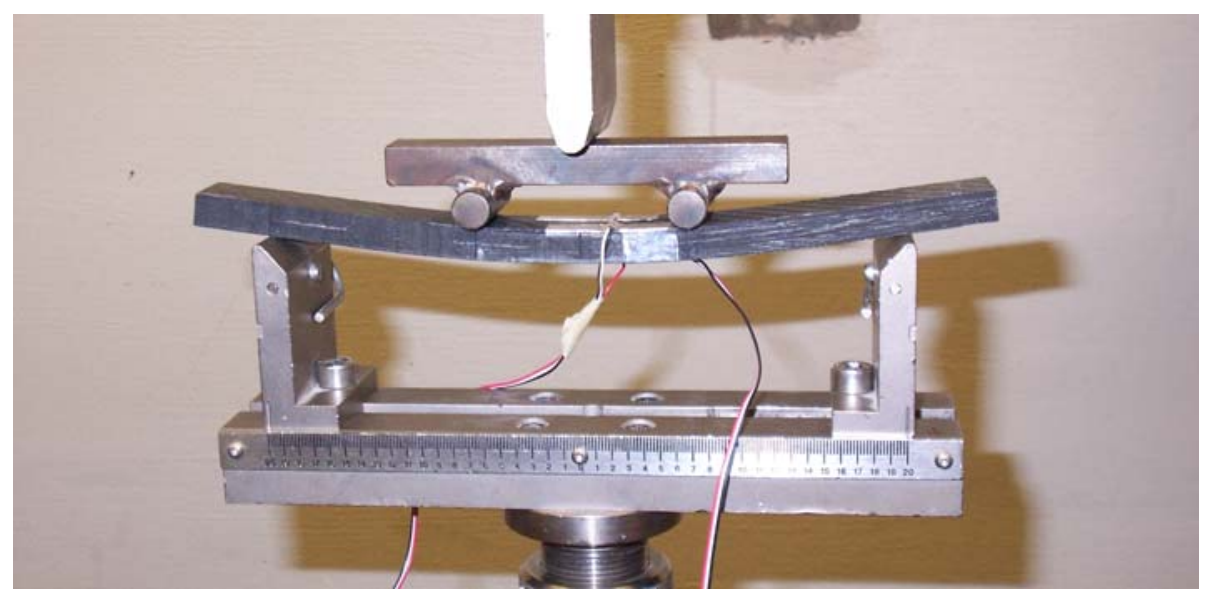

(a)

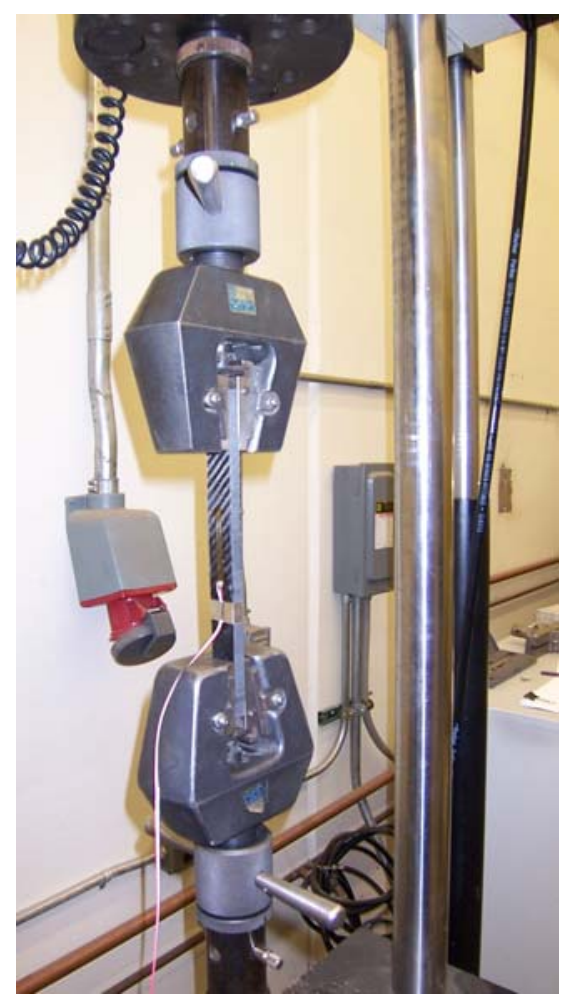

(b)

Figure 5.2: (a) Four-point bending test setup. (b) Uniaxial tensile test setup.

\subsection{Four-Point Bending Tests}

In the four-point bending tests, the specimens were loaded by the procedure shown in Figure 5.3. Strains were measured at the top and bottom of the composite 
specimen as the load increased. The normal stresses were calculated and the stress-strain diagrams were generated. The middle region of the beam is under a uniform bending moment, which produces a failure mode in this region that is independent from the effect of shearing force due to the reaction at the supports.
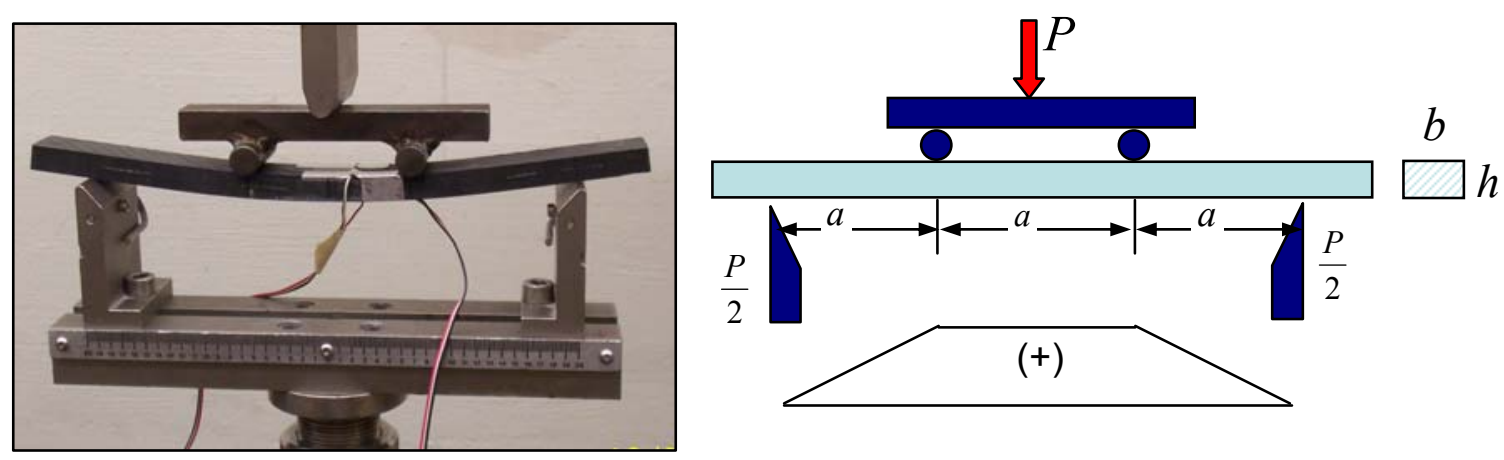

Figure 5.3: Deformed specimen during a four-point bending test and its respective bending moment diagram.

Under the effect of the applied load, $\mathrm{P}$, the maximum bending moment is calculated by:

$$
M=P a / 2
$$

The flexural stress at the top or bottom surface of the specimen can be calculated as:

$$
\sigma=(M / I) h / 2
$$

The strain due to bending, $\varepsilon_{b}$, is calculated from the measured strains by:

$$
\varepsilon_{b}=\frac{\varepsilon_{\text {top }}-\varepsilon_{\text {bottom }}}{2}
$$

The testing results of specimens with thicknesses 0.375 inch $(10 \mathrm{~mm})$ and 0.875 inch $(18 \mathrm{~mm})$ are presented in Figures 6.4 and 6.5, respectively. It can be noticed that 0.375 inch thick specimens failed in compression of the top fibers as seen in Figure 5.4 (c), while the 0.875 inch thick specimens failed by interlaminar shear at the support as shown in Figure 5.5 (c). None of the specimens failed in tension. This indicates that the calculated strength from the tests represent the lower bound value for the tensile strength of such a carbon fiber composite that was used for the tank prototype. The stress-strain diagrams for both specimens, shown in Figures 5.4 (b) and Figure 5.5 (b), indicate linear relationships from initial loading to the point of failure. 


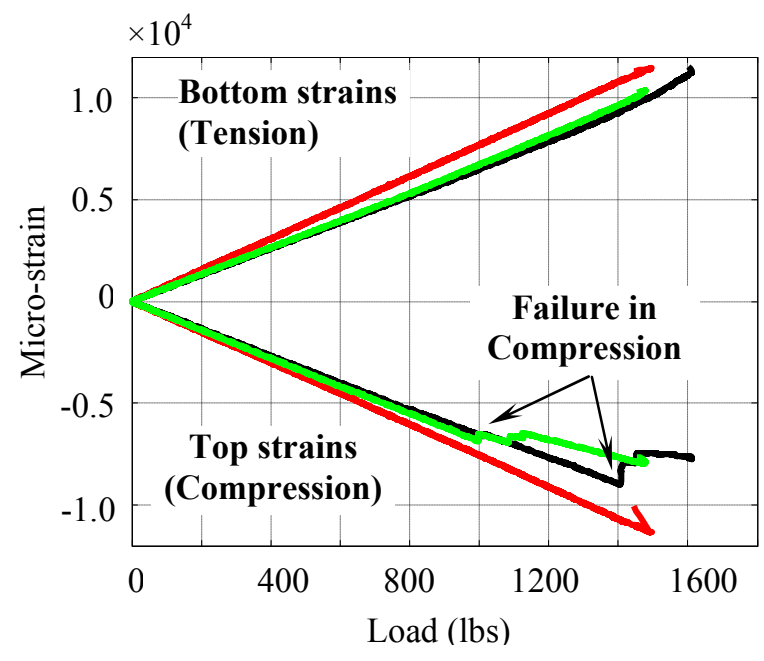

(a) Tensile and Compressive Strains

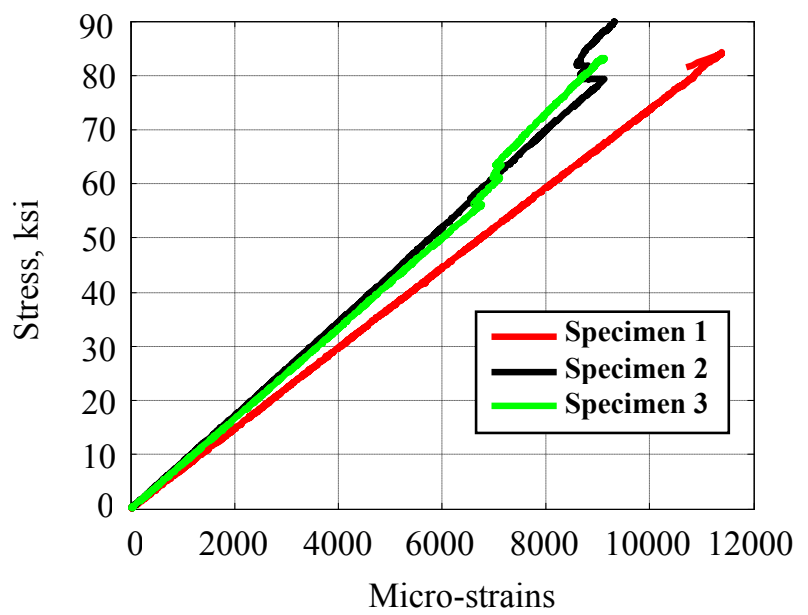

(b) Stress-Strain Diagram

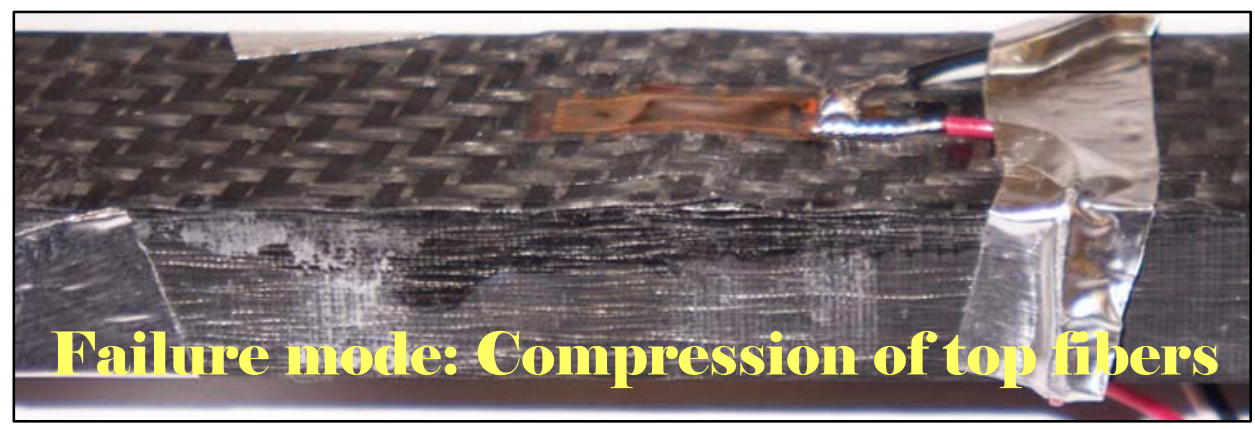

(c) Failure Mode

Figure 5.4: Four-point bending test of $10 \mathrm{~mm}$ thick specimens (a) tensile and compressive strains (b) stress-strain diagram (c) failure mode showing compression of top fibers.

Based on the results shown in Figure 5.4 and Figure 5.5, a laminate tensile strength of $84.5 \mathrm{ksi}$ is achievable. As mentioned earlier, this value may underestimate the actual tensile strength since none of the specimens failed in tension. Adopting such strength value in pressure vessel design, one could estimate the corresponding burst pressure in spherical tank using Equation 6.4 as follows: 


$$
\sigma_{\max }=\frac{P \times r_{\text {tank }}}{t_{\text {tank }}}
$$

Where $\mathrm{P}$ is the expected magnitude of the burst pressure,

$r_{\text {tank }}$ is the vessel radius,

$t_{\text {tank }}$ is the vessel wall thickness.

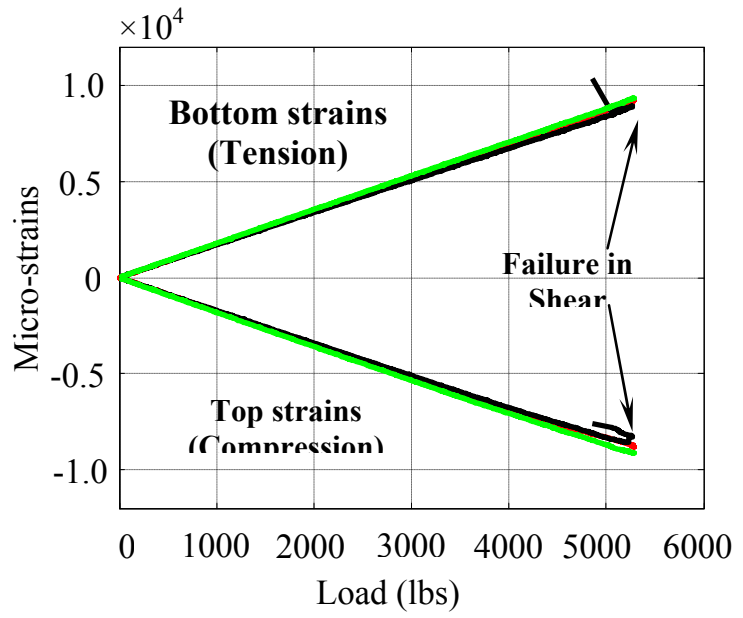

(a) Tensile and Compressive Strains

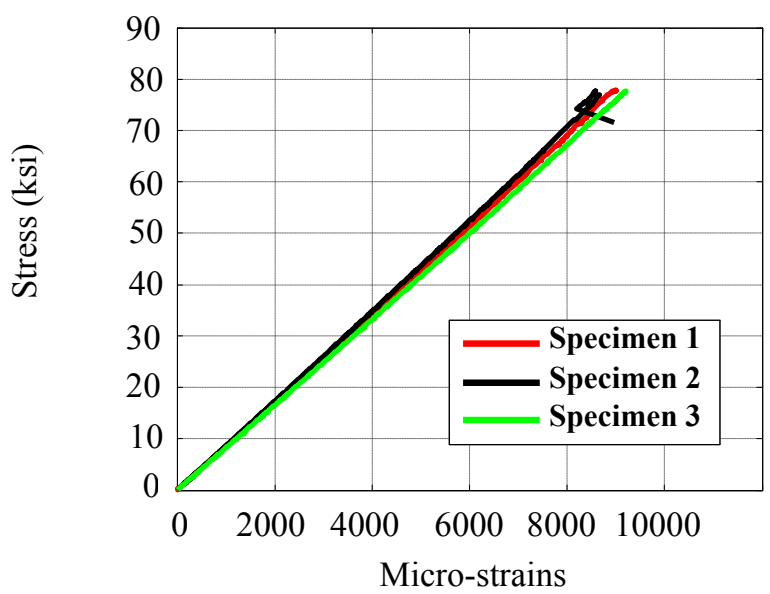

(b) Stress-Strain Diagram

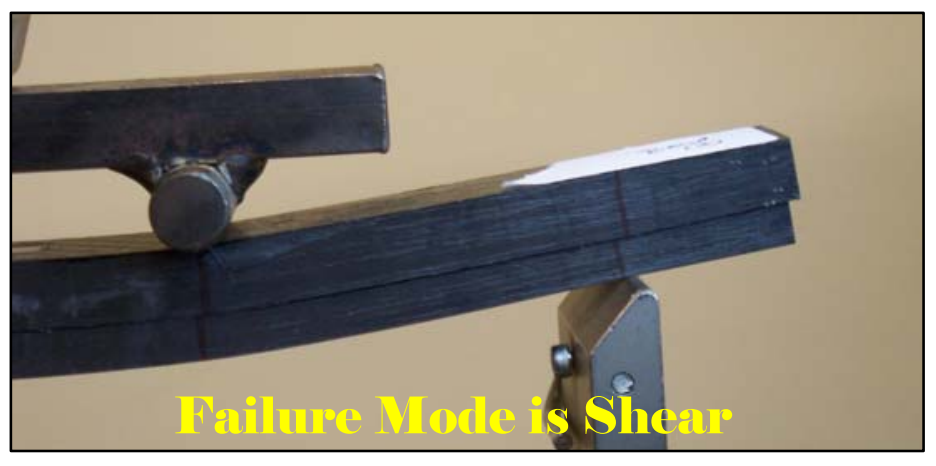

(c) Failure Mode

Figure 5.5: Four-point bending test of $18 \mathrm{~mm}$ thick specimens (a) tensile and compressive strains (b) stress-strain diagram (c) failure mode 


\subsection{Uniaxial Tensile Tests}

Specimens of dimensions similar to those used in four-point bending tests were subjected to uniaxial tensions as depicted in Figure 5.2 (b). However, holding the specimens by the grips of the testing machines created surface damage to the exterior layers of the composite specimens. As a result, these specimens failed at the grip location. The top layer of the carbon fiber laminate was broken in this region as shown in Figure 5.6.

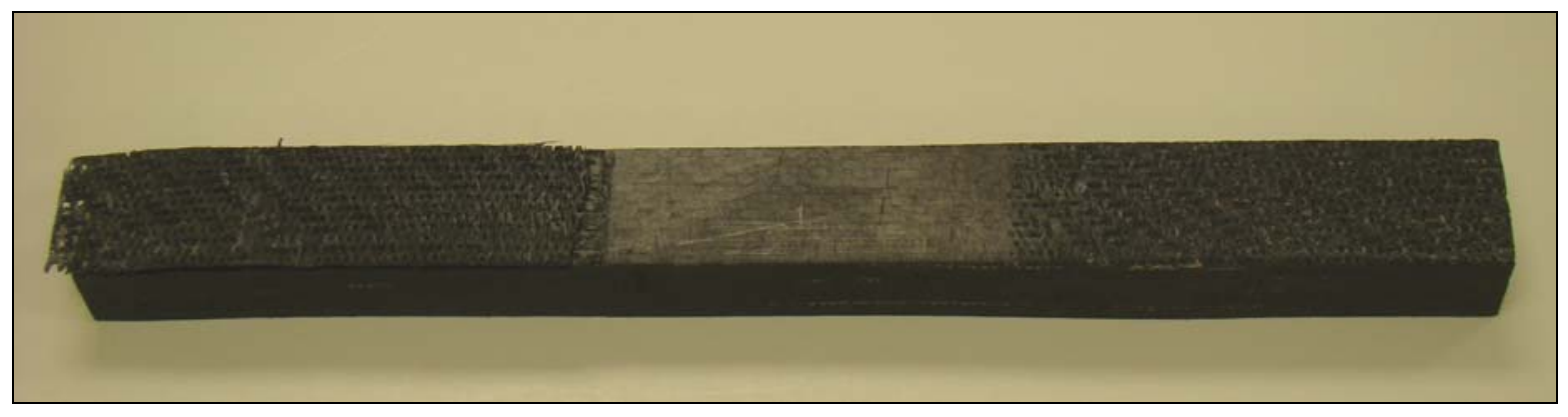

(a)

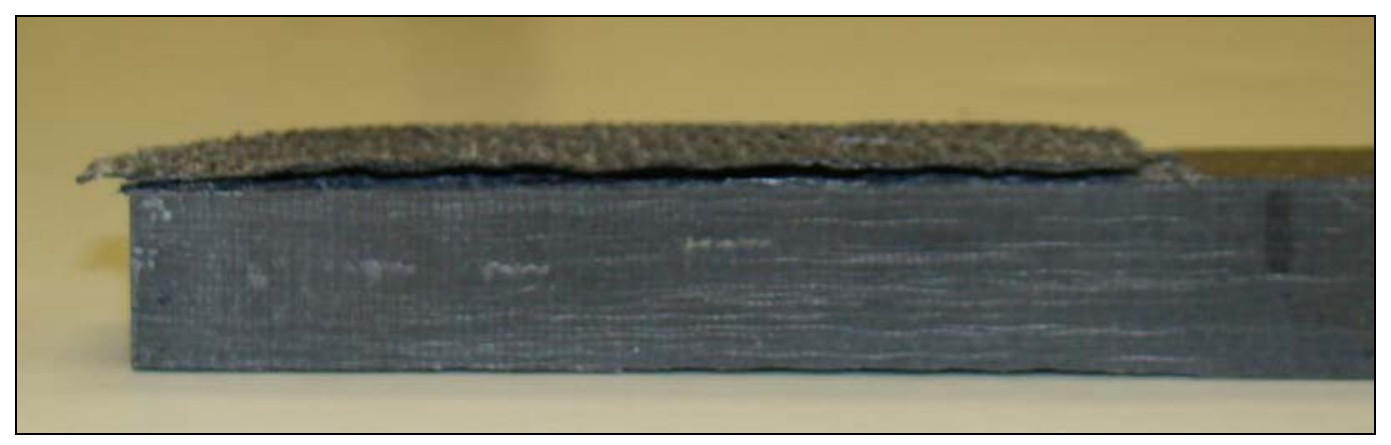

(b)

Figure 5.6: (a) Tensile test specimen (b) delamination and fracture of the top composite layer at the grip location.

The premature failure was due to the discontinuity in the stress distribution and possible local fiber damage, both caused by the clamping force of the grips. The results attained from these trials are not plotted because of the irrelevancy of their output when a failure within the body of the specimen did not occur. 


\section{Chapter 6}

\section{Preliminary Study of Filament Wound Composite Pressure Vessels}

Many high-strength composite structures are manufactured using the automated filament winding processes. In many applications, the fiber and matrix system of composite materials, whether filament wound or by layer fabrication, produce lighter, stronger, and more cost effective products when compared with traditional materials such as metals. Development of on on-board hydrogen storage system must consider the following parameters and objectives:

- Lightweight

- High pressure containment

- Volume constraints

- Safety

The quality and control associated with the filament winding process makes utilizing this manufacturing process the rational means of production and design for highpressure vessel systems. Therefore, filament wound, composite pressure vessels are common in space, missile and aircraft systems. However, in order to implement new designs, evaluations and studies to prevent failure must thoroughly be performed prior to any application. Experimental analysis of composite pressure vessels is costly and complex compared to typical experimental procedures. In order to experimentally determine the burst pressure of a high storage capability (30,000 psi) pressure vessel, one must apply the pressure with a high performance compressor and monitor the vessel during the loading process. Catastrophic failure must be contained within the environment where the vessel is being tested. The involved process of experimentally evaluating pressure vessel systems cannot always be readily performed. Therefore, detailed and accurate finite element modeling methods are critical as first evaluations of pressure vessel analysis. 
Finite element modeling of layered composite materials is a multifaceted procedure when considering the orthotropic nature of the material utilizing a three dimensional approach. However, the use of shell or solid elements with a built-in layer orientation option is beneficial in composite laminate layer definition but, the nature of filament winding increases the detail of the modeling procedure because the part is comprised of a continuously wound fiber or tape. The filament or tape being wound changes angle orientation with the change in the mandrel geometry and also through the thickness. The path of the fiber and the winding angle varies for different mandrel geometries. Determining the available fiber paths or winding patterns is the first step in the filament winding process. The accuracy of the finite element analysis depends on the determined winding information; therefore, the winding pattern itself must be modeled.

\subsection{Netting Analysis and Isotensoid Theory}

Ideally, the winding pattern of a filament wound structure should follow the mandrel surface geometry without voids or twisting of the filament during the process. Twisting refers to the tendency of a fiber to slip on the mandrel surface or also referred to as slippage $(\lambda)$. The slippage parameter is taken into account in the semi-geodesic path equation for filament wound structures:

$$
\begin{aligned}
& \frac{d \alpha}{d z}=\frac{\lambda\left(A^{2} \sin ^{2} \alpha-x x^{\prime \prime} \cos ^{2} \alpha\right)-x^{\prime} A^{2} \sin \alpha}{x^{\prime} A^{2} \sin \alpha} \\
& A=1+x^{2}
\end{aligned}
$$

where:

$$
\begin{aligned}
& \alpha=\text { winding angle } \\
& z=\text { axial coordinate } \\
& x=\text { radial coordinate } \\
& \lambda=\text { slippage } \\
& x^{\prime}=\frac{d x}{d z}
\end{aligned}
$$


The slippage tendency occurs when the fiber filaments follow a path around the mandrel that allows them to move in a direction other than in extension along the fiber axis. It is desired to wind the filaments in accordance to the geodesic path around the surface of the mandrel. The geodesic path or curve is the shortest distance between two points on a curved surface. The geodesic path is the ideal wind path for a filament wound structure because there will be no fiber slippage within the part and the structure then becomes a geodesic-isotensoid which creates constant stress in any given filament throughout the part.

\section{Geodesic Path}

The geodesic path is an important ideal for filament winding manufacturing and design. The geodesic fiber path can be derived from the semi-geodesic fiber path by setting the fiber slippage parameter, $\lambda$ equal to zero. Under a no fiber slippage condition, the following derivations, as proposed by Kabir, (2000) are as follows. For balanced stress levels in the dome region, shell theory states that the fiber path must satisfy:

$$
\frac{N_{\phi}}{r_{1}}+\frac{N_{\theta}}{r_{2}}=P
$$

where:

$$
\begin{aligned}
& N_{\phi}=\text { meridional force } \\
& N_{\theta}=\text { circumferential force } \\
& r_{1}=\text { meridian radius } \\
& r_{2}=\text { circumferential radius }
\end{aligned}
$$




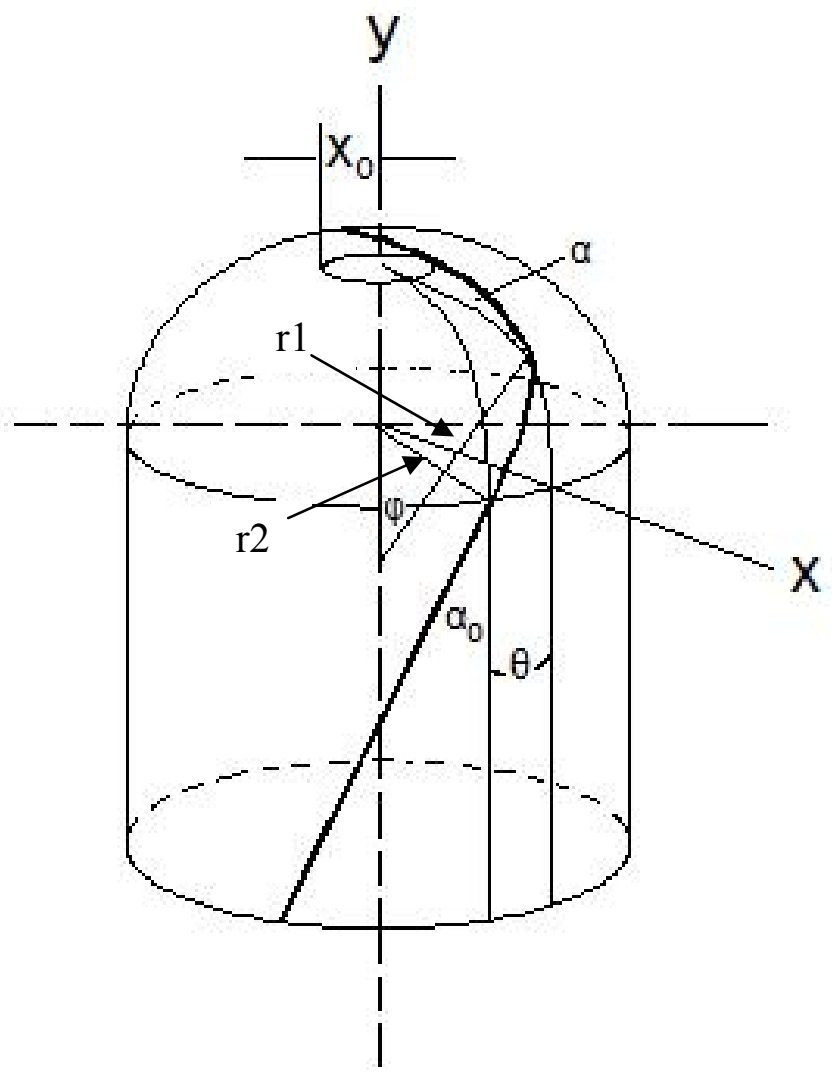

Figure 6.1: Geometric representation of a filament wound pressure vessel and corresponding nomenclature.

The meridian and circumferential radii are defined as:

$$
\begin{aligned}
& r_{1}=-\frac{\left(1+y^{\prime 2}\right)^{3 / 2}}{y^{\prime \prime}} \\
& r_{2}=-x \frac{\left(1+y^{\prime 2}\right)^{1 / 2}}{y^{\prime}}
\end{aligned}
$$

The $x$ and $y$ terms are the coordinates along the dome contour. Where $y^{\prime}$ and $y^{\prime \prime}$ are the first and second derivatives of $y$ with respect to $x$. Transforming the stress from the direction of the fiber path winding angle to the meridian and circumferential directions and using the ultimate tensile strength of the fiber, $\sigma_{u}$ the forces $N_{\phi}$ and $N_{\theta}$ are:

$$
N_{\phi}=\sigma_{u} t \cos ^{2} \alpha
$$


$N_{\theta}=\sigma_{u} t \sin ^{2} \alpha$

Noticing that the filament must be tangent at the boss opening where $x_{o}$ is the boss radius, the condition of filaments lying along geodesic paths holds true when:

$x \sin \alpha=x_{o}$

Equation 7.8 enforces the condition in the winding pattern that the fibers throughout the dome contour must lay along geodesic paths. Therefore, the winding angle at any location $x$ throughout the dome contour can be calculated from:

$\sin \alpha=\frac{x_{o}}{x}$

The corresponding $y$ location of the radius values $x$ through the change of the dome geometry is then determined, giving the geodesic dome contour of the vessel. First the meridian and circumferential radii are related by:

$\frac{r_{1}}{r_{2}}=\frac{x y^{\prime \prime}}{y^{\prime}\left(1+y^{\prime 2}\right)^{1 / 2}}=2-\tan ^{2} \alpha$

Substituting equation (6.9) into equation (6.10) and solving for $y$ as a function of the axial coordinate $x$ yields an elliptic integral of the third kind:

$y=-\int \frac{x^{3} d x}{\left[\left(1-x^{2}\right)\left(x^{2}-a_{1}\right)\left(x^{2}-a_{2}\right)\right]^{1 / 2}}+C$

where:

$a_{1}=\frac{1}{2}\left[\left(\frac{1+4 x_{o}^{2}}{1-x_{o}^{2}}\right)-1\right]$ and $a_{2}=-\frac{1}{2}\left[\left(\frac{1+4 x_{o}^{2}}{1-x_{o}^{2}}\right)^{1 / 2}+1\right]$ 
Integration of equation 6.11 will produce the coordinates of the dome contour geometry. The complexity of this integral requires a computer based solution and is done by MATLAB software. The corresponding plot of the normalized isotensoid dome contour with respect to normalized $\mathrm{x}$ and $\mathrm{y}$ axes is shown in Figure 6.2.

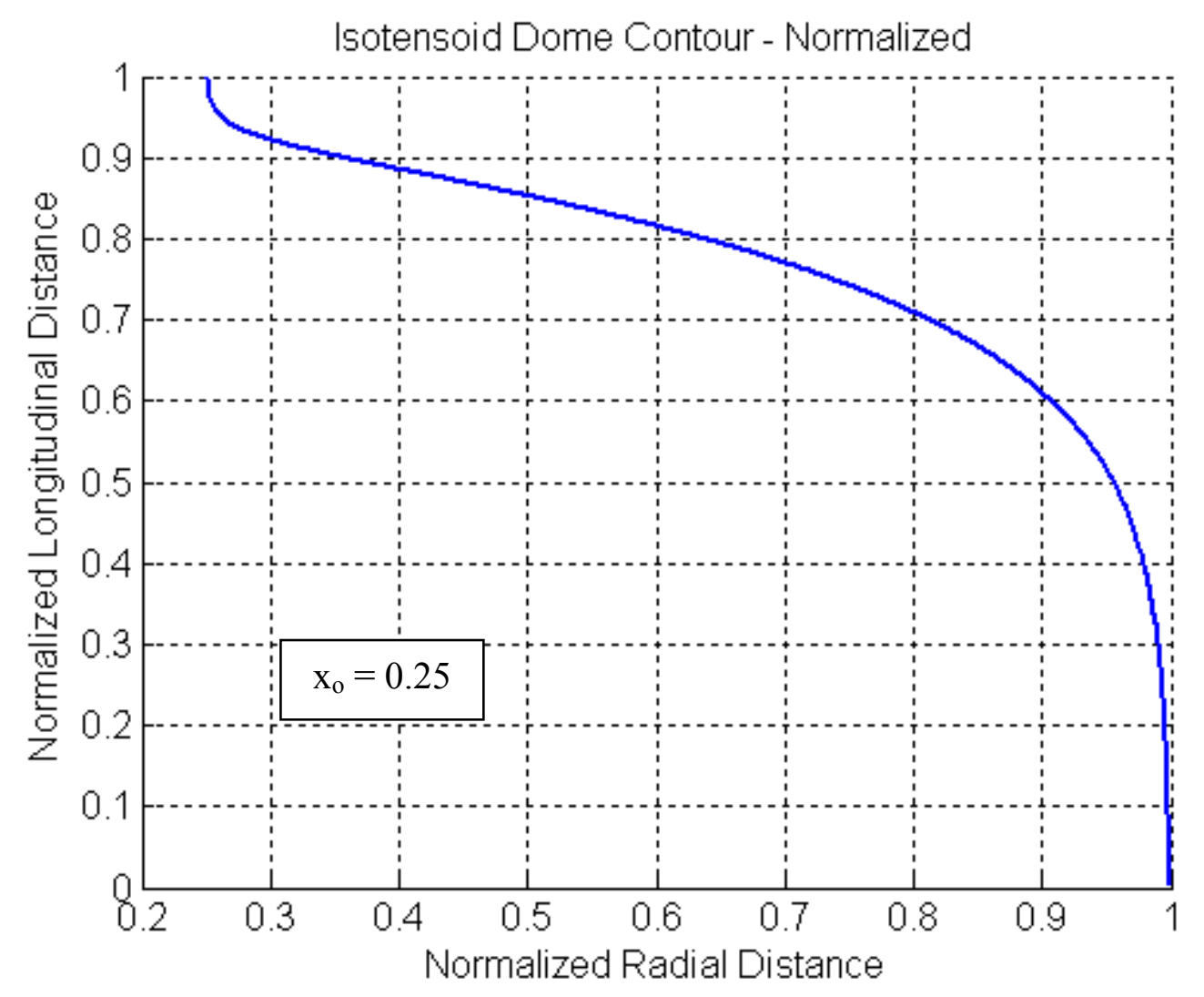

Figure 6.2: Normalized isotensoid dome contour.

From the previous analysis the orientation of the winding angle throughout the change in the dome contour is determined. The shape of the dome contour is then calculated from equation 6.11. The last parameter to determine is the change in thickness throughout the dome contour. The thickness of the filament wound reinforcement at each point of the dome is obtained by:

$t=\frac{x_{c y l}}{x} \frac{\cos \alpha_{c y l}}{\cos \alpha} t_{c y l}$ 
where:

$\alpha_{c y l}=$ winding angle at cylinder / dome juncture

$t_{c y l}=$ thickness of composite at cylinder / dome juncture

$x_{c y l}=$ radius at cylinder / dome juncture

\subsection{Initial Winding Angle and Thickness Calculations}

The system of parameter calculations which determine the angle orientation and thickness of the filament wound reinforcement throughout the dome contour must be initialized by defining the initial winding angle at the cylinder/dome juncture and initial thickness at the cylinder/dome juncture. The winding angle at the juncture is directly determined from the boss radius and Eq. 6.9. Taking the boss radius of $x_{0}=0.25$, the winding angle plot for a normalized isotensoid dome contour is solved for each step of the axial distance and plotted using MATLAB software, as displayed in Figure 6.3.

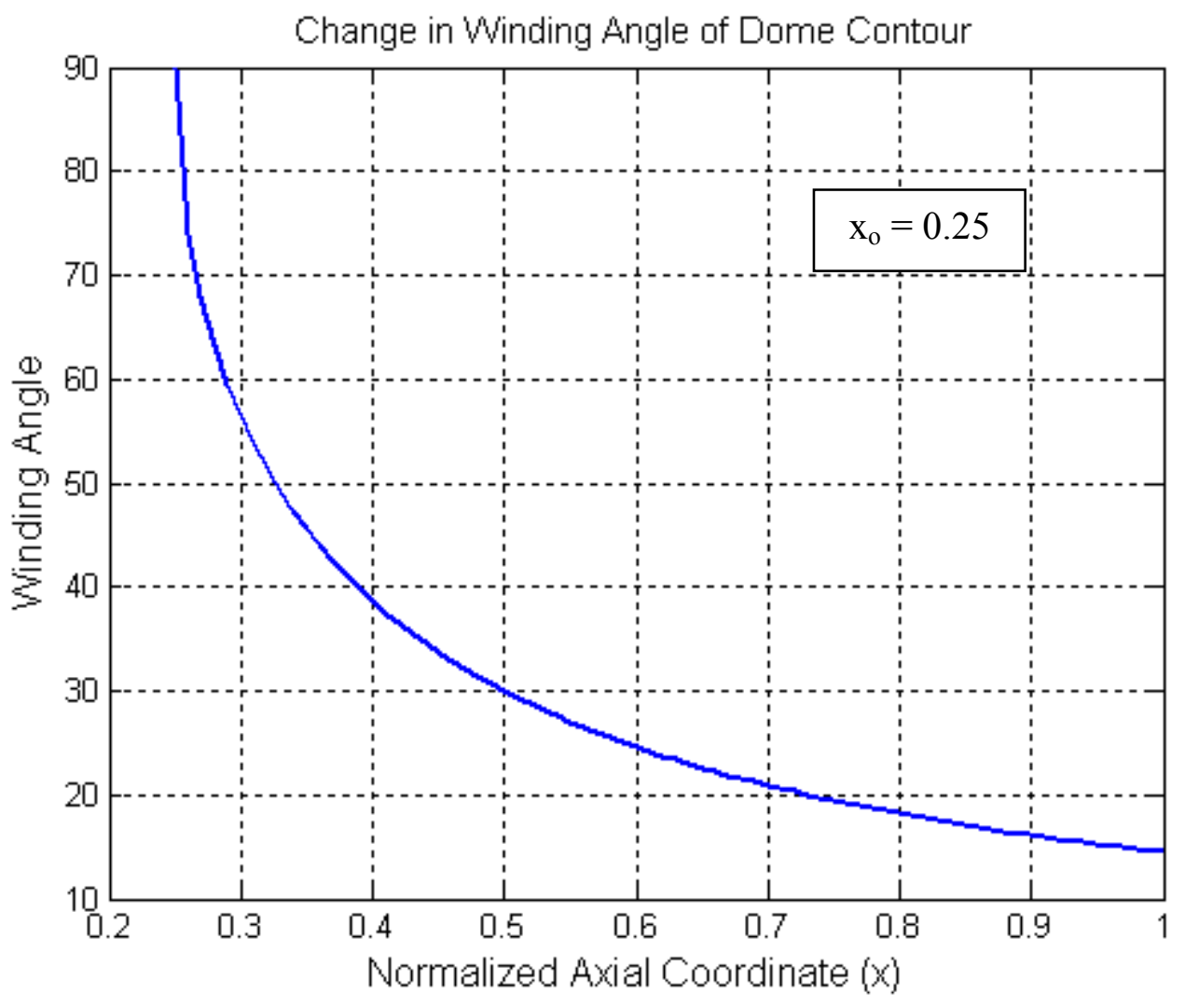

Figure 6.3: Normalized winding angle variation for an isotensoid dome contour. 
The thickness required in the hoop and helical directions will be determined according to Peters (2003). The approach to calculate the required thickness to carry a declared internal pressure is as follows: Consider a filament wound cylinder of radius $r$ and internal pressure P; the vessel is wound with both helical and hoop oriented fibers; summation of forces in the axial direction as shown in Figure 6.4 and solving for $t$ yield the required helical fiber thickness, Eq. (6.14).

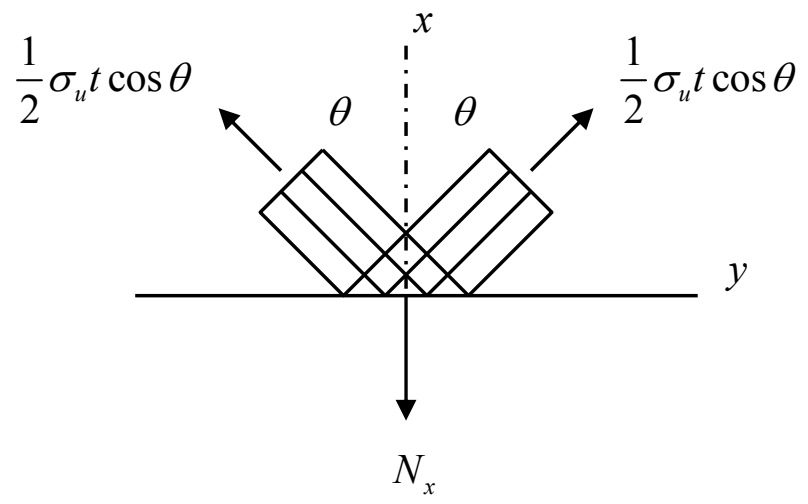

Figure 6.4: Summation of forces in axial direction of a cylindrical pressure vessel.

$t_{f}=\frac{P r}{2 \sigma_{f} \cos ^{2} \theta}$

Using the result for the thickness, Eq. (6.14), and summing forces in the hoop direction is shown in Figure 6.5. 


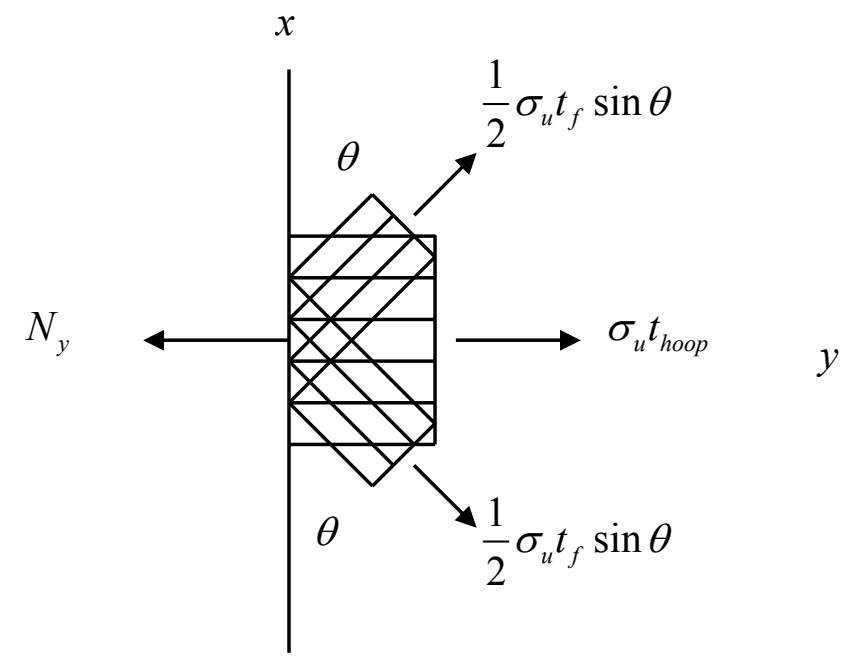

Figure 6.5: Summation of forces in the hoop direction of a cylindrical pressure vessel.

$t_{f_{\text {hoop }}}=\frac{P r}{2 \sigma_{u}}\left(2-\tan ^{2} \theta\right)$

The thickness variation for a normalized, isotensoid dome structure is plotted in Figure 6.6. This thickness plot is determined for a boss radius of $\mathrm{x}_{0}=0.25$ which corresponds to a 1.5 inch boss opening for the 6 inch internal radius pressure vessel. 


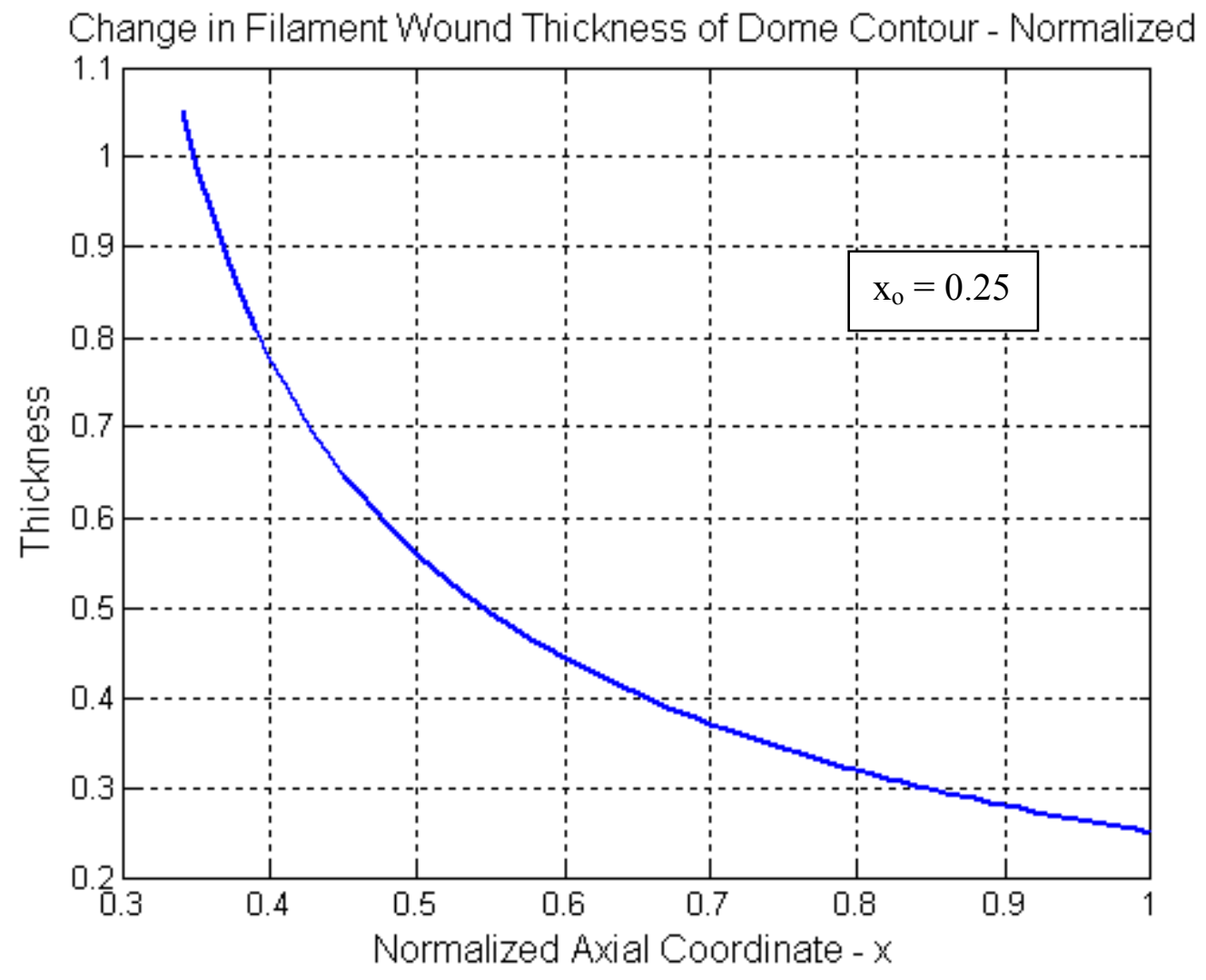

Figure 6.6: Thickness variation for a normalized axial component and boss radius of 0.25 .

The MATLAB programming procedure described in this section is summarized by the flow chart depicted in Appendix A. 


\subsection{Determination of Transient Material Properties by Composite Macromechanics for Axisymmeteric Finite Element Analysis}

Sections 6.1 and 6.2 detailed the dome geometry and contour and the change in material winding angles and material thickness through the dome region. The most accurate representation of a filament wound structure will account for both the change in winding angle and the change in thickness. The desire of this work is to represent the transient nature of the material properties with respect to the element coordinate system to effectively analyze different dome shapes and valve connection structures. The representation of the winding angle and thickness change is accounted for by transforming the material properties to the respective orientation by composite macromechanics. Section 6.3 shows how the material properties of the orthotropic composite material can be transformed to represent the complex nature of filament winding.

\subsubsection{Material Transformation to Obtain Global Laminate Properties}

The orientation of a filament wound composite will adhere to a $\pm \alpha$ orientation where $\alpha$ is the winding angle with respect to the longitudinal axis of the vessel or mandrel. The material property transformations start from the layer properties which can be obtained from periodic microstructure micromechanics. These values are $\mathrm{E}_{1}, \mathrm{E}_{2}, \mathrm{G}_{12}$, $\mathrm{G}_{23}, v_{12}, v_{13}$, and $v_{23}$. The path from the layer properties to the global properties follows the steps listed.

First, the compliance matrix $\left[S^{\prime}\right]$ is computed from the layer and is defined for an orthotropic material as: 


$$
\left[S^{\prime}\right]=\left[\begin{array}{cccccc}
\frac{1}{E_{1}} & -\frac{v_{21}}{E_{2}} & -\frac{v_{31}}{E_{3}} & 0 & 0 & 0 \\
-\frac{v_{12}}{E_{1}} & \frac{1}{E_{2}} & -\frac{v_{32}}{E_{3}} & 0 & 0 & 0 \\
-\frac{v_{13}}{E_{1}} & -\frac{v_{23}}{E_{2}} & \frac{1}{E_{3}} & 0 & 0 & 0 \\
0 & 0 & 0 & \frac{1}{G_{23}} & 0 & 0 \\
0 & 0 & 0 & 0 & \frac{1}{G_{13}} & 0 \\
0 & 0 & 0 & 0 & 0 & \frac{1}{G_{12}}
\end{array}\right]
$$

The transformation matrix $[T]$ which accounts for the change in angle from winding angle to the desired coordinate system is:

$$
\begin{aligned}
& {[T]=\left[\begin{array}{cccccc}
l_{1}^{2} & m_{1}^{2} & n_{1}^{2} & 2 m_{1} n_{1} & 2 l_{1} n_{1} & 2 l_{1} m_{1} \\
l_{2}^{2} & m_{2}^{2} & n_{2}^{2} & 2 m_{2} n_{2} & 2 l_{2} n_{2} & 2 l_{2} m_{2} \\
l_{3}^{2} & m_{3}^{2} & n_{3}^{2} & 2 m_{3} n_{3} & 2 l_{3} n_{3} & 2 l_{3} m_{3} \\
l_{2} l_{3} & m_{2} m_{3} & n_{2} n_{3} & m_{2} n_{3}+n_{2} m_{3} & l_{2} n_{3}+n_{2} l_{3} & l_{2} m_{3}+m_{2} l_{3} \\
l_{1} l_{3} & m_{1} m_{3} & n_{1} n_{3} & m_{1} n_{3}+n_{1} m_{3} & l_{1} n_{3}+n_{1} l_{3} & l_{1} m_{3}+m_{1} l_{3} \\
l_{1} l_{2} & m_{1} m_{2} & n_{1} n_{2} & m_{1} n_{2}+n_{1} m_{2} & l_{1} n_{2}+n_{1} l_{2} & l_{1} m_{2}+m_{1} l_{2}
\end{array}\right]} \\
& \begin{array}{lll}
l_{1}=\cos \theta & m_{1}=\sin \theta & n_{1}=0
\end{array} \\
& \text { where: } \quad l_{2}=-\sin \theta \quad m_{2}=-\cos \theta \quad n_{2}=0 \\
& \begin{array}{lll}
l_{3}=0 & m_{3}=0 & n_{3}=1
\end{array}
\end{aligned}
$$

The global compliance matrix $[S]$ is determined from the transformation matrix and the compliance matrix by:

$$
[S]=[T]^{T}\left[S^{\prime}\right][T]
$$

The global stiffness matrix $[C]$ is determined for each layer of the composite by: 
The global stiffness matrix of a symmetric laminate $[C]$ with a total of $\mathrm{N}$ layers is compiled by summing the individual global stiffness matrix for each layer $\left[C_{k}\right]$ and weighting it by the ratio of the layer thickness $t_{k}$ to the overall laminate thickness, $t$. $[C]=\sum_{k=1}^{N} \frac{t_{k}}{t}\left[C_{k}\right]$

Inverting back to the compliance matrix [S] it is possible to extract that apparent engineering properties of a laminate in terms of laminate compliance by now attaining:

$$
[S]=[C]^{-1}=\left[\begin{array}{cccccc}
\frac{1}{E_{x}} & -\frac{v_{y x}}{E_{y}} & -\frac{v_{z x}}{E_{z}} & 0 & 0 & 0 \\
-\frac{v_{x y}}{E_{x}} & \frac{1}{E_{y}} & -\frac{v_{z y}}{E_{z}} & 0 & 0 & 0 \\
-\frac{v_{x z}}{E_{x}} & -\frac{v_{y z}}{E_{y}} & \frac{1}{E_{z}} & 0 & 0 & 0 \\
0 & 0 & 0 & \frac{1}{G_{y z}} & 0 & 0 \\
0 & 0 & 0 & 0 & \frac{1}{G_{x z}} & 0 \\
0 & 0 & 0 & 0 & 0 & \frac{1}{G_{x y}}
\end{array}\right]
$$

The previous steps to the material transformation of properties are performed through MATLAB programming. The process starts from the local composite material properties determined from periodic microstructure. The programming performs the formation of the compliance matrix, transformation to the desired orientation, determination of the global compliance, inversion of the global compliance to global stiffness matrix, summation of the global stiffness, and inversion back to the compliance 
matrix to extract the apparent laminate properties. This process is performed for each section denoting the change in winding angle through the dome contour. 


\section{Chapter 7}

\section{Finite Element Study of Composite Over-Wrapped Pressure Vessels}

Thus far, manufacturing methods and experimental analysis have proven the feasibility of composite over-wrapped pressure vessel (COPV) fabrication methods and the material strengths of thick laminate layup configurations. This thickness is correlated to the required reinforcement thickness of the composite material used for a COPV.

Previous experimental work and literature has proven that the most critical region for effective design and of failure exists in the dome region of a pressure vessel. A specific interest is shown in the valve connection configuration and its effect on the location of a critical failure. Failure is defined as any malfunction within the structure which is directly related to the high pressure containment of pressurized gases, specifically hydrogen.

Acquiring insight into the analysis of filament wound structures, specifically composite over-wrapped pressure vessels is complex due to the nature of the composite reinforcement. Introduced in this chapter is a method to model filament wound isotensoid and hemispherical dome contours with accurate representation of the geometry, fiber orientation, and thickness contour determined in Chapter 6.

\subsection{Finite Element Analysis Approach}

Finite element models detailing the dome structure of composite over-wrapped pressure vessel used for hydrogen storage applications were created using ANSYS finite element software. The designs in this study highlight the isotensoid geometry, thickness variation and varying winding angle orientation. Liner systems and insert applications using configurations of aluminum, stainless steel and high density polyethylene (HDPE) were also analyzed. 
The material used for the filament wound exterior reinforcement is T800 carbon fiber and epoxy. The orthotropic material properties are listed in Table 7.1.

Table 7.1: Material Property of T800/Epoxy. Reference: Kim et al.2004

\begin{tabular}{ccc}
\hline Property & SI Units & US Customary Units \\
\hline $\mathrm{E}_{1}$ & $161.3 \mathrm{GPa}$ & $23.4 \mathrm{Msi}$ \\
$\mathrm{E}_{2}, \mathrm{E}_{3}$ & $8.820 \mathrm{GPa}$ & $1.28 \mathrm{Msi}$ \\
$\mathrm{G}_{12}, \mathrm{G}_{13}$ & $5.331 \mathrm{GPa}$ & $0.78 \mathrm{Msi}$ \\
$\mathrm{G}_{23}$ & $2.744 \mathrm{GPa}$ & $0.40 \mathrm{Msi}$ \\
$v_{12}, v_{13}$ & 0.33 & 0.33 \\
$v_{23}$ & 0.45 & 0.45 \\
$\mathrm{X}_{\mathrm{t}}$ & $2300 \mathrm{MPa}$ & $0.334 \mathrm{Msi}$ \\
$\mathrm{X}_{\mathrm{c}}$ & $1080 \mathrm{MPa}$ & $0.261 \mathrm{Msi}$ \\
$\mathrm{Y}_{\mathrm{t}}$ & $30 \mathrm{MPa}$ & $4351 \mathrm{psi}$ \\
$\mathrm{Y}_{\mathrm{c}}$ & $70 \mathrm{Mpa}$ & $10152 \mathrm{psi}$ \\
Density, $\rho$ & $1.5 \times 10^{-6} \mathrm{~kg} / \mathrm{mm}^{3}$ & $0.054 \mathrm{lb} / \mathrm{in}^{3}$ \\
\hline
\end{tabular}

The goal of the finite element analysis within this work is to model filament wound pressure vessels using a 2-dimensional axisymmetric approach to represent the geometry, orthotropic material properties, and isotensoid characteristics. Most, current finite element representations of filament wound pressure vessels utilize solid modeling of a narrow strip of the pressure vessel. This approach has limitations of:

- Inaccurate representation of the material properties with the respect to the global axis (axis to which the material properties are defined) due to the thickness of the solid structure.

- In this type of modeling, if layered shell elements are used to represent the filament winding layer orientation and thickness, a through-the-thickness stress contour plot is not attainable. Often, shell elements only output stress resultants for a bottom, middle, and top layer locations.

- A refined mesh for accurate output results and analysis is needed to study filament wound applications. Creating a 3-dimensional solid model and refining the mesh to appropriate accuracy significantly increases the number of nodes and elements within the model, which in turn increases the computation requirement. 
The 2D Axisymmetric modeling introduced in this work takes a unique approach to the finite element modeling of filament wound reinforced pressure vessels by utilizing the parameters determined from netting analysis and isotensoid theory (Chapter 6) and implementing them into the model by segmented area divisions representing the angle change and its respective material transformation in its own local coordinate system.

The local coordinate system is defined to align the $\mathrm{x}$-axis of the system with the fiber direction $(+\alpha)$. The composite macromechanics material transformations are used to transform the corresponding $(-\alpha)$ material properties to the local $\mathrm{x}$-axis. The concept of a local coordinate system is beneficial for an accurate representation of the angle ply fiber orientation and for post processing analysis. The stress resultants and strains can be evaluated at each local coordinate system, therefore giving the resultants in the desired fiber direction. Isotensoid theory states that the stress induced by internal pressure will be constant in all fibers throughout the vessel, therefore making the principal stresses oriented in the fiber direction.

The area divisions and their corresponding winding angles are shown in Figure 7.1 (a). The local coordinate system assigned to each area segment is shown from both a frontal and side view. A schematic representation of a specific local coordinate system in relation to the fiber winding angle in that region is shown in Figure 7.1 (b). 


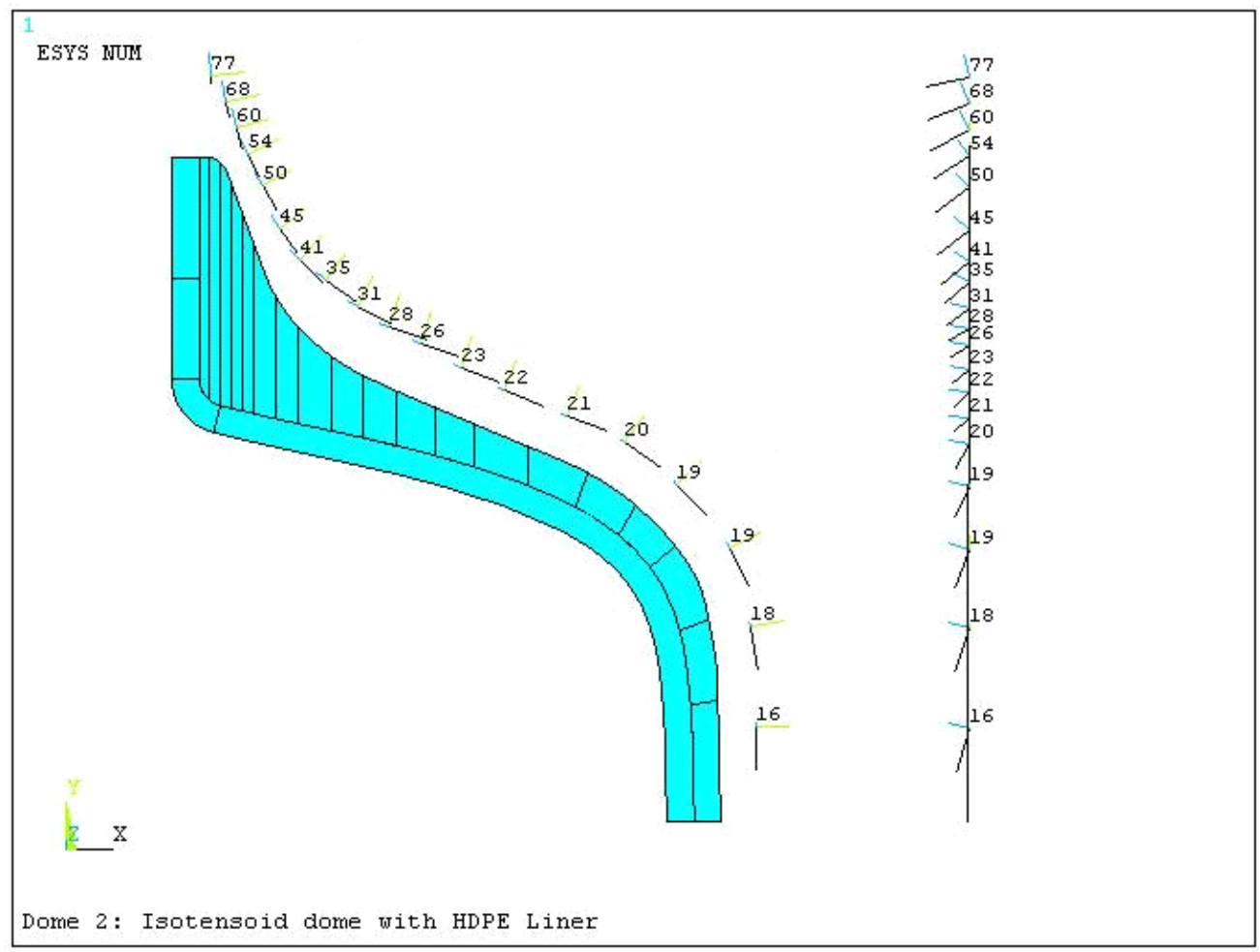

(a)

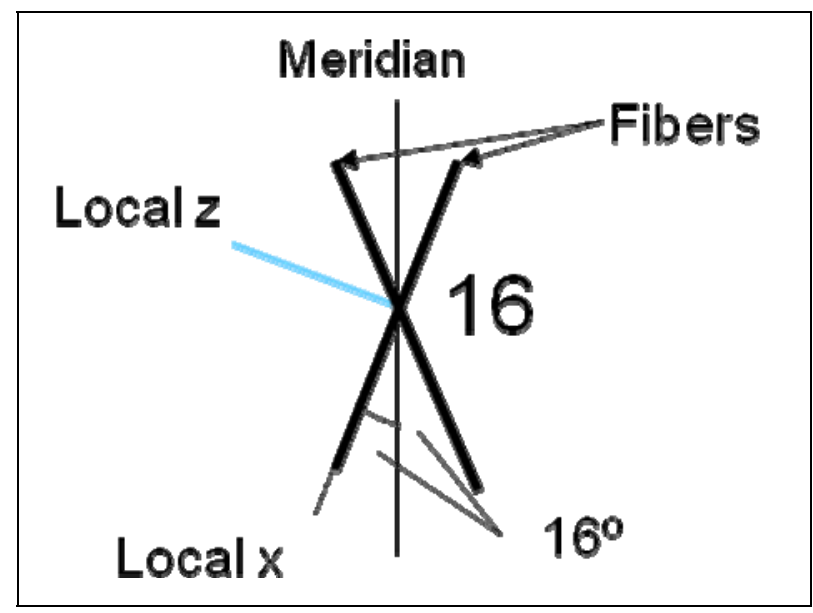

(b)

Figure 7.1: (a) Dome contour with area divisions and local coordinate systems (b) schematic of area local coordinate system 16 relating to a fiber angle of $16^{\circ}$ from the meridian.

The elements in each area division are assigned to a respective local coordinate system as a referencing coordinate system for input and analysis. In other words, the element $(\mathrm{x}, \mathrm{y}, \mathrm{z})$ direction is aligned with the local coordinate system $(\mathrm{x}, \mathrm{y}, \mathrm{z})$ direction. 
With knowledge of the coordinate system, the material transformation in relation to the winding angle and local coordinate system is more readily defined. Figure 7.2 is a representation of two different local coordinate systems taken from the 2-D axisymmetric modeling used in this work.
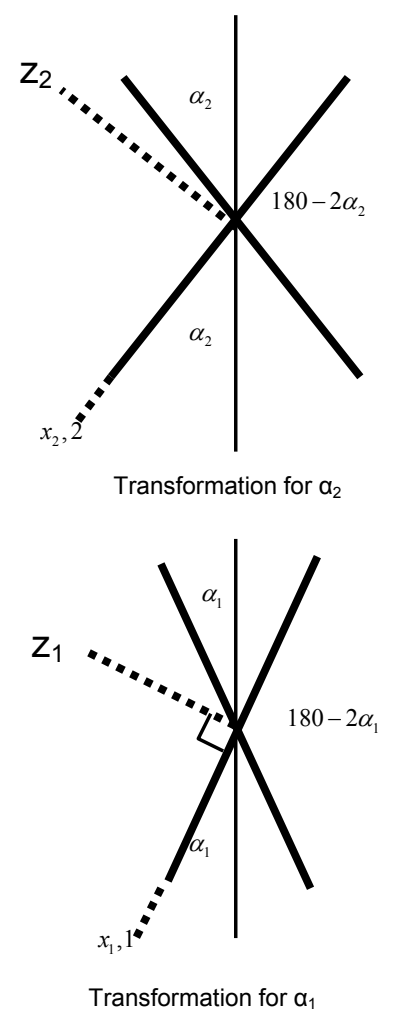

Figure 7.2: Transformations to local coordinate systems.

It is shown that the winding angles are different between the two representative coordinate systems. The local coordinate system is shown as the $\mathrm{x}_{1}, \mathrm{z}_{1}$ and $\mathrm{x}_{2}, \mathrm{z}_{2}$ directions. The fibers form angles $\alpha_{1}$ and $\alpha_{2}$ with the meridional plane, respectively. The material transformation procedure described in Chapter 6, Section 3 transforms the material property of the two angle-ply fibers into the local coordinate system. Once the apparent properties are determined from the MATLAB output they are assigned to their respective elements.

This procedure is repeated in MATLAB to output all the material properties for the required winding angles. 
The 2-D axisymmetric modeling introduced in this work is effective for modeling filament wound composite pressure vessels for the listed reasons:

- Isotensoid calculations are based on axisymmetric geometry and calculated from a meridional section (Park, 2000). The most accurate representation of the revolution of material properties in an axisymmetric pressure vessel is by a plane section model. Netting analysis derives angle orientation and thickness change by a meridional plane representation.

- Representation of solid axisymmetric models with layered solid elements requires a large magnitude of nodes and elements. ANSYS 11.0 Student Edition was the available modeling software and applies a node and element restriction to the user, therefore, a unique 2-D axisymmetric model was created to adhere to limitations in node and element quantities. This innovative approach optimizes the amount of available nodes and elements to most accurately represent the characteristics of the filament wound pressure vessel.

- A stress representation through the thickness can be attained.

- The approach limits the amount of nodes and elements required to accurately model a filament wound pressure vessel and still allow for a refined mesh through the filament wound cross section and liner geometries. The 2-D axisymmetric model with material transformations and local coordinate system designation, as shown in this work, is an effective approach to maximize the efficiency from a limited node and element bank.

- Assigning local coordinate systems to be aligned with the fiber winding angle allows for accuracy in assigning material properties and post-processing endeavors where the stress resultants in the fiber directions can be attained by the local coordinate systems.

- Attaining stress resultants in the local coordinate systems aligned with the fibers directly determines the stress in the fiber direction and avoids a stress transformation for a 2-D axisymmetric model defined relative to a global coordinate system. 


\subsection{Dome Configurations}

Thus far, several analyses have been performed to attain all the required parameters to accurately model a filament wound composite pressure vessel. The finite element analysis serves to analyze an isotensoid dome configuration in comparison to a traditional hemispherical dome. Also, various configurations created in order to analyze the implementation of the metallic boss connection structure were studied. These configurations include the effects of a full-body aluminum liner, a combination of a high density polyethylene (HDPE) and metallic insert, and designs containing the metallic insert to the boss region.

The modeling procedure utilizing the output from the MATLAB programming for determining the isotensoid dome geometry and filament thickness is shown in Figure 7.3. Figure 7.3 (a) displays the points of the determined isotensoid dome geometry from the previous defined MATLAB plot (Figure 6.2). Points of the curve are input into ANSYS as a text file and the result is the plot shown in Figure 7.3 (a). Figure 7.3 (b) shows the addition of the thickness contour of the exterior filament wound reinforcement as plotted as a function of the radial distance in Figure 6.6. The plane geometry is created with the addition of an interior liner. The area of the exterior reinforcement is divided into segments. The size of the area segments is in relation to the amount the winding angle changes with respect to the radial distance from the centroidal axis or the axial coordinate of Figure 7.3 (d). Each area is then assigned a local coordinate system which aligns the local coordinate system $\mathrm{x}$-axis with the fiber direction; these concepts are shown in Figure 7.3 (c). The change in winding angle for the 6" internal radius isotensoid dome pressure vessel is shown in Figure 7.3 (d). As seen, the change in winding angle is minimal as the axial coordinate decreases from the outer radius of 6 inches, therefore making the area segments shown in Figure 7.3 (c) larger. As the axial coordinate in Figure 7.3 (d) moves closer to the boss radius the winding angle changes drastically with respect to the axial coordinate creating small area segments in this region, as shown in Figure 7.3 (c). 


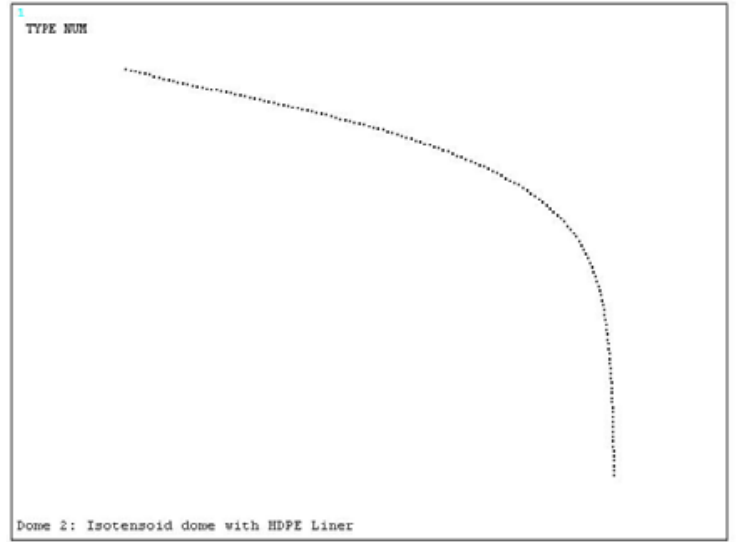

(a)

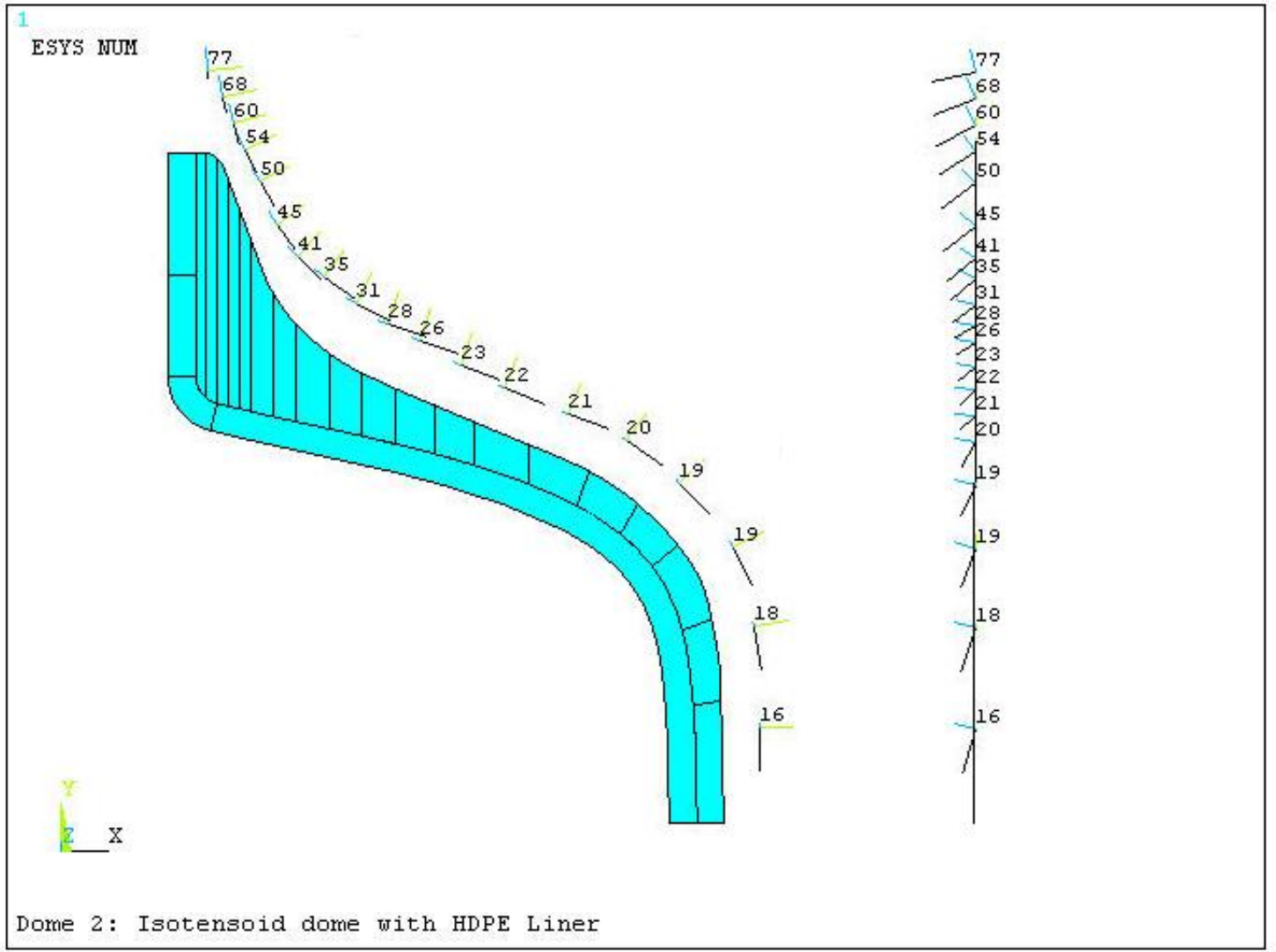

(c)

(b)

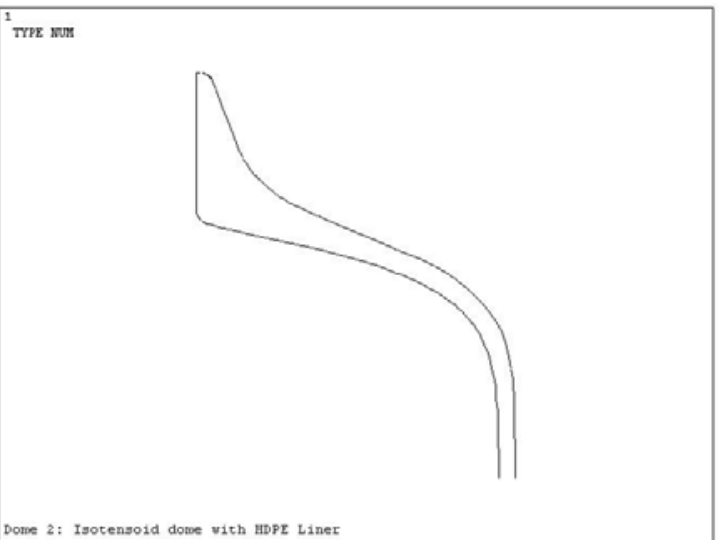




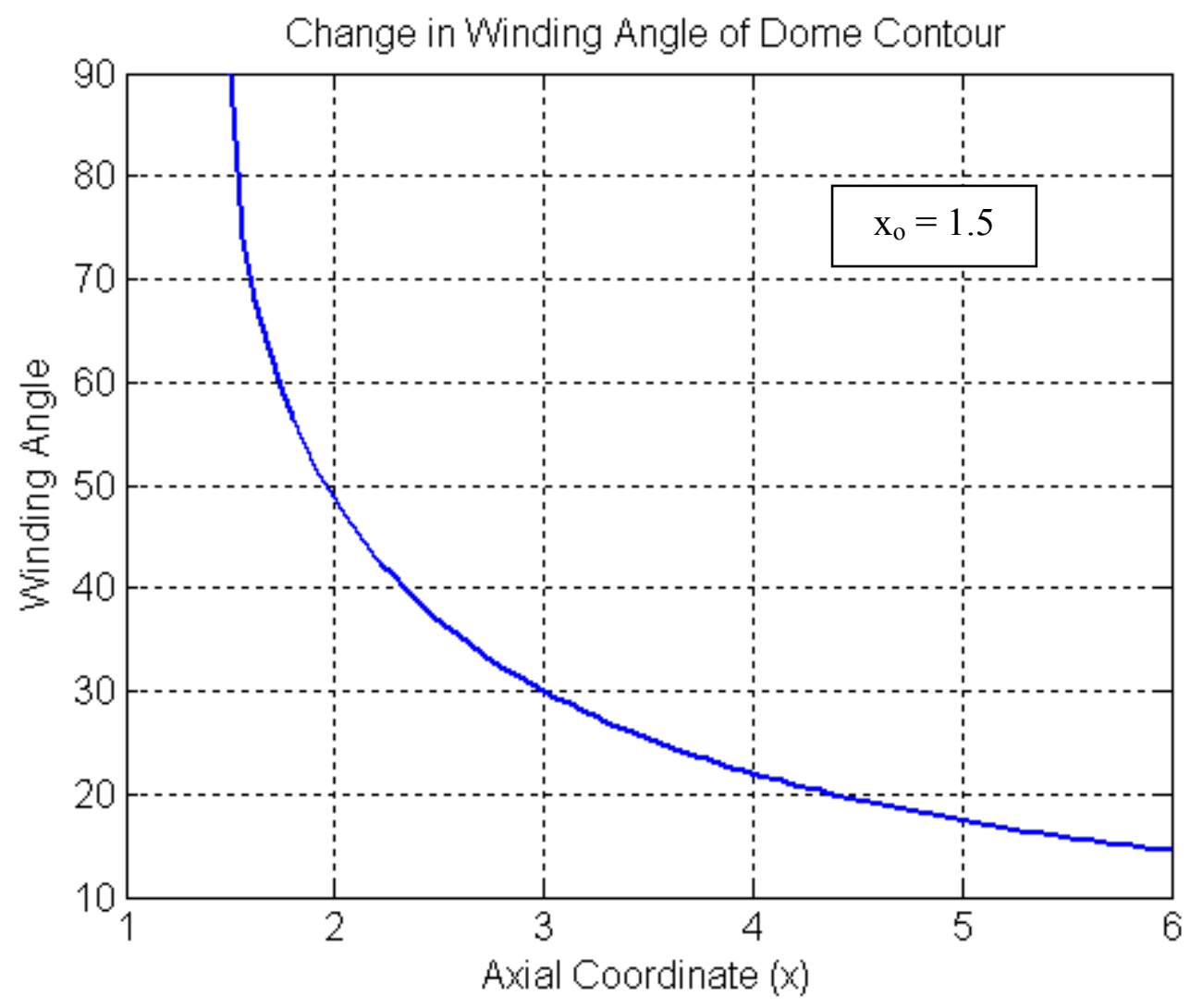

(d)

Figure 7.3: (a) Dome contour points imported from MATLAB output (b) addition of thickness contour to dome geometry (c) 2D model with local coordinate systems (d) winding angle orientation as a function of the radius.

The procedure for creating the modeled pressure vessels was repeated for each finite element model in this section. The models differ by either a hemispherical dome design or isotensoid. These vessels are modeled with HDPE liners, aluminum liners, or metallic inserts of varying length. Within the realm of composite pressure vessel design, emphasis is placed on the dome region and the boss nozzle/valve connection geometry. Proprietary rights have kept the existing designs from being available for analysis. This work aims to determine the affect of the dome geometry and the varying style of the 
nozzle/valve connection. The different geometries and liner configurations are shown in the following figures.

\subsubsection{Material Properties}

The material properties are given for high density polyethylene, stainless steel, aluminum, and T800 carbon fiber (Table 8.1).

Table 7.2: High Density Polyethylene material properties. Reference: Velosa et al. 2007

\begin{tabular}{ccc}
\hline & \multirow{2}{*}{ SI Units } & US Customary \\
Property & $650 \mathrm{MPa}$ & $94.2 \mathrm{ksi}$ \\
\hline Tensile Modulus & $19 \mathrm{MPa}$ & $2.75 \mathrm{ksi}$ \\
Yield Stress & $11 \%$ & $11 \%$ \\
Yield Strain & $>1000 \%$ & $>1000 \%$ \\
Elongation at Break & $0.94 \mathrm{~g} / \mathrm{cm}^{3}$ & $0.034 \mathrm{lb} / \mathrm{in}^{3}$ \\
Density &
\end{tabular}

Table 7.3: Material Properties of Steel. Reference: Hibbeler, 2005.

\begin{tabular}{ccc}
\hline & SI Units & US Customary \\
Property & $193 \mathrm{GPa}$ & $29 \times 10^{6} \mathrm{psi}$ \\
$\mathrm{E}$ & $75 \mathrm{GPa}$ & $11 \times 10^{6} \mathrm{psi}$ \\
$\mathrm{G}$ & $19 \mathrm{MPa}$ & $30 \times 10^{6} \mathrm{psi}$ \\
Yield Stress & 0.27 & 0.27 \\
$v$ & $7.86 \mathrm{~g} / \mathrm{cm}^{3}$ & $0.284 \mathrm{lb} / \mathrm{in}^{3}$ \\
\hline
\end{tabular}

Table 7.4: Material Properties of Aluminum. Reference: Hibbeler, 2005.

\begin{tabular}{ccc}
\hline & SI Units & US Customary \\
Property & $73.1 \mathrm{GPa}$ & $10.6 \times 10^{6} \mathrm{psi}$ \\
$\mathrm{E}$ & $27.0 \mathrm{GPa}$ & $3.90 \times 10^{6} \mathrm{psi}$ \\
$\mathrm{G}$ & $414 \mathrm{MPa}$ & $60.0 \times 10^{6} \mathrm{psi}$ \\
Yield Stress & 0.35 & 0.35 \\
$v$ & $2.80 \mathrm{~g} / \mathrm{cm}^{3}$ & $0.101 \mathrm{lb} / \mathrm{in}^{3}$ \\
\hline
\end{tabular}




\section{Isotensoid Dome-HDPE Liner Full Vessel Helical Winding}

The section analyzes the isotensoid geometry, fiber angle orientation, and thickness of the filament wound reinforcement through finite element modeling. Netting analysis theory which considers equating the circumferential force and meriodional force with respect to the helix winding along geodesic curves determined the aforementioned parameters (Ch.6). A high density polyethylene liner was modeled with the reinforcement geometry. The insertion of a boss system or metallic connection for a nozzle configuration is addressed in later models. This model is used to show the response of the isotensoid geometry, transient orientation angles and corresponding thickness alone. The geometry consisting of divided areas for assigning material properties to different angle orientations and the respective local coordinate systems are displayed in Figure 7.4 (a).

Applying a 10,000 psi load and placing symmetric boundary conditions the

displacement sum is plotted in Figure 7.4 (b). It should be noted that the fiber reinforcement contains only helical angle orientation in the cylindrical body. Resistance to hoop stress and displacements in this region will be addressed with the addition of $90^{\circ}$ hoop fiber reinforcement in the optimization of the design. 


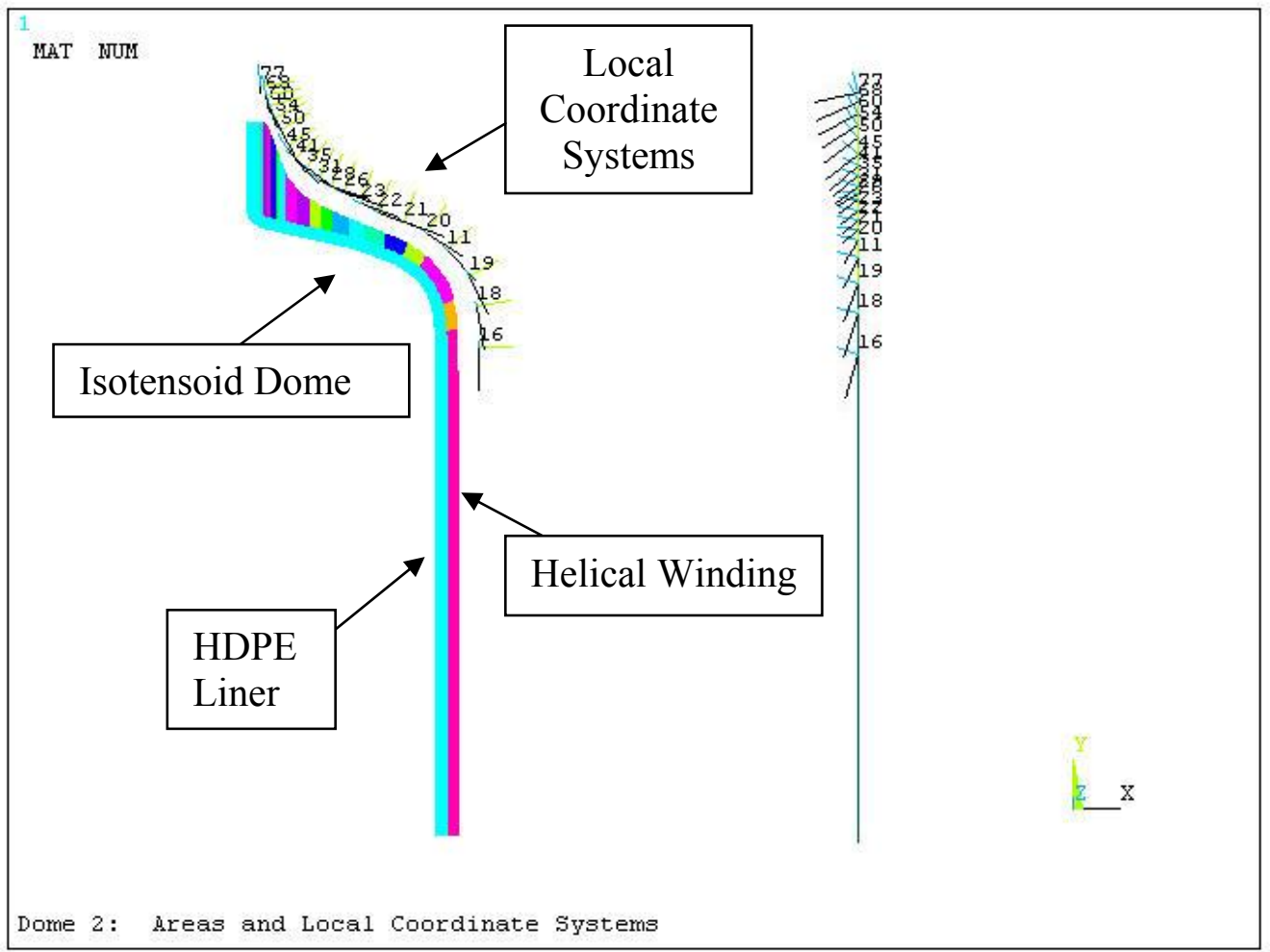

(a)

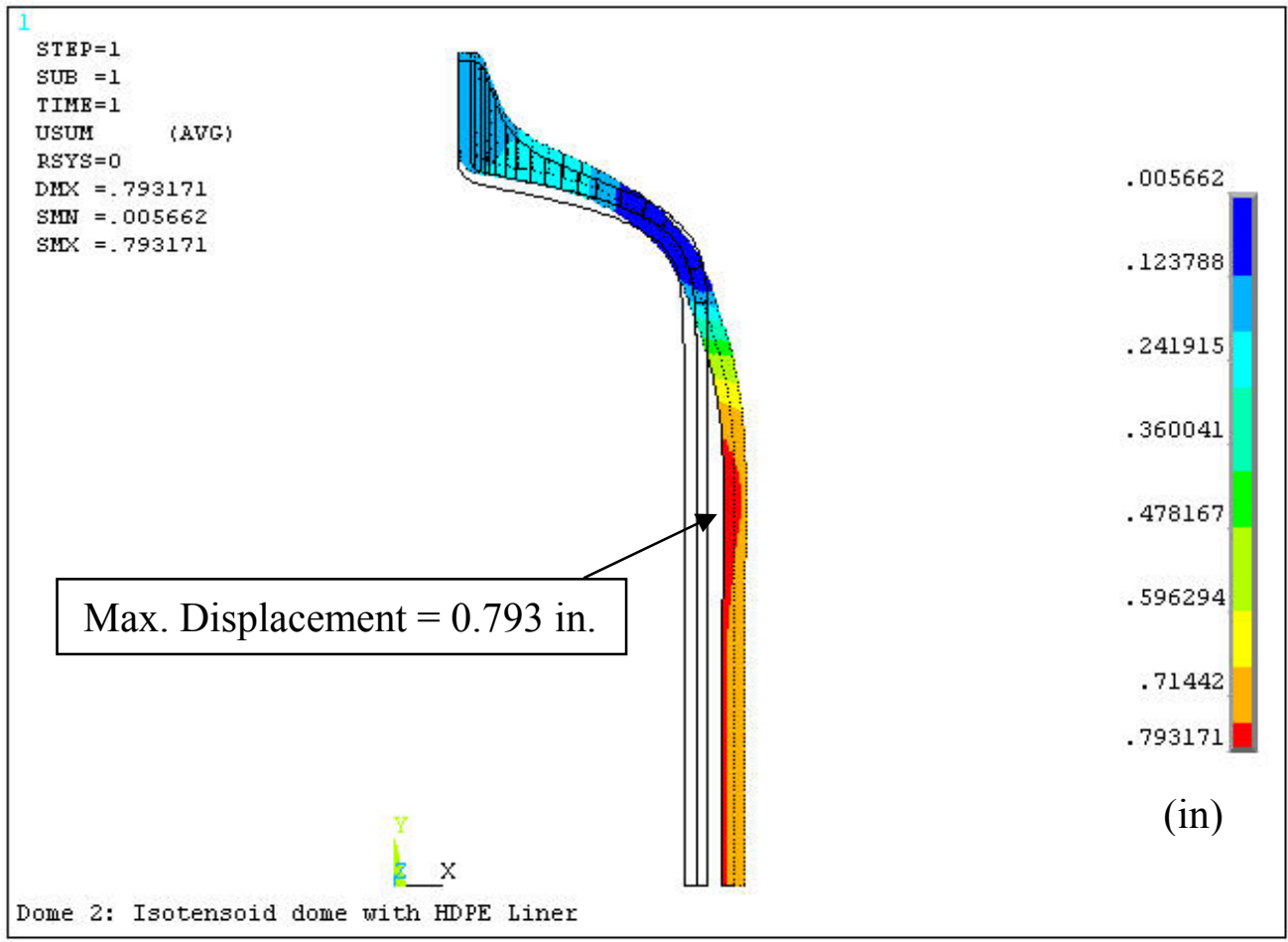

(b) 


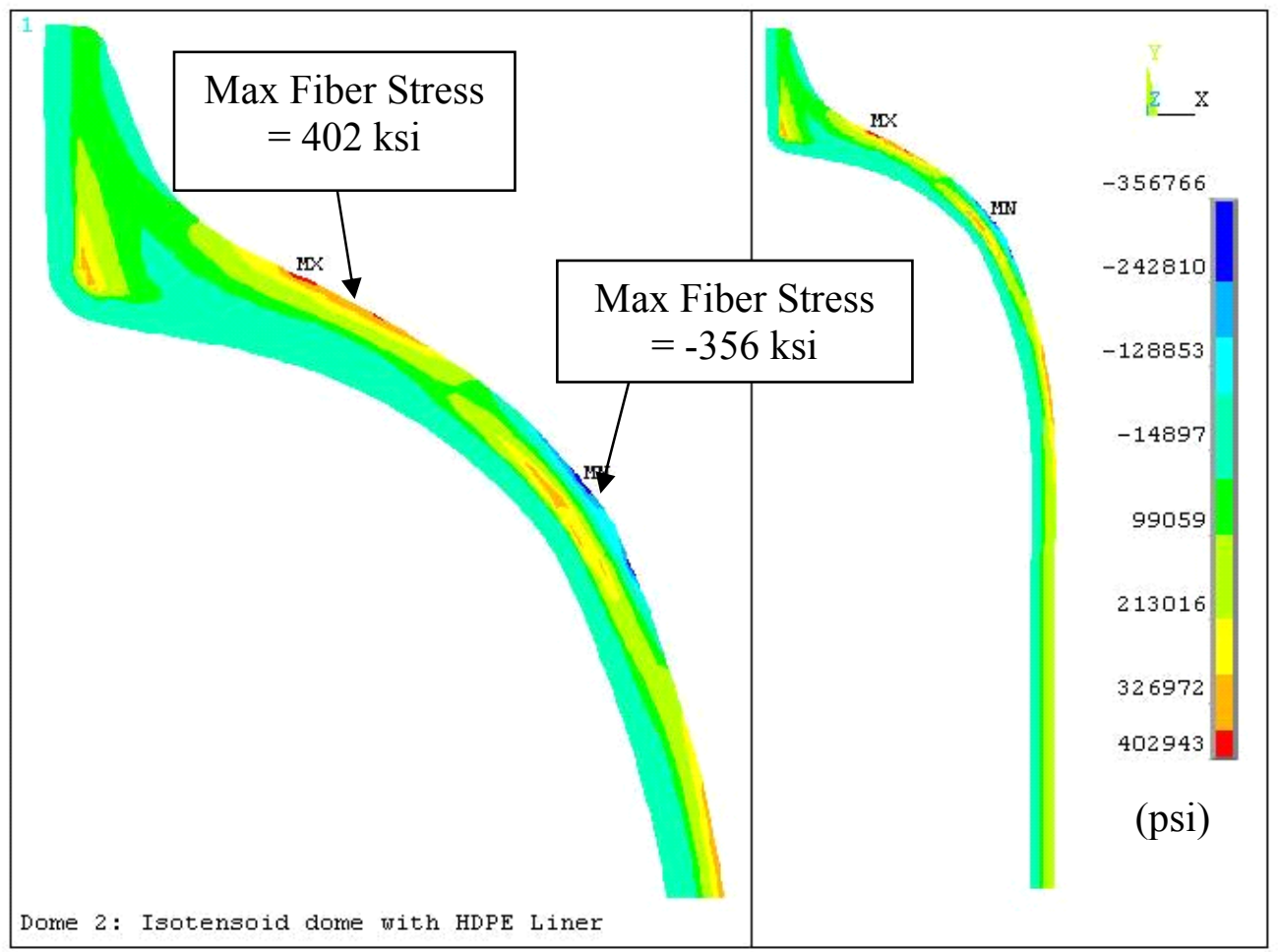

(c)

Figure 7.4: (a) Geometry of the Isotensoid dome and HDPE model (b) displacement (c) stress in fiber directions.

\begin{tabular}{|c|c|c|c|}
\hline & Effective Stress (ksi) & Strength (ksi) & $\boldsymbol{\sigma}_{\mathbf{u}} / \boldsymbol{\sigma}$ \\
\hline Fiber & 402 & 334 & $334 / 402=0.83$ \\
\hline Metallic Insert & N/A & 65 & N/A \\
\hline
\end{tabular}

The fiber stress which is attained by viewing the resultant stress in the x-direction of the defined local coordinate (refer to Figure 7.1) is used to govern the performance of the composite exterior reinforcement and is compared to the ultimate fiber direction tensile and compressive strengths of the composite listed in Table 7.1 as 334 ksi and 261 ksi, respectively. The model in Figure 7.4 is developed by helical winding only. The addition of hoop reinforcement in the cylindrical body is displayed in Figure 7.5. Adding a 0.15 inch layer of $90^{\circ}$ hoop oriented fibers decreases the displacement in the body by $70 \%$. However, the addition of hoop reinforcement increases the displacement in the dome region by $43 \%$ as indicated by Figure 7.5 (a). 
Isotensoid Dome-HDPE Liner with Hoop Reinforcement

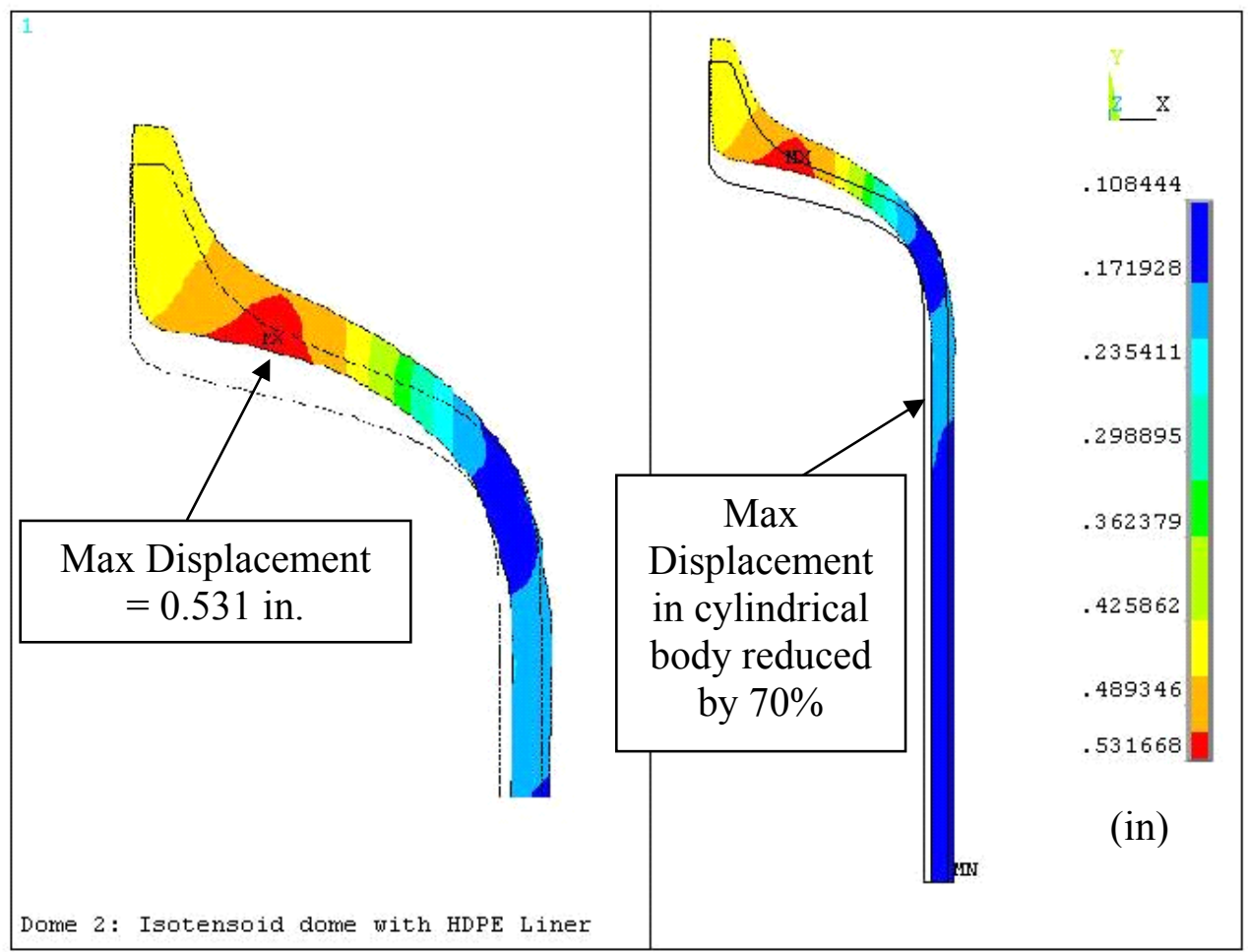

(a)

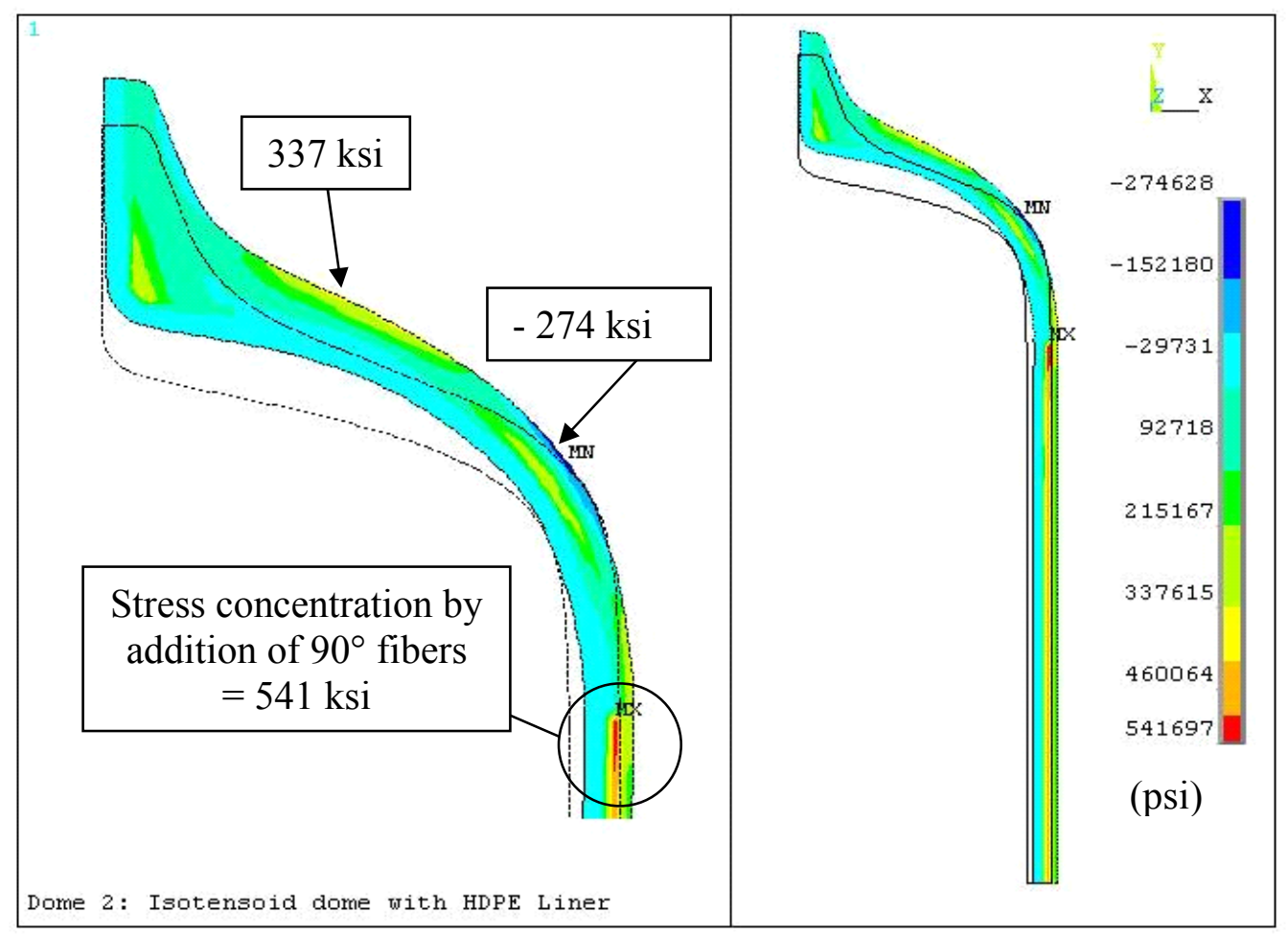

(b) 


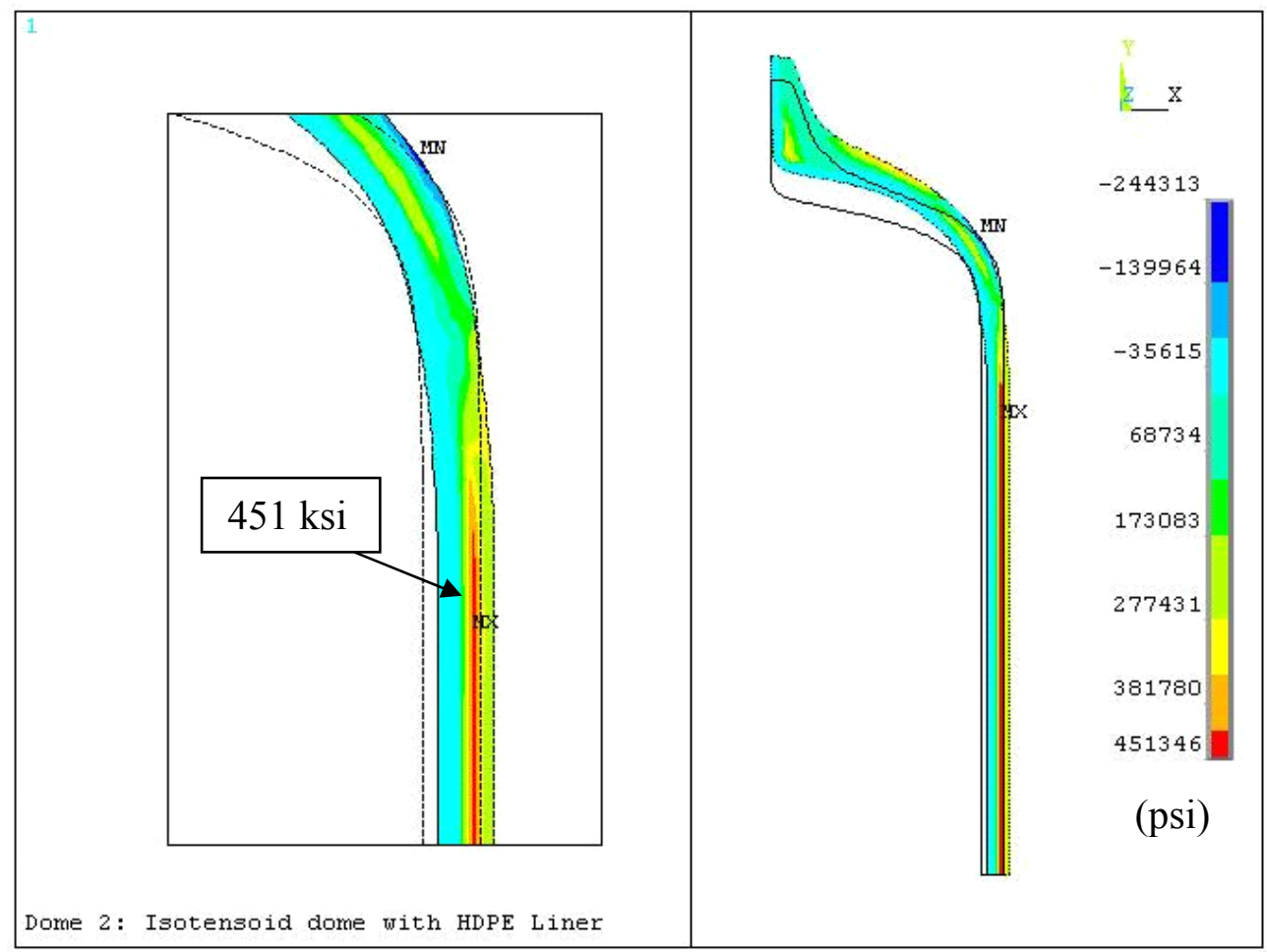

(c)

Figure 7.5: Isotensoid dome with added hoop reinforcement in the cylindrical body (a) displacement (b) stress in the fiber direction (c) stress in the fiber direction after tapering $90^{\circ}$ fiber reinforcement in the stress concentration zone.

\begin{tabular}{|c|c|c|c|}
\hline & Effective Stress - ksi & Strength - ksi & $\boldsymbol{\sigma}_{\mathbf{u}} / \boldsymbol{\sigma}$ \\
\hline Fiber & 451 & 334 & $334 / 451=0.74$ \\
\hline Metallic Insert & N/A & 65 & N/A \\
\hline
\end{tabular}

Hemispherical Dome - HDPE Liner with Full Vessel Helical Winding

The hemispherical end dome is a traditional dome contour which closes the vessel at a constant radius from the cylindrical body to the boss closure. The geometry of a hemispherical dome with filament wound reinforcement is shown in Figure 7.6 (a). The model is designed as a comparison to the isotensoid dome (Figure 7.4). The modeling method was held constant between both designs. 


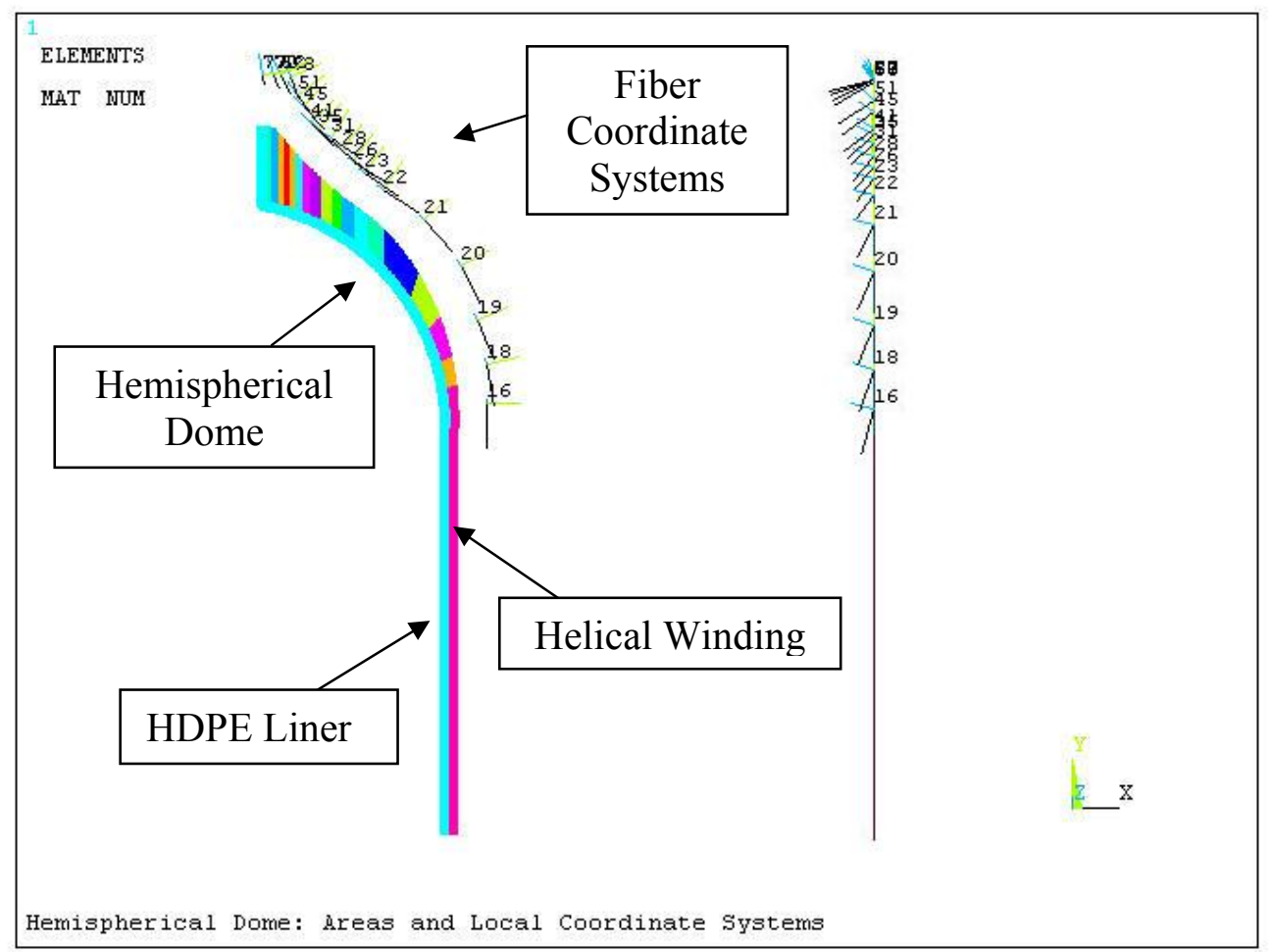

(a)

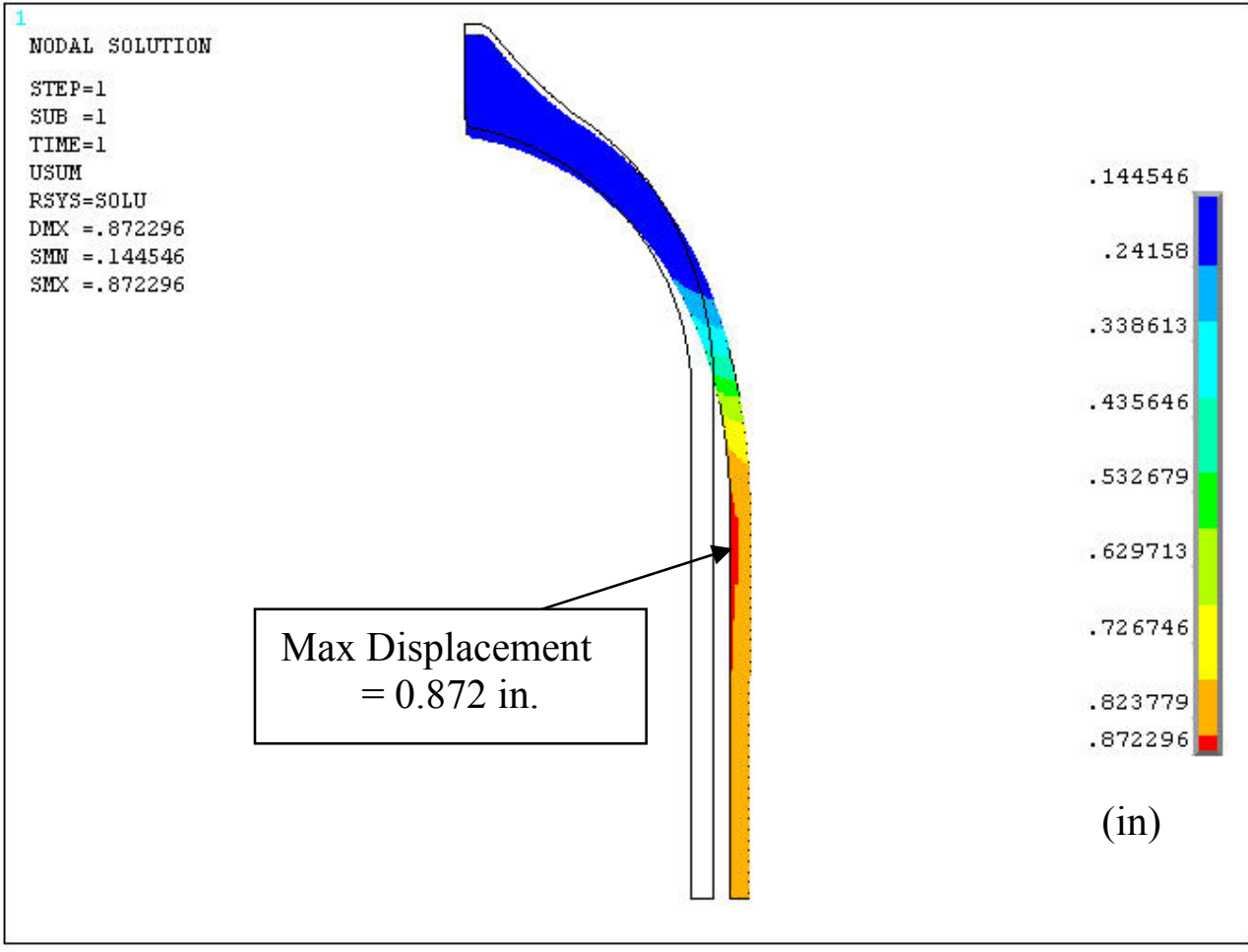

(b) 


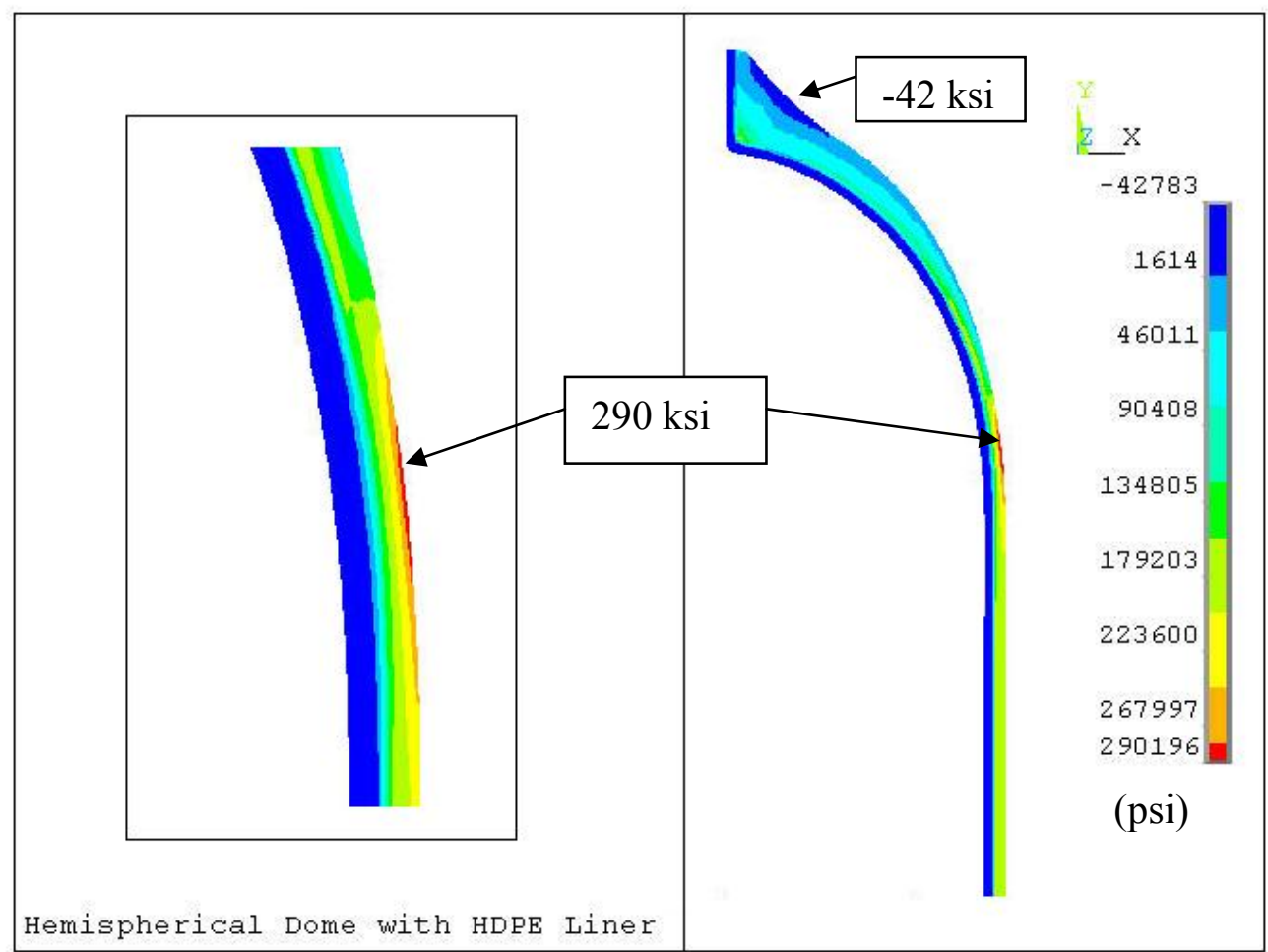

(c)

Figure 7.6: Hemispherical dome with (a) area material divisions and local coordinate systems (b) displacement sum (c) stress in the fiber directions

\begin{tabular}{|c|c|c|c|}
\hline & Effective Stress (ksi) & Strength (ksi) & $\boldsymbol{\sigma}_{\mathbf{u}} / \boldsymbol{\sigma}$ \\
\hline Fiber & 290 & 334 & $334 / 290=1.15$ \\
\hline Metallic Insert & N/A & 65.0 & N/A \\
\hline
\end{tabular}

$\underline{\text { Hemispherical Dome - HDPE Liner with Hoop Reinforcement }}$

The addition of hoop reinforcement to cylindrical body of the dome effects the displacement by creating a "bulging" effect at the cylinder/dome juncture. The higher stiffness in the hoop direction of the cylinder compared to that in the dome creates a discontinuity in the expansion of the vessel as seen in Figure 7.7 (a). 


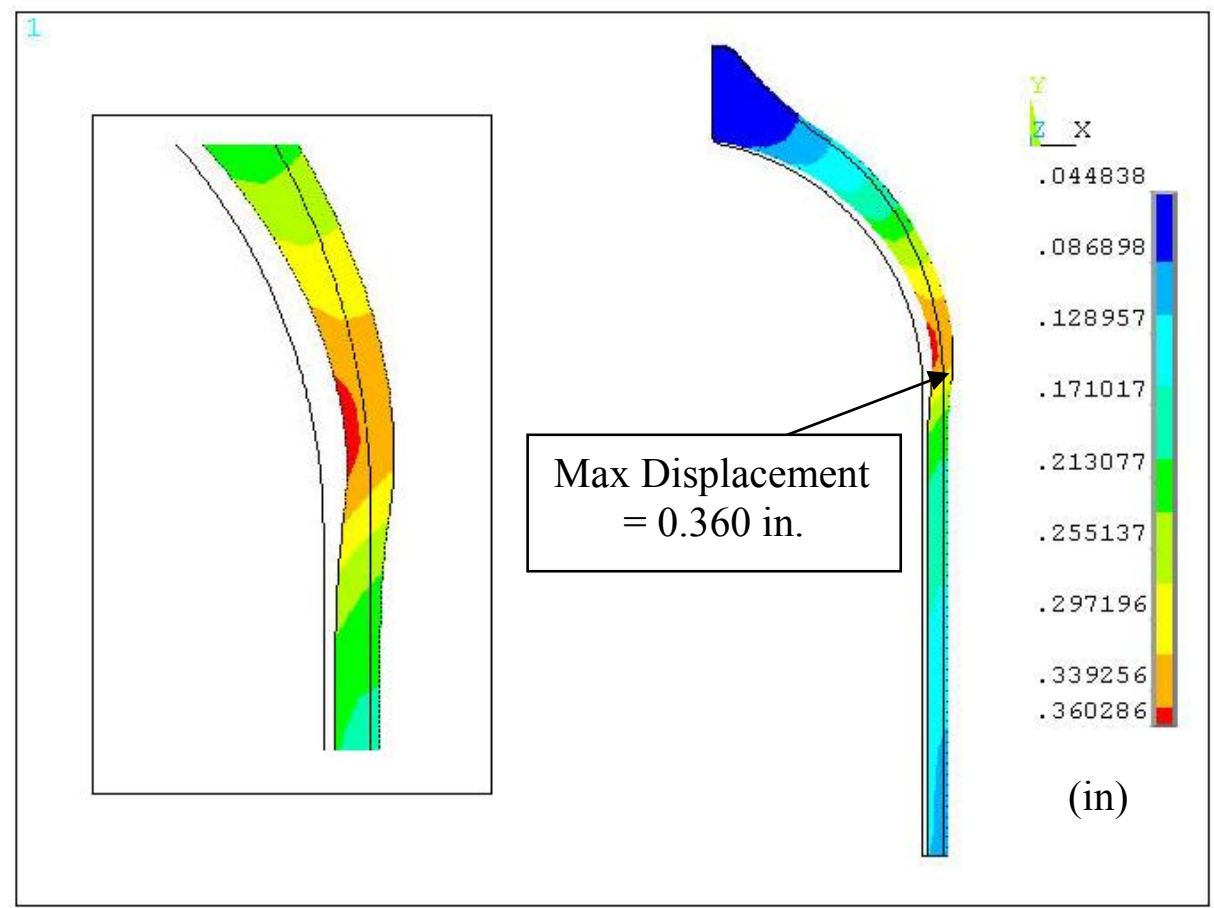

(a)

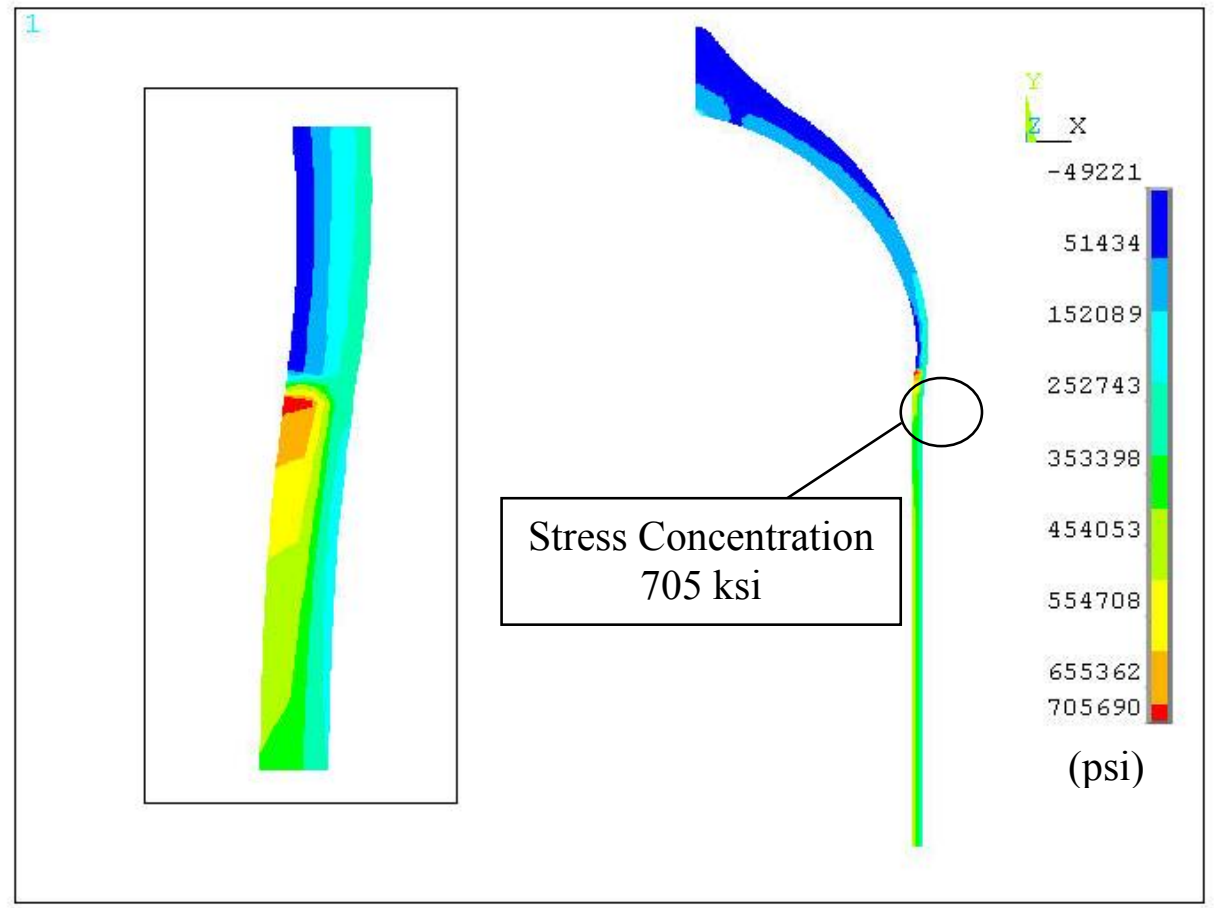

(b)

Figure 7.7: Hemispherical dome with hoop reinforcement in the cylinder (a) displacement (b) stress in the fiber directions 


\begin{tabular}{|c|c|c|c|}
\hline & Effective Stress (ksi) & Strength (ksi) & $\boldsymbol{\sigma}_{\mathbf{u}} / \boldsymbol{\sigma}$ \\
\hline Fiber & 705 & 334 & $334 / 705=0.474$ \\
\hline Metallic Insert & N/A & 65 & N/A \\
\hline
\end{tabular}

$\underline{\text { Isotensoid Dome - HDPE and Aluminum Liner }}$

The initiation of a full body aluminum liner into the isotensoid design is modeled in Figure 7.12. A thin HDPE interior is implemented in the design to serve as a permeation barrier and interface between a hydrogen gas and metallic liner. The intent is to study how the addition of a load-bearing aluminum will affect the displacements and stress resultants. Analysis of the liner is included to study where initial failure will occur.

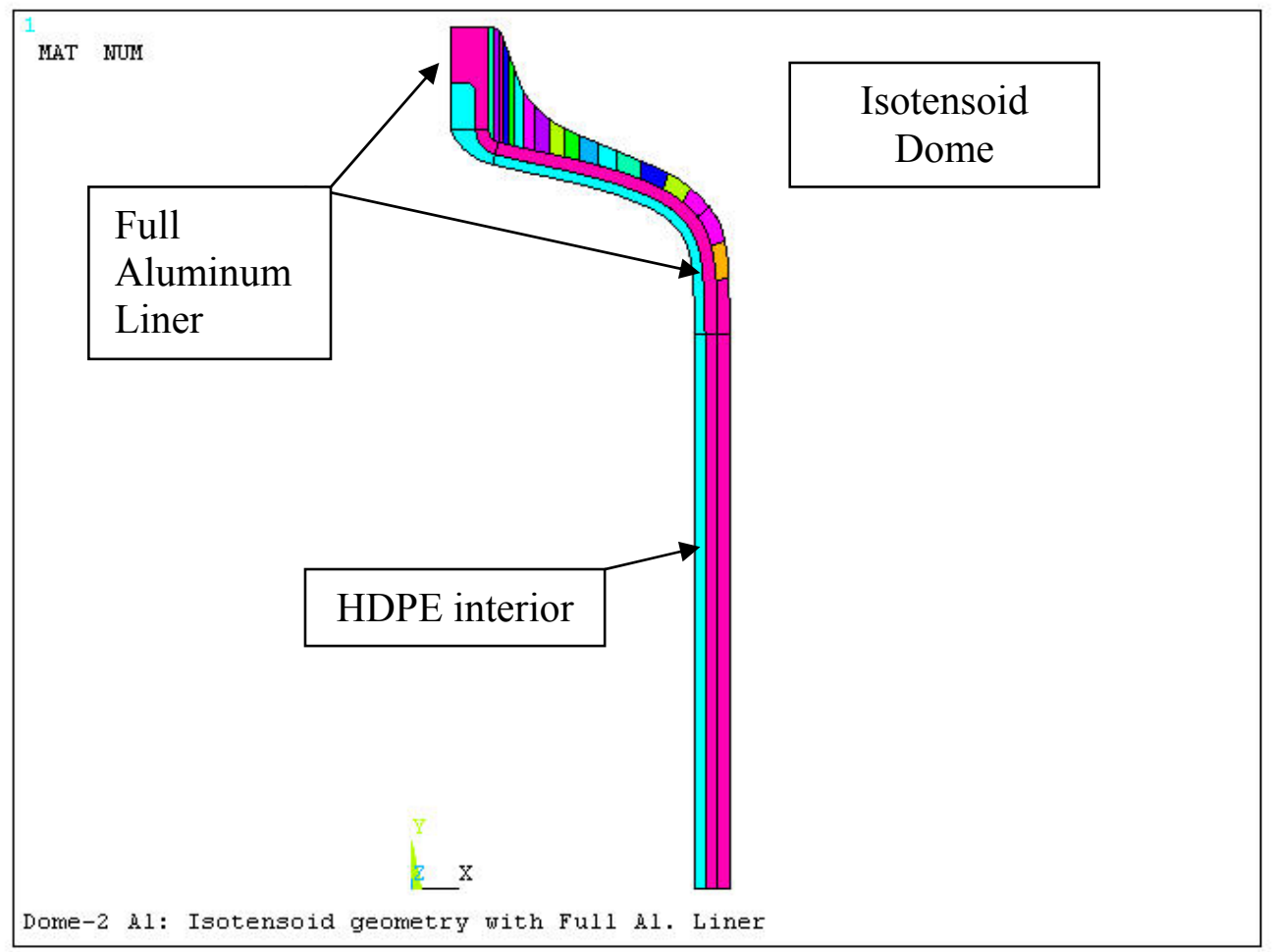

(a) 


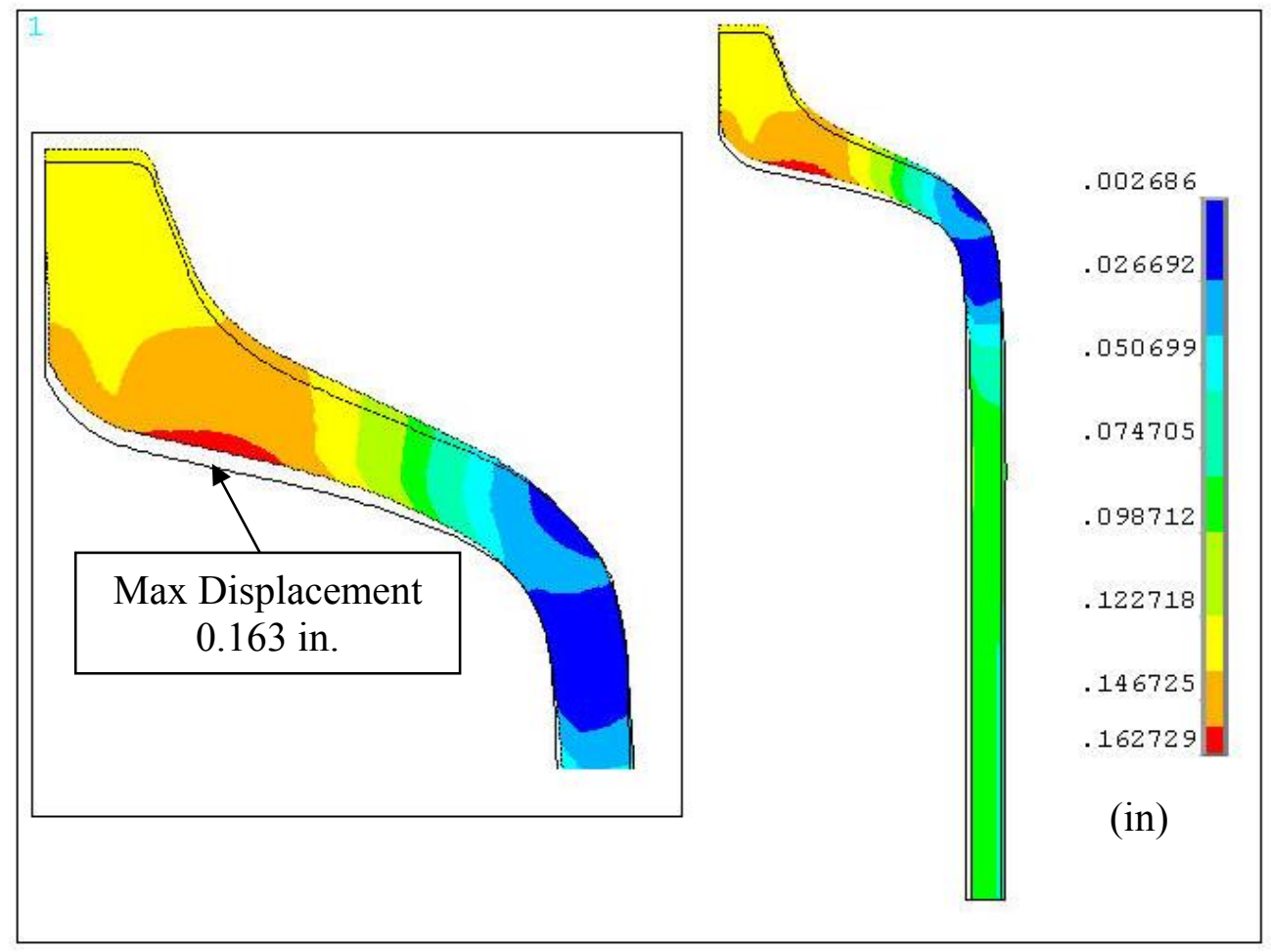

(b)

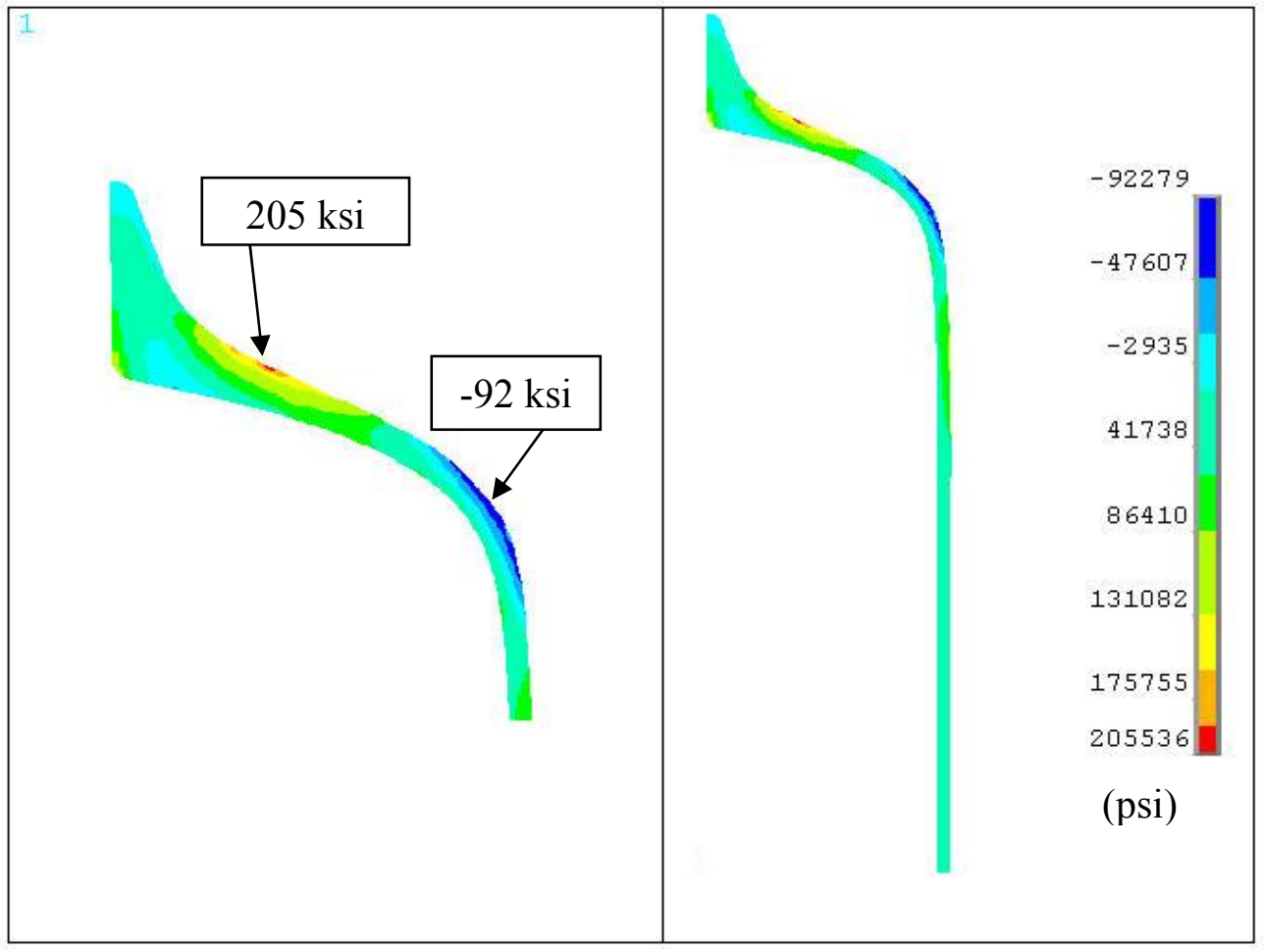

(c) 


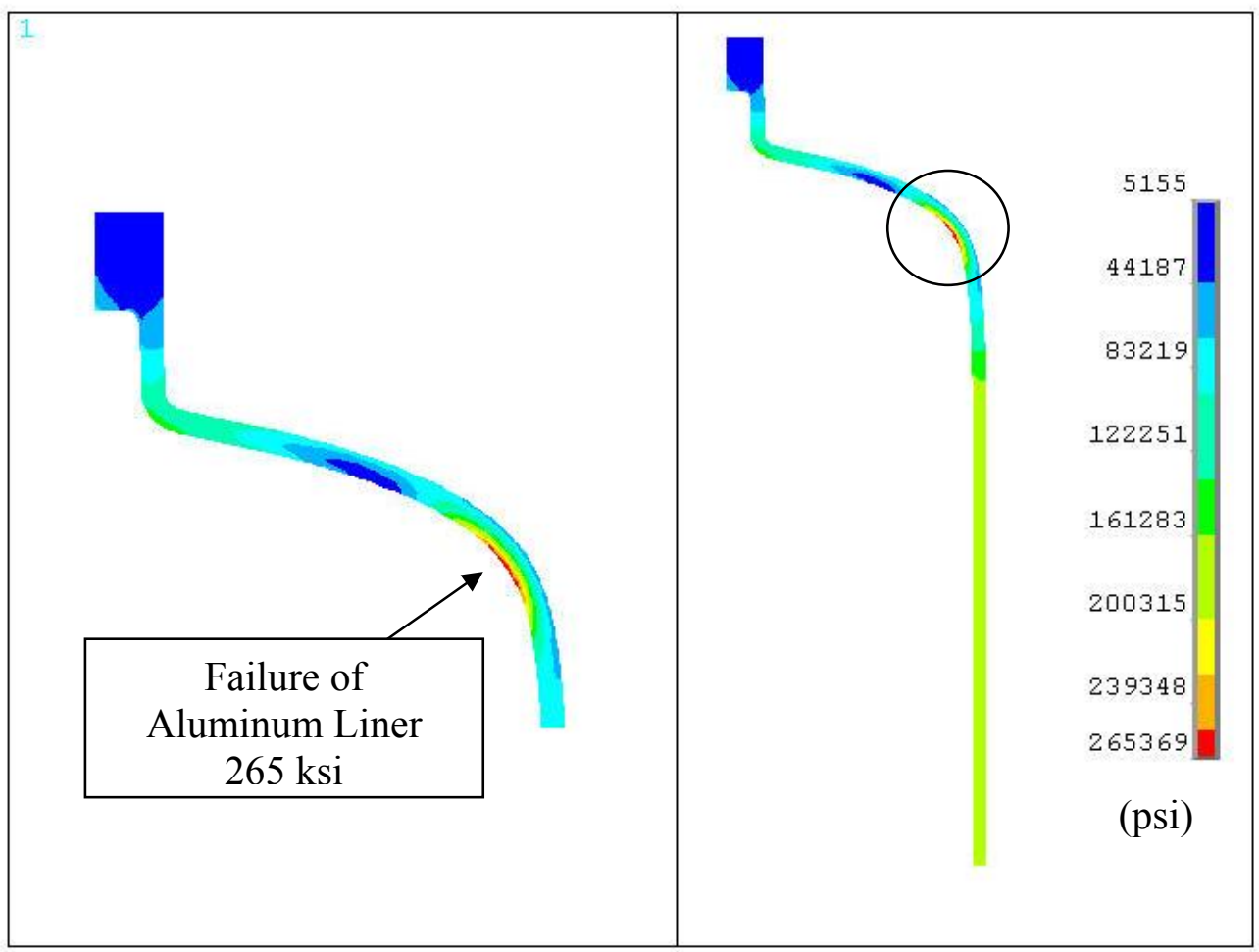

Figure 7.8: Isotensoid dome with full aluminum liner and only helical winding in the cylindrical body (a) geometry (b) displacement (c) stress in the fiber directions (d) equivalent stress in the aluminum liner.

\begin{tabular}{|c|c|c|c|}
\hline & Effective Stress (ksi) & Strength (ksi) & $\boldsymbol{\sigma}_{\mathbf{u}} / \boldsymbol{\sigma}$ \\
\hline Fiber & 205 & 334 & $334 / 205=1.63$ \\
\hline Metallic Insert & 265 & 65 & $65 / 265=0.25$ \\
\hline
\end{tabular}

The addition of a full body aluminum liner is beneficial to the isotensoid design. The load-bearing aluminum liner decreases the displacement in the dome region and the cylindrical body without the addition of hoop reinforcement. The comparison of the isotensoid design with a full aluminum liner to isotensoid geometries with an HDPE liner with and without hoop is summarized in Table 7.4.

Table 7.5: Comparison of full aluminum liner to HDPE liner for an isotensoid dome.

\begin{tabular}{|c|c|c|c|}
\hline Design & Displacement & $\boldsymbol{\sigma}_{\max }$ Tension & $\boldsymbol{\sigma}_{\max }$ Compression \\
\hline Iso- Full Al. Liner & 0.1309 & $205 \mathrm{ksi}$ & $-92 \mathrm{ksi}$ \\
\hline Iso-HDPE no Hoop & 0.7925 & $402 \mathrm{ksi}$ & $-356 \mathrm{ksi}$ \\
\hline Iso - HDPE w/ Hoop & 0.5316 & $337 \mathrm{ksi}$ & $-274 \mathrm{ksi}$ \\
\hline
\end{tabular}




\section{Hemispherical Dome - HDPE and Aluminum Liner}

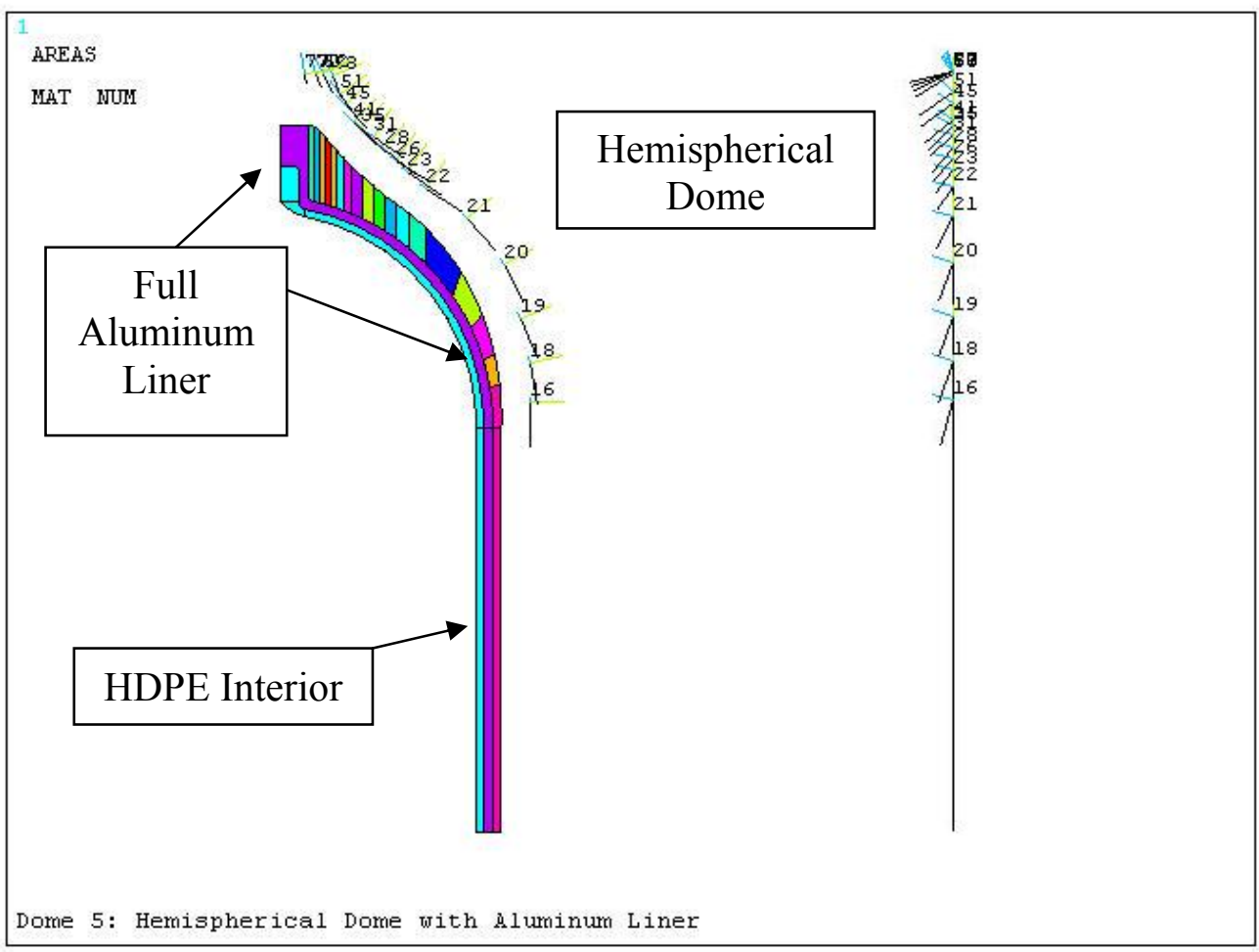

(a)
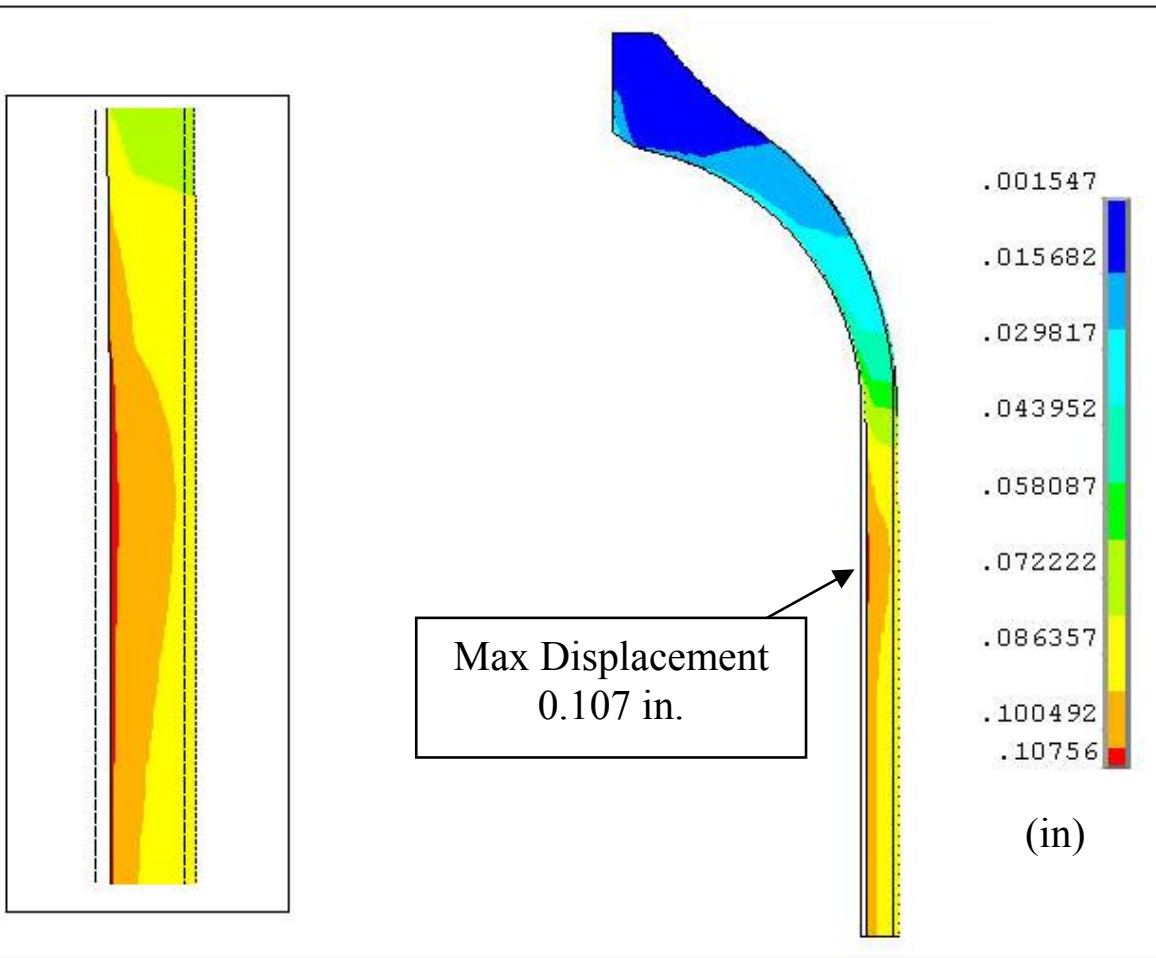

(b) 


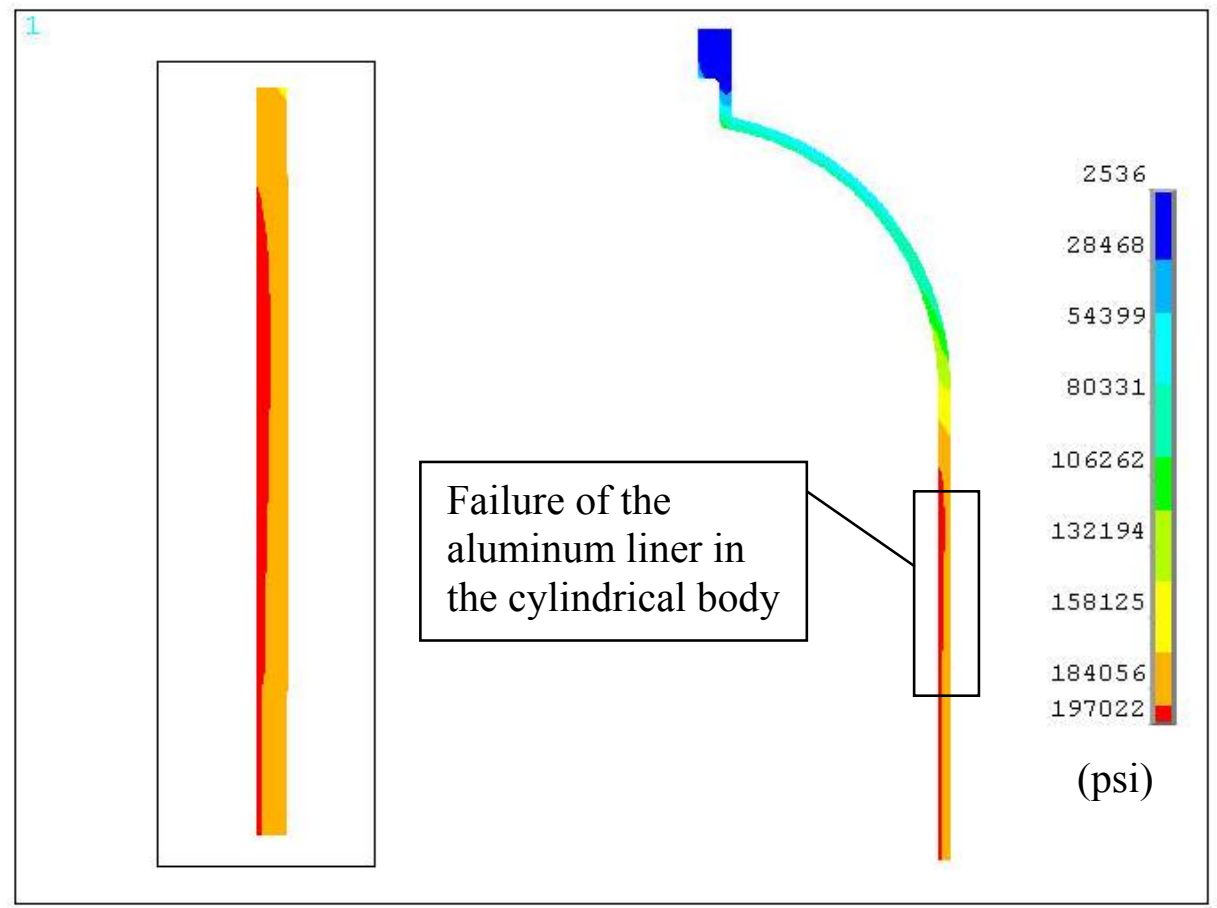

(c)

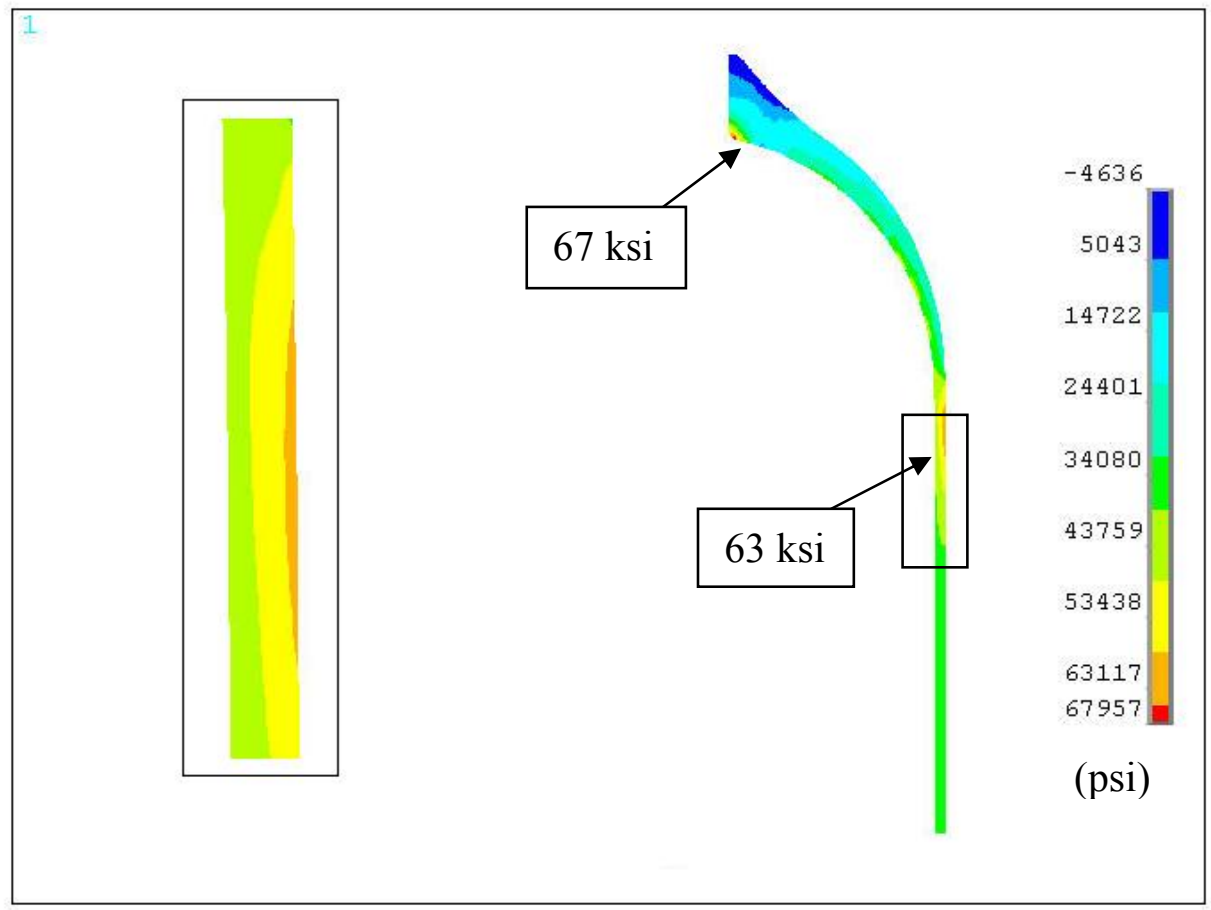

(d)

Figure 7.9: Hemispherical dome with a full aluminum liner (a) geometry (b) displacement (c) equivalent stress in the aluminum liner (d) stress in the fiber directions of the composite reinforcement. 


\begin{tabular}{|c|c|c|c|}
\hline & Effective Stress (ksi) & Strength (ksi) & $\boldsymbol{\sigma}_{\mathbf{u}} / \boldsymbol{\sigma}$ \\
\hline Fiber & 68 & 334 & $334 / 68=4.91$ \\
\hline Metallic Liner & 197 & 65 & $65 / 197=0.33$ \\
\hline
\end{tabular}

Isotensoid Dome - Metallic Insert Extending to the Cylinder-Dome Juncture

The concept of relieving the cylindrical body of the full aluminum liner and only extending an aluminum liner to the cylinder-dome juncture was generated by the results of the previous models. It has been shown that the hoop reinforcement is significant for minimizing displacements and carrying hoop stress in the cylinder body. Therefore, if the aluminum liner was fabricated to extend only to the cylinder-dome juncture and created to the thickness of the required hoop reinforcement to carry the cylinder stress, the hoop reinforcement winding will replace the area the full aluminum liner occupied.

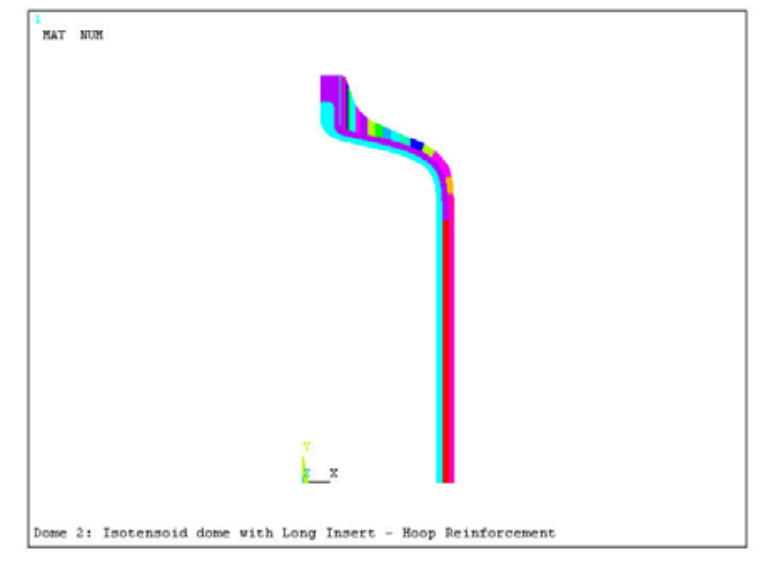

With Hoop Reinforcement

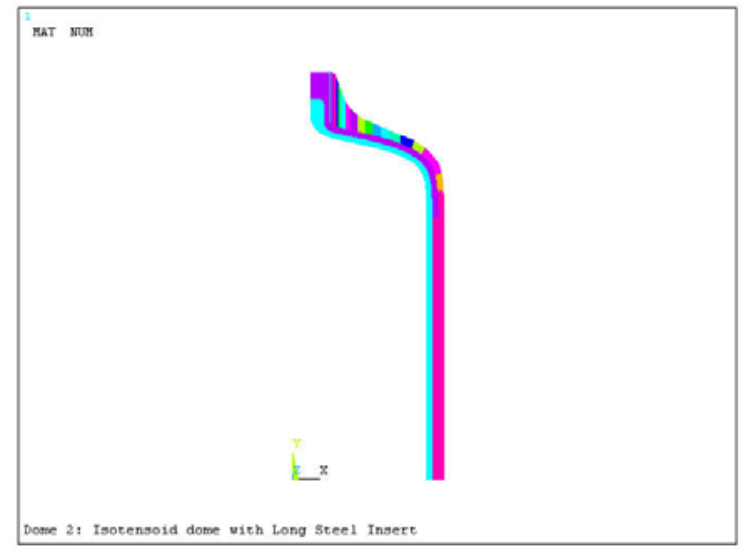

Without Hoop Reinforcement 


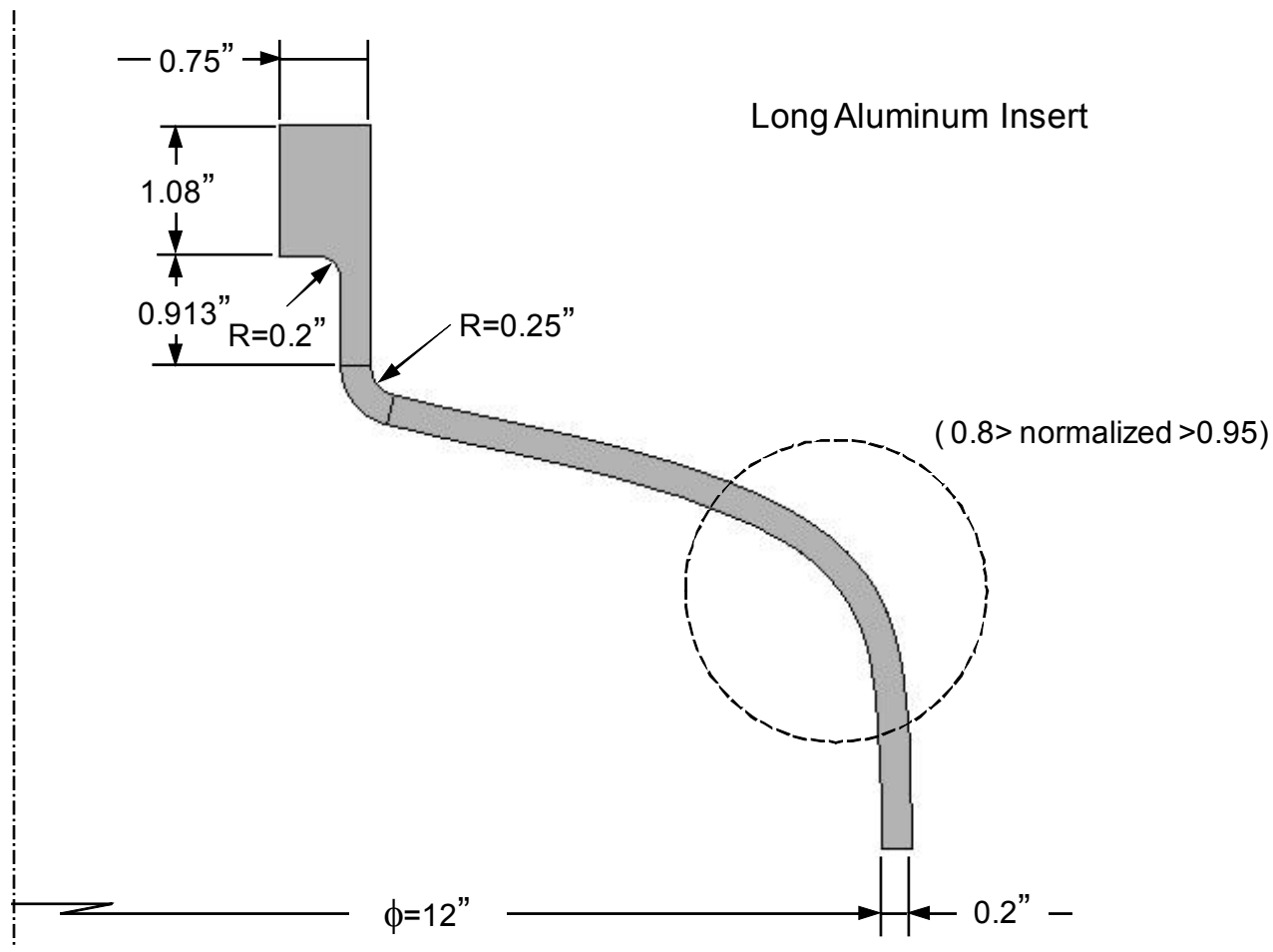

(a)

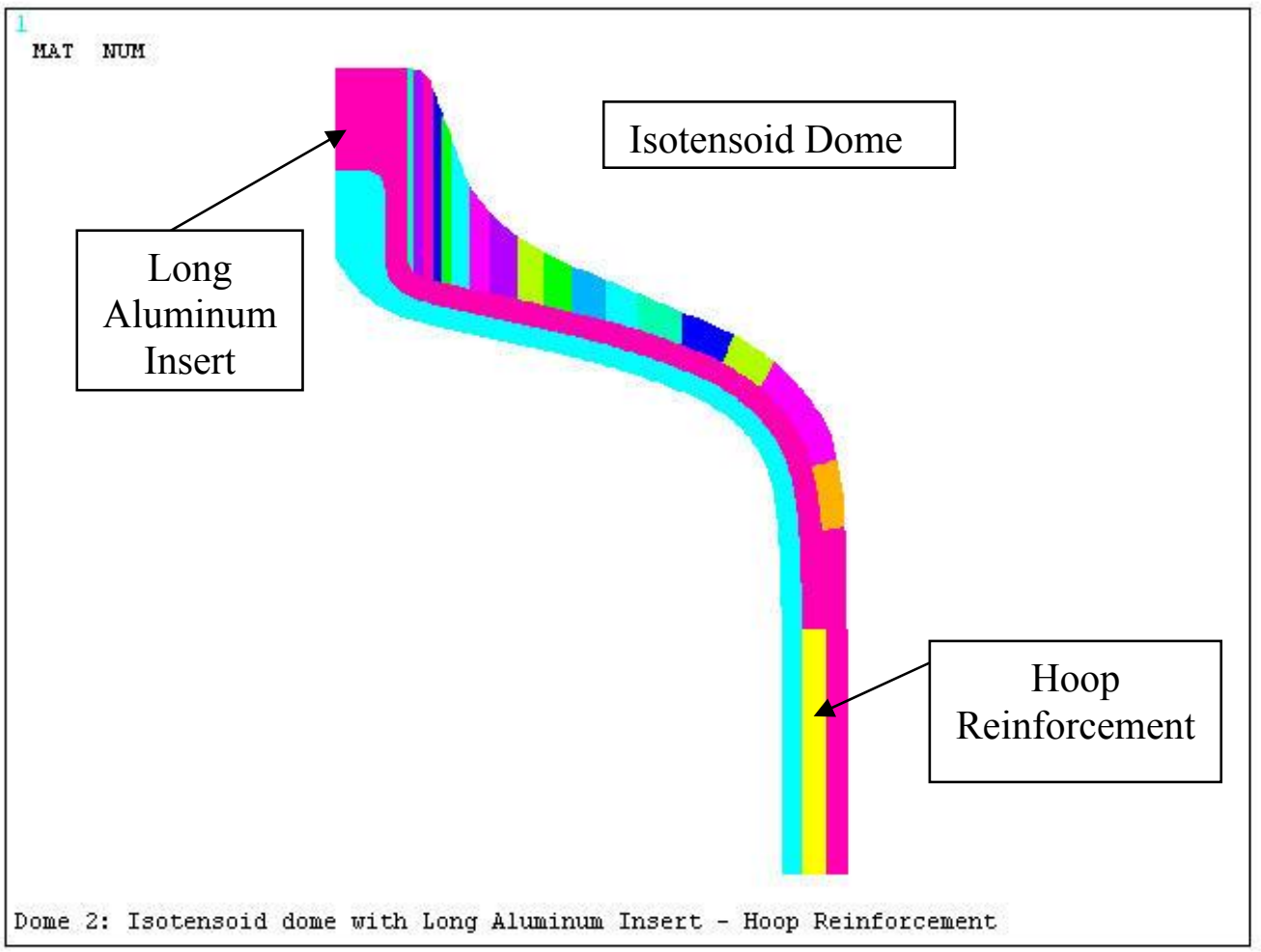

(b) 


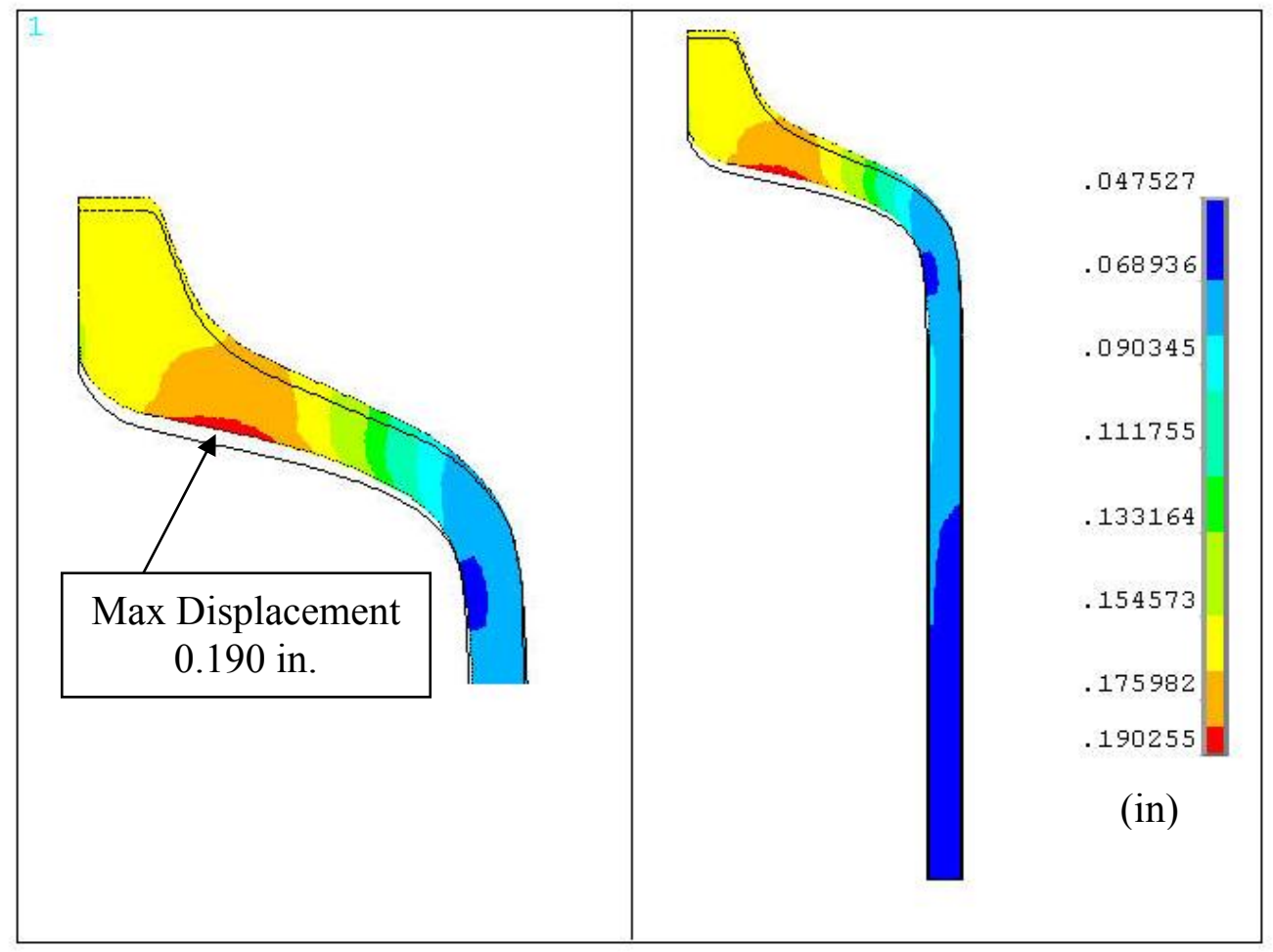

(c)

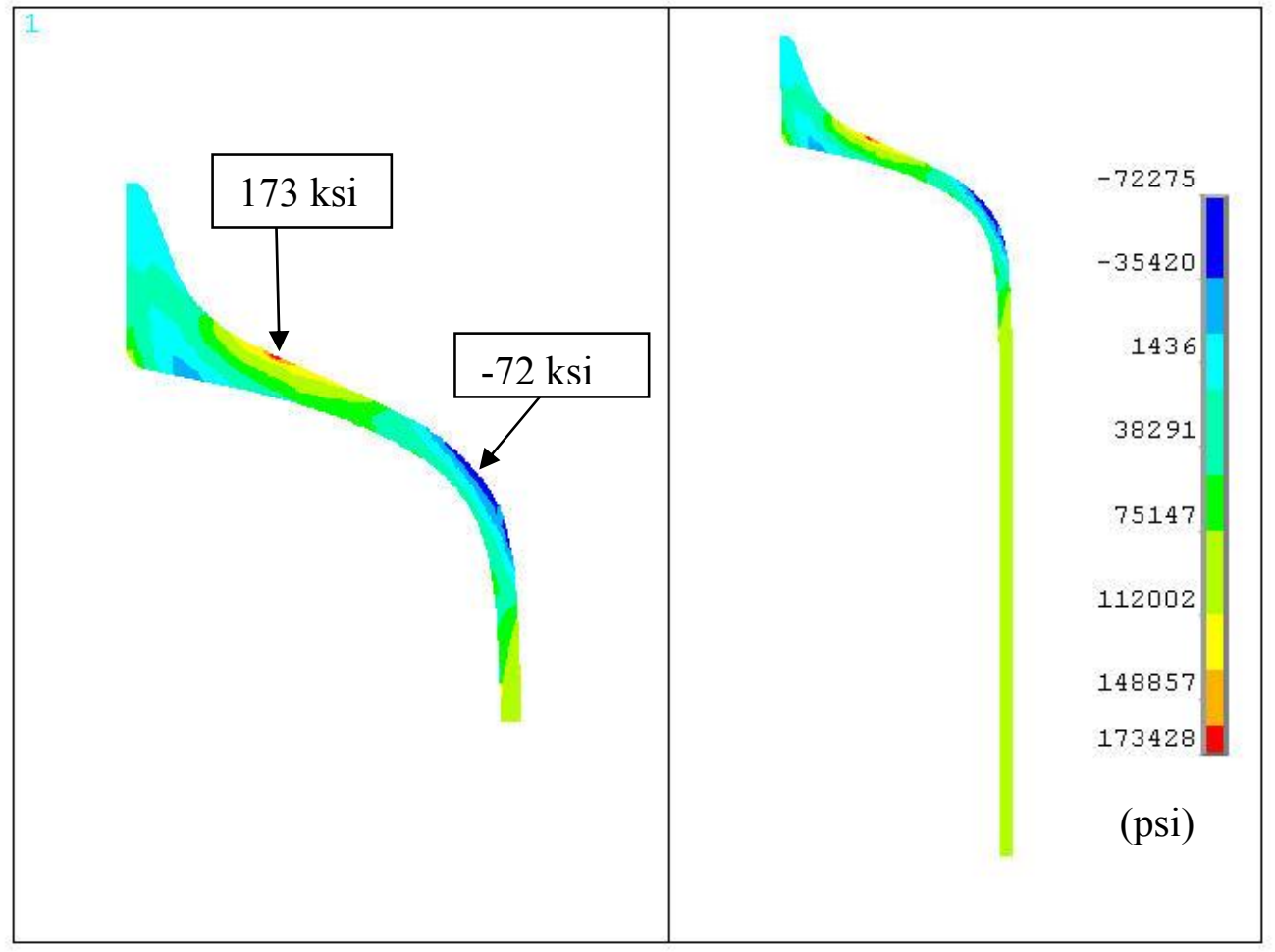

(d) 


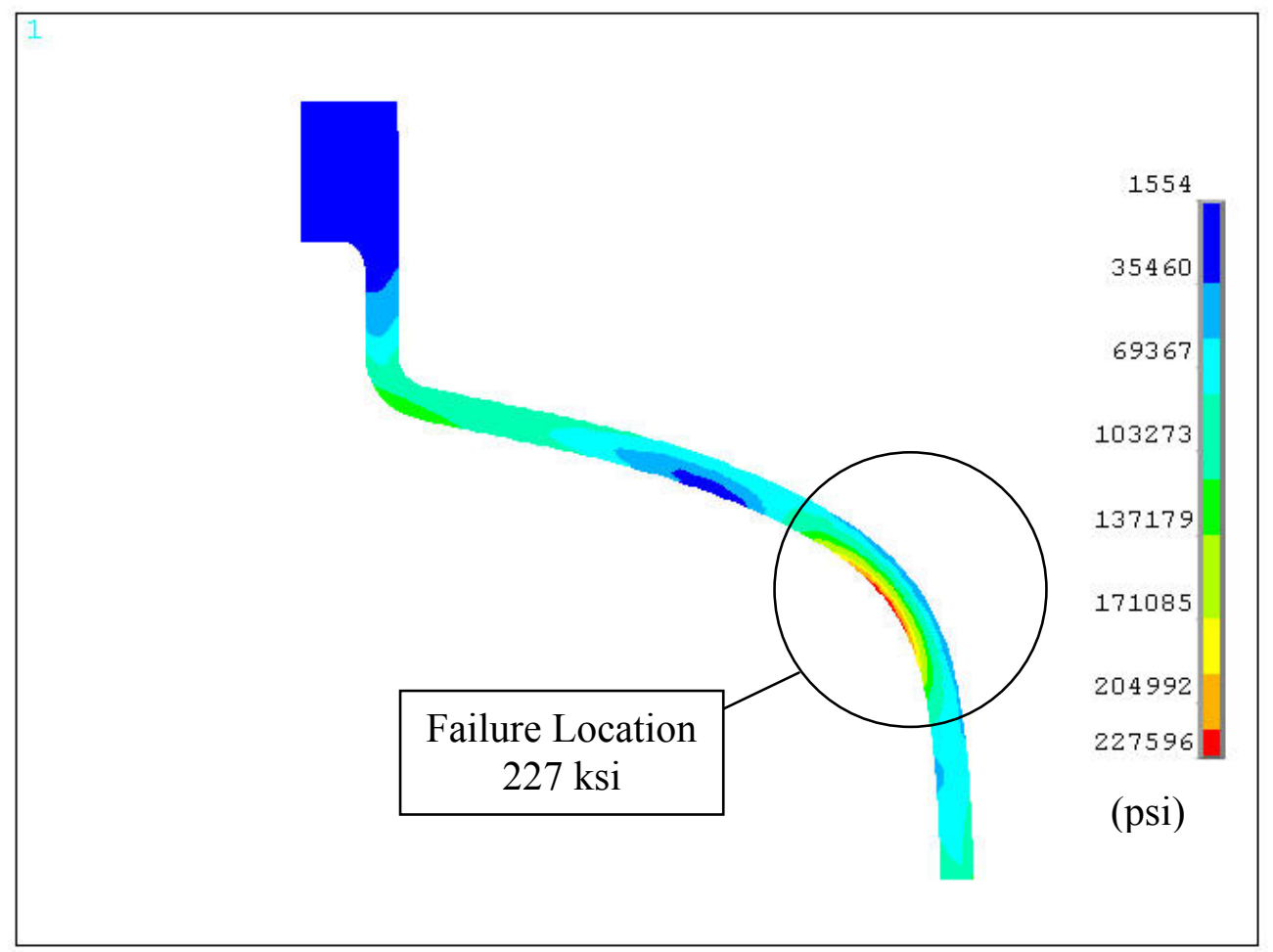

(e)

Figure 7.10: Isotensoid dome with aluminum liner extending to the cylinder-dome juncture (a) dimensions and (b) geometry showing the aluminum liner (purple) in the dome and $90^{\circ}$ hoop fibers (yellow) in the cylinder body (c) displacement (d) stress in the fiber directions (e) equivalent stress in the aluminum insert.

\begin{tabular}{|c|c|c|c|}
\hline & Effective Stress (ksi) & Strength (ksi) & $\boldsymbol{\sigma}_{\mathbf{u}} / \boldsymbol{\sigma}$ \\
\hline Fiber & 173 & 334 & $334 / 173=1.93$ \\
\hline Metallic Insert & 227 & 65 & $65 / 227=0.29$ \\
\hline
\end{tabular}

Comparing the isotensoid with a full aluminum liner to the long aluminum insert extending to the cylinder/dome juncture, it is shown that the full liner limits the displacement by $15 \%$ ( 0.190 to 0.163$)$ however, the stress in the fiber directions is reduced in the tension zone to $173 \mathrm{ksi}$ and $-72.0 \mathrm{ksi}$ in the dome bend for the long aluminum insert. 


\section{$\underline{\text { Hemispherical Dome - Aluminum Insert to the Cylinder/Dome Juncture }}$}

Examining the hemispherical dome with an aluminum liner extending to the cylinder dome juncture, the magnitude and direction of the displacements are very similar to the hemispherical dome with a full aluminum liner and differ by only $0.0003 \mathrm{in}$. Referring back to Figure 7.9 (c), shows the full aluminum liner to be in failure at equivalent magnitude of $197 \mathrm{ksi}$. Therefore, the long insert to the cylinder dome juncture removes the failed aluminum region and replaces it with hoop oriented fibers. Reducing the length of the aluminum liner as an insert extending the cylinder-dome juncture reduces the equivalent stress of the part to $147 \mathrm{ksi}$.

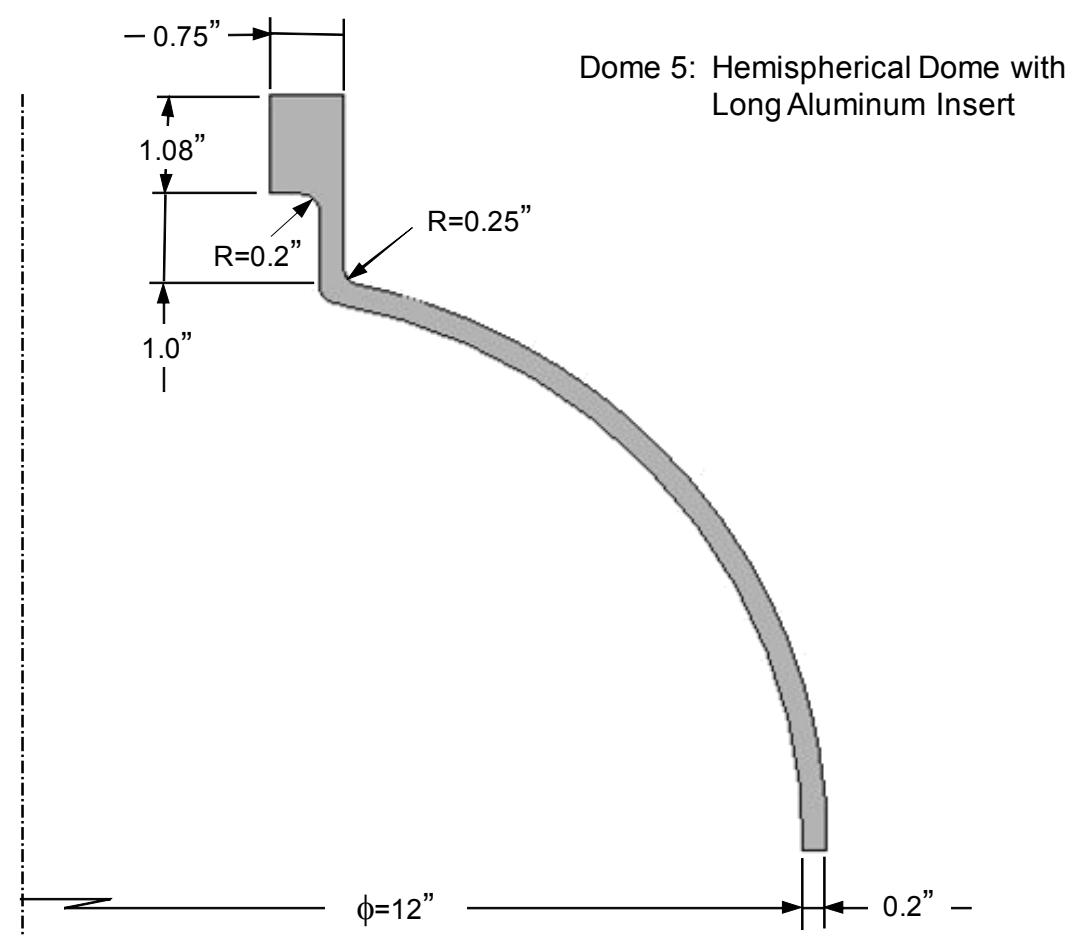

(a) 




(b)

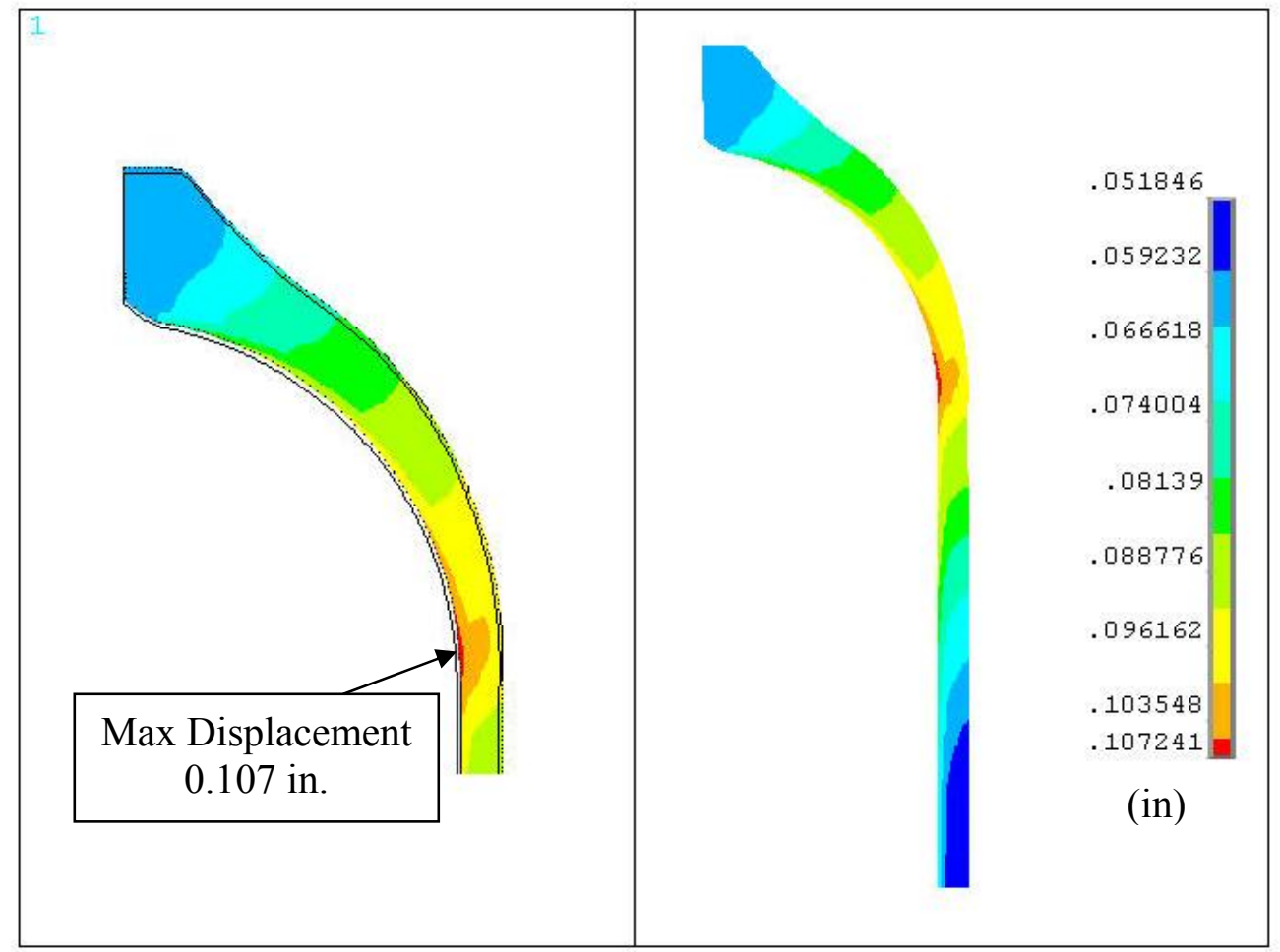

(c) 


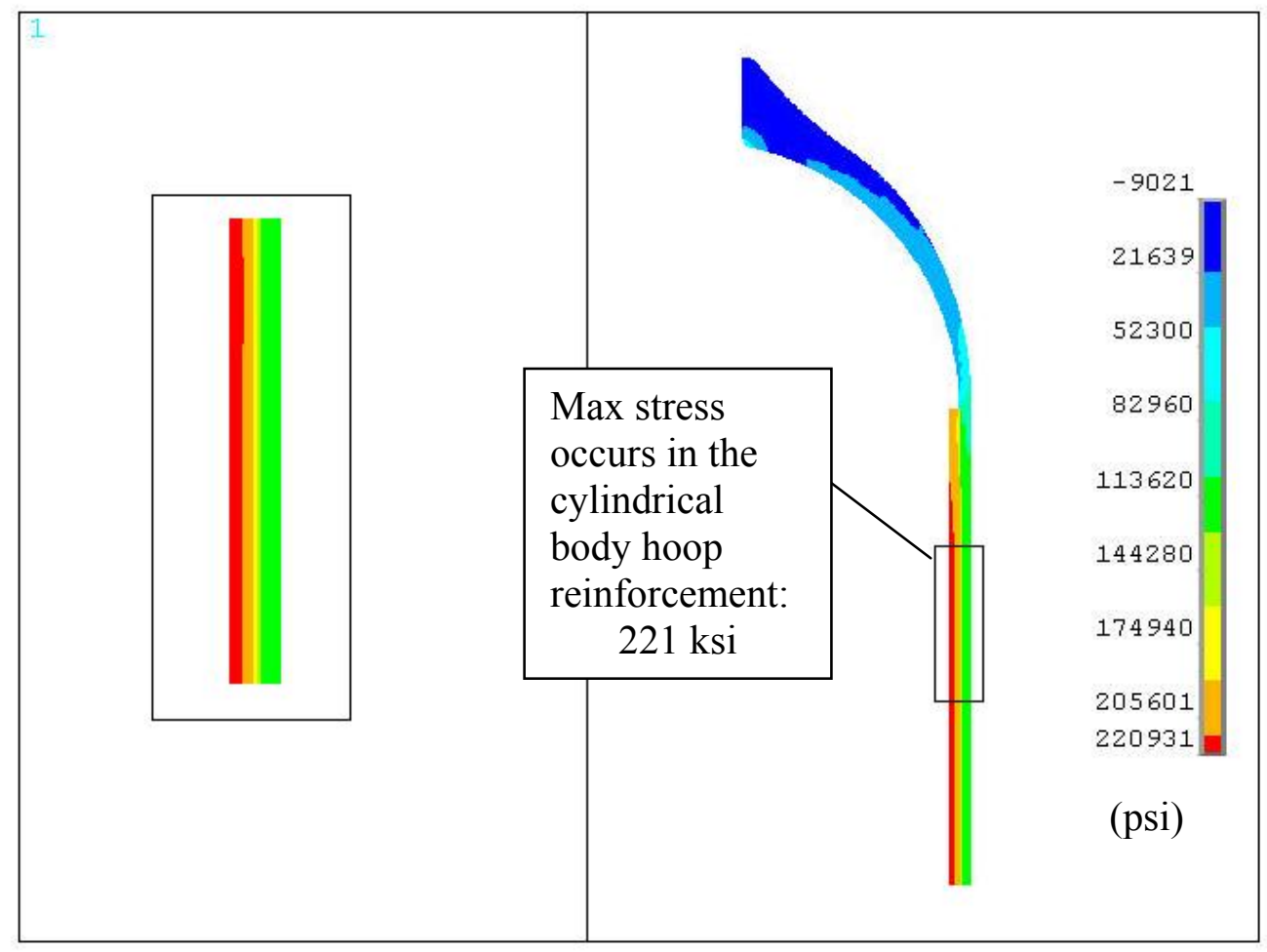

(d)

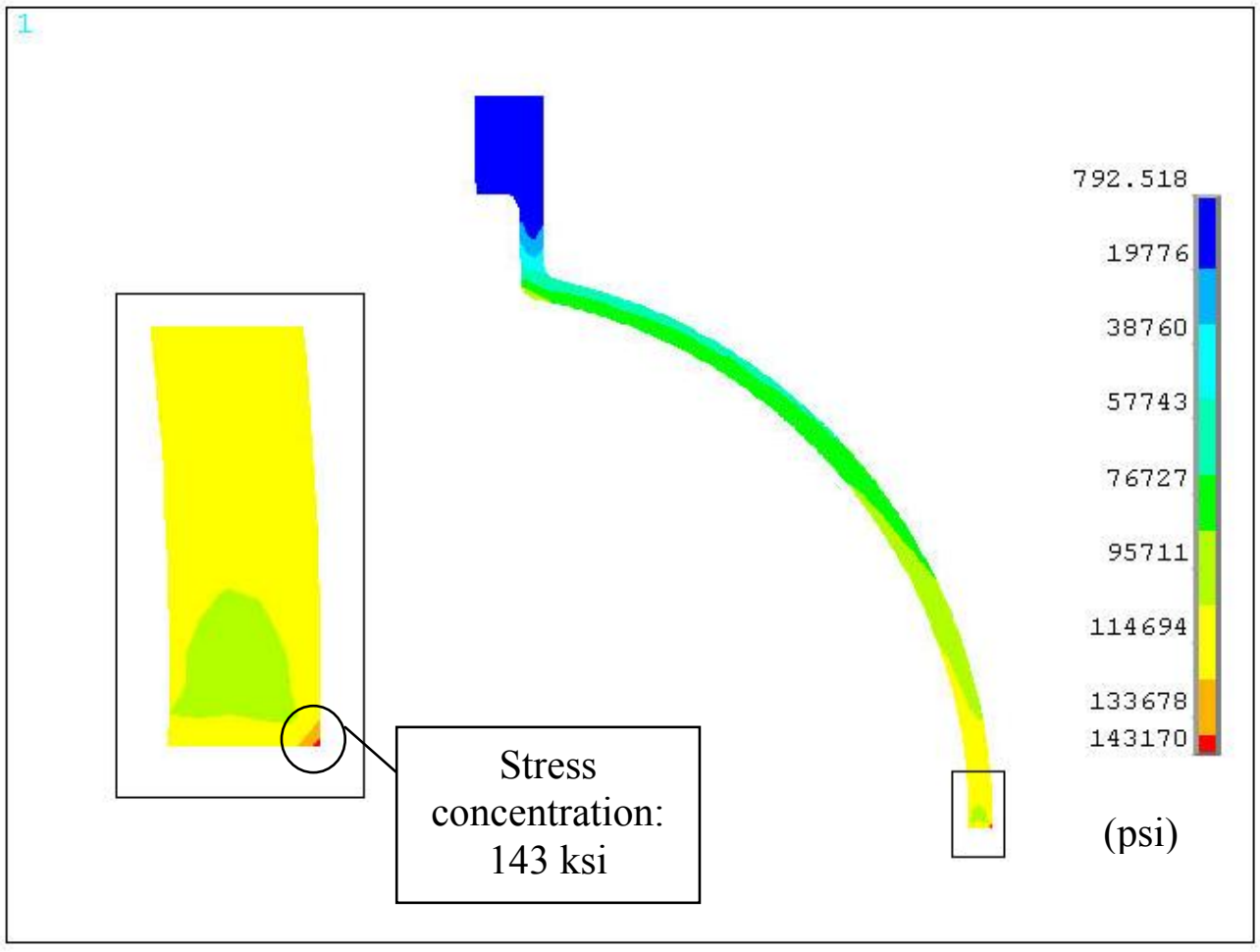

(e) 
Figure 7.11: (a) Dimensions of the hemispherical dome aluminum liner extending to the cylinder dome juncture (b) geometry (c) displacement (d) stress in the fiber directions (d) equivalent stress in the aluminum insert.

\begin{tabular}{|l|l|l|l|}
\hline & Effective Stress (ksi) & Strength (ksi) & $\boldsymbol{\sigma}_{\mathbf{u}} / \boldsymbol{\sigma}$ \\
\hline Fiber & 221 & 334 & $334 / 221=1.51$ \\
\hline Metallic Insert & 143 & 65 & $65 / 143=0.45$ \\
\hline
\end{tabular}

$\underline{\text { Isotensoid - Aluminum Boss Insert }}$

Reducing the metallic connector for nozzle/valve to the boss region is shown in Figure 7.12. The innovation behind this concept is to utilize the mandated hoop or tangent winding around the boss region to control the positioning of the insert and provide strength for the connection to the filament wound reinforcement and the boss. An annular ring is milled from the metallic insert as shown in the inset of Figure 7.12 (b). This ring in the geometry enables the filament wound fibers to build a reinforcement zone of $90^{\circ}$ oriented fibers to resist hoop stress and lateral displacement in the nozzle region. 


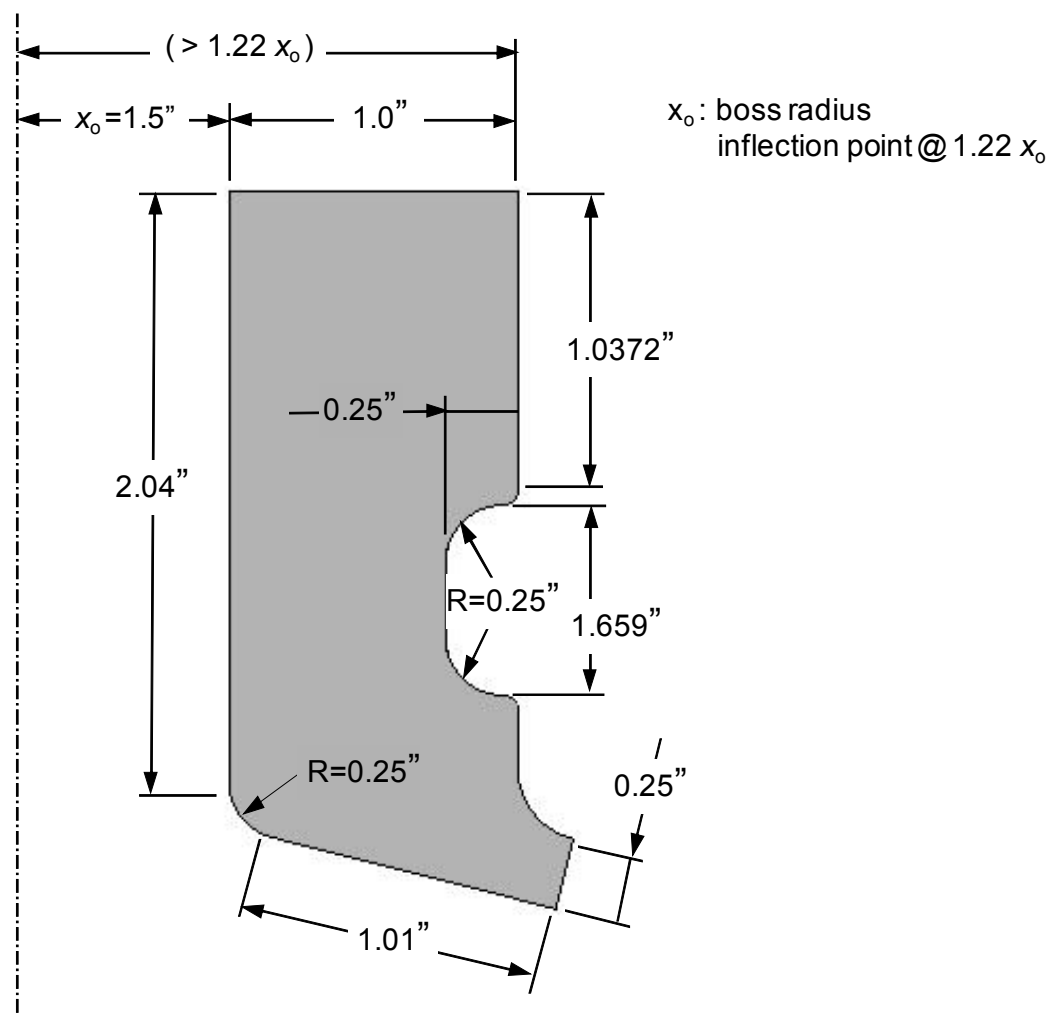

(a)

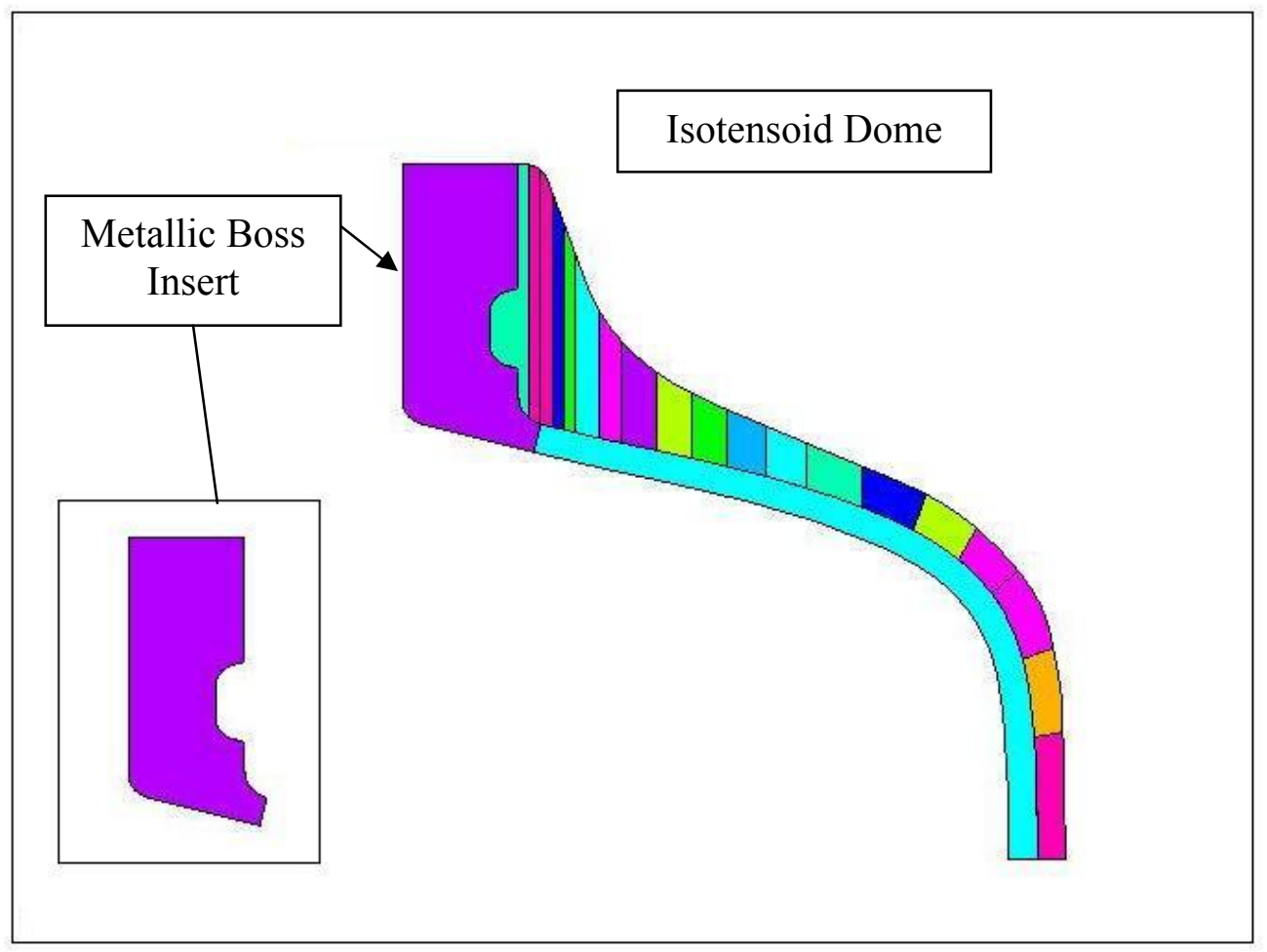

(b) 


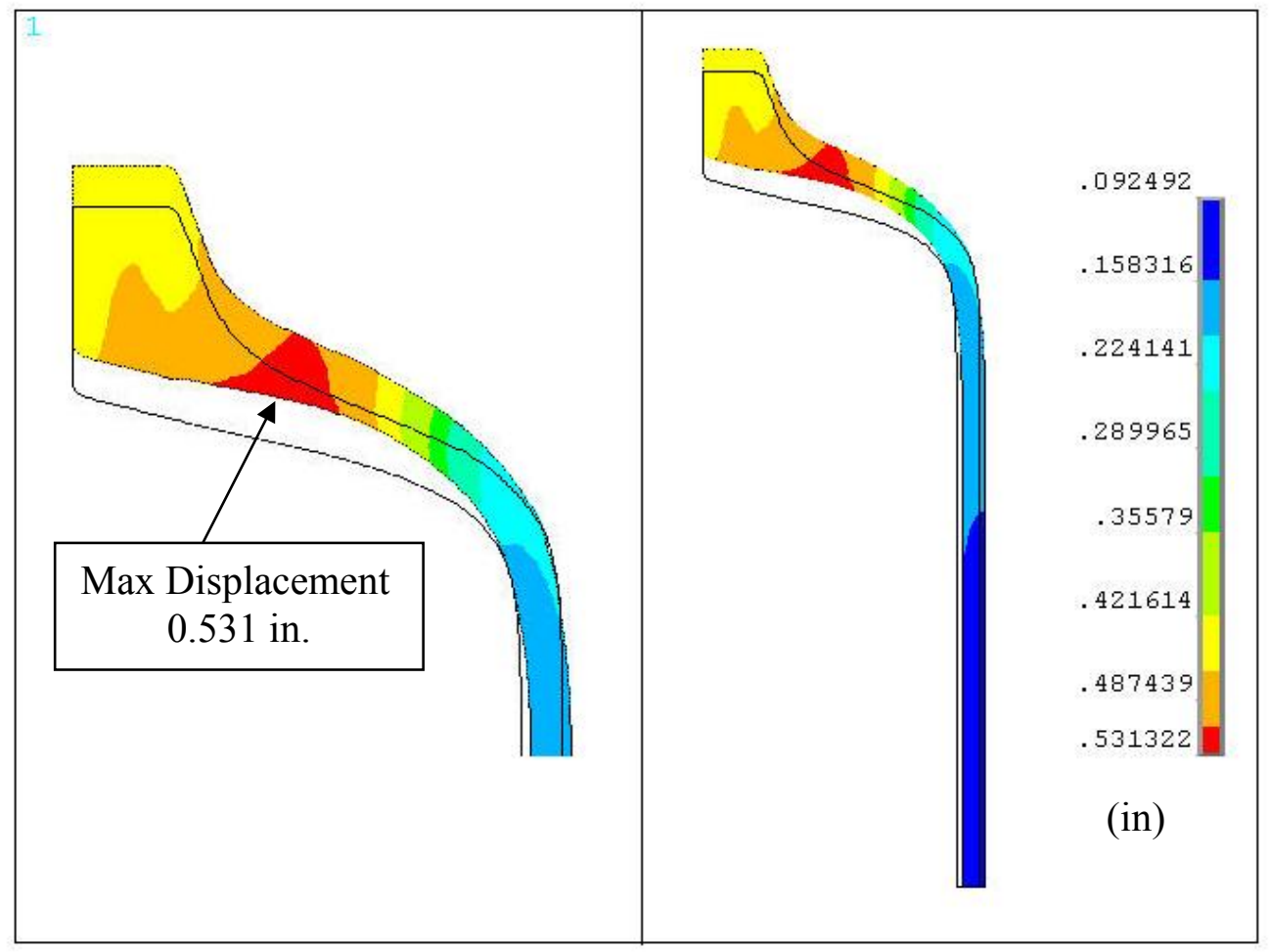

(c)

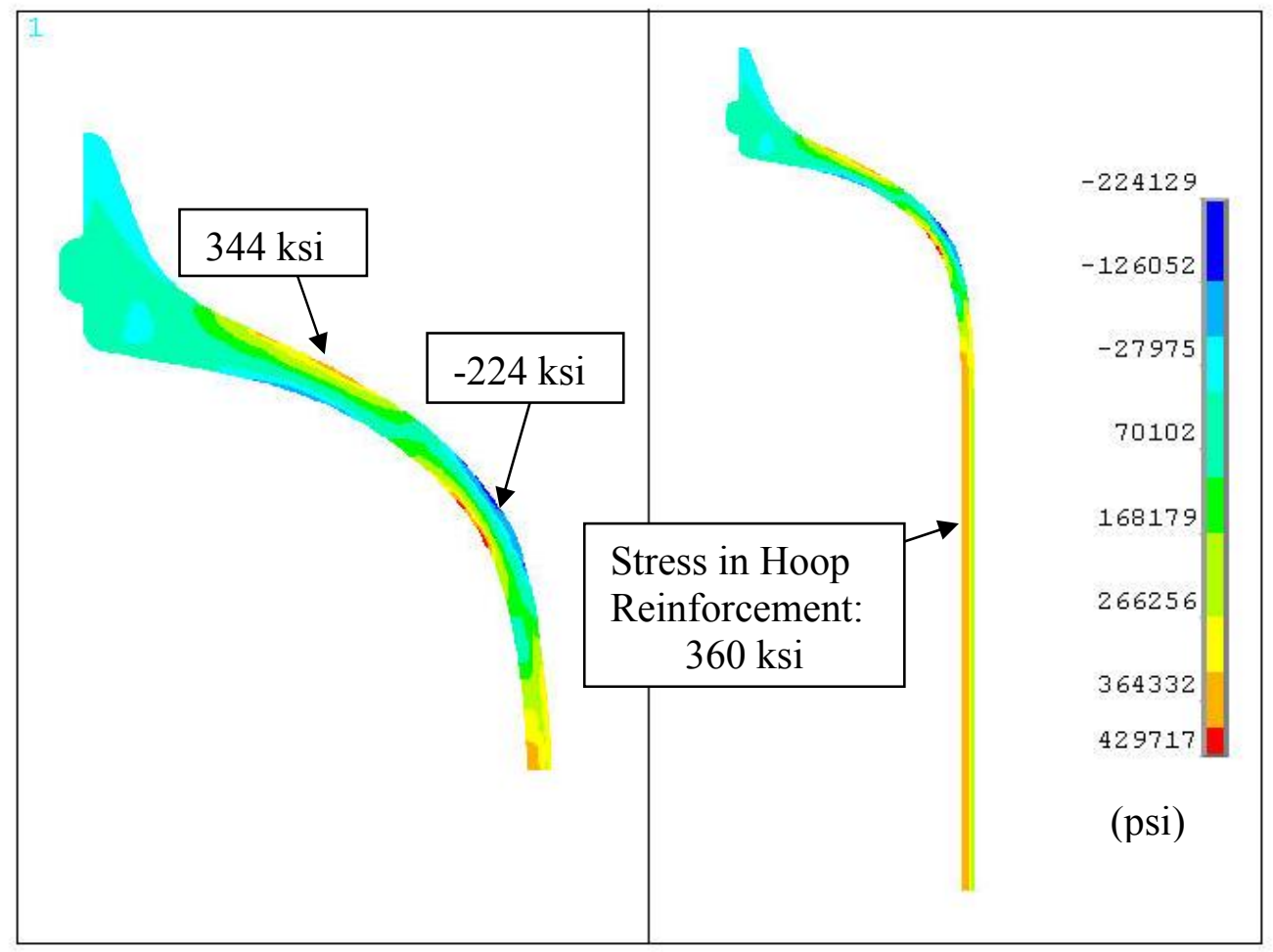

(d) 


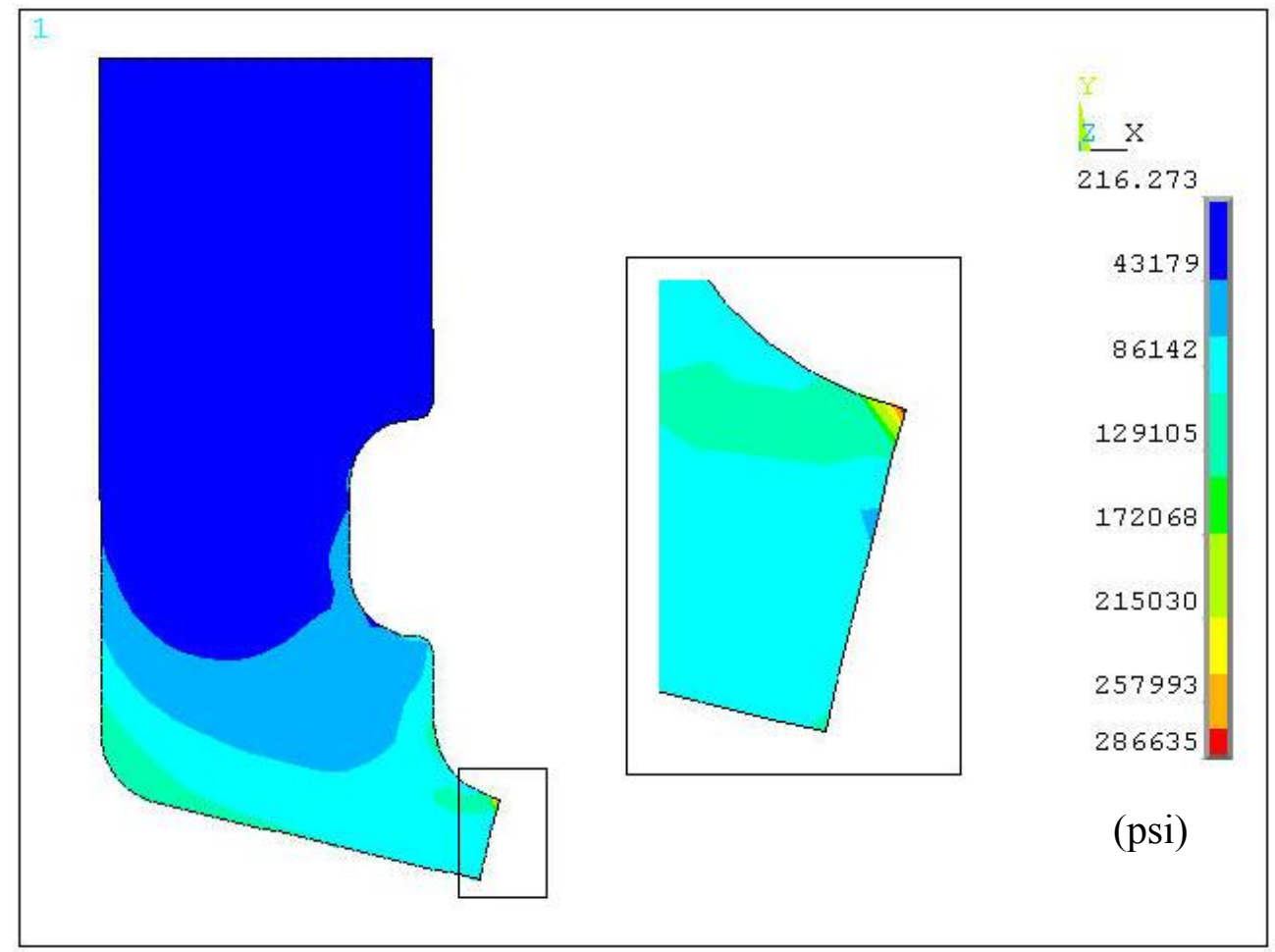

(e)

Figure 7.12: Isotensoid dome with metallic insert (a) dimensions and (b) geometry with inset showing annular ring (c) displacement (d) stress in the fiber directions (e) equivalent stress in the aluminum boss insert.

\begin{tabular}{|c|c|c|c|}
\hline & Effective Stress (ksi) & Strength (ksi) & $\boldsymbol{\sigma}_{\mathbf{u}} / \boldsymbol{\sigma}$ \\
\hline Fiber & 429 & 334 & $334 / 429=0.78$ \\
\hline Metallic Insert Al. & 286 & 65 & $65 / 286=0.23$ \\
\hline Metallic Insert Steel & 340 & 75 & $75 / 340=0.22$ \\
\hline
\end{tabular}

As shown, in Figure 7.12 (c), the isotensoid dome contour is maintained during loading at the bend of the contour but a large vertical displacement still occurs where the reinforcement thins from the nozzle/valve buildup. Due to the maintained contour at the isotensoid bend, the large compressive principal stress in this region has diminished except for the extreme exterior. 


\section{$\underline{\text { Hemispherical - Metallic Boss Insert (Steel and Al. models) }}$}

Application of the boss insert to the hemispherical dome is shown in Figure 7.13. The displacement is a maximum at the cylinder-dome juncture and is again attributed to the discontinuity in the radial stiffness at point where the hoop reinforcement changes to helical winding. Disregarding the stress concentration from the change in orientation from helical to hoop winding, the principal stresses are in proximity to the fiber failure strength.

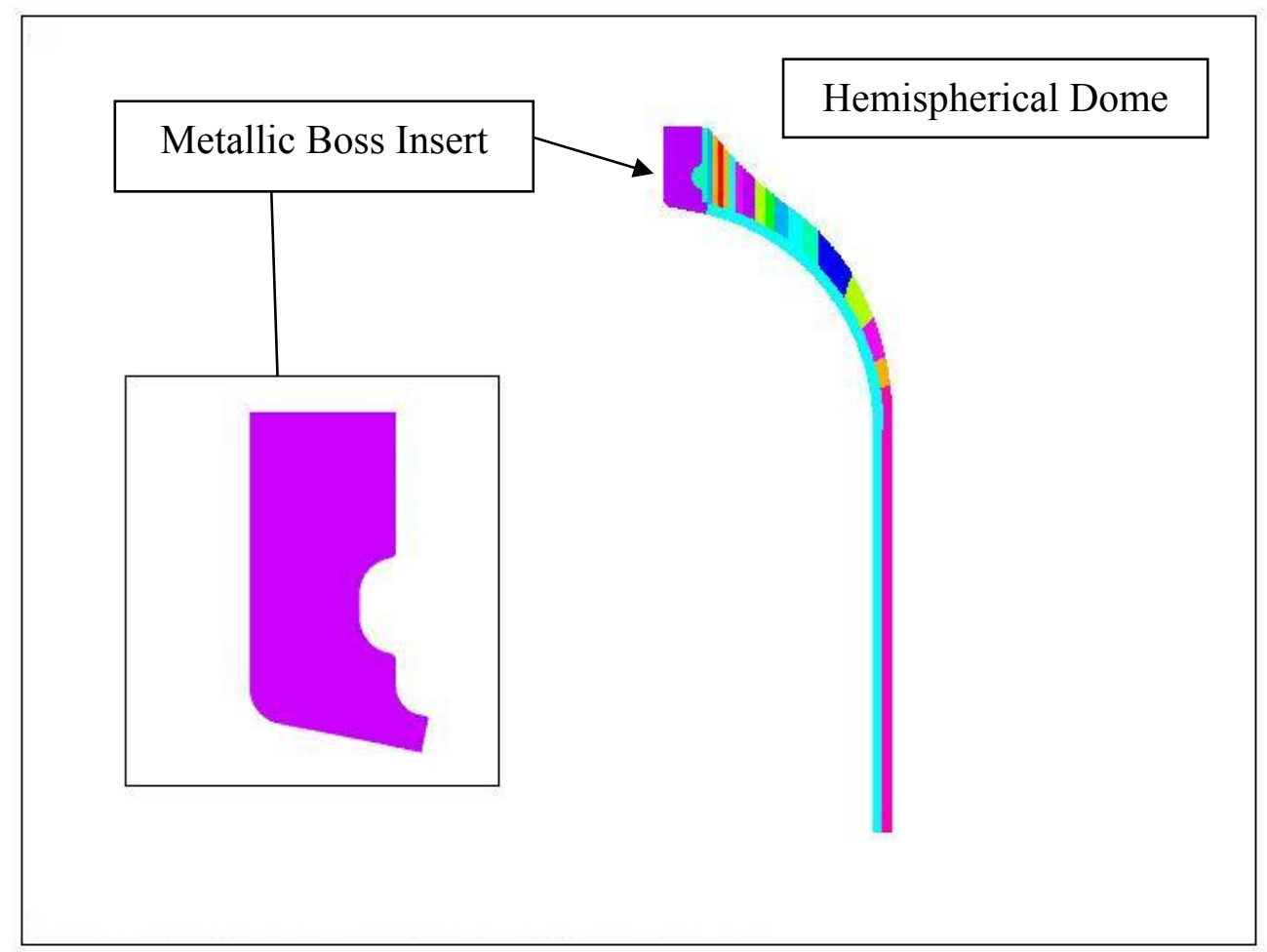

(a) 


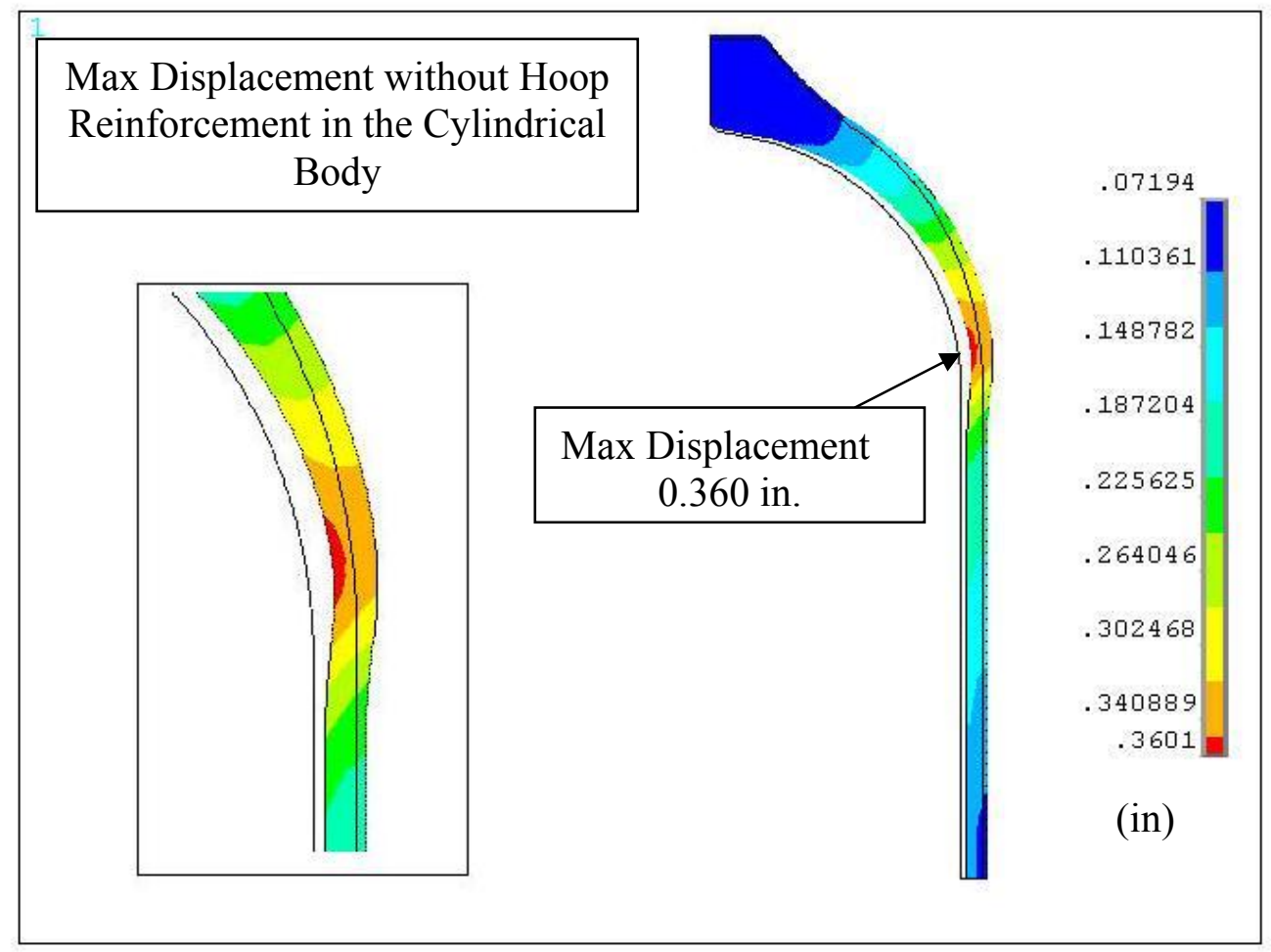

(b)

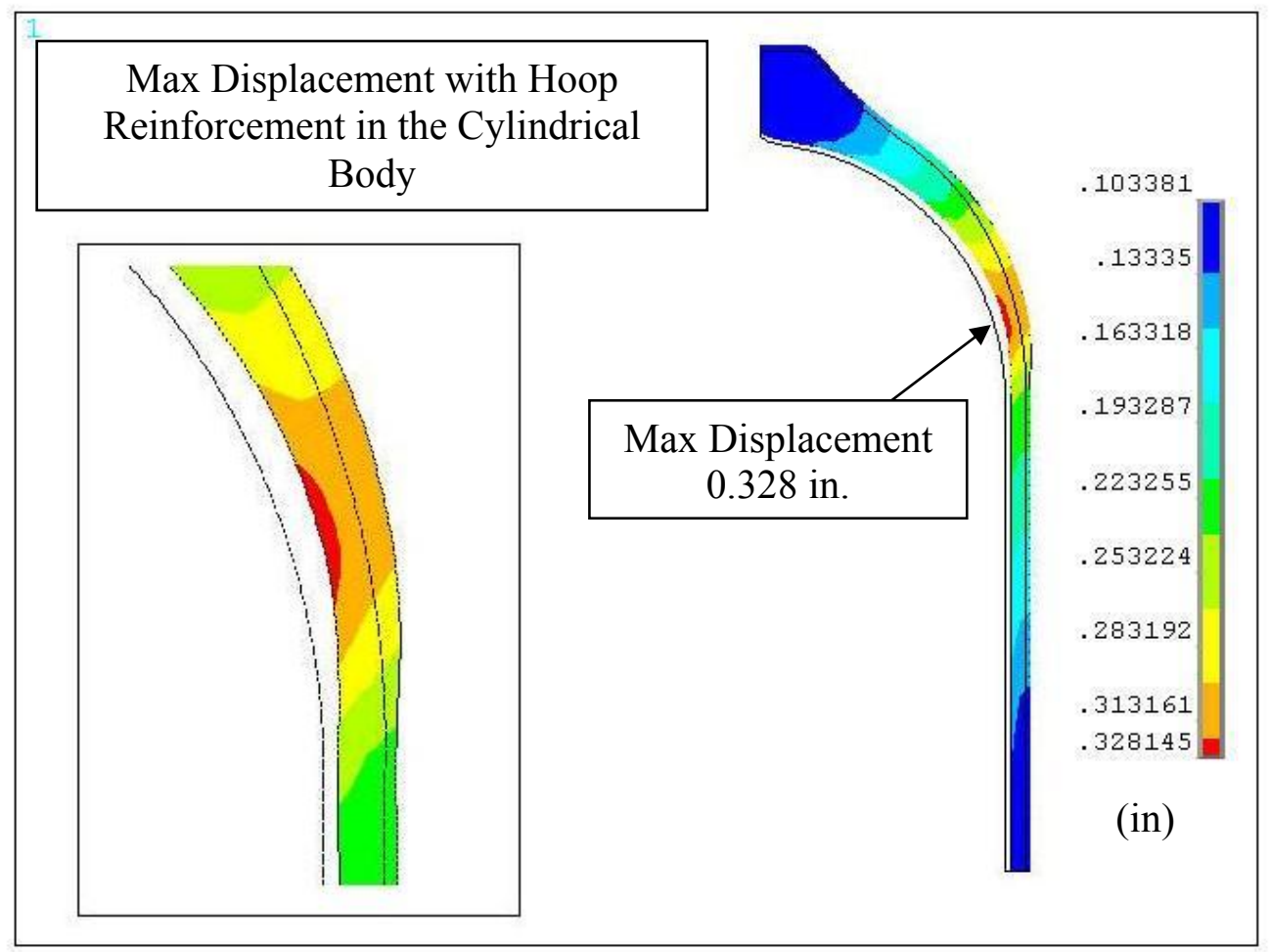

(c) 


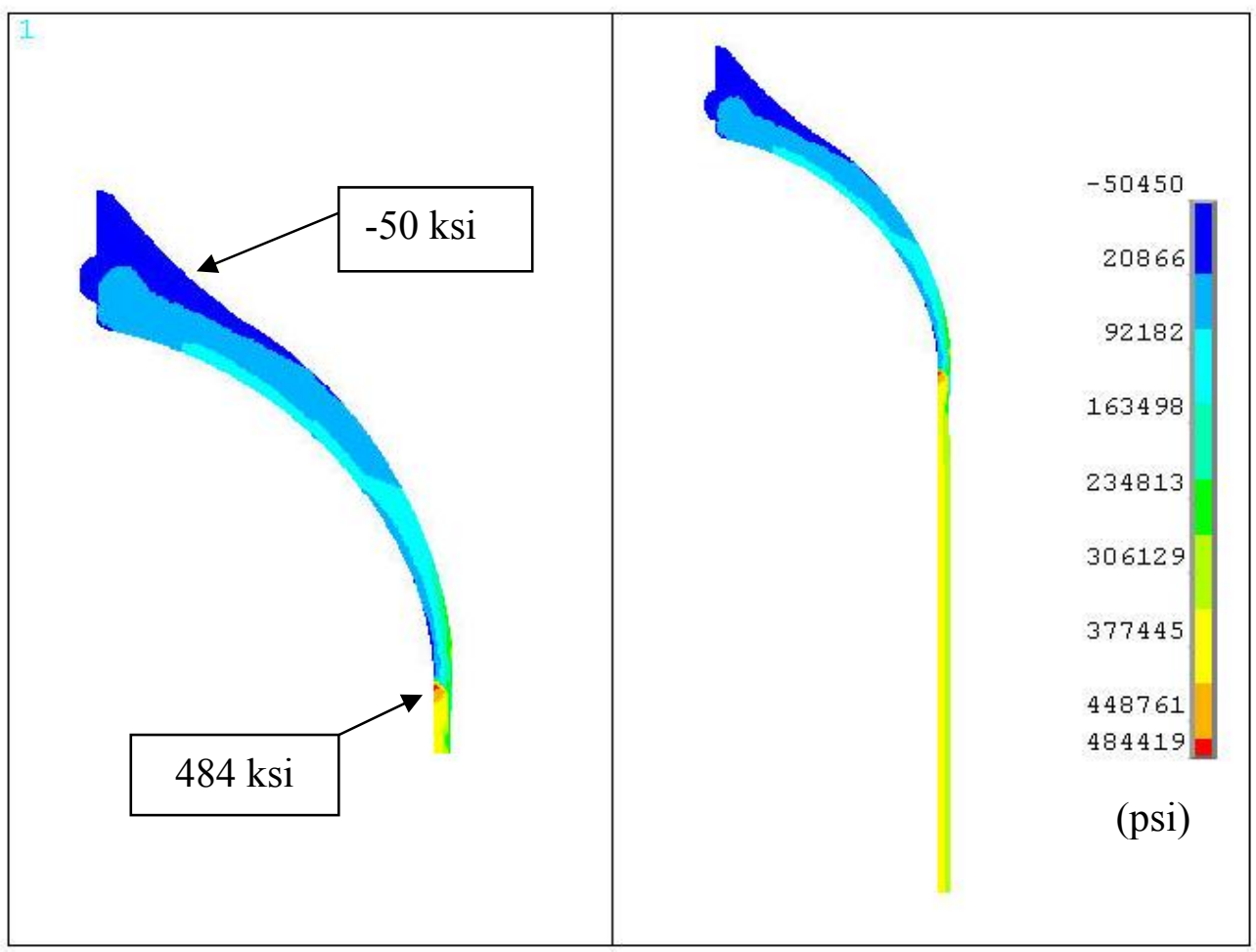

(d)

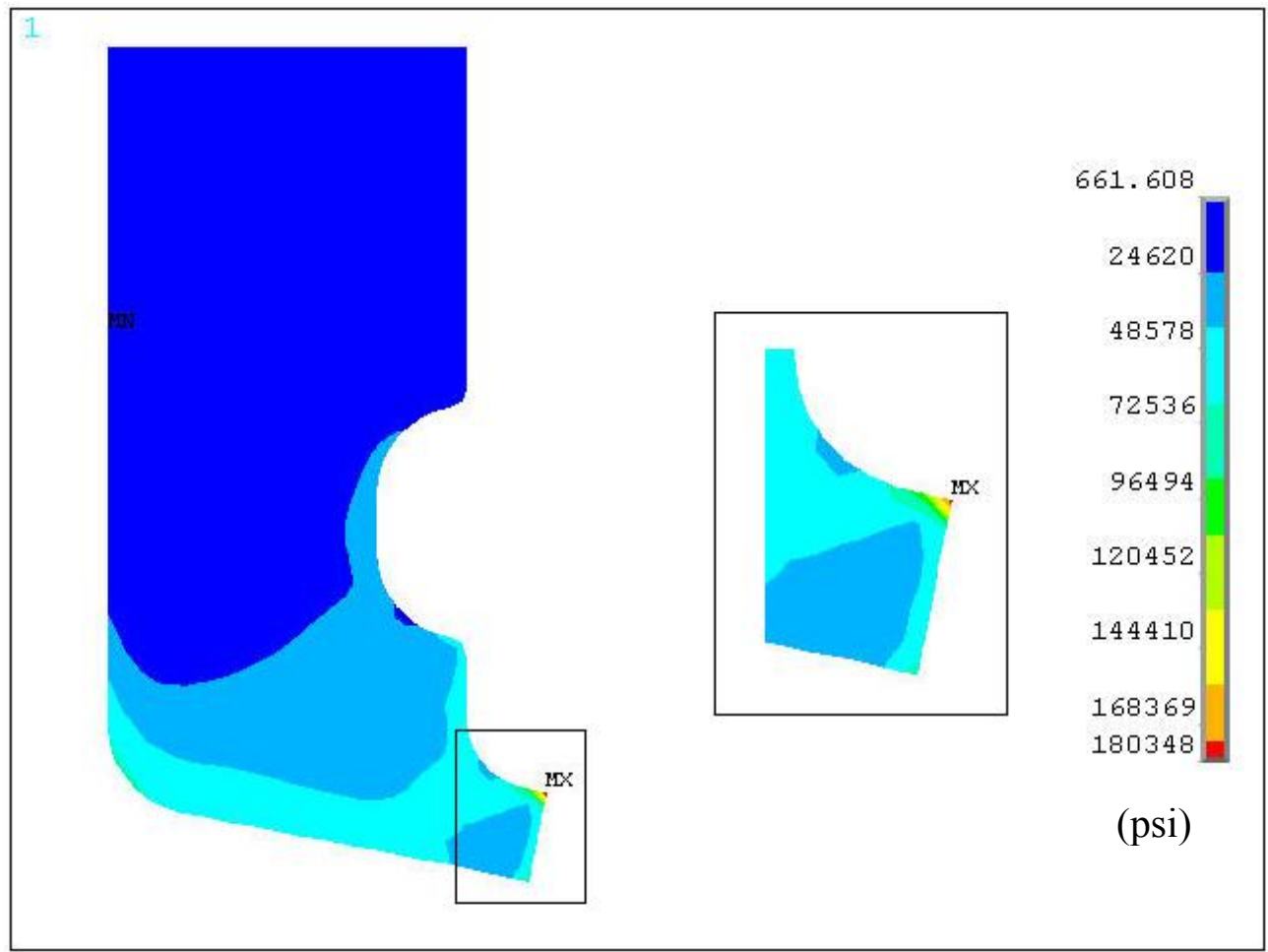

(e)

Figure 7.13: Hemispherical dome with metallic insert (a) geometry with inset of insert (b) displacement without tapering of hoop reinforcement (c) displacement with tapering of hoop reinforcement (d) stress in the fiber directions (e) equivalent stress of aluminum boss insert. 


\begin{tabular}{|c|c|c|c|}
\hline & Effective Stress (ksi) & Strength (ksi) & $\boldsymbol{\sigma}_{\mathbf{u}} / \boldsymbol{\sigma}$ \\
\hline Fiber & 484 & 334 & $334 / 484=0.69$ \\
\hline Metallic Insert Al. & 180 & 65 & $65 / 180=0.36$ \\
\hline Metallic Insert Steel & 242 & 75 & $75 / 242=0.31$ \\
\hline
\end{tabular}

The configurations of the isotensoid and hemispherical domes with different liner geometries, such as, full body metallic liner, long aluminum insert to the cylinder dome juncture and containment of the metallic insert to the boss region exhibited failure in the metallic liner or insert system at an internal pressure of 10,000 psi. The exterior filament wound composite reinforcement, in most cases, was maintained to the designed ultimate tensile and compressive strengths of $334 \mathrm{ksi}$ and $261 \mathrm{ksi}$, respectively. Optimizing by the addition of hoop fibers and tapering of hoop oriented fibers into the initial dome contour.

Further evaluation into failure of the metallic liner system or insert to serve as a connection to the nozzle/valve configuration was performed. Different candidate materials were selected and analyzed in the finite element analysis to determine if failure would still occur. Also, the liner system was analyzed under and increased thickness to two times the 0.2 in. initial thickness.

The candidate materials used and their properties are listed in the following tables:

Table 7.6: Material Properties for Ti-6Al-4V Titanium Ref: Collins, 2003

\begin{tabular}{ccc}
\hline & SI Units & US Customary \\
Property & $120 \mathrm{GPa}$ & $17 \times 10^{6} \mathrm{psi}$ \\
$\mathrm{E}$ & $44 \mathrm{GPa}$ & $6.2 \times 10^{6} \mathrm{psi}$ \\
$\mathrm{G}$ & $1,000 \mathrm{MPa}$ & $150 \times 10^{6} \mathrm{psi}$ \\
$\sigma_{\mathrm{u}}$ & 0.36 & 0.36 \\
$v$ & $4.43 \mathrm{~g} / \mathrm{cm}^{3}$ & $0.160 \mathrm{lb} / \mathrm{in}^{3}$ \\
\hline
\end{tabular}


Table 7.7: Material Properties for Am 1004-T61 Magnesium Alloy. Ref: Collins, 2003

\begin{tabular}{ccc}
\hline & SI Units & $\begin{array}{c}\text { US Customary } \\
\text { Units }\end{array}$ \\
\hline $\mathrm{E}$ & $44.7 \mathrm{GPa}$ & $6.48 \times 10^{6} \mathrm{psi}$ \\
$\mathrm{G}$ & $18.0 \mathrm{GPa}$ & $2.5 \times 10^{6} \mathrm{psi}$ \\
$\sigma_{\mathrm{u}}$ & $152 \mathrm{MPa}$ & $40 \times 10^{6} \mathrm{psi}$ \\
$v$ & 0.30 & 0.30 \\
Density & $1.83 \mathrm{~g} / \mathrm{cm}^{3}$ & $0.066 \mathrm{lb} / \mathrm{in}^{3}$ \\
\hline
\end{tabular}

Table 7.8: Material Properties for AM 350 Stainless Steel. Ref: Collins, 2003

\begin{tabular}{ccc}
\hline & SI Units & $\begin{array}{c}\text { US Customary } \\
\text { Units }\end{array}$ \\
\hline Property & $193 \mathrm{GPa}$ & $28.0 \times 10^{6} \mathrm{psi}$ \\
$\mathrm{G}$ & $68.9 \mathrm{GPa}$ & $10.6 \times 10^{6} \mathrm{psi}$ \\
$\sigma_{\mathrm{u}}$ & $1,420 \mathrm{MPa}$ & $206 \times 10^{6} \mathrm{psi}$ \\
$v$ & 0.31 & 0.31 \\
Density & $7.86 \mathrm{~g} / \mathrm{cm}^{3}$ & $0.284 \mathrm{lb} / \mathrm{in}^{3}$ \\
\hline
\end{tabular}

Table 7.9: Material Properties for AISI UHS 4340 Ultra High Strength Steel. Ref: Collins, 2003

\begin{tabular}{ccc}
\hline & SI Units & $\begin{array}{c}\text { US Customary } \\
\text { Units }\end{array}$ \\
\hline Property & $207 \mathrm{GPa}$ & $30.0 \times 10^{6} \mathrm{psi}$ \\
$\mathrm{G}$ & $79.2 \mathrm{GPa}$ & $11.5 \times 10^{6} \mathrm{psi}$ \\
$\sigma_{\mathrm{u}}$ & $1,979 \mathrm{MPa}$ & $287 \times 10^{6} \mathrm{psi}$ \\
$v$ & 0.27 & 0.27 \\
Density & $7.86 \mathrm{~g} / \mathrm{cm}^{3}$ & $0.284 \mathrm{lb} / \mathrm{in}^{3}$ \\
\hline
\end{tabular}

Utilizing the material properties listed in Tables 7.7 through 7.9, an investigative study into the metallic insert liner systems was completed. The study determined what combination of geometry and material could prevent failure in the metallic liner. The results for the isotensoid and hemispherical dome shapes of a 6 in. internal radius COPV are listed in Table 7.10. 
Table 7.10: Analysis for Liner Systems of Isotensoid and Hemispherical Dome Shapes of a COPV with 6 inch Internal Radius

\begin{tabular}{|c|c|c|c|c|c|c|}
\hline Dome & Liner & $\begin{array}{l}\text { Thickness } \\
\text { (in) }\end{array}$ & Material & Failure & $\begin{array}{c}\text { Failure } \\
\text { Location }\end{array}$ & $\sigma_{\mathbf{u}} / \boldsymbol{\sigma}$ \\
\hline Isotensoid & Full & 0.2 & Al 2014-T6 & Yes & Bend & 0.256 \\
\hline Isotensoid & Full & 0.4 & Al 2014-T6 & Yes & Bend & 0.367 \\
\hline Isotensoid & Full & 0.4 & Ti-6A1-4V & Yes & Bend & 0.725 \\
\hline Isotensoid & Full & 0.4 & Am 1004-T61 & Yes & Bend & 0.258 \\
\hline Isotensoid & Dome & 0.2 & Al 2014-T6 & Yes & Bend & 0.267 \\
\hline Isotensoid & Dome & 0.4 & Al 2014-T6 & Yes & Bend & 0.378 \\
\hline Isotensoid & Dome & 0.4 & 304 Stainless & Yes & Bend & 0.329 \\
\hline Isotensoid & Dome & 0.4 & 350 Stainless & At & Bend & 0.903 \\
\hline Isotensoid & Dome & 0.4 & AISI UHS 4340 & No & & 1.260 \\
\hline Isotensoid & Dome & 0.4 & Ti-6A1-4V & Yes & Bend & 0.725 \\
\hline Isotensoid & Dome & 0.4 & Am 1004-T61 & Yes & Bend & 0.274 \\
\hline Isotensoid & Boss & NA & Al 2014-T6 & Yes* & $\mathrm{SC}$ & 0.238 \\
\hline Isotensoid & Boss & NA & 304 Stainless & Yes* & Gen. & 0.232 \\
\hline Isotensoid & Boss & NA & 350 Stainless & Yes* & $\mathrm{SC}$ & 0.638 \\
\hline Isotensoid & Boss & NA & AISI UHS 4340 & Yes* & $\mathrm{SC}$ & 0.889 \\
\hline Isotensoid & Boss & NA & Ti-6A1-4V & Yes* & $\mathrm{SC}$ & 0.459 \\
\hline Isotensoid & Boss & NA & Am 1004-T61 & Yes & Gen. & 0.183 \\
\hline Hemispherical & Full & 0.2 & Al 2014-T6 & Yes & Cylinder & 0.345 \\
\hline Hemispherical & Full & 0.4 & Al 2014-T6 & Yes & Cyl-Dome & 0.571 \\
\hline Hemispherical & Full & 0.4 & Ti-6A1-4V & No & & 1.20 \\
\hline Hemispherical & Full & 0.4 & Am 1004-T61 & Yes & Cylinder & 0.354 \\
\hline Hemispherical & Dome & 0.2 & Al 2014-T6 & Yes* & Cyl-Dome & 0.475 \\
\hline Hemispherical & Dome & 0.4 & Al 2014-T6 & Yes* & Cyl-Dome & 0.531 \\
\hline Hemispherical & Dome & 0.4 & 304 Stainless & Yes* & Cyl-Dome & 0.361 \\
\hline Hemispherical & Dome & 0.4 & 350 Stainless & $\mathrm{At}^{*}$ & Cyl-Dome & 0.990 \\
\hline Hemispherical & Dome & 0.4 & AISI UHS 4340 & No & & 1.260 \\
\hline Hemispherical & Dome & 0.4 & Ti-6A1-4V & Yes* & Cyl-Dome & 0.890 \\
\hline Hemispherical & Dome & 0.4 & Am 1004-T61 & Yes* & Cyl-Dome & 0.533 \\
\hline Hemispherical & Boss & NA & Al 2014-T6 & Yes* & $\mathrm{SC}$ & 0.378 \\
\hline Hemispherical & Boss & NA & 304 Stainless & Yes* & $\mathrm{SC}$ & 0.310 \\
\hline Hemispherical & Boss & NA & 350 Stainless & Yes* & $\mathrm{SC}$ & 0.851 \\
\hline Hemispherical & Boss & NA & AISI UHS 4340 & No & & 1.19 \\
\hline Hemispherical & Boss & NA & Ti-6A1-4V & Yes* & $\mathrm{SC}$ & 0.690 \\
\hline Hemispherical & Boss & NA & Am 1004-T61 & Yes* & $\mathrm{SC}$ & 0.320 \\
\hline
\end{tabular}

* - Stress concentration is present

Full - A full body liner occupying the complete interior of the pressure vessel

Dome - Insert extends from the boss through dome to the cylinder-dome juncture

Boss - Insert contained in the boss region only.

Bend - Bend location of the isotensoid dome

$\mathrm{SC}-$ Stress concentration

NA- Not available, dimensions of metallic insert are shown in Figure 7.12(a). 
The selections of Table 7.10 which are highlighted in green are the four configurations which do not fail by the comparison of the equivalent Von Mises stress to the ultimate strength of the applied material as determined by the applied finite element analysis.

\subsection{Results and Discussion}

In this section, several finite element models were created and analyzed. The motivation of this study was to take the prior knowledge of manufacturing methods and a more intricate understanding of filament winding such as winding patterns, thickness criteria to study a comparison between different dome contours. The specifics from netting analysis and isotensoid theory provided the knowledge for inputs into finite element modeling.

The path of optimization for each design started with proper representation of loading, boundary conditions and material representation. The first analysis simply replicated an isotensoid vessel with an interior radius of 6.0 in., initial winding angle of $15^{\circ}$, helical thickness of $0.1 \mathrm{in}$ and hoop thickness of $0.15 \mathrm{in}$. The thickness dimensions were calculated from netting analysis to withstand an internal pressure of 10,000 psi. For the models to represent the theory the output results will be at the allowable stress of the material. The allowable stress for T800 / Epoxy carbon fiber is 334 ksi (tension) and 261 ksi (compression) as a lamina.

Initially, the isotensoid dome was compared with a traditional hemispherical model. Both models used an HDPE liner and were analyzed with and without hoop reinforcement. The results showed a large displacement in the cylindrical body when hoop fibers were not present. Applying hoop fibers decreased the displacement in the cylindrical body by $70 \%$. However, addition of hoop reinforcement in the body of the vessel increased the axial displacement in the dome region.

A full aluminum liner was studied in both the isotensoid and hemispherical designs. Aluminum liners have failed for high pressure containment by hydrogen embrittlement creating premature failure and by wall thinning in the dome region. The full aluminum liners proved beneficial for reducing the displacements in both the dome and the cylindrical regions of both the isotensoid and hemispherical designs. The 
displacement in the isotensoid design was further decreased by $71 \%$ ( 0.531 in. to 0.163 in.) and the maximum principal stress was reduced to $205 \mathrm{ksi}$, well under the allowable of 334 ksi. However, the interior region of the aluminum liner has an equivalent stress greater than the ultimate strength of the liner, inducing failure in the part. This observation initiated the concept of maintaining the aluminum liner solely in the dome region for bending resistance and replacing the cylindrical section of the aluminum liner with hoop oriented fibers. This design is manufactured by shear forming the liner to the length where the cylinder meets the dome then rotational molding an HDPE interior to complete the mandrel structure.

The alteration of only extending the aluminum liner to cylinder-dome juncture increased the displacement from 0.131 in. to 0.181 in. while maintaining the principal stress levels (170-180 ksi) of the isotensoid dome with a full-body aluminum liner. The hoop oriented fibers were now shown to carry the e hoop stress, attaining a maximum of $173 \mathrm{ksi}, 1.93$ times within the fiber failure strength.

Applying the long aluminum insert to the hemispherical dome reduced the equivalent stress in the aluminum by $27 \%$. The hoop fibers in the cylindrical body are now carrying the hoop stress with a maximum value of $221 \mathrm{ksi}$. However, the stiffness in the hoop region due to the added hoop fibers creates a large displacement at the cylinderdome juncture at the immediate end of the hoop reinforcement.

The concept to limit the metallic insert to the boss region is made feasible by utilizing the fiber orientation at the boss which is tangent to the surface and oriented in a $90^{\circ}$ hoop direction. These hoop oriented fibers are wound around an annular ring milled from the insert during manufacturing. This connection mechanism makes feasible the use of stainless steels or more dense metals as a structural connection since the metallic volume is minimized resulting in a minimal weight penalty. The axial deformation is increased in the isotensoid dome region, as predicted by netting analysis, without any load-carrying structural liner in the body and dome, the fiber filaments are slightly above the fiber allowable strength. 


\section{Chapter 8}

\section{Conclusions}

This work has studied the current development of compressed gas hydrogen storage systems and the progressions and limitations within this field of study. Development of a compressed gas hydrogen system initiated with closed form solutions of the resultant forces in the hoop and axial directions and the corresponding thickness requirements to maintain the internal pressure loading for candidate materials. Using the closed form solutions as a starting point, initial finite element models applying shell elements to cylindrical and spherical geometries without openings at the polar boss regions were developed and analyzed. The analysis showed a dependency on the fiber orientation and prompted further evaluation.

Shape optimization studies proved the benefit of the spherical design as a loadbearing pressure vessel. Due to unavailable means to manufacture and experimentally test a composite overwrapped pressure vessel design, a full pressure vessel experimental analysis could not be performed. Experimental studies were performed testing coupon specimens of the required vessel thickness and thus proving the strength of the hand fabricated structure as limited compared to automated manufacturing. Even without confirmation from experimental validation, it is known that the hand fabricated design of a spherical and cylindrical prototype utilizing layered components is greatly inferior to advanced filament winding techniques.

A further investigation into filament winding and the applications of isotensoid and existing hemispherical configurations was initiated after the experimental work ceased. The goal of this endeavor was to utilize theory to completely understand the nature of a filament wound structure and to use this understanding as a means to model designs by finite element analysis.

A unique approach to analyzing filament wound composite pressure vessels through finite element analysis was utilized to study the isotensoid dome configuration 
for high internal pressure endeavors. The filament winding parameters such as dome shape, winding angle variation, and thickness contour were first derived from netting analysis and programmed through MATLAB software to determine the input for the finite element program. The finite element approach involved using two-dimensional axisymmetric modeling with composite material transformations to account for the change in winding angle and the initiation of local fiber coordinate systems to define the orientations with respect to the elements. Therefore, the post processing of results could directly be analyzed according to the fiber directions which corresponded with the axes of the local coordinate systems.

The derived method of finite element modeling was initiated due to constraints applied within ANSYS student version 11.0. This version of finite element software has a limited number of nodes and elements available to the user. To efficiently optimize the available elements and nodes, 2-D axisymmetric modeling to represent 3-D orthotropic material nature was innovated in conjunction with MATLAB programming. A properly refined mesh of elements through the cross section thickness was desired and achieved by this method of finite element modeling even when constrained by a limited node and element bank.

Applying the previously described method of finite element modeling, a comparative study between different liner and metallic insert configurations was performed. The study was to determine the effects of different prototype design configurations to house a metallic liner or insert required for a connection to the nozzle/valve structure. A full body liner, liner extending to the cylinder-dome juncture, and metallic insert contained in the boss were studied for both the isotensoid and hemispherical dome shapes. This analysis lead to a specific study into the liner systems composed of different candidate materials and local thicknesses.

The path of research, defined in the previous paragraphs, has drawn the following conclusions:

1. Preliminary analysis of axial and hoop forces occurring from internal pressure applied to cylindrical composite reinforced pressure vessels proved the effectiveness of carbon fiber and initialized the thickness dimensions required to 
conduct finite element modeling. Initial finite element modeling showed the dependency on fiber orientation to carry the applied internal pressure loading and induced stress. Applying $60 \%$ of the fiber orientations in an off-axis direction of $45^{\circ}$ to the vessel centroidal axis reduced axial displacements by $34 \%$. An allcomposite pressure was shown to carry the stress levels developed on the inner wall surface of the pressure vessel. The addition of a load-bearing aluminum liner which is implemented for gas permeation purposes and analyzed by finite element modeling. The preliminary evaluation proved the interior aluminum is susceptible to failure at elevated internal pressures.

2. Examination of netting analysis and isotensoid geometry determined the plotting and parameter input to analyze filament wound pressure vessels. MATLAB programming and ANSYS finite element modeling were used to attain analysis of composite reinforced pressure vessels by 2-D axisymmetric modeling. This approach allowed for the following analysis:

- Normalized parameters of isotensoid dome geometry including winding angle variation and thickness contour.

- Transformations of composite material properties with respect to the local coordinate system of the fibers in the exterior composite reinforcement.

- Comparative study between the isotensoid and hemispherical dome shapes and the method of each to house a metallic inlet/outlet valve connection.

- Liner systems analysis of candidate materials and dimensions to maintain stress levels below the material allowable stress.

3. The isotensoid dome geometry develops a high stress zone located in the midregion bend of the dome contour corresponding to the normalized $\mathrm{x}$-axial dimension range of $0.83-0.90$. The defined region undergoes a rapid change in slope of the dome geometry resulting in bending of a curved geometry. The critical stresses occur as interior tension and exterior compression. 
4. Maximum displacement of the isotensoid dome develops at the inflection point occurring at the change in slope of the dome meridian line. The displacement in this zone increases with stiffening of the cylindrical body.

5. The critical zone of the hemispherical dome contour occurs at the cylinder dome juncture. The stress and displacement attained in the cylinder-dome juncture increased when excessive hoop reinforcement (fibers oriented $90^{\circ}$ to the vessel centroidal axis). This result shows the optimization step of additional hoop reinforcement is discretionary for pressure vessel geometries.

6. Liner systems designed to carry $20 \%$ of the internal pressure exhibited failure in several models. An investigation into preventing failure by increasing the wall thickness by a factor of two and altering the liner material was performed. The results showed the insert/liner system with equivalent stress below the allowable stress occurred in the following designs:

- An isotensoid dome shape containing a 0.4 inch thick AISI 4340 ultra high strength steel insert extending to the cylinder dome juncture.

- A hemispherical dome shape with a full, 0.4 inch Ti-6A1-4V titanium liner.

- A hemispherical dome shape containing a 0.4 inch thick AISI 4340 ultra high strength steel insert extending to the cylinder dome juncture.

- A hemispherical dome shape containing an AISI 4340 ultra high strength steel boss insert.

7. From netting analysis theory, it was stated that the fiber directions of a filament wound pressure vessel on an isotensoid shaped mandrel will coincide with the orientations of principal stresses. This study has shown this to be true when the primary displacements occur from radial expansion, however, when out of the fiber plane bending is induced in the dome, a tension-and-compression distribution with respect to the interior and exterior filament winding locations occurs. 


\subsection{Future Work}

This work can be continued with by performing experimental validation of the pressure vessel systems analyzed throughout Chapter 7. The means to experimentally validate the designs shown in this work were not available. Experimental stress data attained along a meridian plane of the pressure vessels systems would provide a comparison to the resultants of the finite element output.

Additional study and emphasis should be given to the liner system based on a nonmetallic material in the body of the pressure vessel. Few metallic liner configurations exhibited structural integrity to withstand the applied internal pressures. Manufacturing and testing of the liner systems implemented within this work would determine the practicality and benefit for each concept. 


\section{References Cited}

1. Able, A.R. (2006). Quantum Hydrogen Storage Systems. Presentation at the ARB Zero Emission Vehicle Technology Symposium, Sacramento, California, USA.Website:

http://www.arb.ca.gov/msprog/zevprog/symposium/presentations/abele1_storage. pdf

2. Amaseder, F; Krianz, G., "Liquid Hydrogen Storage Systems developed and manufactured for the first time for Customer Cars" SAE 2006 World Congress Exhibition, April 2006.

3. Aström, B.T. (2002). Manufacturing Process, ASM Handbook Volume 21Composites. ASM International, Material Park, Ohio, USA.

4. Barbero, E. (1999). Introduction to Composite Material Designs. Taylor and Francis, Philadelphia, Pennsylvania, USA.

5. Bogdanovic, B. and Schwickardi, M. Ti-Doped NaAlH4 as a Hydrogen Storage Material-prerparation by Ti-catalyzed hydrogenation of Aluminum Powder in conjunction with Sodium Hydride, Applied Physics, A 72, 221-223, 2001.

6. Coguill, S., Galbraith, S., Tuss, D., Thermal Spray Formation of Polymer Coatings. John H. Glenn Research Center, 2008.

7. Collins, J., Mechanical Design of Machine Elements and Machines - A Failure Prevention Perspective, John Wiley \& Sons, 2003.

8. Crawford, R., Rotational Moulding of Plastics. 2002.

9. Daimler Chrysler (2006). A Zero Emission Future-Vehicles with Hydrogen and Fuel Cell Technology. Daimler Chrysler AG.

10. Daimler Chrysler (2008). Designs for Tomorrow - New Inspirations from Mercedes Benz Advanced Design Studio in California. Daimler HighTech Report 1/2008, Daimler Chrysler AG.

11. Delay, T., Making a Metal-Lined Composite Overwrapped Pressure Vessel. Marshall Space Flight Center, Al., 2005.

12. Dubno, W. (2007). Low Cost, High Efficiency, High Pressure Hydrogen Storage. FY 2007 Annual Progress Report on DOE Hydrogen Program, U.S. Department of Energy, Washington, D.C., pp. 608-610. 
13. Dunn, B., "Space Storage of Liquid Hydrogen and Liquid Oxygen" Future Orbital Transfer Vehicle Technology Stud, V. II, November 2001.

14. Eichenberg, D., The Fuel Cell Powered Club Car Carryall. 2005 National Aeronautics and Space Aministration, Glenn Research Center.

15. Green Car Congress.com"BMW to Display Liquid Hydrogen Storage Systems and Bi-fuel Engine at NHA 2006”, Green Car Congress, March,2006. $\mathrm{http}: / / w w w . g r e e n c a r c o n g r e s s . c o m / 2006 / 03 / \mathrm{bmw} t$ to_display_html.

16. Hibbeler, R.C., Mechanics of Materials, $6^{\text {th }}$ Edition, Pearson Prentice Hall, Upper Saddle River, NJ, 2005.

17. Honda (2008). The Zero-Emission Sedan of the Future-A Reality Today. American Honda Motor Co., Inc., Website: http://automobiles.honda.com/fcxclarity/

18. Kabir, M., Finite Element Analysis of Composite Pressure Vessels with a Load Sharing Metallic Liner, Composite Structures, vol. 49, pp. 247-255, 2000.

19. Kim, C., Kang, J., Hong, C., Optimal design of filament wound structures under internal pressure based on the semi-geodesic path algorithm. Composite Structures vol. 67 pp. $443-452,2005$.

20. Kirchheim, R.; Mutschele, T.; Kieninger, W (1988). "Hydrogen in amorphous and nanocrystalline metals". Materials Science and Engineering 99: 457-462. doi:10.1016/0025-5416(88)90377-1

21. Ko, J., K. Newell, B. Geving and W. Dubno (2004). Low Cost Efficiency, High Pressure Hydrogen Storage. FY 2005 Annual Progress Report on DOE Hydrogen Program, U.S. Department of Energy, Washington, D.C., pp. 653-656.

22. Ko, J., K. Newell, B. Geving and W. Dubno (2005). Low Cost Efficiency, High Pressure Hydrogen Storage. FY 2005 Annual Progress Report on DOE Hydrogen Program, U.S. Department of Energy, Washington, D.C., pp. 653-656.

23. Krainz, G., P. Hödl, and F. Hofmister (2004). Automotive Production of Liquid Hydrogen Storage Systems. Proceedings of the International German Hydrogen National Energy Congress, Essen, Germany.

24. Larminie, James; Dicks, Andrew. Fuel Cell Systems Explained

25. Lee, D.G. and N.P. Suh (2006). Axiomatic Design and Fabrication of Composite Structures: Applications in Robotics, Machine Tools, and Automobiles. Oxford Series on Advanced Manufacturing, Oxford University Press, New York, USA. 
26. Lee, N., Blow Molding Design Guide. Cincinnati, Hanser/Gardner Publications. 1998

27. Mallick, P.K. (1993). Fiber-Reinforced Composites: Materials, manufacturing and Design-Second Edition. Marcel Deckker, New York.

28. Meade, L.E., "Fabrication of Advanced Composites," Handbook of Composites.

29. Lockheed Aircraft, Marietta, GA. pp 491-513, 1982.

30. Murray, C., Newhouse, N., Schimenti,J. "Development of Composite Pressure Vessels with Nonmetallic Liners", AIAA Joint Propulsion Conference, Nashville, TN. 1992.

31. Niera, J.E., and A.C. Schudelari (2005). A Sudy of Non-Traditional Geometries and Alternative Alloys for NGV Storage Gas Tanks. Proceedings of the $18^{\text {th }}$ International Congress of Mechanical Engineering, Brazilian Society of Mechanical Sciences and Engineering ABCM, Ouro Preto, Brazil.

32. Newhouse, N., "ASME Standards Development for High Pressure Composite Hydrogen Pressure Vessels in Section X," ASME/UCSG Marine Technology Conference, June, 2004.

33. Park, J., Kim, C., and Hong, C., "Structural Analysis and Strain Monitoring for the Filament Wound Motor Case", Journal of Composite Materials, 36, p. 2373 2388.

34. Peschka, W., "State of Hydrogen Cryofuel Technology for Internal Combusion Engines", "Hypothesis" Conference, Grimstad, Norway, August 1997.

35. Peters, S.T., W.D. Humphrey, and R.F. Foral (1991). Filament Winding Composite Structure Fabrication- $2^{\text {nd }}$ Edition. SAMPE Publication, Covina California, USA.

36. Rogers, H. C. (1999). "Hydrogen Embrittlement of Metals". Science 159 (3819): 1057-1064. doi: $10.1126 /$ science.159.3819.1057

37. Rosato, R. Blow Molding Handbook. Munich Vienna, NY. 1989.

38. Rosato, D., Plastics Engineering, Manufacturing and Data Handbook. Springer, 2001.

39. Sarkar, A., and R. Banerjee (2005). Net Energy Analysis of Hydrogen Storage Options. International Journal of Hydrogen Energy, Elsevier, Vol. 30, pp. 867877. 
40. Shen, F.C. (1995). A Filament-Wound Structure Technology Overview. Materials Chemistry and Physics, Vol. 42, No. 2, pp. 96-100.

41. Sirosh, N. (2002). Hydrogen Composite Tank Program. Proceedings of the 2002 U.S. DOE Hydrogen Program Review. NREL/CP-610-32405.

42. Slobodzinsky, A., Bag Molding Processes, Handbook of Composites. PLASTEC, Picatinni Arsenal, Dover, NJ. pp 368-390, 1982.

43. Song, M., Weiqiang, W., Yafan, Z., "Urea Reactor Integrity Evaluation Based on Failure Analysis," Journal of Pressure Vessel Technology, v. 129, November 2007.

44. Stanley, D., "ECD-Ovonics Tests Solid Storage in Prius Hybrid," Hydrogen Forecast, May 2006.

45. Starr, T.F. Structural Applications for Pultruded Profiles, Composite Structures 2, Applied Science Publishers, London, pp. 192-211, July 2000.

46. Strubel, V. (2006). Hydrogen Storage Systems for Automotive Applications. Periodic Activity Report No. 502667, MAGNA STEYR Fahrzeugtechnik AG \& CO KG.

47. http://www.storhy.net/pdf/StorHy_SecondActivityReport_PublishableExecutiveS ummary_V3.pdf

48. "The Hydrogen Economy: Opportunites, Costs, Barriers, and R\&D Needs”, 2004.

49. Todd, R., Manufacturing Processes References Guide, Industrial Press, 1994.

50. Velosa, J., Nunes, P., Antunes, P., Development of a new generation of filament wound composite pressure cylinders, Science and Technology of Materials, vol. $19,2007$.

51. Veys, R.B., A.R. Cederberg, and D.B. Tiller (1989). Design and Development of an Aluminum Lined Composite Overwrapped Spherical Pressure Vessel. AIAA89-2642, ASME, SAE, and ASEE, Joint Propulsion Conference, 25th, Monterey, California, USA.

52. Wald, Mathew L.; "Questions About a Hydrogen Economy” Scientific American. May 2004.

53. Wronzki, Z., Materials for rechargeable batteries and clean hydrogen energy sources, International Materials Review (USA), vol. 46, no. 1, 2001 
54. Young, Robert, P., Thermoset Matched Die Molding, Handbook of Composites, Associates Brooklyn, NY, pp 391-448, 1982

55. Yurum, Y., Hydrogen Energy Systems: Production and utilization of hydrogen and future aspects, Fuel and Energy Abstracts. vol. 37, no. 3, 1996.

56. Zittel, W., Wurster, R.; "Hydrogen in the Energy Sector" Issue 8.7.1996 


\section{Appendix A: MATLAB Input Code - Isotensoid Analysis}

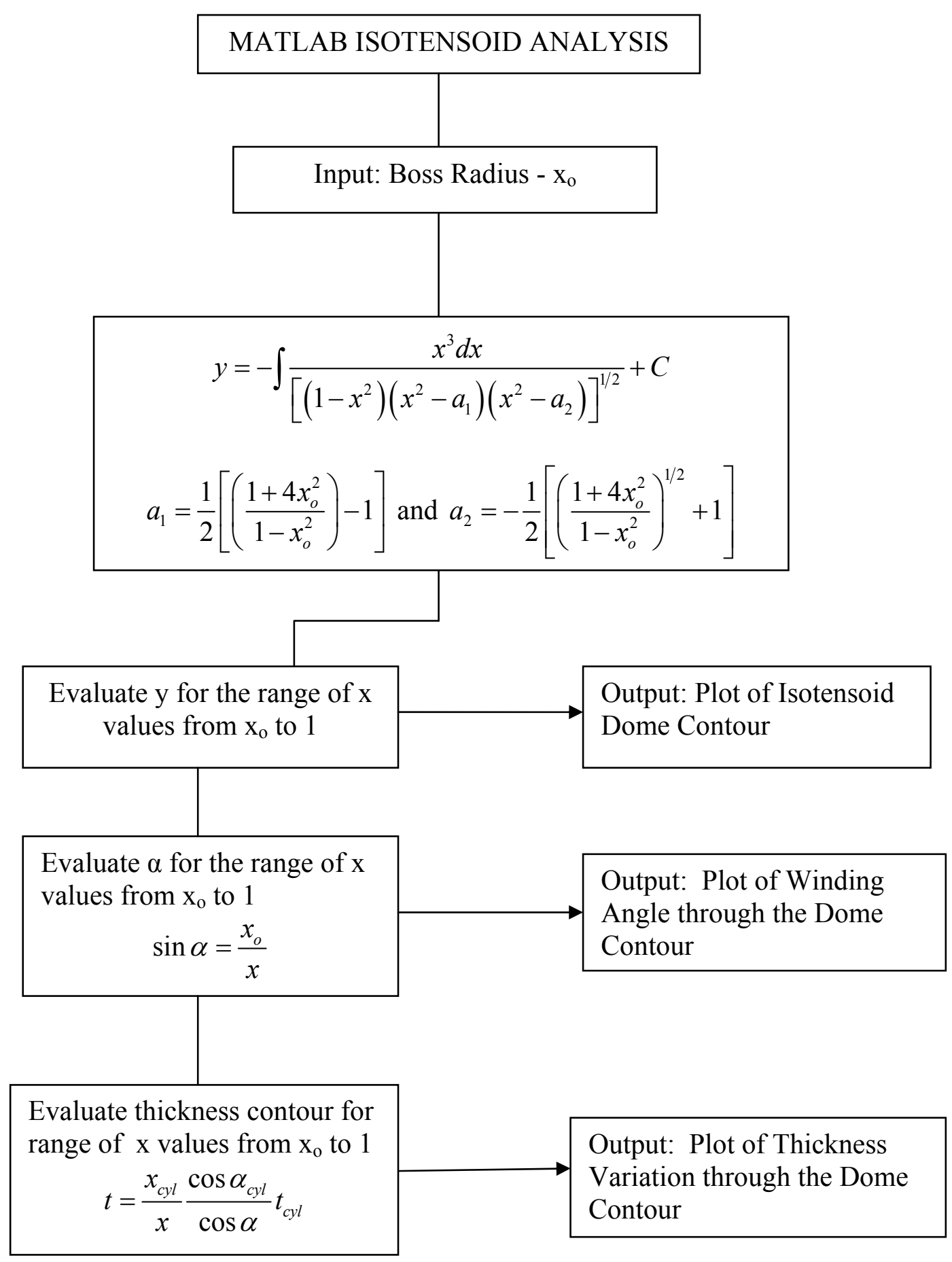


The code presented in this section determines the normalized isotensoid dome contour, the winding angle variation and thickness contour. The program was written using MATLAB 7.0. Comments are preceded by the percent symbol, \%.

\author{
$\%$ Dome Geometry \\ clear \\ clc
}

syms $\mathrm{x}$

$\mathrm{Xo}=0.25 \%$ boss radius

a1 $=1 / 2 *\left(\operatorname{sqrt}\left(\left(1+\left(4 *\left(\mathrm{Xo}^{\wedge} 2\right)\right) /\left(1-\left(\mathrm{Xo}^{\wedge} 2\right)\right)\right)\right)-1\right)$

$\mathrm{a} 2=-1 / 2 *\left(\operatorname{sqrt}\left(\left(1+\left(4 *\left(\mathrm{Xo}^{\wedge} 2\right)\right) /\left(1-\left(\mathrm{Xo}^{\wedge} 2\right)\right)\right)\right)+1\right)$

$y=-\operatorname{int}\left(x^{\wedge} 3 /\left(\left(\left(1-x^{\wedge} 2\right)^{*}\left(x^{\wedge} 2-a 1\right) *\left(x^{\wedge} 2-a 2\right)\right)^{\wedge} 1 / 2\right)\right)$

$\mathrm{n}=0$;

for $\mathrm{xval}=0.25: .001: 0.999$

$$
\mathrm{n}=\mathrm{n}+1 \text {; }
$$

$\mathrm{X}(\mathrm{n})=\mathrm{xval}$;

$Y(n)=\operatorname{subs}(y, x, x v a l)+22.1851966$;

end

figure(1)

axes1 = axes('XGrid','on','YGrid','on');

\%xlim(axes1,[0 6]);

\%ylim(axes1,[0,4]);

hold(axes1,'all');

$\operatorname{plot}(\mathrm{X}, \mathrm{Y} / 3.95) \quad \%(\mathrm{Y} / 3.95))$

title('Isotensoid Dome Contour')

xlabel('Normalized Radial Distance')

ylabel('Normalized Longitudinal Distance') 


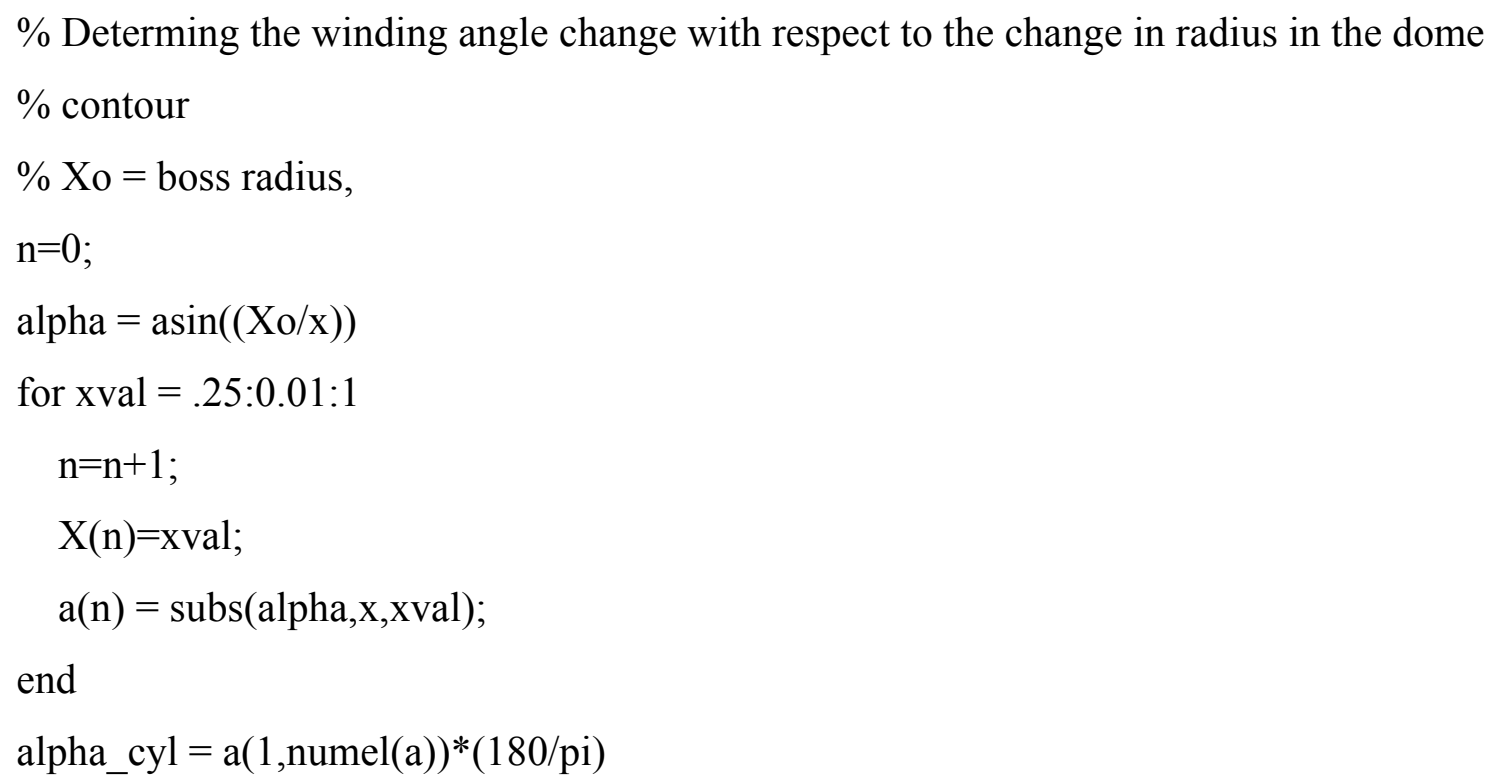


$\operatorname{plot}(X(10: n), t(10: n))$

title('Change in Filament Wound Thickness of Dome Contour')

xlabel('Axial Coordinate - x')

ylabel('Thickness') 


\section{Appendix B: MATLAB Input Code - Fiber Material Property Transformations}

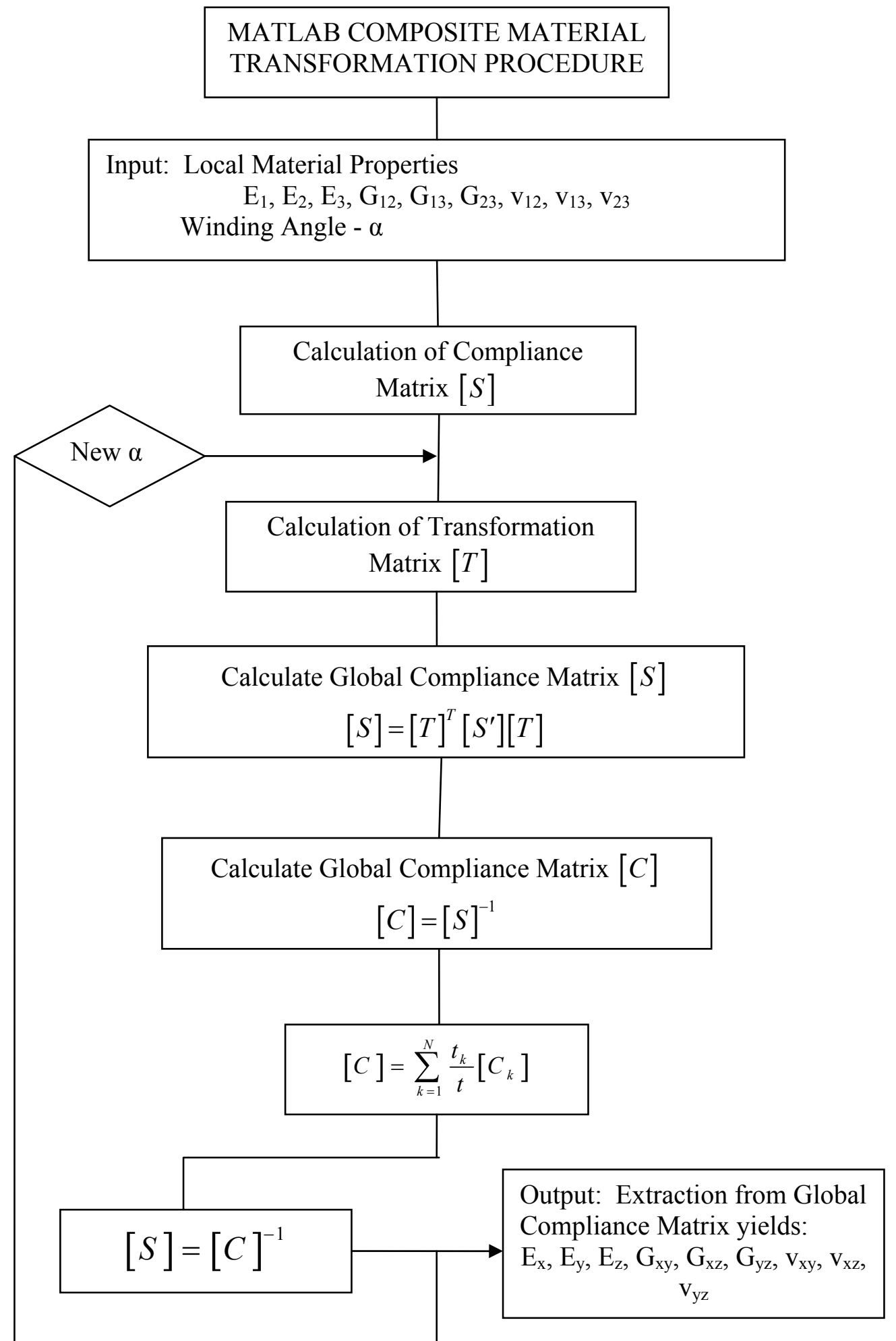


$\%$ Change of orthotropic material properties for proper orientation in the $\%$ dome region of a filament wound pressure vessel

$\%$ theta $1=$ orientation change of area 1

$\%$ psil $=$ helical winding angle in area 1

$\% \mathrm{E} 1, \mathrm{E} 2, \mathrm{E} 3, \ldots$ local material props orientation is given in reference to

$\%$ the longitudinal axis of the pressure vessel

$\% \mathrm{Ex}, \mathrm{Ey}, \mathrm{Ez}, \ldots$ global mat props orientation referenced to the global

$\%$ coordinate system about which the model geometry was created.

clear

clc

\%Area 1 Calculations - Local Material Properties

$\mathrm{E} 1=23.4 \mathrm{e} 6 ; \% \mathrm{psi}$

$\mathrm{E} 2=1.28 \mathrm{e} 6 ; \% \mathrm{psi}$

$\mathrm{E} 3=\mathrm{E} 2$;

$\mathrm{G} 12=0.78 \mathrm{e} 6$

$\mathrm{G} 13=\mathrm{G} 12$;

$\mathrm{v} 23=0.45$

$\mathrm{G} 23=0.4 \mathrm{e} 6$;

$\mathrm{v} 12=0.33$;

$\mathrm{v} 13=\mathrm{v} 12$;

$\% \mathrm{v} 21=\mathrm{v} 12 *(\mathrm{E} 2 / \mathrm{E} 1)$

$\% \mathrm{v} 32=\mathrm{v} 23 *(\mathrm{E} 3 / \mathrm{E} 2)$

$\% \mathrm{v} 31=\mathrm{v} 13 *(\mathrm{E} 3 / \mathrm{E} 1)$

$\%$ Calculation of S' Compliance Matrix

$\mathrm{S}(1,1)=1 / \mathrm{E} 1 ; \mathrm{S}(1,2)=-\mathrm{v} 12 / \mathrm{E} 1 ; \mathrm{S}(1,3)=-\mathrm{v} 13 / \mathrm{E} 1 ; \mathrm{S}(1,4)=0 ; \mathrm{S}(1,5)=0 ; \mathrm{S}(1,6)=0$;

$\mathrm{S}(2,1)=-\mathrm{v} 12 / \mathrm{E} 1 ; \mathrm{S}(2,2)=1 / \mathrm{E} 2 ; \mathrm{S}(2,3)=-\mathrm{v} 23 / \mathrm{E} 2 ; \mathrm{S}(2,4)=0 ; \mathrm{S}(2,5)=0 ; \mathrm{S}(2,6)=0$;

$\mathrm{S}(3,1)=-\mathrm{v} 13 / \mathrm{E} 1 ; \mathrm{S}(3,2)=-\mathrm{v} 23 / \mathrm{E} 2 ; \mathrm{S}(3,3)=1 / \mathrm{E} 3 ; \mathrm{S}(3,4)=0 ; \mathrm{S}(3,5)=0 ; \mathrm{S}(3,6)=0$;

$\mathrm{S}(4,1)=0 ; \mathrm{S}(4,2)=0 ; \mathrm{S}(4,3)=0 ; \mathrm{S}(4,4)=1 / \mathrm{G} 23 ; \mathrm{S}(4,5)=0 ; \mathrm{S}(4,6)=0$;

$\mathrm{S}(5,1)=0 ; \mathrm{S}(5,2)=0 ; \mathrm{S}(5,3)=0 ; \mathrm{S}(5,4)=0 ; \mathrm{S}(5,5)=1 / \mathrm{G} 13 ; \mathrm{S}(5,6)=0$;

$\mathrm{S}(6,1)=0 ; \mathrm{S}(6,2)=0 ; \mathrm{S}(6,3)=0 ; \mathrm{S}(6,4)=0 ; \mathrm{S}(6,5)=0 ; \mathrm{S}(6,6)=1 / \mathrm{G} 12$;

\% Transformation Matrix T

theta $=(0 *$ pi $) / 180$

$11=\cos ($ theta $) ; 12=-\sin ($ theta $) ; 13=0$;

$\mathrm{m} 1=\sin ($ theta $) ; \mathrm{m} 2=\cos ($ theta $) ; \mathrm{m} 3=0$;

$\mathrm{n} 1=0 ; \mathrm{n} 2=0 ; \mathrm{n} 3=1$;

$\mathrm{T}=\left[11^{\wedge} 2, \mathrm{~m} 1 \wedge 2, \mathrm{n} 1 \wedge 2,2 * \mathrm{~m} 1 * \mathrm{n} 1,2 * 11 * \mathrm{n} 1,2 * 11 * \mathrm{~m} 1\right.$

$12^{\wedge} 2, \mathrm{~m} 2 \wedge 2, \mathrm{n} 2 \wedge 2,2^{*} \mathrm{~m} 2 * \mathrm{n} 2,2 * 12 * \mathrm{n} 2,2 * 12 * \mathrm{~m} 2$

$13^{\wedge} 2, \mathrm{~m} 33^{\wedge} 2, \mathrm{n} 3 \wedge 2,2^{*} \mathrm{~m} 3 *^{*} \mathrm{n} 3,2 * 13 * \mathrm{n} 3,2 * 13 * \mathrm{~m} 3$

$12 * 13, \mathrm{~m} 2 * \mathrm{~m} 3, \mathrm{n} 2 * \mathrm{n} 3,(\mathrm{~m} 2 * \mathrm{n} 3)+(\mathrm{n} 2 * \mathrm{~m} 3),(12 * \mathrm{n} 3)+(\mathrm{n} 2 * 13),(12 * \mathrm{~m} 3)+(\mathrm{m} 2 * 13)$;

$11 * 13, \mathrm{~m} 1 * \mathrm{~m} 3, \mathrm{n} 1 *_{\mathrm{n}} 3,\left(\mathrm{~m} 1 *_{\mathrm{n}} 3\right)+\left(\mathrm{n} 1 *^{*} \mathrm{~m} 3\right),\left(11 *_{\mathrm{n}} 3\right)+(\mathrm{n} 1 * 13),(11 * \mathrm{~m} 3)+(\mathrm{m} 1 * 13)$; 


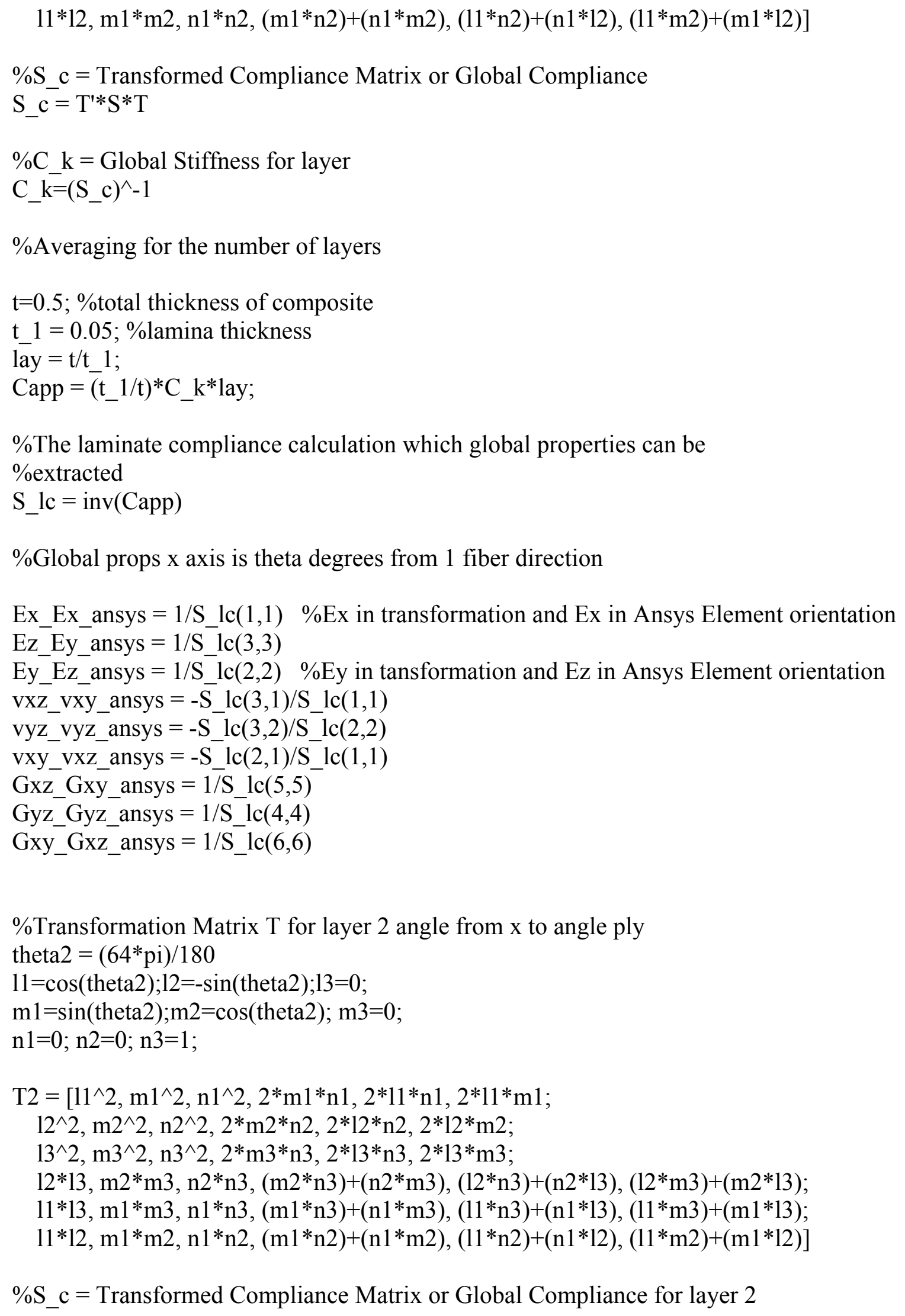


$\mathrm{S} \_\mathrm{c} 2=\mathrm{T} 2 \cdot * \mathrm{~S} * \mathrm{~T} 2$

$\% \mathrm{C} \_\mathrm{k}=$ Global Stiffness for layer 2

C_k $2=\left(S_{-} \text {c } 2\right)^{\wedge}-1$

$\%$ Averaging for the number of layers

$\mathrm{t}=0.5 ; \%$ total thickness of composite

t $1=0.05$; \%lamina thickness

lay $=\mathrm{t} / \mathrm{t} \_$;

Capp2 $=\left(\mathrm{t} \_1 / \mathrm{t}\right) * \mathrm{C} \_\mathrm{k} 2 *$ lay;

\%The laminate compliance calculation which global properties can be

$\%$ extracted

S_lc2 $=\operatorname{inv}($ Capp2)

\%Global props $\mathrm{x}$ axis is theta degrees from 1 fiber direction

Ex2_Ex_ansys $=1 / \mathrm{S} \_1 \mathrm{c} 2(1,1) \quad \%$ Ex in transformation and Ex in Ansys Element \%orientation

Ez2_Ey_ansys $=1 / \mathrm{S} \_1 \mathrm{c} 2(3,3)$

Ey2_Ez_ansys $=1 / \mathrm{S} \_$lc2 $(2,2) \quad \%$ Ey in tansformation and Ez in Ansys Element \%orientation

vxz2_vxy_ansys $=-S \_1 c 2(3,1) / S \_1 c 2(1,1)$

vyz2_vyz_ansys $=-$ S_lc $_{-}(3,2) / \mathrm{S} \_$_c $2(2,2)$

vxy2_vxz_ansys $=-S \_l c 2(2,1) / S \_l c 2(1,1)$

Gxz2_Gxy_ansys $=1 / \mathrm{S} \_\mathrm{lc} 2(5,5)$

Gyz2_Gyz_ansys $=1 /$ S_lc $2(4,4)$

Gxy2_Gxz_ansys $=1 / \mathrm{S}_{-} \mathrm{lc} 2(6,6)$

Capp_total $=\left(\mathrm{C}_{-} \mathrm{k}+\mathrm{C} \_\mathrm{k} 2\right) / 2$

S_tot=inv(Capp_total)

$\mathrm{Ex}=1 / \mathrm{S}$ tot $(1,1) \quad \% \mathrm{Ex}$ in transformation and Ex in Ansys Element orientation

$\mathrm{Ey}=1 / \mathrm{S}_{-}$tot $(3,3) \% \mathrm{Ez}$

$\mathrm{Ez}=1 / \mathrm{S}$ tot $(2,2) \quad \% \mathrm{Ey}$ in tansformation and $\mathrm{Ez}$ in Ansys Element orientation

$\mathrm{vxy}=-\mathrm{S}$ - $t$ tot $(3,1) / \mathrm{S} \_$tot $(1,1) \quad \% \mathrm{vxz}$

$\mathrm{vyz}=-\mathrm{S} \_$tot $(3,2) / \mathrm{S} \_$tot $(2,2) \quad \% \mathrm{vyz}$

$\mathrm{vxz}=-\mathrm{S} \_$tot $(2,1) / \mathrm{S} \_$tot $(1,1) \quad \% \mathrm{vxy}$

$\mathrm{Gxy}=1 / \overline{\mathrm{S}}$ tot $(5,5) \% \mathrm{Gxz}$

$\mathrm{Gyz}=1 / \mathrm{S}$-tot $(4,4) \% \mathrm{Gyz}$

$\mathrm{Gxz}=1 / \mathrm{S} \_$tot $(6,6) \% \mathrm{Gxy}$ 


\section{Appendix C: ANSYS Input Code}

\section{ISOTENSOID MODEL}

The steps in creating the isotensoid finite element model are listed. The preliminary steps utilized the aforementioned MATLAB programs to construct the model geometry. The MATLAB program in Appendix A will provide the dome contour keypoints. From the key-points, the remaining geometry is built. The thickness contour, also determined from Appendix A, will provide the remaining cross-section thickness for the filament wound composite reinforcement.

1. Extract the isotensoid dome geometry from the MATLAB program in Appendix A. The points of the isotensoid dome can directly be compiled into a text file following ANSYS format for creating "keypoints" and imported as an input text file.

2. Apply the "spline" function to the imported points to create the dome shape as a line.

3. Add points from the thickness contour determined from the program contained in Appendix A.

4. "Spline" the points of the thickness contour to create the exterior reinforcement shape as a line.

5. Extrude a liner structure to the desired user thickness and shape along the interior dome shape line, if desired.

6. Create areas by using the previously defined lines.

7. Segment the areas of the filament wound reinforcement to correspond to the percentage of change in the winding angle.

8. Meshing is performed to the users desired element size and refinement.

The material properties and definition of local coordinate systems is applied through the following text file which can be directly imported as a text document into ANSYS finite element software. The material properties and local coordinate systems are defined for the isotensoid dome with a boss radius of $1.5 \mathrm{in}$. and an internal radius of 6 inches. 


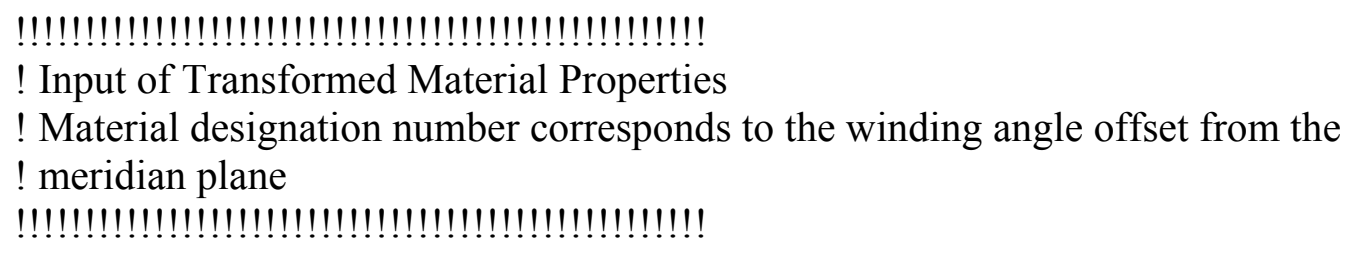




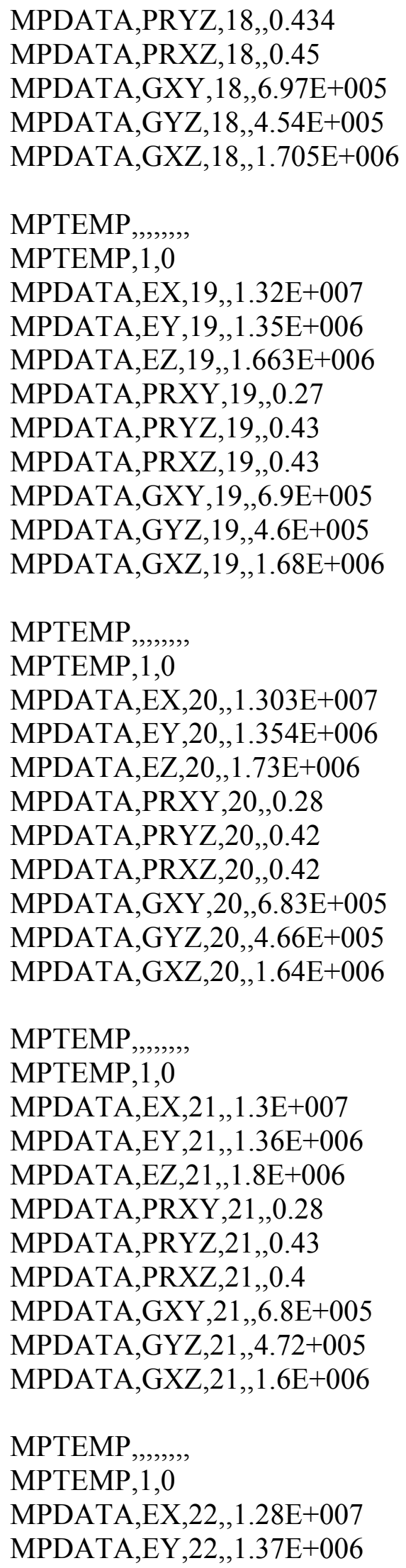




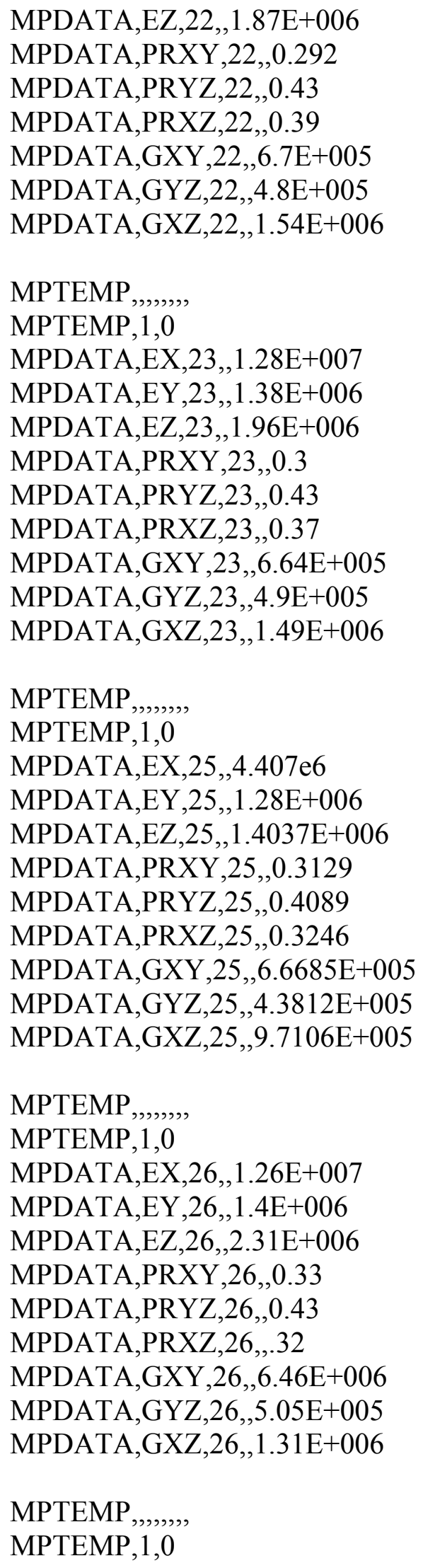




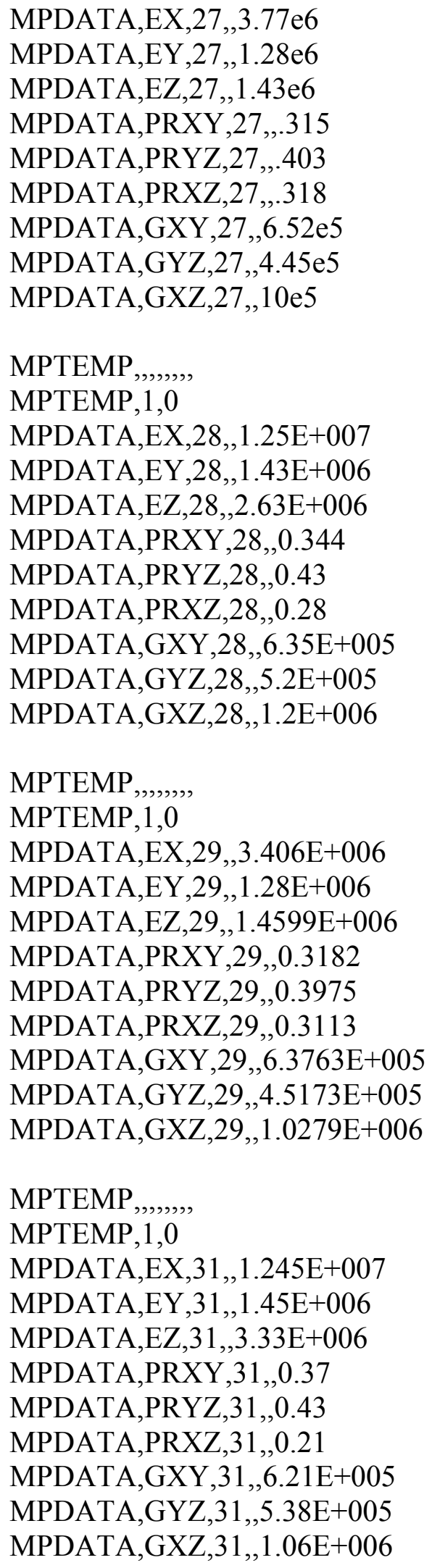




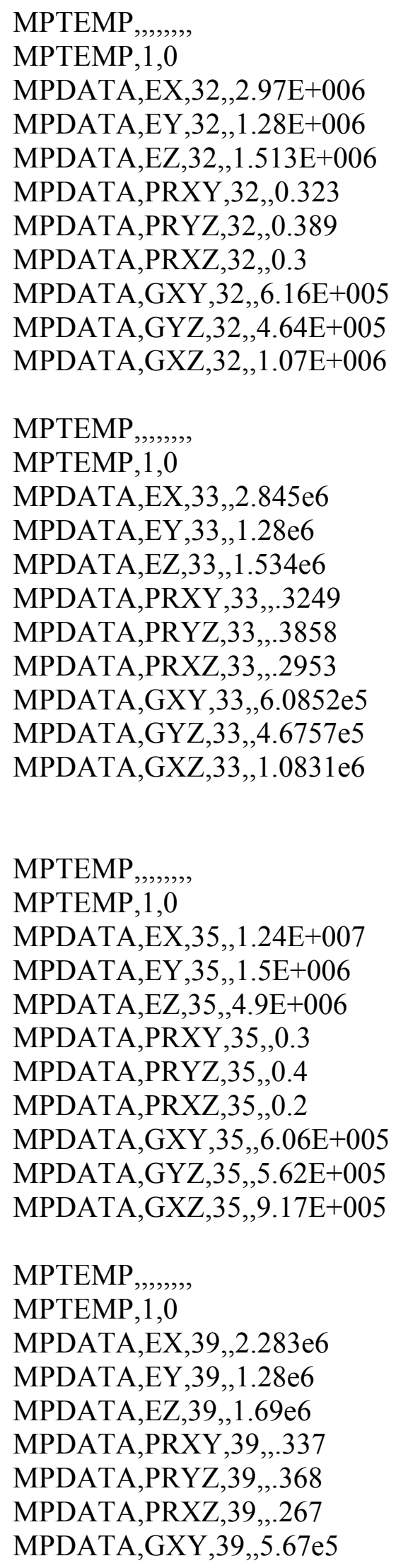




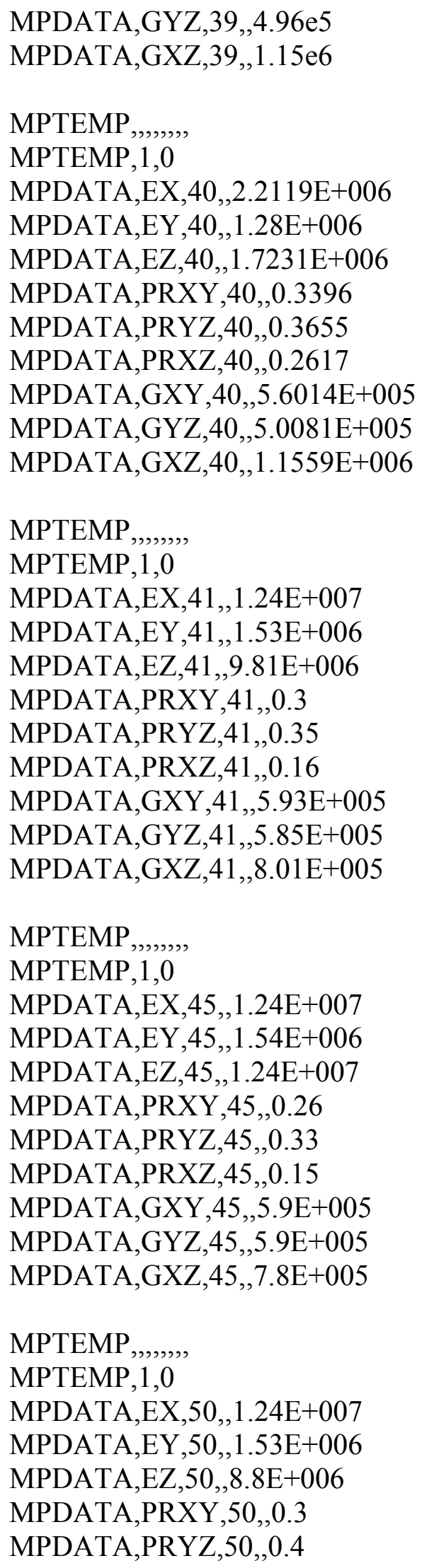




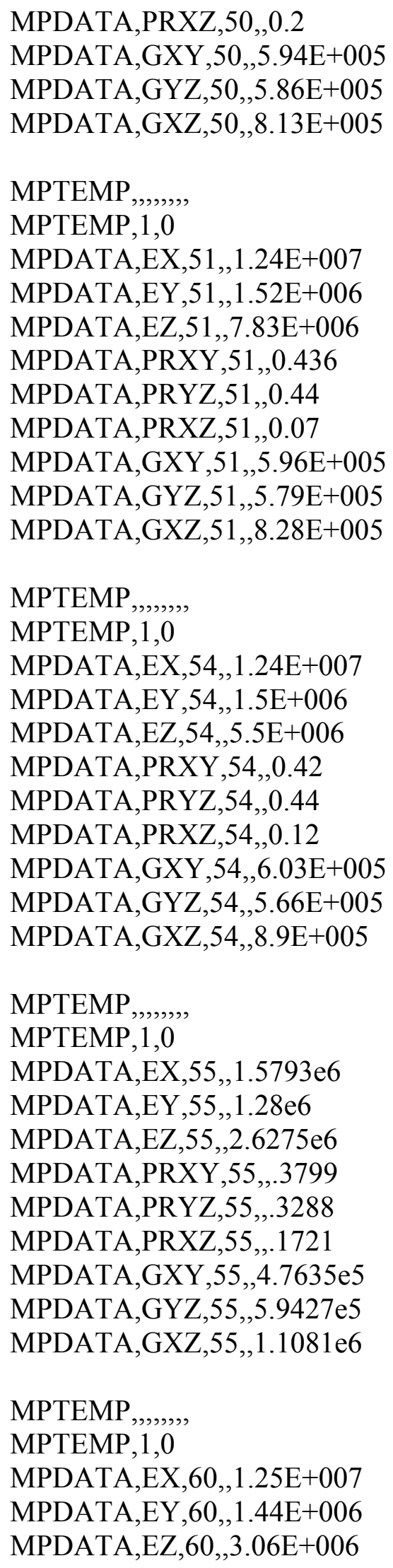




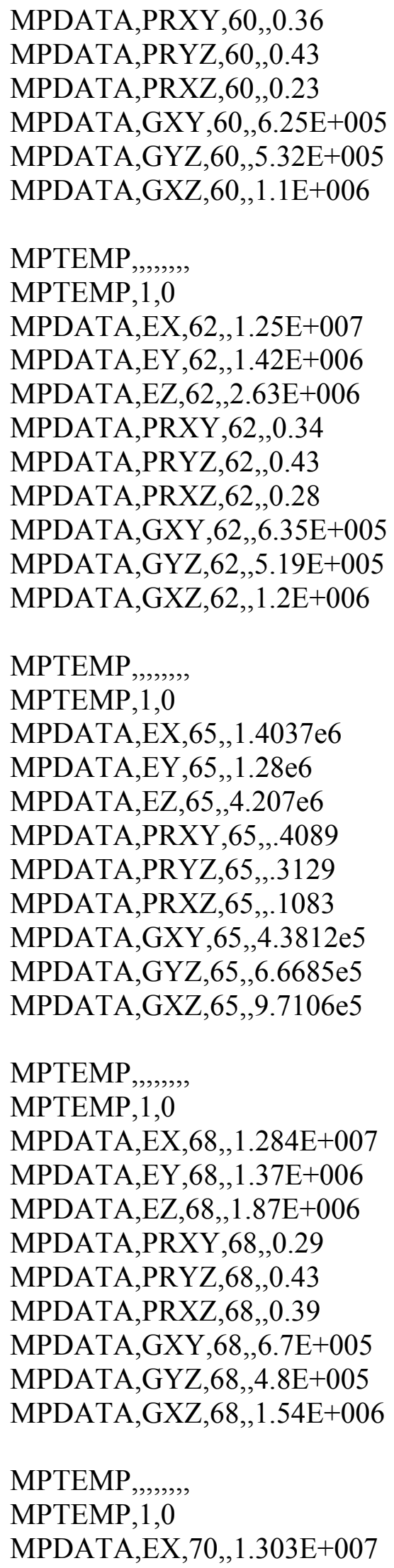




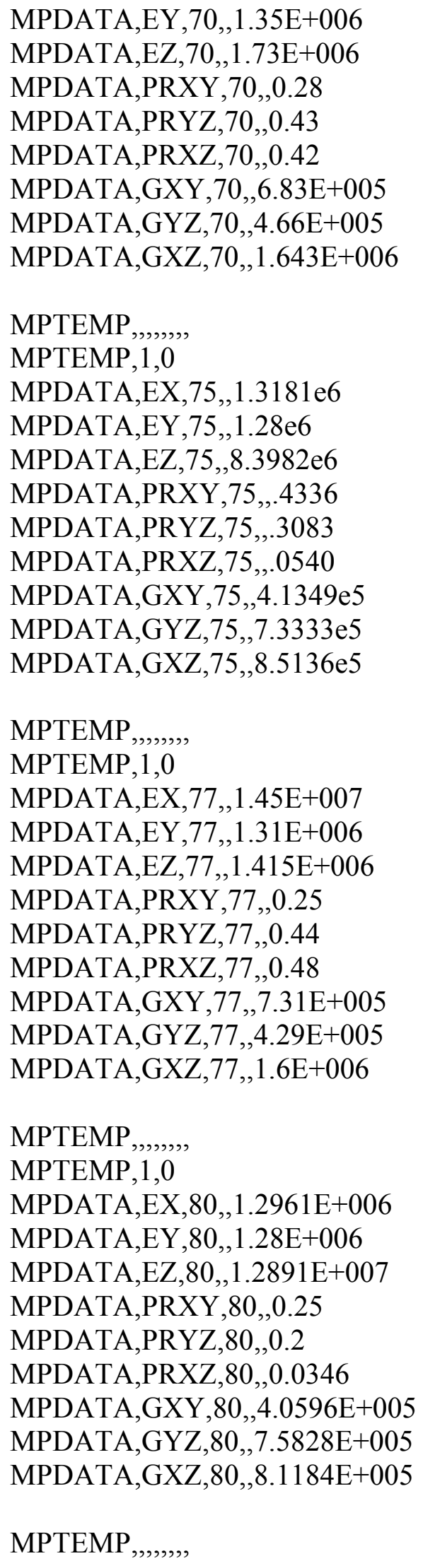




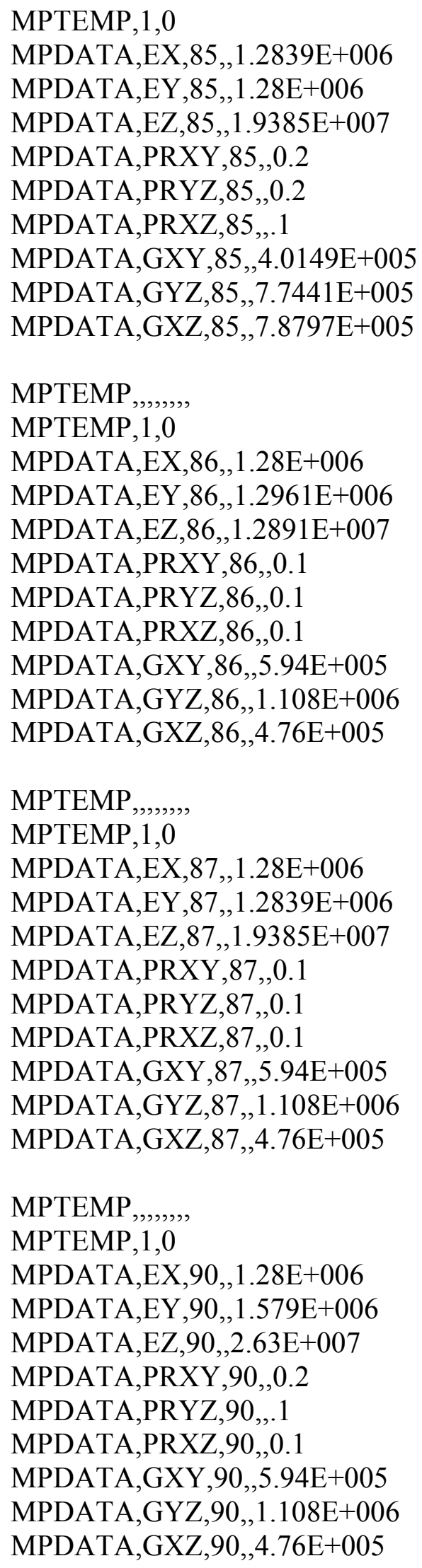


!!!!!!!!!!!!!!!!!!!!!!!!!!!!!!!!!!!!!!!!!!!!!!!!!!!!

! Establishing local Coordinate systems !!!!!!!!!!!!!!!!!!!!!!!!!!!!!!!!!!!!!!!!!!!!!!!!!!!!

LOCAL, 20, 0, 7, 31, 0, -68, 0, -20

LOCAL, 26, 0, 6.5, 32.45, -5, 0, -26

LOCAL, 29, 0, 5.75, 33.2, -50, 0, -29

LOCAL, 32, 0, 5.35, 33.8, -50, 0, -32

LOCAL, 35, 0, 4.9, 34.4, -43, 0, -35

LOCAL, 40, 0, 4.41, 34.918, -41, 0, -40

LOCAL, 45, 0, 4.0, 35.25, -36, 0, -45

LOCAL, 50, 0, 3.65, 35.55, -35, 0, -50

LOCAL, 55, 0, 3.35, 35.75, 0, -33, 0, -55

LOCAL, 60, 0, 3.25, 35.85, 0, -30, 0, -60

LOCAL, 65, 0, 3.1, 35.9, 0, -31, 0, -65

LOCAL, 70, 0, 2.95, 36.05, 0, -30, 0, -70

LOCAL, 75, 0, 36.15, 0, -25, 0, -75

LOCAL, 80, 0, 2.7, 36.2, 0, -20, 0, -80

LOCAL, 85, 0, 2.65, 36.25, 0, -10, 0, -85

LOCAL, 90, 0, 2.55, 36.3, 0, 0, 0, -90

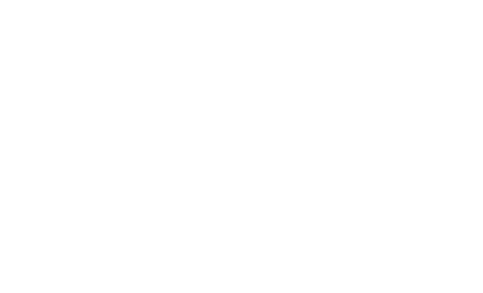

